FHWA/IN/JTRP-2009/13

Final Report

WORKER INJURY PREVENTION STRATEGIES

Carlos A. Ferreira-Diaz

Alma Torres-Zapata

Christopher A. Nanovic

Dulcy M. Abraham

September 2009 


\section{TECHNICAL Summary}

Technology Transfer and Project Implementation Information

INDOT Research

September 2009

Publication No.: FHWA/INDOT/JTRP-2009/13

Final Report

\section{WORKER INJURY PREVENTION STRATEGIES}

\section{INTRODUCTION}

As the trend of increased highway construction and rehabilitation continues to grow, the public often demands that delays in work zones be kept to a minimum. This necessitates that the flow of traffic through the construction zone be maintained while performing pavement maintenance/ repair/ reconstruction activities. At the same time, the safety of personnel and property in highway construction work zones must be ensured.

Three types of risks are encountered by construction and maintenance workers in construction workzones:

a) risks due to underprotection or lack of protection against potential hazards (including lack of hearing protection, eye protection, respiratory protection)

b) effect of speeding through workzones

c) impacts due to the lack of/inadequate visibility issues (both workers and motorists)

There is pressing need to analyze these risks in greater depth and to evaluate the hazards associated with the construction and maintenance operations undertaken by Indiana Department of Transportation (INDOT) workers, particularly as the State of Indiana is engaged in accelerated construction projects and in the rehabilitation of existing structures.
With cooperation from the Indiana Department of Transportation (INDOT) and the Tippecanoe County Highway Department, three separate but inter-related research studies were conducted between September 2006 and June 2008. The first study analyzed OSHA generated reports of accidents in workzones and identified common causes and patterns of fatal accidents in construction and maintenance work zones. The perceptions of work zone personnel about potential hazards, common causes of accidents in work zones, and other safety issues were then identified and evaluated. This analysis was helpful to find deviations in the perception of work zone personnel about work zone accidents (when compared with the analysis of accident reports), and in this manner, provide recommendations for the improvement of safety programs.

The main objective of the second study was to analyze the effectiveness of various safety strategies used on highway construction and maintenance projects. The sources of risk or safety hazards for workers and the currently used safety strategies and procedures were identified by conducting the surveys and field observations. This study can provide INDOT with recommendations for the effective safety strategies based on the perception of the workers, contractors, and owners.

The third study, evaluated the use of radar and camera systems as a measure to reduce the occurrence of accidents related to backing mobile equipment in work zones. The main objective of this research was to evaluate a potential safety strategy to reduce a common cause of fatal injuries in work zones. The 
analysis of the accident reports and the literature review on work zone accidents in the first study, reflected that "workers struck by backing vehicles which were part of the work zone project" was the main accident event where worker fatal injuries occurred and that did not involve passing motorists. The evaluation of three different camera systems and three radar systems was performed as a measure to prevent

\section{FINDINGS}

Analysis of accident reports of fatalities that occurred in work zones in the United States in the 2000-2006 time frame, indicated that most of the fatal occupational accidents in work zones occurred in the accident events "worker struck by passing motorist" and "worker struck by mobile equipment (which was part of the project)." Two relevant behavioral accident causes were found: "negligence of a third party" and "lack of awareness from the injured worker." These results were compared to those obtained from the survey responses provided by work zone workers surveyed Indiana. Workers rated the accident event involving mobile equipment as the second least likely to occur when compared with the other accident events, and the behavioral cause "lack of awareness" as the least likely to occur when compared with the other behavioral causes of accidents. A binomial logit model was developed to describe the likelihood of a worker choosing "lack of awareness" as the primary, or one of the major causes of accidents in work zones. Through the model, the following factors were found to be significant for reducing the probability of workers choosing "lack of awareness" as the primary, or one of the major behavioral causes of accidents: (1) workers with two or more years of experience in road construction or maintenance; (2) workers who attended to at least one safety meeting per month; (3) drivers and heavy equipment operators; and (4) workers that were assigned to perform an activity without receiving safety training for that activity.

Analysis of surveys administered to INDOT personnel, contractors and highway construction workers in Indiana, provided an assessment of various currently used safety strategies and safety hazards in construction and maintenance work zones based on three different perspectives (owners, contractors, and workers). The three groups of stakeholders seemed to agree on the importance of the factors involved in the evaluation of a safety strategy. The most important factor to all three groups of this type of accident. Testing of these camera systems was conducted to achieve the following objectives: (1) evaluation of the performance of the different camera systems and (2) the identification of the factors that affect the identification of a worker (represented by a mannequin) in the path of a backing dump truck when camera systems are used.

stakeholders in evaluating the effectiveness of a safety strategy was the success in injury prevention. The cost of these strategies was considered as the least important factor in evaluating their effectiveness. The three groups of stakeholders who participated in this study showed a common concern about the risk generated by the intrusion of vehicles in the work zone. According to these groups, the safety hazard with the highest level of risk and probability of occurrence appeared to be vehicles striking pedestrian workers.

The perception of the effectiveness of different safety strategies varied considerably among the stakeholders involved in this study. For instance, in the administrative strategies category, law enforcement for traffic control was perceived as the most effective strategy by the owner. However, according to the workers, law enforcement was the least effective in this category. Workers tend to rely more on the effectiveness of the training programs for workers and staff than on any other strategy included in this category.

Other categories that showed high variability in the perception of their effectiveness were the traffic control strategies and the measures to improve safety in the work zones. Within the category of innovative technologies for hazard control, the use of radar triggered speed displays was perceived by both contractors and owners as the most effective of the innovative technologies. The use of alert systems, which appeared to be the most commonly used strategy in this category, was perceived as the most effective by the workers. The category that includes the nighttime traffic control strategies did not show variability in the respondents' perception. The use of retro-reflective clothing was chosen as the most effective strategy and the flashing lights on body or clothing as the least effective by all the stakeholder groups. Workers seemed to be the least "satisfied" group of the three stakeholders. These results may indicate that the perceived effectiveness of a safety strategy may appear to 
be lower when the respondent is directly exposed to the safety hazards than when the respondent is performing an assessment from a different perspective.

Construction workers who received safety training when hired were more likely to perceive the use of warning signs as a highly effective safety strategy. The parameter that had the highest impact on the warning signs effectiveness ratings was the type of projects in which the worker is most frequently involved. If the worker was more frequently involved in construction projects, there was a 0.25 increase in the probability of perceiving the warning signs as highly effective. Workers who attended safety meetings bi-weekly or more frequently and had worked on more than 20 highway projects were more likely to perceive the use retro-reflective clothing for nighttime traffic control as highly effective.

The analysis of the ordered probit model with random effects provided the factors that have a positive impact on the likelihood of a person identifying the mannequin (representing a construction worker) at a relatively safe distance from the truck (more than 50 feet). These factors were the use of camera 1 , the mannequin in a standing position, and an acceptable level of glare in the images displayed by the camera system. Camera \#1 was a heavy duty color camera with the following characteristics (1.0 lux, $118 \times 18$ field of view), with a polyurethane jacketed cable with military-spec connector, and a 6.4TFT color LDC display. Other factors, such as (1) the location of the mannequin near the roller machine while wearing a safety vest, (2) the location of the mannequin in the opposite side of the heavy equipment, and (3) the use of cameras 2 and 3, decrease the likelihood.

Additionally, the use of safety vest Class III had a positive impact on this probability over the use of safety vest Class II.

If Departments of Transportation (DOTs) plan to use cameras on dump trucks performing activities in a specific work zone, workers on foot and drivers should be trained to avoid the factors that decrease the probability of a worker being identified within a relative safe distance (more than 50 feet). For instance, workers wearing a safety vest that might have a camouflage effect with any equipment or object in the work zone should not be positioned near that equipment or object. Similarly, drivers should be more cautious when backing and using the camera system if the sun or any other source of light provokes glare in the image displayed by the camera. The effect of the camera system has on the use of the mirrors should be evaluated. Drivers of construction vehicles should use both the mirrors and the camera system while backing. The use of a camera system should be viewed as a complement, not as a replacement of the use of the mirrors.

Future research should investigate the influence of proper training and the familiarity of the equipment operators with the use of the camera systems installed in their equipment. Drivers should be taught how to use the systems and they should be afforded adequate time to become familiar with the use of such systems.

\section{IMPLEMENTATION}

Continue to explore the content of the safety training materials used by contractors and other DOTs, and the frequency of the training, to determine if good practices could be adopted and/or adapted into INDOT's safety training programs.
Suggestion for future study: Continue to investigate the use of backup camera systems on INDOT trucks. The testing of the camera systems should be done in both summer and winter months to analyze the performance capabilities/challenges in different seasons

\section{CONTACT}

Tommy Nantung

Research \& Development, INDOT

tnantung@indot.in.gov

1205 Montgomery Street

West Lafayette, IN 47906

Phone: (765) 463-1521

Fax: (765) 497-1665 
Dulcy Abraham

School of Civil Engineering

Purdue University

West Lafayette, IN 47907

Phone: (765) 494-2239

Fax: (765) 494-0644

dulcy@ purdue.edu 


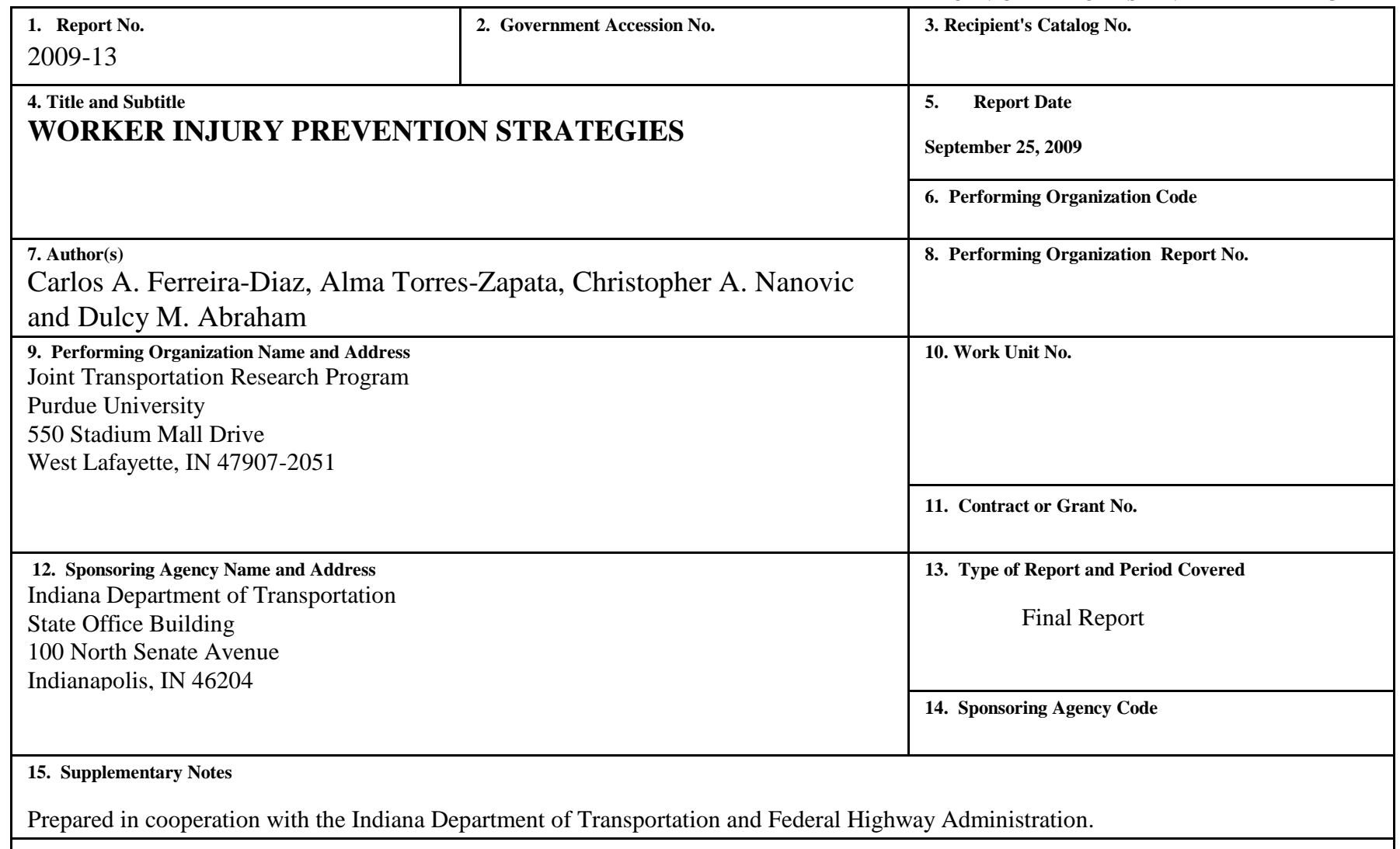

16. Abstract

As the trend of increased highway construction and/or rehabilitation continues to grow, the public often demands that delays in work zones be kept to a minimum. Thus, the flow of traffic through the construction zone must be maintained while performing pavement maintenance/ repair/ reconstruction activities. At the same time, the safety of personnel and property in highway construction work zones must be ensured. Three types of risks are encountered by construction and maintenance workers in construction workzones: (a) risks due to underprotection or lack of protection against potential hazards (including lack of hearing protection, eye protection, respiratory protection); (b) effect of speeding through workzones, and (c) impacts due to the lack of/inadequate visibility issues (both workers and motorists).

This report presents the findings of three separate, yet interrelated projects that explored the hazards in highway construction and maintenance workzones, and evaluated workzone safety strategies. The evaluation of the safety strategies was performed by analyzing the perceptions of three groups of stakeholders (INDOT personnel, contractors, and highway construction and maintenance workers). The report also discusses the use of camera and radar systems to prevent workers from being struck by mobile equipment. Finally, it provides some recommendations for more effective implementation of safety strategies and provides suggestions for further research in the domain of highway construction safety.

\section{Key Words}

Highway construction and maintenance, safety, workers, cameras, accident reports, fatality, binary logit models, mobile equipment
18. Distribution Statement

No restrictions. This document is available to the public through the National Technical Information Service, Springfield, VA 22161

\begin{tabular}{|c|c|l|l|}
\hline 19. Security Classif. (of this report) & 20. Security Classif. (of this page) & 21. No. of Pages & 22. Price \\
Unclassified & Unclassified & &
\end{tabular}




\section{INDOT Research Project Implementation Plan}

Date: January 14, 2010

Research Project Number: C36-58WW

Project Title: Worker Injury Prevention Strateties

Principal Investigator (PI): Dulcy M. Abraham

Project Advisor (PA): Scott Newbolds Signature:

Principal Implementor (PIM): Signature:

INDOT Strategic Goal Impact Areas (select all that the implementation of this project will impact):

$\square$ Mobility $\quad$ Safety $\square$ Economic Development $\square$ Customer Service

$\square$ Resource Management $\bigotimes$ Training

Summary of Implementation Plan:

Item\#1 - Continue to explore the content of the safety training materials used by contractors and other DOTs, and the frequency of the training, to determine if good practices could be adopted and/or adapted into INDOT's safety training programs.

Suggestion for future study:

Continue to investigate the use of backup camera systems on INDOT trucks.

Note: Mr. Skip Claussen from the Borman Traffic Management Center was contacted for further insight. Mr.Claussen reported that the Borman TMC has had very good success with the use of the camera systems installed on their fleet for over 5 years. The current specifications of the camera systems used by Borman TMC are as follows: three (3) camera view and 7 inch widescreen LCD color monitor system Tri-Vue Voyager INDOT approved. Monitor Size: $73 / 4$ " w $x 51 / 4$ " hx $13 / 16^{\prime \prime} d$. Camera size $41 / 4 " w \times 3 " h \times 31 / 4 "$. Heavy-duty rear back-up video system with motorized tilt function and side view body. The system will operate on $10 \mathrm{~V}-32 \mathrm{vDC}$. The camera will be installed on top of the utility body facing the rear of the truck. The camera will meet the following minimum specifications: CCD Pixels:270k 0.1 Lux, Max shock 10G, Max Vibration 10G. The monitor will be installed in the passenger area of the front of truck. The Max Shock 7G, Max Vibration 10G. The exact location is to be approved by INDOT." The cost of this set-up is as follows: system including Voyager 7" color monitor, left and right side stationary color cameras, rear motorized color camera, and mounting kits and wiring harness. - approximately \$1,862 with customer installation.

The cameras used in this research study had the following specifications: Camera \#1 was a heavy duty color camera with the following characteristics (1.0 lux, $118 \times 18$ field of view), with a polyurethane jacketed cable with military-spec connector, and a 6.4TFT color LDC display. Camera 2 had similar features, with a regular $S$-video cable, and a 7 "TFT LCD color monitor. Camera\#l costs $\$ 2,700$ and Camera $\# 2$ costs 1,100. There may be additional costs for mounting the cameras correctly, and also for collecting data under different field conditions.

The testing of the camera systems should be done in both summer and winter months to analyze the 
performance capabilities/challenges in different seasons

Note: If more than one implementor recommended, please fill in the information on each implementor's implementation items:

Name of Implementor/User:

Lyle Sadler (for item\#1)

signature: Syle S.SadLer

Responsible for Implementing:

Help or resources needed for implementation (e.g., help from PI, funding, equipment, etc.): The PI can assist INDOT in this task.

Name of Implementor/User: Signature:

Responsible for Implementing:

Help or resources needed for implementation (e.g., help from PI, funding, equipment, etc.):

Name of Implementor/User: $\quad$ Signature:

Responsible for Implementing:

Help or resources needed for implementation (e.g., help from PI, funding, equipment, etc.):

Signatures of SAC members:

Please send a copy of this form to the INDOT Research \& Development Office and FHWA with the final report. 


\title{
WORKER INJURY PREVENTION STRATEGIES
}

\author{
Final Report
}

\author{
by \\ Carlos A. Ferreira-Diaz \\ Alma Torres-Zapata \\ Christopher A. Nanovic \\ Dulcy M. Abraham \\ School of Civil Engineering, Purdue University \\ Joint Transportation Research Program \\ PROJECT NO. C36-59WW \\ File No. 8-5-49 \\ SPR-3085
}

September 25, 2009 


\section{ACKNOWLEDGEMENTS}

The authors thank the Indiana Department of Transportation (INDOT) for sharing information during the course of the project. Our sincere thanks go to the members of the Study Advisory Committee (SAC): Rick Drumm (FHWA), John Habermann (Indiana LTAP), Mike Houghland (INDOT), Kevin Johnston (INDOT), Dennis Kuchler (INDOT), Calvin Lee (Indiana

Constructors Association - ICA), Chris Nardine (INDOT), Scott Newbolds (INDOT), Lyle Sadler (INDOT), and Mark Wilson (INDOT) for their guidance and help during the course of the research. We also extend our gratitude to the Tippecanoe County Highway Department for granting us access to their highway trucks for mounting the rear view cameras that were used in the experiments in this study. We are very grateful to the supervisors and workers at Tippecanoe County Highway Department, INDOT and different construction companies for participating in the study. Special thanks for Calvin Lee (ICA and John Habermann (Indiana LTAP) for facilitating groups of workers from the Indiana contracting community and local agencies, respectively, to participate in our surveys and interviews. 


\section{TABLE OF CONTENTS}

\section{Page}

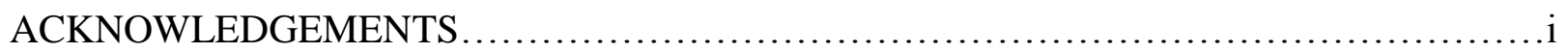

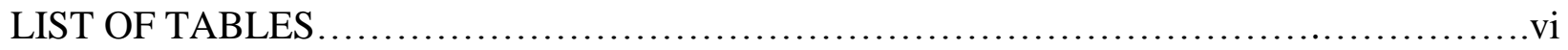

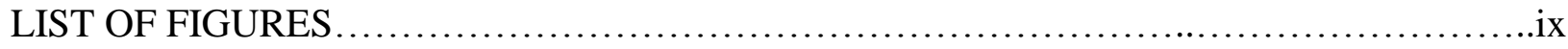

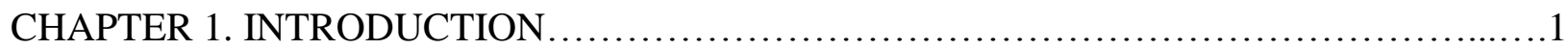

1.1. Project Objectives ....................................................................................................... 2

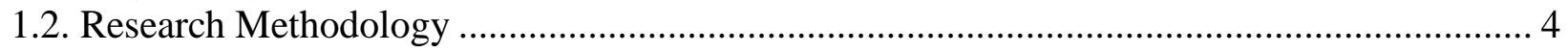

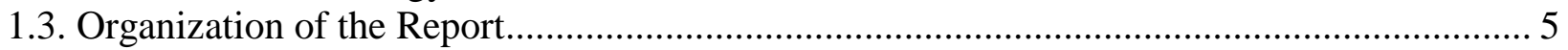

CHAPTER 2. LITERATURE REVIEW ....................................................

2.1. Hazards in Highway Construction and Maintenance Activities .............................................. 8

2.2 Accident Events Leading to Serious and Fatal Injuries in Work Zones .................................. 9

2.2.1. Fatal Occupational Injuries resulting from "Worker Struck by Mobile Equipment" in

Work Zones.............................................................. 12

2.2.2 Intrusion of Vehicles into the Work Zones..................................... 14

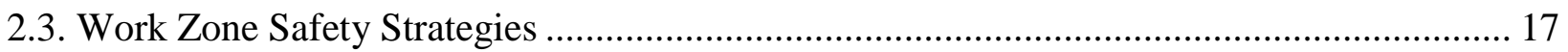

2.3.1 Safety Strategies Controlled by the Owner of the Project .......................... 18

2.3.2 Traffic Control Strategies...........................................................20

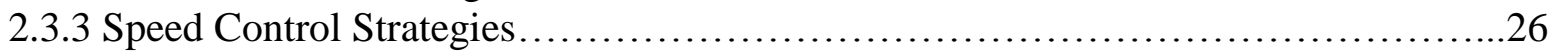

2.3.4 Measures to Improve Safety within Work Zones..................................30

2.3.5 Innovative Technologies for Hazard Control......................................38

2.3.6 Nighttime Traffic Control Strategies...........................................42

2.3.7 Strategies to Prevent Occupational Injuries resulting from "Worker Struck by Mobile

Equipment in Work Zones".................................................4

2.3.8 Identification of Factors Influencing Visibility of Workers in Nighttime Construction

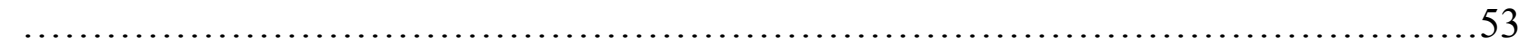

2.3.9 Productivity of Construction Equipment and Equipment Operators..................57

\section{CHAPTER 3. ANALYSIS OF ACCIDENT REPORTS AND PERSPECTIVES OF WORK}

ZONE PERSONNEL OF CAUSES OF ACCIDENTS .......................................61

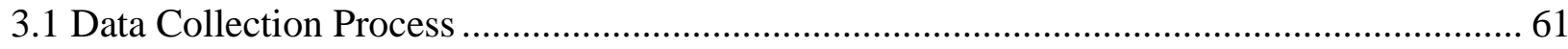

3.1.1 Identification of Primary Causes of Serious Work Zone Injuries from Accident Reports................................................................ 61

3.1.2 Surveys about Causes of Occupational Injuries in Work Zones......................65

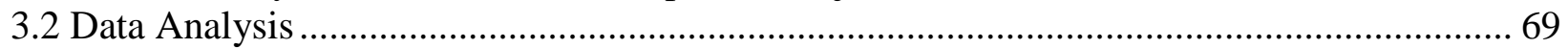

3.2.1 Analysis of Accident Reports Database........................................69

3.2.1.1 Characteristics of the Fatally Injured Workers and Projects where the Incidents Occurred. ..................................................................... 70 
3.2.2 Analysis of Perspectives of Work Zone Personnel about Causes of Accidents in Construction and Maintenance Activities........................................76

3.2.3 Model to Assess the Perception of Workers about "Lack of Awareness" as a Primary

Behavioral Cause of Accidents..................................................... 80

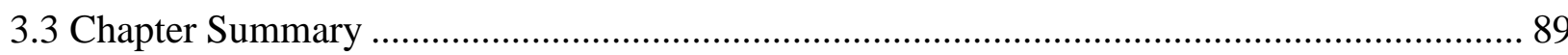

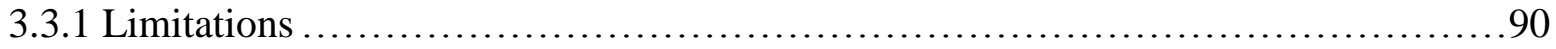

3.3.2 Recommendations for Future Studies............................................ 90

CHAPTER 4. EVALUATION AND ASSESSMENT OF WORK ZONE SAFETY

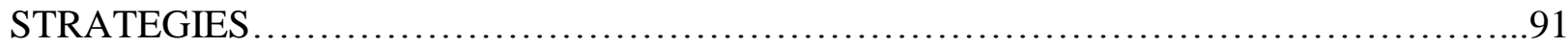

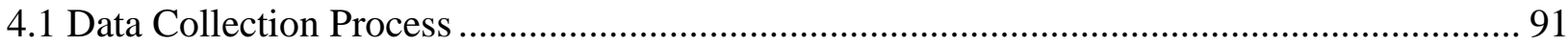

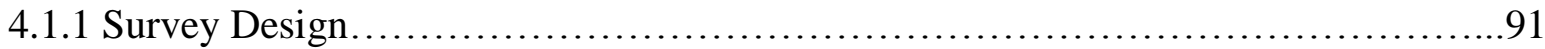

4.1.1.1 Survey Administered to Owners.........................................99

4.1.1.2 Survey Administered to General Contractors...................................93

4.1.1.3 Survey Administered to Construction Workers..................................99

4.1.2 Description of Survey Administration and Sample................................95

4.1.3 Site Visits and On-Site Observations....................................... 98

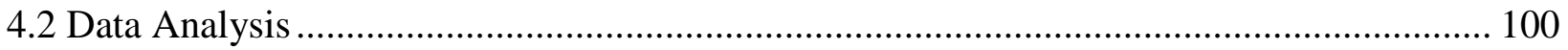

4.2.1 Results from the Administered Surveys...........................................100

4.2.1.1 General Safety and Training Perspective of Workers.............................101

4.2.1.2 Factors Affecting the Effectiveness of Safety Strategies.........................104

4.2.1.3 Level of Risk and Occurrence of Safety Hazards ............................. 106

4.2.1.4 Effectiveness of Administrative Safety Strategies........................... 109

4.2.1.5 Effectiveness of Traffic Control Strategies.................................. 111

4.2.1.6 Effectiveness of Measures to Improve Safety in the Work Zone...................112

4.2.1.7 Effectiveness of Innovative Technologies for Hazard Control.....................115

4.2.1.8 Effectiveness of Nighttime Traffic Control Strategies..........................117

4.2.1.9 Results Summary.........................................................118

4.2.2 Binary Logit Models with Marginal Effects....................................120

4.2.2.1 Binary Logit Model for Administrative Safety Strategies........................125

4.2.2.2 Binary Logit Model for Traffic Control Strategies..............................128

4.2.2.3 Binary Logit Model for Measures to Improve Safety in the Work Zone...........130

4.2.2.4 Binary Logit Model for Innovative Technologies for Hazard Control..............133

4.2.2.5 Binary Logit Model for Nighttime Traffic Control................................135

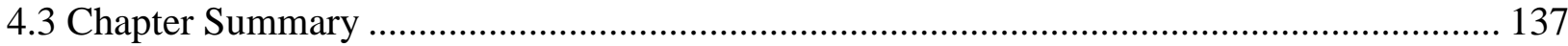

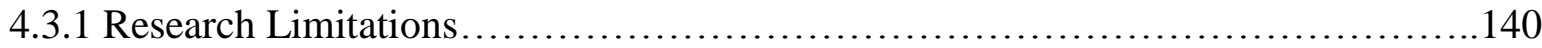

4.3.2 Recommendations for Future Studies.......................................... 141 
CHAPTER 5. USE OF CAMERA AND RADAR SYSTEMS TO PREVENT WORKERS $\begin{array}{lr}\text { INJURED BY MOBILE EQUIPMENT } & 143\end{array}$

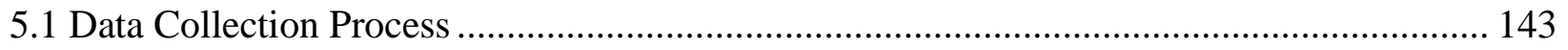

5.1.1 Installation of the Systems................................................... 145

5.1.2 Final Mounting Position of the Systems.....................................147

5.1.3 Camera Field of View and Radar Detection Zone...............................149

5.1.4 Testing to Evaluate the Performance of Camera Systems..........................152

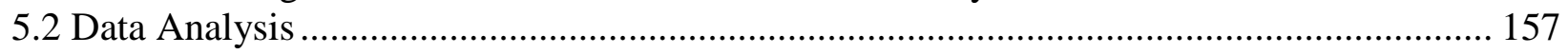

5.2.1 Descriptive Analysis of the Survey for the Evaluation of the Videos.................158

5.2.2 Ordered Probit Models with Random Effects...................................162

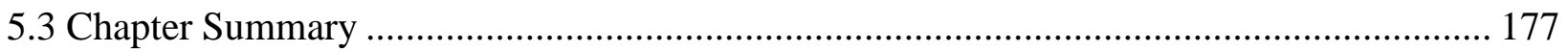

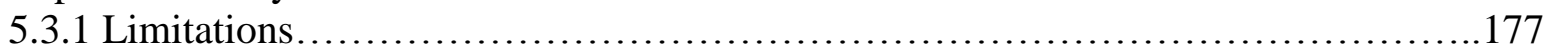

5.3.2 Recommendations for Future Studies.......................................178

CHAPTER 6. USE OF CAMERA SYSTEMS TO PREVENT WORKERS INJURED BY MOBILE EQUIPMENT IN NIGHTTIME OPERATIONS ................................ 179

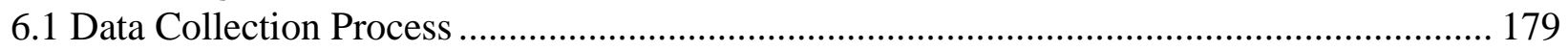

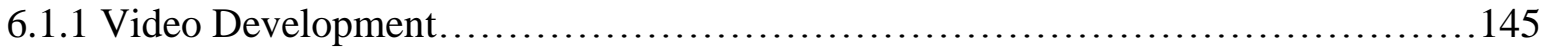

6.1.2 Survey Development and Implementation.....................................147

6.1.3 Measurement of the Safe Stopping Distance Zone............................. 149

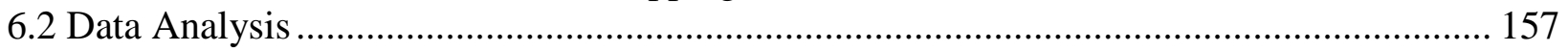

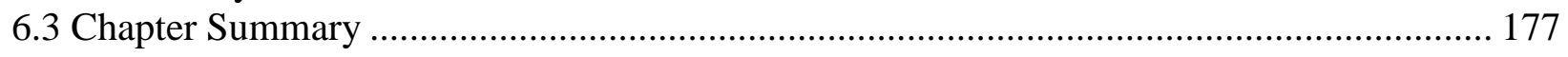

6.3.1 Research Limitations......................................................... 177

6.3.2 Recommendations for Future Studies...................................... 178

CHAPTER 7. USE OF CAMERA SYSTEMS TO INCREASE PRODUCTIVITY OF MOBILE

EQUIPMENT IN NIGHTTIME OPERATIONS ..................................... 143

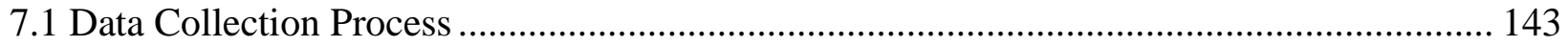

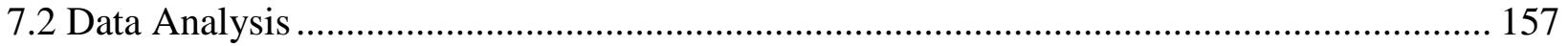

7.2.1 Results of Hypothesis Testing ................................................200

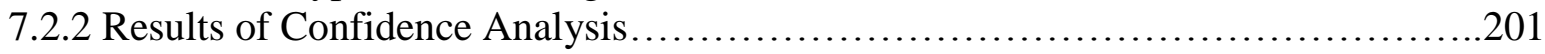

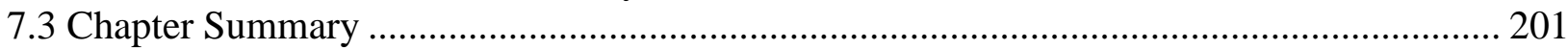

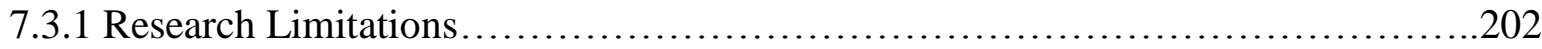

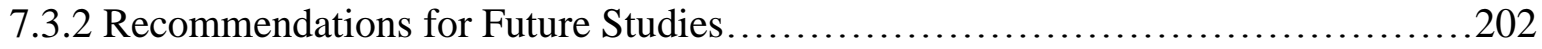

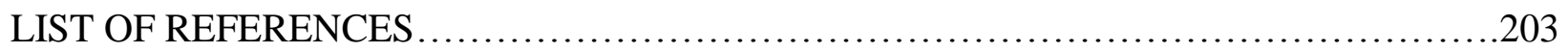

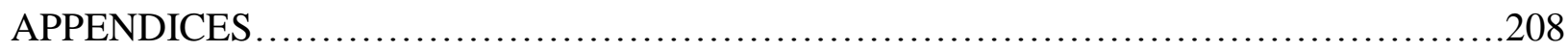

Appendix A. Survey Distributed to Workers............................................................................ 209

Appendix B. Survey Distributed to Safety Officers in Departments of Transportation .............. 217

Appendix C. Survey Distributed to Supervisors in Construction Companies ............................. 225 
Appendix D. Survey Administered to Owners ................................................................ 233

Appendix E. Survey Administered to General Contractors.................................................... 243

Appendix F. Survey Administered to Construction and Maintenance Workers ...................... 253

Appendix G. Survey Distributed to Students for the Evaluation of the Videos ....................... 261 


\section{LIST OF TABLES}

Page

Table 2.1 Hazards leading to serious or fatal occupational injuries in work zones (adapted from LHSFNA2006). .8

Table 2.2 Hazards leading to occupational illnesses and non-serious injuries in work zones (adapted from LHSFNA, 2006) .............................................

Table 2.3 Worker fatalities in work zones over the 1995 to 2000 period, resulting from workers being struck by vehicle or mobile equipment, by source of the fatality................10

Table 2.4 Recurrent events of serious or fatal accidents in work zones in the State of New York, 1993-1997 (Bryden and Andrew).............................................12

Table 2.5 Factors leading to "worker struck by mobile equipment" accident event...............13

Table 2.6 Injury Severities in NYSDOT Construction Project Accidents 1993-1998..............15

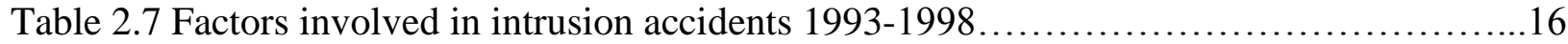

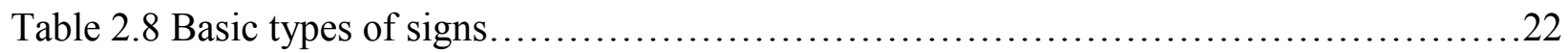

Table 2.9 Channeling devise spacing for particular workzone conditions...................24

Table 2.10 Safety items and sub-items evaluated for safety measures satisfaction survey.........25

Table 2.11 Types of Personal Protective Equipment............................................

Table 2.12 High-visibility apparel classification.............................................

Table 2.13 Strategies to improve the use of high-visibility apparel (NIOSH 2001)..............36

Table 2.14 Strategies to improve safe equipment operation (NIOSH 2001) ....................38

Table 2.15 Strategies to improve workzone safety nighttime construction (TRB 2000)..........42

Table 2.16 Illumination guidelines for Highway Construction (adapted from FHWA)............44

Table 2.17 Recommendations based on safety policies to prevent occupational injuries resulting from 'worker struck by mobile equipment' ................................................45 Table 2.18 Other recommendations to prevent occupational injuries resulting from 'worker struck by mobile equipment' .............................................................. 46 Table 2.19 Accident cases where the back-up alarm system was not an effective tool to prevent fatal injuries in work zones (data from NIOSH-FACE reports).............................48 Table 2.20 Summary of test results for collision warning system on a Komatsu $210 \mathrm{M}$ mining

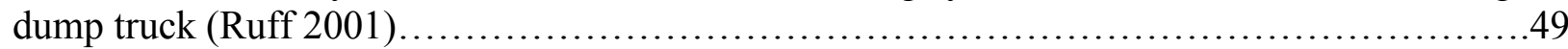

Table 2.21Summary of collision warning systems tested in highway construction and maintenance activities................................................................. 51 Table 2.22Summary of factors and variables related to construction lighting that influence glare and the basis of their selection (adapted from Hyari 2004)..................................56 Table 2.7 List of factors affecting productivity of construction operations (Adapted from Colbert

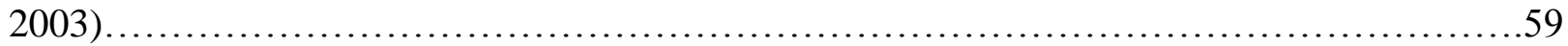

Table 3.1 Classification according to the characteristics of the project and the injured worker(s)

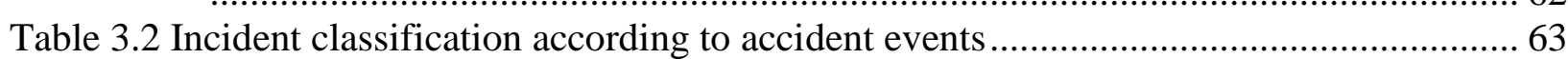

Table 3.3 Incident classification according to behavioral causes.............................64

Table 3.4 Site visits performed to administer the surveys.................................66

Table 3.5 Rate of response for surveys distributed among work zone personnel...............67 
Table 3.6 Distribution of work zone fatal incidents according to occupation of the injured workers, all U.S., 2000-2006........................................... 71

Table 3.7 Distribution of work zone fatal incidents according to industry classification for the employer company of the injured worker(s), all U.S., 2000-2006........................ 73

Table 3.8 Distribution of work zone fatal occupational incidents according to accident events, all U.S., 2000-2006.

Table 3.9 Distribution of work zone fatal occupational incidents according to behavioral causes, all U.S., 2000-2006. 75

Table 3.10 Distribution of mobile equipment related occupational incidents according to the source of injury, all U.S., 2000-2006 ......................................................... 75

Table 3.11 Distribution of mobile equipment related occupational incidents according to the behavioral causes, all U.S., 2000-2006

Table 3.12 Satisfaction level with the training received or provided for different safety provisions

Table 3.13 Average scores of workers and supervisory personnel for the occurrence of five major accident events

Table 3.14 Average scores provided by workers and supervisors for the occurrence likelihood of behavioral causes of accidents. 79

Table 3.15 Independent Variables considered in the development of the binomial logit model.. 81

Table 3.16 Example of the modifications performed to the data collected .............................. 85

Table 3.17 Description and summary statistics for variables in the binomial logit model.......... 86

Table 3.18 Marginal effects for variables in the binomial logit model .................................. 89

Table 4.1 Worker Sample Distribution .............................................................................. 96

Table 4.2 General Contractor Sample Distribution .......................................................... 97

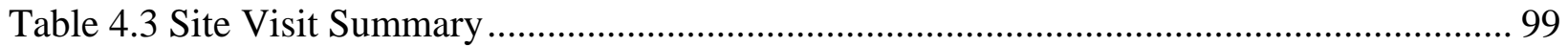

Table 4.4 Effectiveness Ratings for Safety Strategies Evaluated in Administered Surveys ...... 119

Table 4.5 Variables Considered in the Statistical Model Development .................................. 123

Table 4.6 Effectiveness of Training for Workers and Staff: Binary Logit Model.................... 126

Table 4.7 Marginal Effects for the Effectiveness of Training for Workers and Staff: Binary Logit

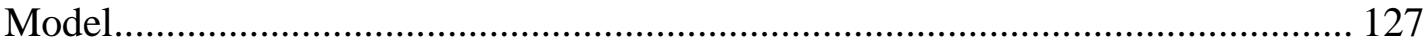

Table 4.8 Effectiveness of Warning Signs: Binary Logit Model.......................................... 128

Table 4.9 Marginal Effects for the Effectiveness of Warning Signs: Binary Logit Model ........ 130

Table 4.10 Effectiveness of Worker Safety Apparel: Binary Logit Model ............................. 131

Table 4.11 Marginal Effects for the Effectiveness of Worker Safety Apparel: Binary Logit Model

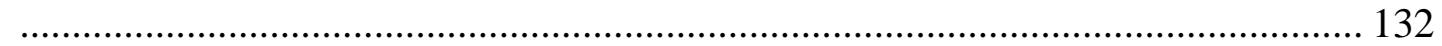

Table 4.12 Effectiveness of Alert Systems: Binary Logit Model .......................................... 133

Table 4.13 Marginal Effects for the Effectiveness of Alert Systems: Binary Logit Model ....... 135

Table 4.14 Effectiveness of Retro-reflective Clothing: Binary Logit Model ........................... 136

Table 4.15 Marginal Effects for the Effectiveness of Retro-reflective Clothing: Binary Logit

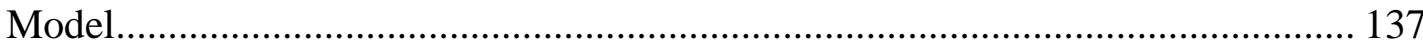

Table 5.1 Cameras systems evaluated during the testing ................................................ 144

Table 5.2 Radar systems evaluated during the testing .................................................. 145

Table 5.3 Truck characteristics and combination of the systems installed in each truck......... 146

Table 5.4 Sample population and rate of response of the survey ........................................ 156 
Table 5.5 Videos evaluated by group 1

Table 5.6 Independent variables considered in the development of the ordered probit model with

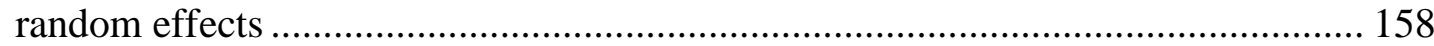

Table 5.7 Number of times each characteristic related to the mannequin/site was evaluated.... 162

Table 5.8 Mean and standard deviations for independent variables in the ordered probit model with random effects

Table 5.9 Ordered probit model with random effects of the distance from the backing dump truck to the mannequin.

Table 5.10 Marginal effects for the ordered probit model with random effects.....

Table 5.11 Ordered probit model with random effects for comparing the difference between Class II and Class III safety vests.

Table 5.12 Ordered probit model with random effects, including only data collected for Camera 1

Table 5.13 Summary of the models performed and recommendations on the use of camera backing systems in work zones.

Table 6.1 Combination of videos recorded for each system. 181

Table 6.2 Characteristics of safety garments used in this research. .181

Table 6.3 Sample population and response rate of the survey.............................184

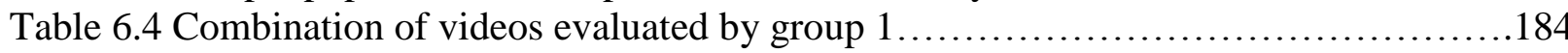

Table 6.5 Truck weights and stopping distance required..................................185

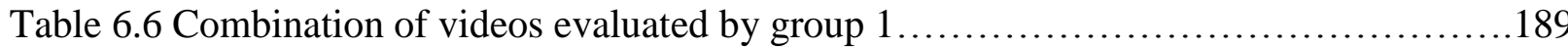

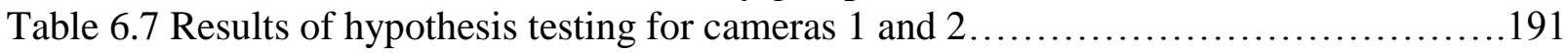

Table 6.8 Results of confidence analysis...........................................191

Table 6.9 Weights of camera characteristics based on responses given by workers

Table 6.10 Scores of camera characteristics based on responses given by students, workers, and the combination of both groups

Table 7.1 Results of hypothesis testing .200

Table 7.2 Results of confidence analysis for cameras 1 and 2 201 


\section{LIST OF FIGURES}

Page

Figure 2.1 Distribution of serious/fatal injuries within the traffic accidents group, New York State Department of Transportation, 1993 to 1997 (adapted from Bryden and Andrew 1999)

Figure 2.2 Distribution of serious/fatal injuries in the construction accidents group, New York 11 State Department of Transportation, 1993 to 1997 (adapted from Bryden and Andrew 1999)

Figure 2.3 Distribution of fatal occupational accidents in the event of worker struck by mobile equipment, by sub-event and source of injury, 2001 to 2005, United States, ,.......... 14

Figure 2.4 Stopping Distances for Motorists (Roadway Safety Program 2003) ....................... 17

Figure 2.5 Strategies to Improve Worker Safety ................................................................... 17

Figure 2.6 Speed Distributions for Daytime, Passenger Cars on I-70 in Kansas (Meyer 2000). . 40

Figure 2.7 Speed Distributions for Daytime, Trucks on I-70 in Kansas (Meyer 2000). ............. 40

Figure 2.8 Detection zone for a person with a pulsed radar-based system (Ruff 2004).............. 52

Figure 3.1 Distribution of the workers by age and tenure working in highway

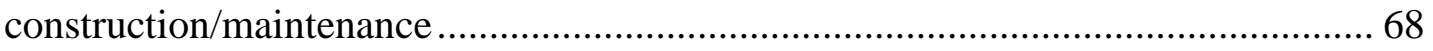

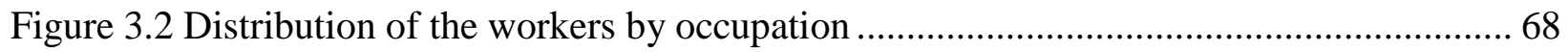

Figure 3.3 Work zone fatal incidents and injuries per year, all U.S., 2000-2006...................... 69

Figure 3.4 Top 10 states according to number of work zone fatal incidents, all U.S ............70

Figure 3.5 Distribution of work zone fatal incidents according to the age of the injured worker, all U.S., 2000-2006................................................................................. 71

Figure 3.6 Distribution of work zone fatal incidents according to the cost of the project, all U.S.,

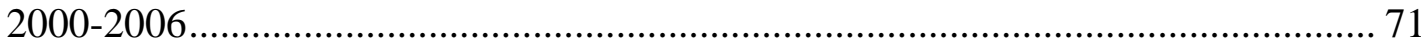

Figure 3.7 Distribution of work zone fatal incidents according to time of the day when the

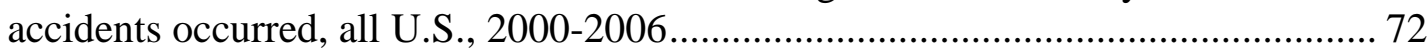

Figure 4.1 Safety Training undertaken by Construction and Maintenance Workers............101

Figure 4.2 Elements in the Work Zone that Make Workers Feel Safe ................................... 102

Figure 4.3 Frequency of Worker Attendance at Safety Meetings........................... 103

Figure 4.4 Commonly Covered Topics on Safety Trainings ................................................. 104

Figure 4.5 Importance of Factors Affecting the Evaluation of the Effectiveness of Safety

Strategies ............................................................................................. 105

Figure 4.6 Level of Risk of Safety Hazards in Highway Construction and Maintenance Work

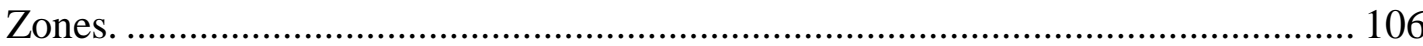

Figure 4.7 Occurrence of Safety Hazards in Highway Construction and Maintenance Work Zones. ....................................................................................................... 108

Figure 4.8 Effectiveness Ratings of Administrative Safety Strategies ................................. 109

Figure 4.9 Effectiveness Ratings of Traffic Control Strategies ............................................ 111

Figure 4.10 Currently-Used Speed Warning Signs in Construction and Maintenance Projects 112 Figure 4.11 Effectiveness Ratings of Measures to Improve Safety in the Work Zone ............. 113 
Figure 4.12 Currently-Used Types of Worker Safety Apparel in Construction and Maintenance Projects.

Figure 4.13 Effectiveness Ratings of Innovative Technologies for Hazard Control.................. 116

Figure 4.14 Effectiveness Ratings of Nighttime Traffic Control Strategies ............................... 118

Figure 4.15 Binary Logit Model Discrete Outcomes................................................................ 121

Figure 5.1 Camera 1 and radar antenna 2 installed in truck 1 .................................................. 146

Figure 5.2 Additional brackets needed for installation of radar antennae in trucks 1 (left) and 2

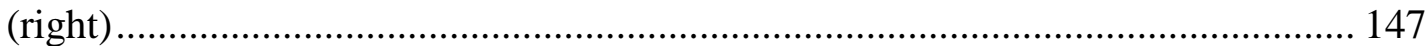

Figure 5.3 Final mounting position for camera and radar antenna on truck 1.......................... 148

Figure 5.4 Final mounting position for camera and radar antenna on truck 2 .......................... 148

Figure 5.5 Final mounting position for camera and radar antenna on truck 3 .......................... 148

Figure 5.6 Steps in measuring the detection zone of the radar systems (drawing not to scale) . 149 Figure 5.7 Field of view of camera 2 and radar 1 detection zone for a 5 feet 7 inches tall person in a standing and a crouching position ................................................................... 151

Figure 5.8 Field of view for camera 1 and instances at which radar 2 detected a 5 feet 7 inches tall person in a standing position......................................................................... 151

Figure 5.9 Field of view of camera 3 and radar 3 detection zone for a 5 feet 7 inches tall person in a standing and a crouching position ............................................................. 152

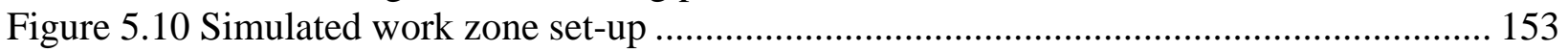

Figure 5.11 Combination of videos recorded from each camera .............................................. 154

Figure 5.12 Comparison of different parameters with mannequin situated in location 1........... 154

Figure 5.13 Example frame for one of the videos evaluated through the survey ...................... 155

Figure 5.14 Age distribution of the respondents ................................................................. 159

Figure 5.15 Academic-year distribution for undergraduate students......................................... 159

Figure 5.16 Field of view, glare, and image quality of each camera provided by the respondents

Figure 5.17 Comparison of the field of view scores for the cameras under different mannequin

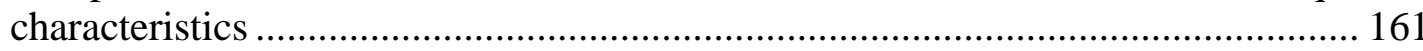

Figure 5.18 Comparison of the safety vests used for the developing of the videos (Valentín 2007)

Figure 5.19 Categorization of the distance from the dump truck to the mannequin into discrete

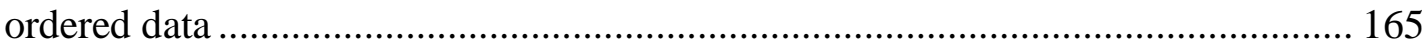

Figure 5.20 Comparison between locations 1a and 1b ....................................................... 169

Figure 5.21 Comparison between video frames when mannequin was wearing a safety vest class II, and when the mannequin was not wearing a safety vest. .................................. 169

Figure 6.1 Setup of simulated work zone used to test camera system performance in assisting equipment operators in viewing equipment blind spot.........................180

Figure 6.2 Sample frame from video used during survey ................................ 183

Figure 6.3 Age distributions of student and worker respondents............................186

Figure 6.4 Summary of student ratings of camera characteristics............................188

Figure 6.5 Summary of worker ratings of camera characteristics........................... 188

Figure 7.1 Setup of simulated workzone used to test camera system performance in assisting equipment operators in viewing equipment blind spot..........................199 


\section{CHAPTER 1}

\section{INTRODUCTION}

As evidenced in recent years, accidents tend to increase when there is an increase in construction activity which has grown due to increased federal/state funding. This trend of increased highway construction and/or rehabilitation is expected to continue into the next decade. The public often demands that delays in work zones be kept to a minimum. Thus, the flow of traffic through the construction zone must be maintained while performing pavement maintenance/ repair/ reconstruction activities. At the same time, the safety of personnel and property in highway construction work zones must be ensured.

The National Safety Council reports that the average economic cost per work related per disabling injury in the U.S. in 2004 was $\$ 34,000$, including lost wages, medical expenses, administrative expenses, and employer costs" translating to more than half a billion dollars in 2004 due to road construction. These costs do not include the impact of the 1,186 fatal injuries (National Workzone Safety Information Clearing House 2003) among road construction and maintenance workers and the impact of these fatalities on the families of the workers and the employers of these workers. The economic cost (including employer costs) per work related fatality was $\$ 1.15$ million. Indirect costs tend to be as high as 30 times the direct cost (International Safety Equipment Association).

Three types of risks are encountered by construction and maintenance workers in construction workzones:

a) risks due to underprotection or lack of protection against potential hazards (including lack of hearing protection, eye protection, respiratory protection)

b) effect of speeding through workzones

c) impacts due to the lack of/inadequate visibility issues (both workers and motorists) 
There is pressing need to analyze these risks in greater depth and to evaluate the hazards associated with the construction and maintenance operations undertaken by Indiana Department of Transportation (INDOT) workers, particularly as the State of Indiana is engaged in accelerated construction projects as part of the Major Moves initiative.

\subsection{Project Objectives}

In partial fulfillment of the study's scope, three separate but inter-related research studies were conducted between September 2006 and June 2008. The first study identified common causes

and patterns of fatal accidents in construction and maintenance work zones. The perception of work zone personnel about these causes was also evaluated in this study. The second study evaluated the perception of the owner, worker, and contractor about safety strategies implemented in work zones. The third study, evaluated the use of radar and camera systems as a measure to reduce the occurrence of accidents related to backing mobile equipment in work zones. The following sections summarize the scope and objectives for the respective studies:

Study 1: Analysis of Accident Reports and Perspectives of Work Zone Personnel of Causes of Accidents

The first objective of this study was to assess common causes and patterns of fatal accidents in construction and maintenance work zones that were not identified by previous studies on the subject. To achieve this objective, accident reports of worker fatalities that occurred in work zones in recent years were analyzed. The second objective of this research was to evaluate the perception of work zone personnel about potential hazards, common causes of accidents in work zones, and other safety issues related to the safety training received by the workers and provided by the supervisory personnel. This second objective included a comparison of the perception of work zone personnel with the wok zone accident information gathered from the analysis of accident reports and other literature on the subject. The purpose of this comparison was to find deviations in the perception of work zone personnel about work zone accidents (when compared with the analysis of accident reports), and in this manner, provide recommendations for the improvement of safety programs. 


\section{Study 2: Evaluation and Assessment of Work Zone Safety Strategies}

The main objective of this study is to analyze the effectiveness of various safety strategies used on highway construction and maintenance projects. Prior to this analysis, the sources of risk or safety hazards for workers and the currently used safety strategies and procedures will be identified by conducting the surveys and field observations. The main objectives of the analyses include:

- Evaluation of the effectiveness of current work zone safety strategies used in highway construction and maintenance projects by assessing the perspectives of construction and maintenance workers, general contractors, and owners (state DOTs).

- Analysis of the factors that affect the worker perception of the effectiveness of safety strategies.

This study will provide INDOT with recommendations for the most effective safety strategies based on the perception of the workers, contractors, and owners, which can be implemented in the agency's safety plans and procedures.

Study 3: Use of Camera and Radar Systems to Prevent Workers Injured by Mobile Equipment

The main objective of this research was to evaluate a potential safety strategy to reduce a common cause of fatal injuries in work zones. The analysis of the accident reports and the literature review on work zone accidents in the second study, reflected that "workers struck by backing vehicles which were part of the work zone project" was the main specific accident event where worker fatal injuries occurred that did not involved passing motorists. The evaluation of three different camera systems and three radar systems was performed as a measure to prevent this type of accident. With the camera systems, a testing was conducted to achieve the following objectives: (1) evaluation of the performance of the different camera systems and (2) the identification of the factors that affect the identification of a worker (represented by a mannequin) in the path of a backing dump truck when camera systems are used. 


\subsection{Research Methodology}

To achieve the objectives of the first study above, a multi-step process was conducted. A literature review was conducted with the purpose of identifying hazards in work zones, sources of occupational injuries information, accident events in highway construction and maintenance work zones, and accident causation models for construction. After the literature review, the next step was the analysis of available accident reports of workers fatalities that occurred in work zones across the United States in recent years. Based on the results obtained from the analysis and the literature review conducted, surveys were developed and distributed to work zone personnel in projects in Indiana to determine their perspectives about the causes of accidents in work zones. The comparison of the analysis of accident reports and the perception of work zone personnel determined a contradiction between the high occurrence of worker lack of awareness in the accident reports analyzed and the perception of workers, who indicated that worker lack of awareness was a less occurring cause of accidents. To evaluate factors that affect the perception of workers in this regard, a binomial logit model was performed.

In order to accomplish the objectives of the second study, a multi-step process was also undertaken. A state-of-the-art literature review was performed to identify the risks for workers in highway construction and maintenance projects, as well as the methods to reduce safety hazards in the work zone. In addition, a preliminary evaluation of various currently used safety strategies was performed by reviewing the safety procedures and policies of several state Departments of Transportation (DOTs) and the Manual of Uniform Traffic Control Devices (MUTCD). This information was then used in the development of the surveys that were administered to owners, general contractors, and workers. The data obtained from the returned surveys and the performed site visits were used to perform a qualitative and quantitative analysis of the effectiveness of the currently used safety strategies. The perspective of the workers obtained from the survey was then analyzed using a discrete outcome model to determine the most significant factors that affect the perception of the effectiveness of the highest rated safety strategies in each category. 
For the third study, a literature review was performed to identify potential strategies to reduce the occurrence of occupational injuries related to mobile equipment in work zones. Radar and camera systems were installed on dump trucks performing maintenance activities in work zones. Different characteristics for both types of systems were measured. The evaluation of the camera systems as a potential measure to prevent the occurrence of workers struck by backing dump trucks was performed through a test set-up, which consisted of the development of videos recorded from the images captured by the cameras installed on three dump trucks while backing through a simulated work zone. A mannequin simulating a worker was placed in the work zone under different parameters (safety vest design, position, location). These videos were then shown to potential drivers who evaluated the images in a survey provided to them. With the responses obtained in the survey, an ordered probit model with random effects was performed to find the factors that influence the detection of a worker in the path of a backing dump truck through the use of camera systems. Similar studies were performed to evaluate the use of these camera systems in preventing workers injured by mobile equipment used in nighttime construction operations. Additionally, the use of camera systems as a measure to increase productivity of mobile equipment used in nighttime construction operations was evaluated.

\subsection{Organization of the Report}

The report is organized into seven chapters. The second chapter provides the review of literature pertaining to identifying hazards in work zones, accident events in highway construction and maintenance work zones, and work zone safety strategies. Chapter 3 summarizes the data collection process about causes of accidents in work zones and the perspectives of different work zone personnel of these causes. This chapter includes also the descriptive analysis of the accident reports and the descriptive and statistical analysis of the survey distributed to work zone personnel. Additionally, the results obtained from this research, the limitations, and recommendations for future studies are also presented in the chapter.

Chapter 4 discusses the data collection process related to the analysis of the currently-used work zone safety strategies. This chapter also includes an analysis the surveys distributed to the workers to determine the effectiveness of safety strategies and the factors that influence their 
safety perception. Five binary logit models were developed using the data collected from the surveys distributed to construction and maintenance workers. In addition, the chapter discusses the results obtained from this research, its limitations, and recommendations for further study.

Chapter 5 as part of the data collection process for the evaluation of the radar and camera systems summarizes the installation of the systems, the development of the experimental testing for the evaluation of the cameras, and the development and implementation of the survey for the videos recorded during the experimental testing. This chapter presents also the results of the ordered probit model with random effects performed to determine the factors influencing the identification of a worker (represented by a mannequin). Limitations for this research, recommendations on the use of camera systems in work zones, and recommendations for future studies on this subject are also presented in Chapter 5.

Chapter 6 presents the evaluation process for the use of camera systems to prevent workers injured by mobile equipment in nighttime operations. The development of videos is described in this chapter. Additionally, the development and implementation of surveys to evaluate the camera systems is described in Chapter 6. The analysis of the data collected from the surveys, limitations of the study, and recommendations for further research are included in Chapter 6.

Chapter 7 discusses the use of rear-mounted camera systems as tools to increase the productivity of mobile equipment used in nighttime construction operations. The development of a simulated loading task is described in this chapter as well as the data collected through time studies. The analysis of the data collected from the time studies, limitations of the research, and recommendations for future studies are presented in Chapter 7. 


\section{CHAPTER 2}

\section{LITERATURE REVIEW}

Safety practices in highway construction differ from safety practices in other sectors of the construction industry. This is mainly due to the continuing interaction between the public (e.g., motorists, bicyclists, pedestrians), and construction project personnel (e.g., laborers, equipment operators, supervisors) in a limited area. This interaction not only generates risk to the public traveling through highway construction sites, but also increases the potential for occupational accidents for workers. The construction or maintenance sites on highways, streets, and bridges are denoted as "work zones." A work zone can be defined as "an area of a highway with construction, maintenance, or utility work activities. A work zone is typically marked by temporary traffic control (TTC) devices, such as signs, channelizing devices, barriers, pavement markings, and/or work vehicles. It extends from the first warning sign or high-intensity rotating, flashing, oscillating, or strobe lights on a vehicle to the END ROAD WORK sign or the last TTC device" (FHWA 2003).

Adding the traveling public to a congested highway construction site has several safety implications. There were, on average, 1,068 fatalities per year in 2001 to 2005 due to work zone crashes in the United States; almost $85 \%$ of the victims were the drivers and other occupants of traveling vehicles (FHWA 2006). Although passing motorists pose a great risk to workers, it is not the only hazard workers confront while performing their regular activities. According to Pratt et al. (2001), 492 work zone occupational fatalities were reported from 1992 to 1998 in the Census of Fatal Occupational Injuries (CFOI). Three hundred and eighteen of these workers (318) were struck by vehicles, 154 of this group were fatally injured by construction equipment.

In order to improve safety programs and thereby reduce the risk of fatal workplace accidents in construction work zones, the prevailing causes of fatal injuries must be identified. The present research aims to evaluate the circumstances leading to fatal occupational injuries in highway work zones and a possible strategy to reduce the occurrence of serious and fatal occupational injuries in a specific accident event. This chapter provides both a descriptive and critical 
analysis of prior research in (1) hazards in highway construction and maintenance activities, (2) accident events leading to serious injuries in work zones, and (3) and strategies to mitigate accidents resulting in occupational injuries in work zones.

\subsection{Hazards in Highway Construction and Maintenance Activities}

Hazards in construction can be classified according to the severity of the injury that might result from them; namely, those that increase the risk of serious and fatal injuries and those that increase the occurrence probability of non-serious injuries and occupational illnesses. Table 2.1lists hazards leading to serious or fatal occupational injuries in highway work zones. Similarly, Table 2.2 shows hazards that increase the risk of occupational illnesses and nonserious injuries in work zones. Along with the hazards, the possible types of accident or illness that can result from each hazard are also presented in both tables. Although the hazards listed in Table 2.2 lead mostly to occupational illnesses and non-serious injuries, in extreme cases, they can lead to serious or fatal workplace injuries.

Table 2.1 Hazards leading to serious or fatal occupational injuries in work zones (adapted from LHSFNA, 2006)

\begin{tabular}{|c|c|}
\hline Hazardous aspect & Manifestation of hazardous aspect \\
\hline Passing motorists near workers & Risk of workers being struck by vehicles \\
\hline \multirow{3}{*}{ Heavy equipment } & Risk of workers being run or backed over by equipment \\
\hline & Risk of worker coming in contact with equipment \\
\hline & Risk of workers being caught or crashed in or between equipment \\
\hline \multirow{4}{*}{ Nighttime work } & $\begin{array}{l}\text { Lack of visibility for motorists, workers on foot, and equipment } \\
\text { operators, which can increase the occurrence of the consequences } \\
\text { for the previous two hazards }\end{array}$ \\
\hline & $\begin{array}{l}\text { Increment in the number of speeders, therefore increment in the } \\
\text { risk for workers }\end{array}$ \\
\hline & Drowsy drivers increase risk for workers \\
\hline & Sleep disruption and drowsiness for workers \\
\hline \multirow{5}{*}{ Excavation activities } & Risk of cave-ins \\
\hline & Flammable/toxic gas can build up \\
\hline & Gas from nearby sewer or gas lines can seep into a trench \\
\hline & Contact with buried power lines \\
\hline & Risk of falls from ground level to lower level \\
\hline Overhead power lines & Contact of workers and/or equipment with electric current \\
\hline Embankments & Equipment roll or slid over \\
\hline Elevations & $\begin{array}{l}\text { Risk of falls from equipment, bridges, and formwork to a lower } \\
\text { level }\end{array}$ \\
\hline
\end{tabular}


Table 2.2 Hazards leading to occupational illnesses and non-serious injuries in work zones (adapted from LHSFNA, 2006)

\begin{tabular}{|c|c|}
\hline Hazardous aspect & Manifestation of hazardous aspect \\
\hline Holes and irregular ground & Falls from the same level, trips \\
\hline Noise & $\begin{array}{l}\text { Distracted workers may not hear warnings, can lead to serious } \\
\text { injury from mobile equipment or motorists; damage to worker's } \\
\text { hearing }\end{array}$ \\
\hline \multirow{4}{*}{ Toxic substances } & Silicosis from silica dust from concrete, rocks \\
\hline & Asphalt can cause respiratory irritation and skin burns \\
\hline & Wet concrete can lead to dermatitis and skin burns \\
\hline & Lead can cause damages in nervous and reproductive systems \\
\hline $\begin{array}{l}\text { Inappropriate postures, handling of } \\
\text { heavy materials, and repetitive work }\end{array}$ & Hand/wrist problems, back injuries, sprains, strains, overexertion \\
\hline \multirow{4}{*}{ Outdoor work } & Sun exposure might cause skin cancer and sunburn \\
\hline & Hot weather may lead to heat stress, heat exhaustion, stroke \\
\hline & Hypothermia, frostbite due to cold weather exposure \\
\hline & $\begin{array}{l}\text { Exposure to animals and plants can cause rashes, illnesses, even } \\
\text { death }\end{array}$ \\
\hline
\end{tabular}

\subsection{Accident Events Leading to Serious and Fatal Injuries in Work Zones}

Prior studies have all presented some degree of statistics, listing parameters such as occupation of the injured worker, type of event, and sources of fatal or serious occupational fatalities as the most remarkable parameters found to be the causes of injuries. However, prior studies did not analyze cases that resulted in less serious injuries due to the lack of available data and written/recorded narratives of these types of accidents. Pegula (2004) developed a classification of 844 fatal occupational injuries that took place in work zones during 1995 to 2002 in the United States. Classification was done according to the following parameters: the demographic characteristics of the worker, the state in which the injury occurred, the event or exposure, the industry, and the worker's occupation.

One of the most significant findings from this study was that most of the workers were fatally injured in the event "worker struck by vehicle or mobile equipment" (approximately 60\% of the injured workers). Classification of the fatalities within this type of event according to characteristics such as the source (i.e., type of vehicle or equipment) and the worker activity are also evaluated. There was no distinction, however, whether the sources of fatalities were or were not directly related to the work zone project. Table 2.3 lists the sources of fatalities for the event of a worker struck by a vehicle or mobile equipment. As shown in the table, dump trucks were 
the main source of fatal injuries in work zones with about $20 \%$ of the total fatalities for that event.

Bryden and Andrew (1999) documented an analysis of 240 accidents that resulted in hospitallevel or fatal occupational injuries. These accidents occurred during a five-year period (1993 to 1997) in highway and bridge construction projects awarded by the New York State Department of Transportation (NYSDOT). The accidents were classified by event in two main categories: traffic and construction accidents. The former refers to accidents involving a motorist traveling through the work zone resulting in an injured worker. The construction category includes accidents related to construction activities. It also involves accidents related to work vehicles on the construction project. In the study the accidents within the construction category were categorized into three main sub-groups: falls, injuries from tools and equipment, and other (Bryden and Andrew 1999).

Table 2.3 Worker fatalities in work zones over the 1995 to 2000 period, resulting from workers being struck by vehicle or mobile equipment, by source of the fatality

\begin{tabular}{|c|c|}
\hline Source & Number of fatalities \\
\hline Vehicles & 446 \\
\hline Highway vehicle-motorized. & 441 \\
\hline Automobile & 143 \\
\hline Truck.......... & 274 \\
\hline Dump truck & 100 \\
\hline Pick up truck............................ & 57 \\
\hline Semi-trailer, tractor trailer, or trailer truck & 53 \\
\hline 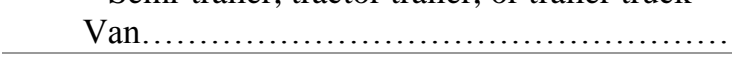 & 14 \\
\hline Machinery & 63 \\
\hline Construction, logging, and mining machinery... & 56 \\
\hline Excavating machinery & 21 \\
\hline Backhoes..................... & 9 \\
\hline Bulldozers & 6 \\
\hline Road grading and surfacing machinery....... & 30 \\
\hline Graders, levelers, planers, and scrapers & 20 \\
\hline Steam rollers and road pavers.............. & 6 \\
\hline
\end{tabular}

The distribution of the accidents in the traffic accidents category presented in Bryden and Andrew (1999) is shown in Figure 2.1. The total number of occupational injuries in the construction category was 53 , including six fatalities. The most representative group was "worker struck by vehicle in work space" with nine hospital-level injured workers. 
Alternatively, Figure 2.2 illustrates the distribution of construction accidents within its three main sub-groups.
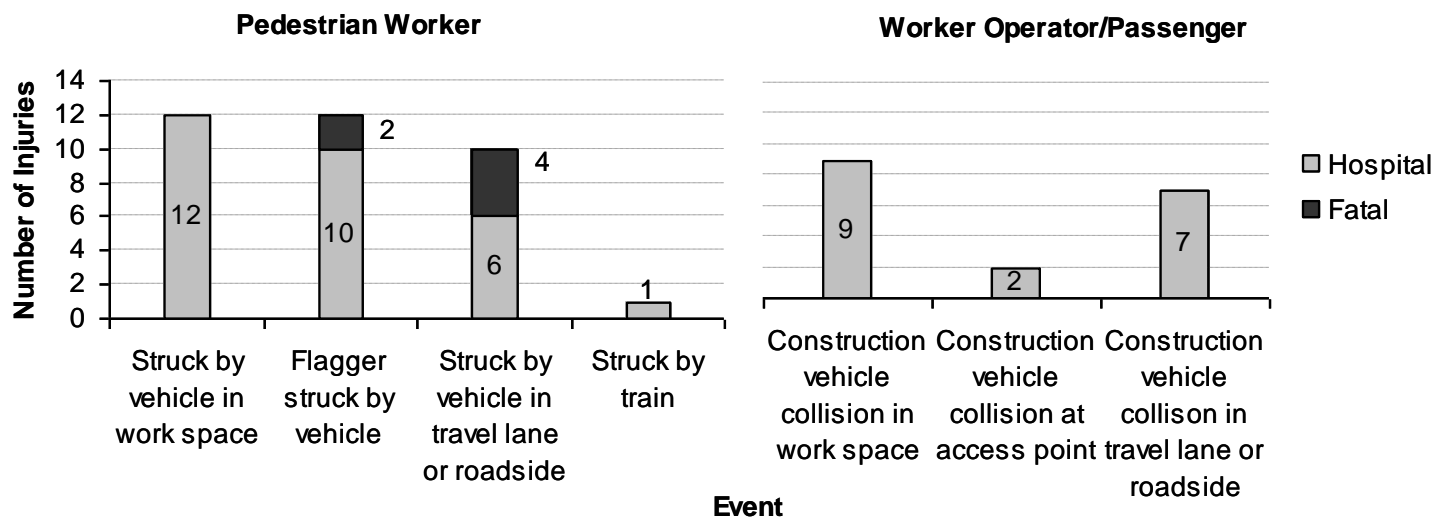

Figure 2.1 Distribution of serious/fatal injuries within the traffic accidents group, New York State Department of Transportation, 1993 to 1997 (adapted from Bryden and Andrew 1999)

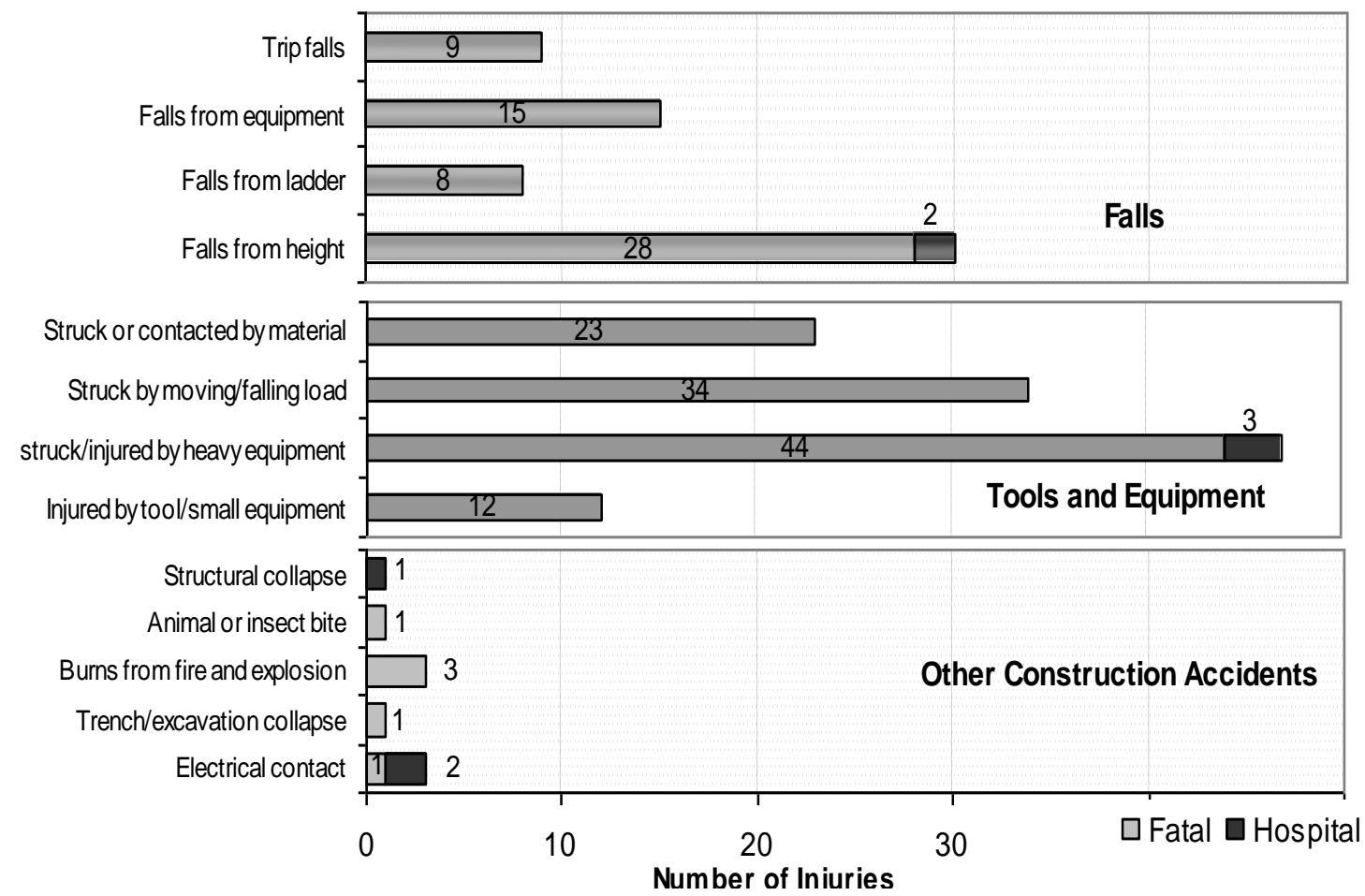

Figure 2.2 Distribution of serious/fatal injuries in the construction accidents group, New York State Department of Transportation, 1993 to 1997 (adapted from Bryden and Andrew 1999) 
The results obtained by Bryden and Andrew (1999) are significant in terms of serious occupational injuries that do not result in fatalities. There was a remarkable number of hospitallevel accidents related to tools and equipment, which represented exactly $50 \%$ of the total number of "hospital-level accidents" for the five-year period. This result infers that materials, moving or falling loads, and tools or small equipment are also relevant hazards not acknowledged separately by other studies and/or statistics. The study also documents some specific and repetitive accident events, which are listed in Table 2.4

Table 2.4 Recurrent events of serious or fatal accidents in work zones in the State of New York, 1993 to 1997 (Bryden and Andrew 1999)

\begin{tabular}{lc}
\hline \multicolumn{1}{c}{ Type of accident } & $\begin{array}{c}\text { Number of } \\
\text { injuries }\end{array}$ \\
\hline Struck by backing equipment or truck & 8 (2 fatal) \\
Struck by moving equipment or truck & 4 \\
Struck by backhoe or loader bucket & 6 \\
Pinched or crushed by moving equipment or truck & 5 \\
Struck by broken chain or cable & 5 \\
\hline
\end{tabular}

Although Bryden and Andrew (1999) developed specific classifications for work zone events, these classifications are somewhat generic. For instance, there is no consideration of the most common source of injury (e.g., dump truck, tanker truck, and roller) involved in the event of workers backed over by vehicle/equipment. Another aspect not evaluated by Bryden and Andrew (1999) was responsibility of the accidents; for example, the percentage of accidents that occurred due to driver negligence (e.g., intoxicated driver), or the number of workers injured from falls due to inappropriate use or lack of use of fall protection. Knowledge of these factors can optimize prevention strategies and safety budget allocation.

\subsubsection{Fatal Occupational Injuries resulting from "Worker Struck by Mobile Equipment” in Work Zones}

The Fatality Assessment and Control Evaluation (FACE) program has published 33 accident reports of 34 fatal occupational injuries that occurred in work zones during 2001 to 2005 in the United States. According to the analysis of FACE reports where the event was worker struck by mobile equipment, at least one of the following six factors existed when these accidents 
occurred: (1) lack of awareness, (2) reduced visibility, (3) unsafe methods or sequencing, (4) misjudgment of a hazardous situation, (5) lack of communication, (6) and reduced audibility. Explanations for each factor are described in Table 2.5.

Table 2.5 Factors leading to "worker struck by mobile equipment" accident event

\begin{tabular}{|c|c|}
\hline Factor & Definition \\
\hline Lack of awareness & $\begin{array}{l}\text { Workers on foot and drivers/operators are not aware of the presence of } \\
\text { equipment and co-workers. }\end{array}$ \\
\hline Reduced visibility & $\begin{array}{l}\text { Problems related to blind spots for drivers/operators; inadequate light } \\
\text { conditions (night time activities); poor Personal Protective Equipment (PPE); } \\
\text { inappropriate conditions of visibility elements of trucks and equipment such } \\
\text { as dusty mirrors and/or windows glasses. }\end{array}$ \\
\hline $\begin{array}{l}\text { Unsafe methods or } \\
\text { sequencing }\end{array}$ & $\begin{array}{l}\text { Normal sequencing of construction activities does not occur. Risk of } \\
\text { accidents increases in the tasks performed (Toole 2002). }\end{array}$ \\
\hline $\begin{array}{l}\text { Misjudgment of a } \\
\text { hazardous situation }\end{array}$ & Workers do not properly consider the risk that different situations represent. \\
\hline Lack of communication & $\begin{array}{l}\text { Misunderstanding of the assignments; drivers/operators and workers do not } \\
\text { inform each other about their work plans. }\end{array}$ \\
\hline Reduced audibility & $\begin{array}{l}\text { Capacity of hearing among workers is affected; inoperable reverse alarm } \\
\text { systems; working environment sound level is above the operational sound } \\
\text { level of the alarm. }\end{array}$ \\
\hline
\end{tabular}

The accidents within the event of worker struck by mobile equipment were classified in the following three sub-events: (1) Worker backed over by mobile equipment, (2) worker run over by mobile equipment, and (3) worker crushed or pinned by mobile equipment. The distribution of the accidents according to this classification and the sources of accidents are shown in Figure 2.3. This categorization of the event worker struck by mobile equipment is less generic than the one performed by Pegula (2004), and Bryden and Andrew (1999). However, with only 33 available reports it was not possible to assess how recurrent each event and each source of fatality were. 


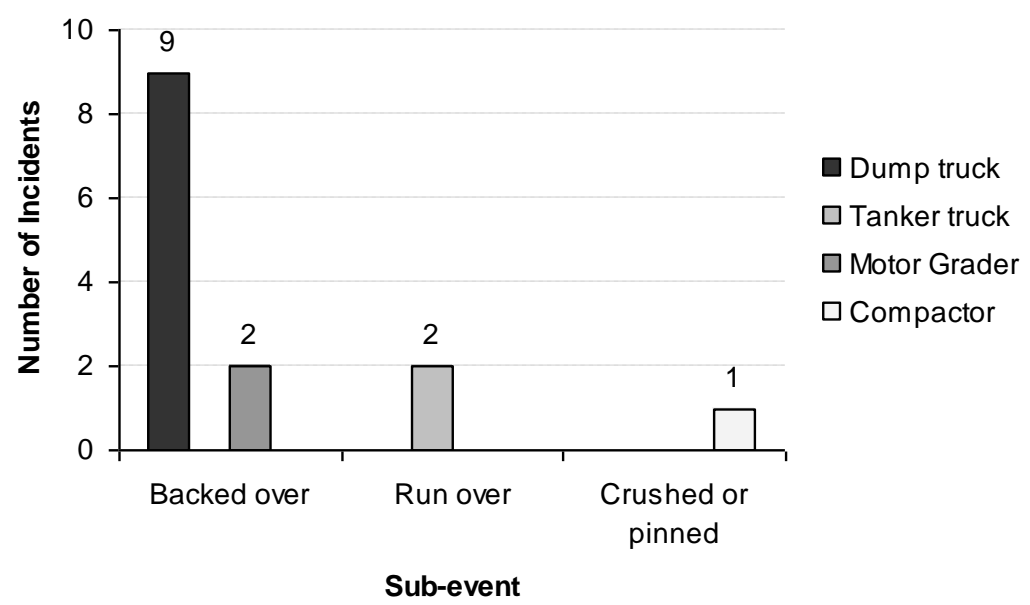

Figure 2.3 Distribution of fatal occupational accidents in the event of worker struck by mobile equipment, by sub-event and source of injury, 2001 to 2005, United States,

\subsubsection{Intrusion of Vehicles into the Work Zones}

Highway work zones generally present temporary and constantly changing conditions that are unexpected by the road user, which generates an even higher degree of vulnerability for workers on or near the roadway. Vehicle intrusion incidents occur when a vehicle, generally operated by the motoring public, enters the work zone and strikes a worker or when a worker is injured trying to avoid the intruding vehicle.

Within a work zone there are several risks, such as unawareness of work zone, lack of visibility, aggressive driving, and inadequate travel space, all of which should be considered for public safety. In case of an accident it is of vital importance to identify the key factors that caused the intrusion into the work zone. Some of the contributing factors causing work zone accidents include the following:

- Inadequate or damaged traffic control devices

- Excessive speed

- Equipment failure

- Adverse weather conditions

- Driver inattentiveness or impairment

- Visibility obscured by sun glare or dust

- Following construction vehicles into the work area 
The severity of the accident should be assessed in order to identify the factors that can be controlled to minimize risk. In the absence of adequate traffic control, driver awareness, and precautions, the rate of injuries and fatalities increases significantly. An analysis of the intrusion accidents in highway construction work zones in New York State, over a six-year period, found that, although vehicle intrusions were not common, they caused a consequential portion of fatalities and severe worker injuries, as shown in Table 2.6 (Najafi and Davis 2002).

Table 2.6 Injury Severities in NYSDOT Construction Project Accidents 1993-1998 (Adapted from Najafi and Davis 2002)

\begin{tabular}{|c|c|c|c|}
\hline \multirow[b]{2}{*}{ Accident Category } & \multicolumn{3}{|c|}{ Number of Accidents } \\
\hline & Fatal & $\begin{array}{c}\text { Non-Fatal } \\
\text { Injuries }\end{array}$ & Total \\
\hline Traffic Accidents & 58 & 3189 & 3247 \\
\hline Intrusion Accidents & 4 & 286 & 290 \\
\hline Traffic Accidents - Workers Involved & 6 & 560 & 566 \\
\hline Intrusion Accidents - Workers Involved & - & 131 & 131 \\
\hline Intrusion Accidents - Pedestrian Workers Involved & - & 29 & 29 \\
\hline Non-Traffic Accidents- Workers Involved & 13 & 1188 & 1201 \\
\hline
\end{tabular}

A total of 290 intrusion accidents were reported in New York State Department of Transportation (NYSDOT) highway construction work zones from 1993 through 1998. Studies performed by NYSDOT regarding this issue included the investigation of the locations where the accidents occurred and their characteristics. These intrusions were compared with other traffic and construction accidents, and intrusion accidents accounted for nearly $10 \%$ of all work-zone traffic accidents and about eight percent of serious injury accidents. Further, four of these were fatalities and 60 were serious injury accidents. About two-thirds of these intrusion accidents involved a vehicle entering an area defined by channelizing devices, including the transition area, buffer space, and work space. About $20 \%$ of the accidents involved moving operations. Most of the intrusions resulted in a collision between the intruding vehicle and work vehicles, equipment, or roadway features (Bryden et al. 2007).

Pedestrian workers were involved in less than $10 \%$ of the intrusions but were at greater risk for serious injury than workers in vehicles or equipment. It was determined that excessive speed was a major factor, identified in about one-fourth of all intrusion accidents. Also, driver incapacity 
due to lack of sleep, medical problems, roadway conditions, alcohol use, or vehicle failure, was involved in the other one-fourth of intrusion accidents. Based on circumstantial evidence in the accident reports and a substantial number of impacts on highly visible arrow panels, it appears that driver inattention is also a significant factor (Bryden et al. 2007). This study concluded that while not quantified, driver inattentiveness seemed to be a real contributor to the intrusion accidents. Other factors that were determined to contribute to the intrusion accidents are presented in Table 2.7.

Table 2.7 Factors Involved in Intrusion Accidents 1993-1998 (Adapted from Najafi and Davis 2002)

\begin{tabular}{|l|c|}
\hline \multicolumn{1}{|c|}{ Factor } & Number of Instances \\
\hline Excessive Speed & 70 \\
\hline Alcohol & 17 \\
\hline Medical & 13 \\
\hline Improper Traffic Control & 9 \\
\hline Falling Asleep & 7 \\
\hline Followed Construction Vehicle & 6 \\
\hline Equipment or Mechanical Failure & 6 \\
\hline Sun Glare & 5 \\
\hline Weather & 4 \\
\hline Forced Off Roadway & 3 \\
\hline Dust & 2 \\
\hline
\end{tabular}

Between 1992 and 1998, the Census of Fatal Occupational Injuries (CFOI) reported that for fatalities involving traffic vehicles, the major injury sources were divided among cars (43\%) and trucks (47\%). In all but 13 of the incidents involving a traffic vehicle, the motorist left the traffic space and intruded into the work zone, striking a worker. For $71 \%$ of these intrusion fatalities, the CFOI accident narrative indicated the worker's activity at the time of the accident. The most common work tasks were road repairs (38\%), flagging (25\%), and setting or moving traffic control devices (22\%).Pedestrian workers, such as flaggers, are constantly exposed to the risk of being struck by traffic if they are not visible to motorists. Twenty flaggers on average are killed each year by motorists (Roadway Safety Program 2003). Flaggers are exposed to hazards such as high speed traffic, aggressive drivers, and low visibility. Studies have shown that after seeing the worker, a motorist traveling at $60 \mathrm{mph}$ needs almost 400 feet to stop, as shown in Figure 2.4. 


\section{Stopping Distance Dry Pavement}

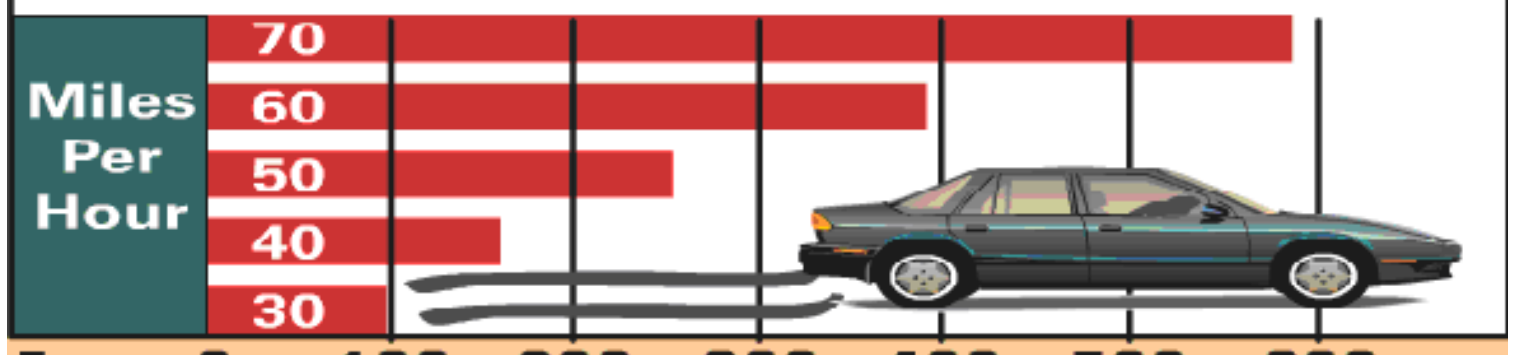

$\begin{array}{llllllll}\text { Feet } & 0 & 100 & 200 & 300 & 400 & 500 & 600\end{array}$

Figure 2.4 Stopping Distances for Motorists (Roadway Safety Program 2003)

\subsection{Work Zone Safety Strategies}

Contracting agencies, contractors, and personnel in charge of work zone safety face the constant challenge of providing a safe work environment while allowing the safe movement of traffic through a work zone. Highway construction and maintenance work presents a complex situation in which workers are exposed to multiple injury risks under conditions that change constantly without warning. To improve worker safety in highway construction and maintenance work zones, some safety strategies consider reducing the worker's exposure to risks internal and external of a work zone, as shown in Figure 2.5.

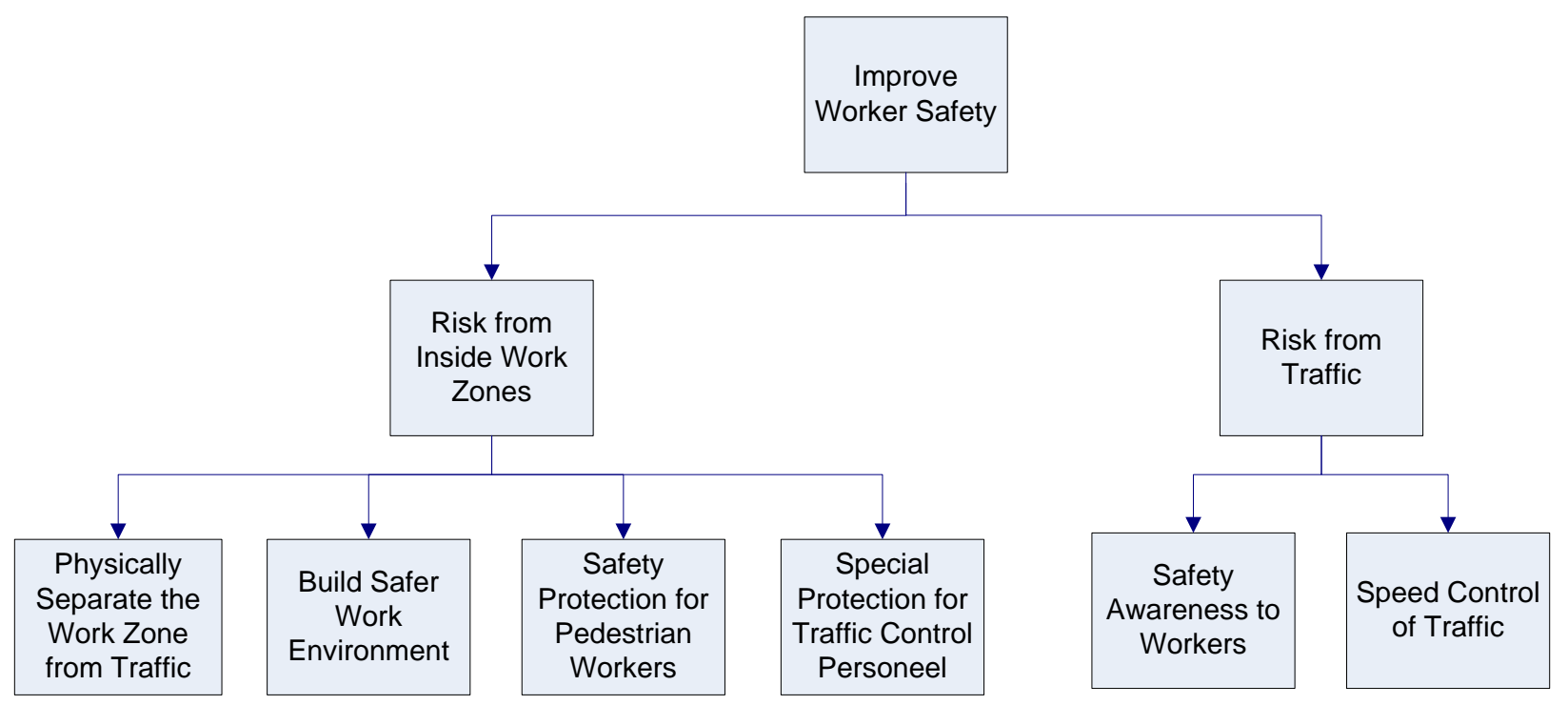

Figure 2.5 Strategies to Improve Worker Safety 


\subsubsection{Safety Strategies Controlled by the Owner of the Project}

Safe and efficient traffic flow through a work zone constitutes a major concern to state DOTs, transportation officials, and the highway industry. The majority of the federal transportation funds are being allocated for projects geared towards preserving the existing highway system, such as resurfacing, restoration, and reconstruction. At the same time, the development of these projects within the existing highway system has created a significant effect on motorists' mobility caused by traffic congestion in the work zone area. Mobility is also a concern to the owners of these projects due to its effects on safety in work zones (FHWA 1998). The increase in traffic congestion affects the safety of construction and maintenance workers due to possible "road rage" by delayed motorists who are not able to travel at regulatory speed limits through the work zone.

The FHWA has developed several recommendations to assure continuous improvements in efforts to decrease and mitigate traffic congestion generated by work zones, which include:

- Emphasize and promote planning to minimize construction interference with traffic while ensuring safety through its routine operations and in all worker and staff training.

- Develop research in innovative methods to improve safety and reduce traffic congestion during construction.

- Provide technical assistance to the state DOTs in the development and implementation of programs to promote safety and effective construction traffic management.

Public information and education campaigns to increase awareness of work zones is one of the safety strategies that can be implemented and controlled by the owners of the highway maintenance and construction projects or its contracting agencies. Many highway safety programs can be effectively enhanced using a properly designed public information and education campaign to increase the awareness of work zones that includes coordination with media outlets (FHWA 2006). Such campaigns should be designed considering location-specific problems, such as a history of severe crashes. Authorities should consider the increased use of public information campaigns to increase public awareness of the hazards to both work zone personnel and drivers, particularly for construction projects in areas of high traffic volume. The MUTCD and FHWA's “Building Safer Highway Work Zones” include public information as an 
element of a traffic management plan. These campaigns offer the opportunity to positively impact driver behavior, which is a critical issue to work zone safety.

An Internal Traffic Control Plan (ITCP) involves the planning of internal work space and activities at a job site. It describes how a specific work zone is set up to ensure the safety of workers and motorists traveling through it. An ITCP is a tool that project owners and managers can use to improve workers safety at job sites by coordinating the flow of construction equipment, vehicles, and workers operating in close proximity within the activity area. Federal, state, and local highway agencies can establish guidelines for the development of an ITCP, as well as develop sample ITCPs for selected road construction operations. Contracting agencies can assist contractors in the development of their own ITCPs and review their compatibility with the project Traffic Control Plan (TCP). The safety elements that should be considered in the development of an ITCP include the following (MUTCD 2003):

- Identification of an ITCP coordinator assigned to the project with a description of the role and authority of the coordinator.

- Description of the role of employees in recognizing, reporting, and mitigating safety hazards.

- Description of the role of employees involved in the implementation process of an ITCP.

- A process for reviewing accidents and potential hazards involving workers and equipment within the work zone.

The development of an ITCP involves the following steps and considerations (NIOSH 2004):

- Review existing ITCPs.

- Determine the sequence of the construction operations.

- Establish a specific layout of the workspace, including personnel, vehicles, and equipment.

- Apply the principles of safe traffic control established in the MUTCD.

- Locate utilities, determine locations for material and equipment storage, and locate staging and parking areas for visitors and workers.

- Prepare diagram of on-site personnel and equipment. 
- List injury reduction measures, including equipment operating rules and pedestrian-free areas.

The ITCP implementation process requires coordination between the policymakers for the state DOTs and the contractor of the project. Once the ITCP is designed, the contractors and state DOTs can do the following activities (NIOSH 2001):

- Train their workers in the implementation of the ITCP for each project.

- Assign a trained ITCP coordinator at each job site, who can respond immediately to hazard situations.

- Evaluate the effectiveness of the ITCP throughout the project, documenting required changes as the project progresses. Also, it is recommended to retain schematic drawings and other related documents in the project file for use in developing future ITCPs.

- Distribute site-specific safety material to motorists and visitors passing through the work zone. Other means of communicating ITCP-related information include toolbox meetings and distributing the plan to truck drivers.

\subsubsection{Traffic Control Strategies}

Traffic control can be defined as the process of guiding, regulating, and warning road users and advising them to traverse a section of highway in a proper manner (Lewis 1989). The main objective of traffic control strategies is to provide for safe and efficient traffic movement through and around the work zone while protecting workers and equipment. This category includes temporary traffic control devices such as signals, signs, markings or channelizing and delineation devices placed on or adjacent to a highway through the authority of an official or a public body having jurisdiction to regulate, guide, or warn road users. All of the national safety procedures to control traffic through work zones are contained in the MUTCD, which is the official standard required for traffic control on all streets and highways open to motorists. The majority of the states and local jurisdictions in the United States have adopted the MUTCD as their standard. In several cases, however, specific applications, designs, or requirements in the MUTCD have been modified by some states, which in most cases reflect stricter requirements than the minimum expressed in the MUTCD. 
One of the primary focuses of the MUTCD is the interaction between the road users and the work zone. The design, installation, operation, and maintenance of traffic control devices are vital elements in a safe work zone (Traffic Control Devices Handbook 2001). Traffic control devices are usually the primary and often the only, method of communicating to motorists what conditions to expect while passing through the work zone, and they should be used in a uniform and effective manner to assure correct motorist interpretation and response (Traffic Control Devices Handbook 2001). The motorists must receive the appropriate regulatory, guidance, and warning information in a uniform manner in order to drive safely through the work zone in varying weather, traffic, and terrain conditions. The procedures for establishing temporary traffic control zones vary with several conditions, such as (MUTCD 2000):

- Work activity

- Location of work

- Road configuration

- Duration of work

- Road user volume

- Road vehicle mix (number of trucks, buses, cars)

- Road user speed

Traffic signs compose one type of temporary traffic control measure and are devices mounted on portable or fixed supports with the purpose of conveying an official message by means of symbols or words (Traffic Control Devices Handbook 2001). The main objective of traffic signs is regulating, warning, and guiding traffic through the work zone. The three basic types of signs are shown in Table 2.8 . 
Table 2.8 Basic Types of Signs (adapted from Traffic Control Devices Handbook 2001)

\begin{tabular}{|c|c|c|}
\hline Sign Type & Intended Use & Typical Use \\
\hline Warning Signs & $\begin{array}{l}\text { Warn traffic of unusual or potentially } \\
\text { hazardous conditions }\end{array}$ & $\begin{array}{l}\text { - Horizontal and vertical } \\
\text { alignments } \\
\text { - Crossings and entrances to } \\
\text { streets or highways } \\
\text { - Road construction and } \\
\text { maintenance operations }\end{array}$ \\
\hline Regulatory Signs & $\begin{array}{l}\text { Inform users of traffic laws and } \\
\text { regulations which apply at definite } \\
\text { locations at specific times }\end{array}$ & $\begin{array}{l}\text { - Speed limits } \\
\text { - Exclusions and prohibitions } \\
\text { - Regulations for construction } \\
\text { or maintenance operations }\end{array}$ \\
\hline Guide Signs & $\begin{array}{l}\text { Provide specific information to aid } \\
\text { motorists to reach their destination }\end{array}$ & - Route markings \\
\hline
\end{tabular}

Since the publication of the MUTCD 2000, portable changeable traffic signs (PCMS) have become an essential part of work zone traffic control. These devices advise motorists of unexpected routing and traffic situations. When properly used, they can attract the attention of motorists better than any other static work zone signing (Ullman et al. 2006). Also, these devices provide the benefit of presenting a wide variety of information to motorists, making them a highly versatile strategy for traffic control (Ullman et al. 2006). They are recommended for high speed, high volume roadways, or work operations that require a highly visible message. The Texas Transportation Institute (TTI) has studied PCMS with the purpose of determining the ability of motorists to capture and process information displayed on PCMS used in sequence. The results of this study demonstrated the need to keep messages or warnings displayed to motorists at or below the four-unit maximum recommended in existing guidelines. During the research it was found that displaying over five messages or warnings in sequential PCMS resulted in low comprehension rates, below the acceptable range for highway applications. Comprehension rates comparable to those obtained by displaying the same information using a single sign or a large dynamic message sign (DMS) can be achieved by keeping the message length to four units. Also, it was determined that motorist comprehension can be enhanced by repeating one of the lines in the message on the PCMS used in sequence (Ullman, et al. 2006). 
Some of the applications of PCMS in both highway construction and maintenance operations include the following (TRB 2007):

- Alert motorists of future changes which will be made to current traffic conditions

- Notify motorists to turn to a highway advisory radio (HAR) station, where available

- Warn motorists of changes in alignment or surface conditions

- Warn motorists of new detours or changes in existing ones

- Emphasize to motorists the existence of reduced speed limits

- Warn motorists of the presence of flaggers or work crews

- Warn motorists of traffic queues

The use of signals also can be classified as a traffic control strategy. Traffic control signals are defined as power operated devices, other than a barricade warning light or a steady electric lamp, by which traffic is warned or directed to take some specific action (MUTCD 2003). These devices are used to control the right-of-way in locations were conflicts may occur or where passive devices, such as signs and markings, present limitations in providing the necessary control to properly guide traffic in a safe and efficient manner. The technology related to traffic signals is more dynamic than that related to other traffic control devices. For example, portable traffic signal systems have the potential for replacing flaggers in many work zones that require one-way traffic alteration. Studies conducted by the TTI showed that a substantial decrease in flagger labor costs could be achieved by using a portable fixed-time signal with only a minimal increase in motorist delay costs (Ullman, et al. 2006). In terms of safety, this system significantly reduces the exposure of flaggers to traffic hazards.

Another strategy used for traffic control is reducing the spacing of channelizing devices. This safety practice is commonly used in both construction and maintenance projects (Andrew and Brynden 2001). The MUTCD (2003) recommends a device spacing in feet equal to the travel miles in tapers, and double the travel speed in tangents. The New York Department of Transportation (NYSDOT) found that frequent intrusions occurred in work zones using these spacings. In a study performed by NYSDOT, reduced channelizing device spacing (12 m (40 ft)) on stationary work sites where workers are exposed to traffic proved to be an effective strategy in reducing the risk of vehicle intrusions and providing improved guidance for motorists to 
reduce their speed. NYSDOT also established additional channelizing device spacing guidelines for particular work zone conditions, as shown in Table 2.9. One of the advantages offered by this strategy is low cost and easy implementation. On the other hand, it may require additional effort from workers for its set-up and removal. The only concern presented in the study is that the reduced spacing makes it difficult for heavy equipment and work vehicles to enter and exit the work area. This difficulty can be reduced by providing wider channelizing devices spacing according to the established MUTCD (2003) guidelines at periodic intervals as needed.

Table 2.9 Channelizing Device Spacing for Particular Work Zone Conditions (adapted from NYSDOT 2005)

\begin{tabular}{|c|c|c|}
\hline \multirow{2}{*}{ Work Zone Location/ Condition } & \multicolumn{2}{|c|}{ Spacing in Feet } \\
\cline { 2 - 2 } & $\begin{array}{c}\text { Low Speed } \\
(45 \mathrm{mph} \text { or less })\end{array}$ & $\begin{array}{c}\text { High Speed } \\
\text { (greater than 45 mph) }\end{array}$ \\
\hline Work Zone Activity Area & & \\
\hline Transitions and Curves & & \multirow{2}{*}{$40 \mathrm{ft}$} \\
\hline Intersections & $20 \mathrm{ft}$ & \\
\hline Hazardous Conditions & & \\
\hline Nighttime Operations & & \\
\hline
\end{tabular}

Burgess (2006) conducted a research study of traffic control strategies in nighttime construction and maintenance work zones in Indiana. In this study, surveys were distributed to project supervisors involved in nighttime construction-related activities. The objective of the surveys was to identify five out of ten safety strategies that could improve traffic control safety, from the supervisor's perspective. A total of 24 construction and maintenance supervisors participated in the study. During the study similar surveys were distributed to construction and maintenance workers with experience on nighttime projects. A total of 61 subjects that completed the survey were asked to indicate, based on their experience, five out of 10 safety strategies that could improve traffic control safety (Burgess 2006). The results of this study showed that increased law enforcement, proper training control set-up, and increased public awareness were the safety strategies believed by both, supervisors and workers, to improve traffic safety the most. 
Hirasawa et al. (2006) conducted a study to determine the overall satisfaction with safety measures at roadway construction work zones in Japan. In this study, traffic safety contractors and trucking companies were the survey subjects. Traffic safety contractors were chosen to participate because they conduct traffic control, and therefore should be aware and able to identify the deficiencies of the commonly used safety measures. Hirasawa et al. (2006) stated that his study showed that trucking companies had the best understanding of current roadway work zones, enabling them to give a strong and valuable evaluation of safety measures. The subjects were asked to evaluate their level of satisfaction regarding the following items and subitems presented in Table 2.10.

Table 2.10 Safety Items and Sub-Items Evaluated for Safety Measures Satisfaction Survey (Adapted from Hirasawa et al. (2006))

\begin{tabular}{|c|l|}
\hline \multicolumn{1}{|c|}{ Safety Item } & \multicolumn{1}{c|}{ Safety Sub-Item } \\
\hline & - Sign location \\
& - Daytime visibility \\
Construction Information Signs & - Nighttime visibility \\
& - Amount \\
& - Understandability of displayed information \\
\hline
\end{tabular}

\begin{tabular}{|c|c|}
\hline Safety Item & Safety Sub-Item \\
\hline Traffic Control Personnel & $\begin{array}{l}\text { - Used safety vest } \\
\text { - Color of uniform } \\
\text { - Positioning } \\
\text { - Amount } \\
\text { - Daytime visibility } \\
\text { - Nighttime visibility }\end{array}$ \\
\hline Electric Signboards & $\begin{array}{l}\text { - Daytime visibility } \\
\text { - Nighttime visibility } \\
\text { - Understandability of displayed information }\end{array}$ \\
\hline Construction Signals & $\begin{array}{l}\text { - Daytime visibility } \\
\text { - Nighttime visibility } \\
\text { - Understandability of displayed information }\end{array}$ \\
\hline Crash Cushions & $\begin{array}{l}\text { - Location } \\
\text { - Size and amount } \\
\text { - Daytime visibility } \\
\text { - Nighttime visibility }\end{array}$ \\
\hline
\end{tabular}


The respondents were asked to rate their satisfaction based on a five-point scale: (1) dissatisfied, (2) somewhat dissatisfied, (3) neither satisfied nor dissatisfied, (4) somewhat satisfied, and (5) satisfied. The response rate of this study was $29.7 \%$ (79 answers out of 266 distributed surveys) for the traffic contractors and 35.2\% (95 answers out of 270 distributed surveys) for the trucking companies. The surveys completed by the traffic safety contractors showed dissatisfaction (score $<3$ ) for eight of the 20 sub-items. The lowest mean scores related to nighttime visibility of construction signs (2.51) followed by nighttime visibility of traffic control personnel (2.73) and nighttime visibility of crash cushions (2.73). The obtained mean score (2.74) for understandability of the displayed information on construction information signs also indicated dissatisfaction. All of the sub-items corresponding to electric signboards received a mean score higher than 3, which indicated satisfaction. The responses obtained from the trucking companies showed dissatisfaction (score <3) for nine of the 20 sub-items. Nighttime visibility of construction signs (2.42) followed by nighttime visibility of traffic control personnel (2.61) obtained the lowest mean scores. Understandability of displayed information on construction information signs also received a dissatisfaction mean score of 2.64. Each of the sub-items included in the traffic control personnel category showed a mean score lower than 3 . Items such as construction signals and electronic signboards had mean scores greater than 3 , indicating satisfaction. The study found that the highest rate of satisfaction for both traffic safety contractors and trucking companies was for nighttime visibility of electronic signboards. The lowest rate of satisfaction perceived by both the traffic safety contractors and the trucking companies was for nighttime visibility of construction information signs.

\subsubsection{Speed Control Strategies}

Accidents rates increase as travel speeds increase (Maze and Kamyab 2000). Hazardous conditions in work zones when combined with a high speed variance may lead to a significantly higher rate of accidents. Having motorists drive through the work zone at an average speed and reducing the speed variance can decrease work zone accidents and fatalities (Maze and Kamyab 2000). A variety of speed control strategies are currently being used by state Departments of Transportation (DOTs) for highway construction and maintenance projects. Some of these strategies include regulatory speed zoning, lane reduction, and speed control technologies. 
Regulatory speed limit signs are used to display to motorists information about reduced speed limits in work zones. Advisory speed limit signs are used to display safe recommended speeds through the work zone. A study performed by Maze and Kamyab (2000) based on 34 state DOTs showed that utilizing a regulatory speed limit is a commonly used work zone safety strategy in the United States. Out of the 34 DOTs that responded, 28 indicated the use of regulatory speed signs among the safety strategies employed in their work zones. Only two DOTs indicated that posting regulatory speed limit signs is an effective strategy in reducing speeding through work zones. Approximately $30 \%$ of the DOTs indicated that regulatory signs are partially effective, yielding an estimated 30-50 percent speed limit compliance. The study also indicated that posting reduced speed limits of $20 \mathrm{mph}$ below the normal speed limit is ineffective. However, reducing speed limits $10 \mathrm{mph}$ below the normal speed is more effective, and nearly $70 \%$ of the DOTs in this study indicated they lower their speed limits by $10-15 \mathrm{mph}$ in work zones. Speed limits displayed on the advisory signs are even lower, especially when the construction takes place near lanes carrying traffic. Another study conducted in 1981 on a two-lane rural road in Maine indicated that the effectiveness of the warning sign sequence suggested in the MUTCD can be increased by the use of flashing beacons on the signs. Later, in the early 1990s the Illinois Department of Transportation (IDOT) added two orange-colored plates and two small strobe lights to their regulatory speed limit signs in order to improve effectiveness. In this case, the lights were turned off when there were no workers at the job site. The orange plates indicated that when the lights were flashing the speed limit was $45 \mathrm{mph}$. The study by Benekohal and Shu (1990) showed that the average speed of cars and trucks was reduced by 1.9-7.1 and 1.3-6.0 mph, respectively. The study concluded that the percentage of vehicles traveling at excessive speeds through work zones decreased when the strobe lights were flashing.

Flagging is another commonly used safety strategy to control motorist speed in work zones. Previous studies to evaluate this strategy have found the incorporation of flaggers in the work zone management plan to be effective. As established in the MUTCD (2003), the flagger needs to be placed at a distance far enough in advance of the work zone to allow motorists to reduce their speed or stop as required. A study performed by Benekohal and Kastel (2000) in a rural Illinois work zone evaluated the effectiveness of flaggers on controlling speed of traffic. During 
the data collection process of this study, speeds were recorded before and after flaggers were given training on the proper MUTCD flagging techniques. This study determined that both passenger cars and trucks reduced their speed as they approached the flagger. This speed reduction was more significant after the flaggers received the MUTCD flagger training. Some of the topics covered in this flagger training include motion, making eye contact with motorists, and proper posture. The results of this study showed an average speed reduction of cars and trucks of 4.9 and $11.9 \mathrm{mph}$, respectively, after the flagger training. Prior to the MUTCD training, the average speed was reduced by $11.7 \mathrm{mph}$ for cars and $9.1 \mathrm{mph}$ for trucks.

Richards et al (1994) measured the effectiveness of innovative flagger techniques, which include more aggressive actions by the flagger by motioning traffic to slow and pointing at reduced speed limit signs. This study determined there was a speed reduction of 4-5 mph at urban freeways and 10-16 mph at rural two-lane highways. A similar study was performed on highway work zones in South Dakota to determine the effectiveness of larger flagger signs and yellowgreen flagger apparel in reducing traffic speed (McCoy et. al 1993). The results of this study showed that the tested flagging procedures were less effective than the MUTCD flagging methods.

Other studies have determined that providing flaggers with devices to increase their visibility to passing motorists can increase their effectiveness. One example that has been field-tested and shown to be effective is the flashing slow/stop paddle, which consists of a standard paddle with a strobe light mounted on its face (Stout et al. 1993). However flagging can present several disadvantages, such as high cost for long-term use and the exposure of the worker to traffic hazards due to the nature of this task. Also to ensure the effectiveness of the flagger, workers need to be rotated in this job on a regular basis and properly trained.

Several studies have shown that police enforcement is one of the most effective speed control strategies. This strategy normally involves two types of enforcement, stationary and mobile. Stationary enforcement is intended to increase compliance with the established speed limit at a certain location. A circulating police vehicle can cover a larger area but has shown to be less effective in reducing traffic speed. Stationary enforcement has resulted in a six to 22 percent 
speed reduction, while the mobile enforcement only reduced speeds by only three to five percent (Richards et al 1994). Another study conducted by McCoy and Bonneson (1993) considered free-flow vehicle speed with stationary enforcement at a work zone with a single-lane closure on an urban multilane street in South Dakota. This study showed that average traffic speeds at the beginning section of the work zone were reduced from 25 to $30 \mathrm{mph}$. Nonetheless, these observed speeds were above the displayed $20 \mathrm{mph}$ advisory speed.

A study on the effects of police enforcement was conducted on a six-lane freeway in Delaware (Noel et al 1988). Police enforcement was analyzed in two ways, 1) an officer standing by the roadside to motion the traffic to slow down and 2) a police car with flashing lights and an active radar. The study also considered the effect of this strategy under one and two-lane closures, as well as for short-term (approximately three days) and long-term (more than 10 days) periods. Both methods were found to be effective in reducing traffic speed during both time periods. Having a police officer standing on the roadside to control traffic speed was shown to be more effective than just using the police car with the flashing lights and radar. Another study performed on a rural interstate work zone in Illinois by Benekohal, Resende, and Orloski (1992) evaluated the impact of the police presence, as well as the absence of an identified police car in an interstate work zone. The first part of this study evaluated the average traffic speeds with the police presence of a marked police car circulating through the work zone for four hours. The second part of the study consisted of analyzing the impact on speeds after the police patrol left the work zone at the end of a four-hour period. The study showed that during the period of time that the police patrol was circulating, the mean speeds of cars and trucks passing though the work zone were reduced approximately four and five $\mathrm{mph}$, respectively. During the presence of the police patrol, the percentages of cars and trucks exceeding the posted speed limit though the work zone were reduced by 14 and 32 percent, respectively. One hour after the police patrol left the work zone, the mean speeds of cars and trucks increased approximately 2.5 and $0.5 \mathrm{mph}$, respectively. This study showed that, for trucks, a lasting speed reduction greater than an hour could be obtained by periodically having the presence of a police vehicle in the work zone.

The Minnesota DOT (1999) analyzed the effectiveness of police enforcement at work zones on three different sites, including a metro location, a rural interstate, and an urban freeway. Speed 
data was collected using a laser gun with and without the presence of a police vehicle. During this study it was determined that the $85^{\text {th }}$ percentile speed was reduced from 51 to $43 \mathrm{mph}$, with the presence of a police vehicle upstream to the work zone, concluding that the presence of law enforcement significantly improves compliance with the established speed limits.

Miller (2007) conducted a study to evaluate speed control strategies for nighttime interstate construction and maintenance projects in Indiana. The study evaluated the effect of speed and traffic control measures on the mean speed and speed variance of motorists traveling through the work zone. The data collection for this study included site visits and 25 telephone interviews with personnel from ten state DOTs and FHWA offices. The data analysis of this study showed that the presence of police enforcement, a high percentage of semi trucks in traffic and high flow rate reduced the mean speed through the work zone. Police enforcement was also indicated as the most effective method of nighttime speed control in the survey of Midwest Transportation Agency personnel (Miller 2007).

\subsubsection{Measures to Improve Safety within Work Zones}

Highway construction and maintenance workers are constantly exposed to significant risks inside the work zone caused by construction operations. According to NIOSH (2001), half of the work zone fatalities occur inside the work area and do not involve motorists. Personnel at greater risk are flaggers and pedestrian workers who are exposed to the risk of being struck by construction vehicles and equipment if they are not visible to equipment operators. Workers who operate construction vehicles or heavy equipment are at risk of getting injured by overturns, collisions, or being trapped in running equipment.

One commonly used strategy to improve worker safety in the work zone is the use of personal protective equipment (PPE), which includes a variety of devices and garments designed to protect employees from serious workplace injuries or illnesses resulting from contact with chemical, radiological, physical, electrical, mechanical, or other workplace hazards (OSHA 2002). This device must be worn when engineering, work practice, and administrative controls 
are not feasible or do not provide sufficient protection (OSHA 2003). PPE devices can be classified according to their use in various categories as shown on Table 2.11.

Table 2.11 Types of Personal Protective Equipment (Adapted from OSHA 3151-12R 2003)

\begin{tabular}{|c|c|c|}
\hline Category & Description & Examples \\
\hline $\begin{array}{l}\text { Eye and Face } \\
\text { Protection }\end{array}$ & $\begin{array}{l}\text { - ANSI Z87.1-1989 (USA Standard for } \\
\text { Occupational and Educational Eye and Face } \\
\text { Protection). } \\
\text { - Required for employees who are exposed to } \\
\text { face and eye hazards from flying particles, } \\
\text { liquid chemicals, molten metal, chemical } \\
\text { gases or vapors, radiant energy or harmful } \\
\text { rays and objects swinging into the eye or } \\
\text { face. }\end{array}$ & $\begin{array}{l}\text { - } \text { goggles } \\
\text { - } \text { welding shields } \\
\text { - laser safety goggles } \\
\text { - face shields }\end{array}$ \\
\hline Head Protection & $\begin{array}{l}\text { - ANSI Z89.1-1989 (Protective Headgear for } \\
\text { Industrial Workers). } \\
\text { - Key element of any safety program } \\
\text { - Required for employees who are exposed to } \\
\text { hazards caused by falling objects, bumping } \\
\text { their heads against fixed objects and } \\
\text { accidental head contact with electrical } \\
\text { hazards. }\end{array}$ & $\begin{array}{l}\text { - hardhats - Class } \\
\text { A, B or C }\end{array}$ \\
\hline
\end{tabular}

\begin{tabular}{|c|c|c|}
\hline Category & Description & Examples \\
\hline $\begin{array}{l}\text { Foot and Leg } \\
\text { Protection }\end{array}$ & $\begin{array}{l}\text { - ANSI Z41.1-1991 (American National } \\
\text { Standard for Personal Protective Footwear). } \\
\text { - Required for employees who are exposed to } \\
\text { foot or leg injuries caused by heavy objects } \\
\text { that might fall or roll on their feet, sharp } \\
\text { objects piercing their soles, hot or corrosive } \\
\text { substances, electrical hazards and hot, wet } \\
\text { or slippery surfaces. }\end{array}$ & $\begin{array}{l}\text { - leggings } \\
\text { - toe guards } \\
\text { - combination of } \\
\text { foot and shin } \\
\text { guards } \\
\text { - safety shoes }\end{array}$ \\
\hline $\begin{array}{l}\text { Hands and Arm } \\
\text { Protection }\end{array}$ & $\begin{array}{l}\text { - } 29 \text { CFR 1910.138(a) } 1994 \\
\text { hequired for employees exposed to potential } \\
\text { bruises, punctures, electrical dangers, } \\
\text { chemical or thermal burns. }\end{array}$ & $\begin{array}{l}\text { - gloves } \\
\text { - finger guards } \\
\text { - arm coverings } \\
\text { - elbow-length } \\
\text { gloves }\end{array}$ \\
\hline $\begin{array}{l}\text { Respiratory } \\
\text { Protection }\end{array}$ & $\begin{array}{l}\text { - } 29 \text { CFR 1915-156(a) } \\
\text { - Required to be provided by the employer } \\
\text { when such equipment is necessary to protect } \\
\text { the health of the employee. }\end{array}$ & $\begin{array}{l}\text { - } \text { respirator mask } \\
\text { respirator }\end{array}$ \\
\hline
\end{tabular}




\begin{tabular}{|c|c|c|}
\hline Body Protection & $\begin{array}{l}\text { - OSHA 3151-12R } 2003 \\
\text { - Required for employees exposed to any } \\
\text { kind of possible bodily injury that cannot } \\
\text { eliminated through engineering, } \\
\text { administrative or work practices controls. } \\
\text { - Employees exposed to hazards such as cuts, } \\
\text { radiation, hazardous chemicals, extreme } \\
\text { temperatures, impacts from tools machinery } \\
\text { or materials }\end{array}$ & $\begin{array}{l}\text { - vests } \\
\text { - jackets } \\
\text { - full body suits } \\
\text { - high-visibility } \\
\text { garments }\end{array}$ \\
\hline Hearing Protection & $\begin{array}{l}\text { - } 29 \text { CFR 1926.101(a), } 1994 \\
\text { - Required for employees wherever it is not } \\
\text { feasible to reduce the noise levels or duration } \\
\text { of exposure to those specified by OSHA. For } \\
\text { example, } 90 \text { dB for } 8 \text {-hour period and } 115 \\
\text { dBA for } 15 \text { minutes (29 CFR 1910.95, Table } \\
\text { G-16) }\end{array}$ & $\begin{array}{l}\text { - } \text { single-use earplugs } \\
\text { - earmuffs } \\
\text { - pre-formed or } \\
\text { molded earplugs }\end{array}$ \\
\hline
\end{tabular}

High visibility apparel is one of the most frequently used types of PPE to improve worker safety in highway construction and maintenance work zones. This strategy serves as a first line of defense to protect workers against the risks of being struck by a vehicle or a piece of equipment operated by someone who otherwise would not be able to see them during the day or at night. The MUTCD (2003) specifies the use of high visibility clothing for flaggers, law enforcement officers, and other personnel involved in the traffic management of the work zone. OSHA (1999) recognizes the importance of high-visibility apparel to protect highway construction and maintenance workers and requires that employers supply employees with highly visible and reflectorized materials to enhance their visibility. Extensive research conducted by NIOSH (2001) determined that existing safety programs do not provide comprehensive guidance to ensure worker safety. Among the recommendations produced by NIOSH from this study was that high-visibility safety apparel should be provided, not only to workers who are directly exposed to traffic but to all workers in construction and maintenance work zones.

The International Safety Equipment Association (ISEA) develops high-visibility apparel to meet the safety needs of every industry. ISEA works closely with federal and state highway agencies and workers to develop designs and innovations in high-visibility apparel to optimize worker safety. The ANSI/ISEA 107-2004 standard established a set of performance criteria for highvisibility apparel. This standard specifies the design, the requirements for background and combined-performance, the photometric and physical performance requirements for retroreflective materials, and care labeling. The specifications in this standard are intended to 
make the worker conspicuous under any light conditions by day and under the illumination of vehicle and equipment headlights during the night. In the standard the apparel is classified into three categories based on the tasks undertaken by workers and the exposure to hazards, the complexity of the work environment, and the vehicular traffic and speed. Table 2.12 presents the classification of these garments.

Table 2.12 High-Visibility Apparel Classification (ANSI/ISEA 107)

\begin{tabular}{|c|c|}
\hline Apparel Classification & Specifications \\
\hline Class 1 & $\begin{array}{l}\text { - For workers in tasks that permit full and undivided attention } \\
\text { to approaching traffic } \\
\text { - Not complex work backgrounds } \\
\text { - Pedestrian workers separated from traffic } \\
\text { - Vehicles moving at speeds not exceeding } 25 \mathrm{mph}\end{array}$ \\
\hline Class 2 & $\begin{array}{l}\text { - For workers in tasks that divert their attention from } \\
\text { approaching traffic } \\
\text { - For workers that require greater visibility under inclement } \\
\text { weather conditions } \\
\text { - Complex work backgrounds } \\
\text { - Work activities that take place closer to vehicle traffic }\end{array}$ \\
\hline Class 3 & $\begin{array}{l}\text { - Workers who are exposed to much higher vehicle } \\
\text { speeds and/or reduced sight distances } \\
\text { - Pedestrian workers and equipment operators } \\
\text { - Wearer must be visible through the full range of body } \\
\text { motions at a minimum of } 1,280 \text { feet } \\
\text { - Wearer must be identifiable as a person }\end{array}$ \\
\hline
\end{tabular}

The selection of the high visibility apparel needs to be based on various considerations, such as the time of day and the season of the year in which the construction or maintenance operations will be performed. Combined materials garments can be used during the day and at night, featuring both conspicuous colors and retroreflection (Cottrell et al. 2006). For instance, during high summer temperatures, some DOTs have reported that safety vests, especially the vests with retroreflective stripes, can impede proper ventilation. When mesh vests are available, they must be worn over bright clothing, otherwise they will not be visible as solid vests. Some DOTs are allowing their workers to wear high visibility T-shirts during the summer. During winter weather, Class E apparel (trousers) that meets ANSI/ISEA 107-2004 consensus standards are recommended in addition to Class 2 or 3 apparel for the upper body. 
In 2002 the University of Kansas in cooperation with the Kansas Department of Transportation (KDOT) conducted a research study funded by the Midwest Smart Work Zone Deployment Initiative (MSWZDI) that compared three different models of self-illuminating vests with the standard safety vest with respect to their nighttime visibility. The models of self-illuminating safety vests had the same characteristics as the standard safety vests but also included blinking or continuous light-emitting diodes (LEDs). This study considered different parameters, such as the vehicle orientation and the distance from the car to the vest. The test setup consisted of mounting the vests at the average height of a worker and recording the vests using a digital video camera. The obtained data from the video was evaluated using software that calculated the visibility indices for each of the vests. The study showed that the LEDs did not have a significant effect on the visibility of the vest when it was in direct orientation with the car. It was determined that at eccentricities greater than 30 degrees, most of the glow of the vests was generated by the LEDs. This study concluded that the self-illuminating vests were more visible under all conditions than the reflective vests used by KDOT (Meyer 2002).

Arditi et al. (2004) tested six safety vests to determine their nighttime effectiveness. The set up of the testing consisted of three torso mannequins, placed next to each other perpendicular to the work zone limit, clothed in different combinations of the six safety vests. The set ups were recorded at various ten-minute intervals with a video camera placed on the shoulder of the work zone. The obtained videos were converted into snapshots to evaluate their luminescence using computer software. The factors considered in this study included the type of setting (rural or urban), lighting, weather conditions, volume of traffic, and location of the vest with respect to the boundary of the work zone. In the same study, six safety vests were shown to graduate students on a parking lot. The students were asked to rate the safety vests in terms of their $360^{\circ}$ visibility, their conspicuity against the background, the brightness of the retroreflective material, their configuration, and their overall perceived effectiveness. Through the results of both the survey and the site tests, this study showed that the two vests that did not have as much as retroreflective material as the others outperformed the ones with orange fabric and yellow retroreflection and yellow mesh with silver retroreflection. The two chosen vests were similar, both having the same overall color (yellow) and retroreflective silver material. As part of this study, a survey was conducted of Illinois Department of Transportation (IDOT) operations 
personnel and resident engineers and contractors in the area. The survey included questions about the performance of their currently used high-visibility safety garments regarding their perceived effectiveness, conspicuity, reflectivity, visibility, durability, comfort, and configuration. The majority of the respondents stated that the performance of their safety vests was very good. The survey also asked about the importance of garment design and safety features, such as definability of the human form, location of the retroreflective material, $360^{\circ}$ visibility, the amount of retroreflective material, the brightness of the retroreflective material, and the acceptable loss of color and brightness. The majority of the respondents classified all these features as very important.

Valentín (2007) conducted a study to evaluate currently used high visibility PPE practices on nighttime construction and maintenance projects. The study was divided in two phases which included a survey to obtain the perspective of owners, workers and general contractors regarding PPE implementation procedures and current high-visibility PPE practices and the effectiveness for improving worker visibility. The results from the survey showed that the characteristics related to the comfort of the worker were rated as very important when choosing a safety garment. For this reason, the sizes of the garments should be chosen based on a size chart provided by the manufacturer or supplier of the garments. The second phase consisted of a testing procedure to compare the visibility of different types of safety garments. For this study, videos of different high-visibility safety garment assemblies were taken on a simulated work zone, these were shown to automobile drivers who were asked to compare the visibility of the different PPE assemblies. The data collection process for this phase consisted of 148 surveys distributed to three different groups of Purdue undergraduate students taking civil engineering classes. Each group performed a different pair-wise comparison between the different videos. The first comparison consisted of the evaluation of each of the assemblies in two positions, worker facing traffic and facing away from traffic. The second and third comparisons were between fifteen clothing assemblies and the INDOT safety vest in both of the studied positions. This phase of the study showed that assemblies comprised of the currently used INDOT safety vest and an additional garment was ranked as the most visible PPE. Statistical analysis identified the characteristics of the garments that could improve worker visibility. For example, a garment with higher retroreflectivity and higher variance in the retroreflectivity would be more likely to 
be seen than the currently used INDOT garment. In addition, if a secondary item (such as safety pants or retroreflective bands) is used, its retroreflectivity variance should be low. The results of this study also suggested that high-visibility garments must be changed periodically to capture the attention of drivers more effectively.

In order to improve the use of high-visibility apparel, the FHWA developed several recommendations to be applied by the parties involved in the planning and development of highway construction and maintenance projects. Some of these recommendations are presented in Table 2.13 .

Table 2.13 Strategies to Improve the Use of High-Visibility Apparel (NIOSH 2001)

\begin{tabular}{|c|c|}
\hline Stakeholder & Strategy \\
\hline $\begin{array}{c}\text { Construction and } \\
\text { Maintenance Contractors }\end{array}$ & $\begin{array}{l}\text { - Require all pedestrian workers to wear high-visibility safety } \\
\text { apparel } \\
\text { - Inspect high-visibility apparel on a regular basis to ensure } \\
\text { that the color has not faded or the retroreflective properties } \\
\text { have not been lost } \\
\text { - Consider seasonal variations in landscape and foliage when } \\
\text { choosing the colors for worker safety apparel so it does not } \\
\text { blend with the background. }\end{array}$ \\
\hline $\begin{array}{l}\text { Policymakers- Federal, State } \\
\text { or Local }\end{array}$ & $\begin{array}{l}\text { - Modify existing MUTCD regulations to require all workers } \\
\text { to wear high-visibility safety apparel } \\
\text { - Perform periodic evaluations of visibility requirements in } \\
\text { OSHA regulations and the MUTCD for changes in } \\
\text { technology } \\
\text { - Develop guidelines that specify retroreflective or fluorescent } \\
\text { material, rather than just colors. According to Turner et al. } \\
\text { (1997), most effective choices for fluorescent colors to be } \\
\text { red-orange, yellow-green, or a combination of these. }\end{array}$ \\
\hline Contracting Agencies & $\begin{array}{l}\text { - Require retroreflective or fluorescent material on head gear } \\
\text { and flagger gloves. }\end{array}$ \\
\hline
\end{tabular}

In highway maintenance and construction operations it is a routine practice for trucks and other heavy equipment to enter and exit the work zone on a regular basis. When any type of heavy equipment, especially dump trucks, backs up in a busy work zone, there is an increased risk of an 
accident or injury for pedestrian workers and other construction vehicles within the work zone (NIOSH 2002). Normally, a highway construction work zone can be a confined and congested area, in which truck drivers and heavy equipment operators must follow established routes in the ITCP and must be constantly aware of the persons, activities, and vehicles that may interfere with their ability to complete their task in a safe manner. One strategy that can be used to improve safety within a work zone is the use of a spotter for assistance when backing-up trucks in a work zone. The spotter can serve as an aid for the truck driver or equipment operator to maneuver safely in and out the work zone. The use of this device provides the driver a "vision" they lack when backing up and reduces "blind spots."

Another strategy to improve safe equipment operation within the work zone is the use of electronic signaling devices or sensors to warn equipment operators of pedestrian workers in the immediate work area. Workers are constantly exposed to the hazards produced by moving heavy equipment. By being exposed daily to the noise of warning devices of backing up equipment, they can become accustomed to it, reducing the effectiveness of these devices in preventing accidents (NIOSH 2002). Therefore, other devices that emit a different noise should be considered in addition to the standard backing up alarms. Other practices to improve safe equipment operation within the work zone while preventing worker accidents and fatalities are presented in Table 2.14. 
Table 2.14 Strategies to Improve Safe Equipment Operation (NIOSH 2001)

\begin{tabular}{|c|c|}
\hline Stakeholder & Strategy \\
\hline $\begin{array}{l}\text { Construction and Maintenance } \\
\text { Contractors }\end{array}$ & $\begin{array}{l}\text { - Train equipment operators never to move equipment without } \\
\text { making positive visual contact with the pedestrian workers near } \\
\text { the equipment. } \\
\text { - Train pedestrian workers and equipment operators in appropriate } \\
\text { communications methods to use when the worker is near the } \\
\text { equipment. Such methods include using hand signals and } \\
\text { maintaining visual contact. } \\
\text { - Schedule tasks to ensure pedestrian workers are out of areas where } \\
\text { heavy equipment is being used. } \\
\text { - Train crews, operators, truck drivers, and subcontractors to } \\
\text { recognize and understand any symbols, markers, and colors used } \\
\text { to separate pedestrian workers from equipment within the work } \\
\text { zone. } \\
\text { - Design work zone areas in order to eliminate or decrease as much } \\
\text { as possible the backing of equipment and "blind spots." } \\
\text { - Channelize trucks and equipment leaving the work zone and keep } \\
\text { pedestrian workers out of that area. Devices such as temporary } \\
\text { pavement markings or flexible colored poles can be use inside the } \\
\text { work zone to delineate pedestrian-free areas or the flow of traffic } \\
\text { lines. }\end{array}$ \\
\hline
\end{tabular}

\subsubsection{Innovative Technologies for Hazard Control}

New innovative technologies are needed to be developed for hazard control in highway construction and maintenance work zones as well as more effective use of existing products and procedures through increased training (FHWA 2006). The implementation and use of these innovative technologies can help improve highway user and worker safety, as well as traffic flow through work zones. There are several essential elements involved in the support of this innovation and increased effectiveness:

- Acceptance and adoption of the new technology by state and local highway agencies.

- A research and evaluation program for new work zone safety products, devices, and procedures.

A radar triggered speed display is a new technology that is commercially available in the United States that consists of a back-lit dynamic speed display, a standard speed limit posted above the display, and a strobe flash. The strobe of the flash can be set to activate when the posted speed 
limit is exceeded. In this system a second threshold speed can be set to activate an alarm horn. The main purpose of this horn is to emit a noise towards the work zone in order to alert that a vehicle is approaching the work zone at an excessive speed that could lead to an intrusion. Also this system allows displaying a maximum speed limit to discourage motorists from competing to post higher speeds on the display. The device also allows setting a camera photo-enforcement (Meyer 2000).

A study conducted by McCoy et al. (1995) analyzed the effectiveness of the radar speed display at a rural interstate work zone in South Dakota. The speed monitoring display was placed on a trailer, with the "WORK ZONE" warning sign, an advisory $45 \mathrm{mph}$ speed limit sign, and a plate displaying the motorist's speed, which was displayed as the motorist approached the merge area. The results of the study showed that the speed monitoring display reduced the average speed by four mph and the percentage of vehicles that were speeding through the work zone. The percentage of passenger cars and trucks above the speed limit was reduced by 20-25 and 40 percent, respectively.

The South Dakota DOT (1996) conducted a research study to evaluate the effectiveness of the display and identify which type was the most suitable for use on interstate highway work zones. One of the systems evaluated in the study consisted of a changeable message sign (CMS) and a laser radar unit. The message displayed by default was "RIGHT LANE CLOSED, KEEP LEFT," with flashing arrows below the text. As soon as the speeding vehicle approached the area and activated the radar gun, the displayed message changed to "YOU ARE SPEEDING SLOW DOWN." The laser radar unit threshold was set at $70 \mathrm{mph}$. During the study, a 10 percent reduction in the number of vehicles traveling at higher speeds than $70 \mathrm{mph}$ was observed. The mean speeds were reduced up to two mph and the $85^{\text {th }}$ percentile speeds decreased by one to four mph. The study showed that the CMS and the laser radar unit provided additional safety to the work zone by reducing the number of speeding vehicles.

Several tests performed by the Kansas DOT (2000) on a construction site on I-70 demonstrated that the radar is quite effective in reducing the mean speeds, as well as the percent of drivers exceeding the posted speed limit, as shown in Figures 2.6 and 2.7. These effects decreased 
downstream of the device, but remained at statistically significant levels for the $0.8 \mathrm{~km}$ over which the speed data were collected. A significant advantage that could be identified during the testing was the ease of the speed display setup, which required less than 10 minutes once the site was identified.

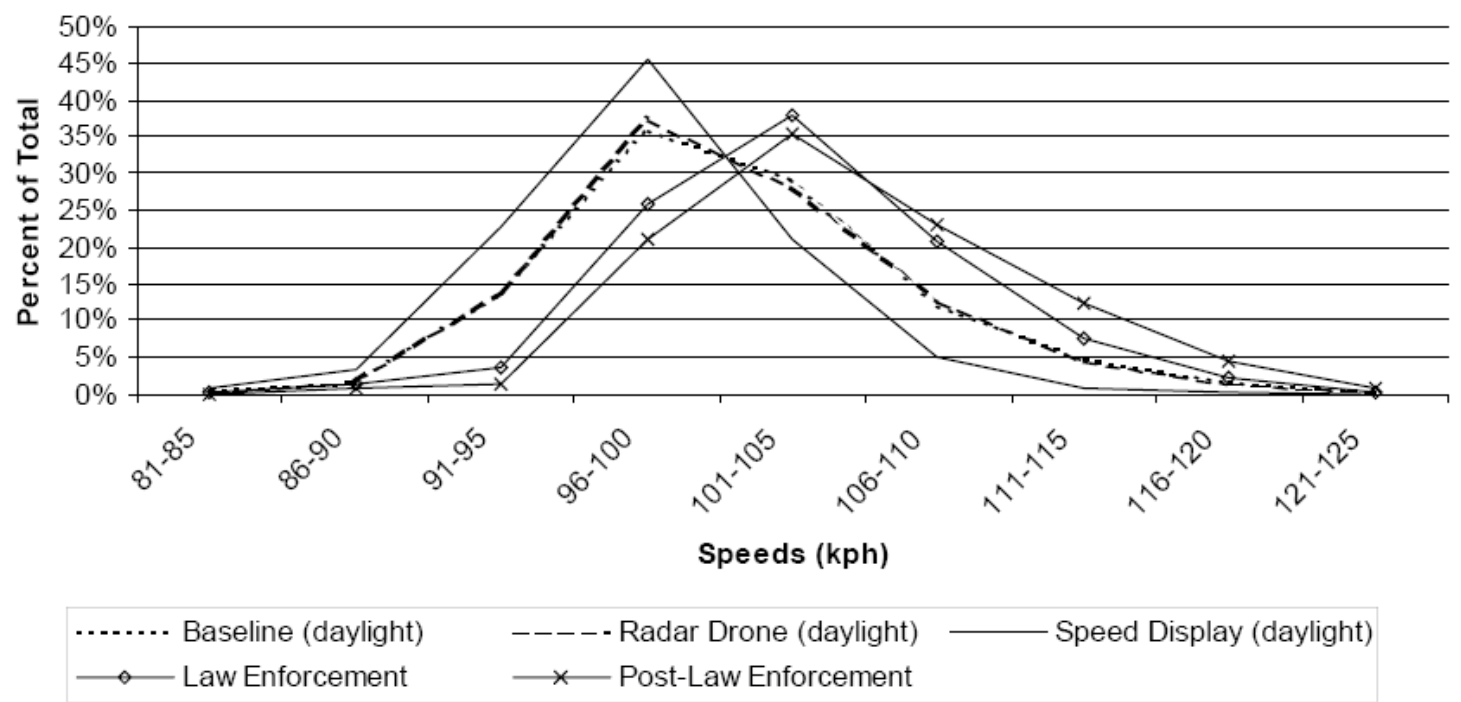

Figure 2.6 Speed Distributions for Daytime, Passenger Cars on I-70 in Kansas (Meyer 2000).

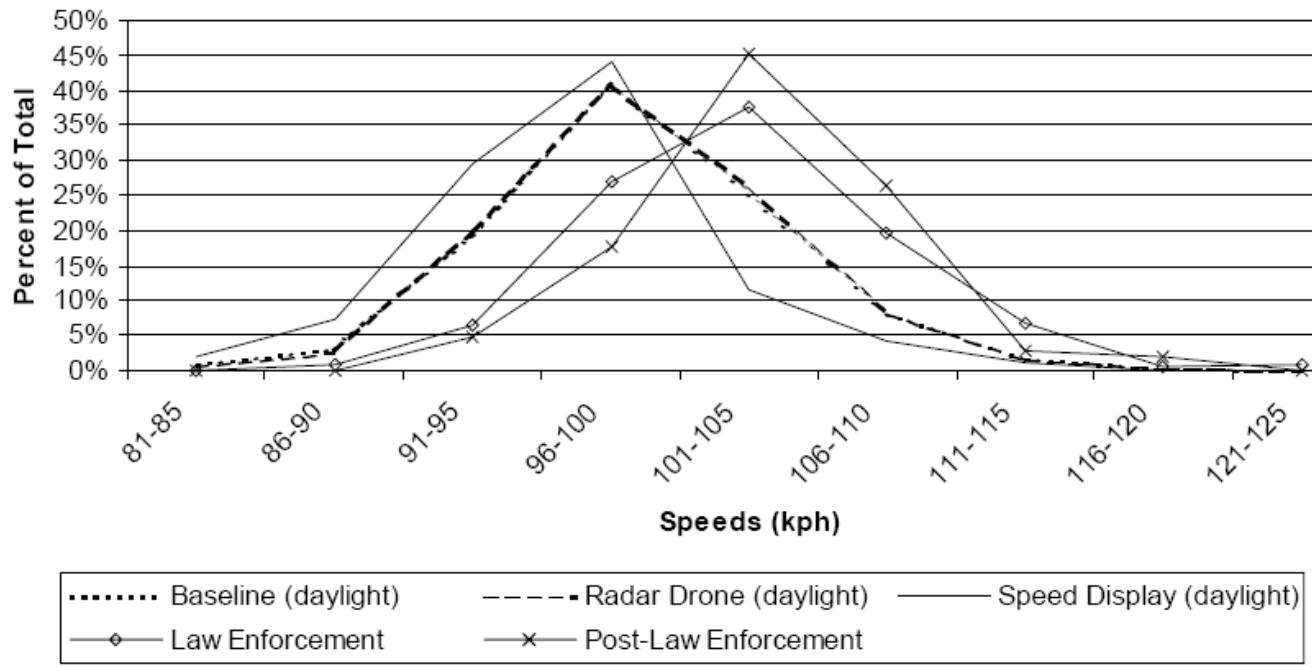

Figure 2.7 Speed Distributions for Daytime, Trucks on I-70 in Kansas (Meyer 2000).

Another type of innovative technology for hazard control is the drone radar, which consists of a system that transmits a microwave frequency band. This band is transmitted to vehicles equipped 
with radar detection devices that perceive the radar signal from the drone as the presence of police enforcement in the work zone. As a result, the motorists reduce their speed, causing other vehicles to slow down. The main purpose of this technology is to reduce the $85^{\text {th }}$ percentile speed rather than the average speed because it can be assumed that the vehicles that have the radar detector devices are more likely to drive above the speed limit. A study was performed by Ullman (1991) on the effectiveness of the drone radar at a rural interstate work zone in Illinois. Average speed reductions were reported to be only $0.2-1.6 \mathrm{mph}$ when the drone radar was active. The data obtained in this study showed that the fastest motorists (greater than $65 \mathrm{mph}$ ) were the most likely to be affected by the presence of the drone radar. Their speed reduction was 0.2 - $2.6 \mathrm{mph}$ greater than the average speed reduction for all vehicles passing through the work zone.

Another study performed by Benekohal et al. (1992) analyzed the effectiveness of the drone radar at a rural interstate work zone in Illinois. This study consisted of three experiments with the objective of determining the immediate, short-term, and lasting effects of the drone radar. The first experiment was conducted using one radar gun operating from a stationary vehicle near the merge area for an hour. The study evidenced an immediate effect by reducing average speeds between eight and $10 \mathrm{mph}$ during the first hour. The second and third experiments evaluated the effects of one and two radar guns, respectively, and the lasting effect of continuous radar transmissions during a three-hour period. Both experiments showed that before the end of the three-hour period there were no speed reductions. By listening to citizens band (CB) radio conversations, the researchers learned that the motorists were quickly able to discover that there was no police presence in the work zone, and that the radar emissions were transmitted by drone radar. In the third experiment, the drone radar units were placed at different locations unknown by the motorists, which resulted in a speed reduction of three to six mph for trucks and three mph for passenger cars.

A study performed by Streff et al. (1995) analyzed the effectiveness of the drone radar without a police vehicle on high-speed freeways and in freeway work zones in Michigan. This study found that drone radar and police presence reduced the speed of high-speed trucks by at least $10 \mathrm{mph}$. Speed reductions were recorded for 30 to 70 percent of the trucks in the passing lane exceeding 
the speed limit by at least $10 \mathrm{mph}$. The results of this study showed that the combination of the police presence and the drone radar was an effective strategy where speeding trucks constitute a hazard.

\subsubsection{Nighttime Traffic Control Strategies}

Nighttime construction has significantly increased during recent years with the objective of minimizing the impact of daytime work zones on traffic flows (Bryden and Mace 2002). Nighttime work generates various risks related to the nature of the work to be performed and to safety. Crews working during low-light conditions are about two and one-half times more likely to be struck by a motor vehicle than those working during the day (3M 2000).

The strategies recommended by the TRB Guidelines for Design and Operation of Nighttime Traffic Control for Highway Maintenance and Construction Operations (2002) for improving worker safety in nighttime work zones can be classified according to their main categories as shown in Table 2.15.

Table 2.15 Strategies to Improve Work Zone Safety in Nighttime Construction (TRB 2000)

\begin{tabular}{|c|c|}
\hline Classification & \multicolumn{1}{|c|}{ Strategy } \\
\hline \multirow{3}{*}{ Work Zone Layout } & - Increase tapper length \\
- & Install low level transitional lights in advance warning and \\
& termination areas in order to make it easier for motorists to adjust \\
& to changing lighting conditions. \\
\hline \multirow{2}{*}{ Temporary Traffic Control } & - Ensure that flashing arrow panels are set at nighttime levels, \\
Devices & having daytime light settings can produce a blinding effect at \\
& night. \\
& - Reduce spacing between channelizing devices (40 ft or less) to \\
& compensate for reduced motorists visibility. \\
& increase driver guidance. \\
- Channelizing devices should be inspected on a regular basis to & ensure that they are in optimal condition and properly placed. \\
& - Use drums, vertical panels, or Type II barricades in tapers instead \\
& of cones. These devices provide more target area than cones. \\
\hline
\end{tabular}




\begin{tabular}{|c|c|}
\hline Visibility of Work Vehicles & $\begin{array}{l}\text { - All trucks and equipment used should have two rotating or } \\
\text { flashing amber beacons visible from 1,000 ft. } \\
\text { - Vehicles should display four-way emergency flashers when } \\
\text { stopped or moving slowly in or adjacent to a work zone. }\end{array}$ \\
\hline Visibility of Workers & $\begin{array}{l}\text { - All workers should wear high visibility apparel that makes them } \\
\text { recognizable over the entire range of body motions. } \\
\text { - The use of colors such as yellow-green for worker apparel may } \\
\text { help to differentiate the worker from the orange-colored work } \\
\text { vehicles, signs, drums, etc. } \\
\text { - Temporary illumination should be provided at all work locations } \\
\text { to make the workers visible. } \\
\text { - If workers are exposed during dusk or dawn situations, visibility } \\
\text { can be improved by using fluorescent colors. } \\
\text { - An operational plan should be developed for night work to assess } \\
\text { the risks associated with worker exposure to traffic, equipment, } \\
\text { and work vehicles. } \\
\text { - Workers should be trained in procedures to avoid hazards } \\
\text { associated with reduced visibility. }\end{array}$ \\
\hline $\begin{array}{l}\text { Speed Control and Increasing } \\
\text { Awareness of Drivers }\end{array}$ & $\begin{array}{l}\text { - Law enforcement. } \\
\text { - Credible speed limits. } \\
\text { - Real-time information on CMS. } \\
\text { - Media work zone information updates. } \\
\text { - Pavement rumble strips. } \\
\text { - Advanced diversion and detour information. }\end{array}$ \\
\hline Illumination of the Work Zone & $\begin{array}{l}\text { - During the installation of lighting within the work zone, proper } \\
\text { illumination of the work zone should be ensured while controlling } \\
\text { glare, which can cause a blinding effect on workers and motorist. } \\
\text { - Lower the height of lighting devices to reduce glare for motorists. } \\
\text { - Use glare-free light balloons and glare screens. }\end{array}$ \\
\hline
\end{tabular}

Lighting was reported to be one of the most important factors affecting the quality, cost, productivity, and safety on nighttime construction work zones (Kumar 1994). Researchers at the University of Florida (2003) developed the Illumination Guidelines for Highway Construction. These guidelines were developed through a comprehensive literature review process and field reviews of several projects with different nighttime operations. Some of these operations included: in-situ concrete construction of bridge decks, excavation, filling, asphalt concrete paving of intersections, milling, and resurfacing. The guidelines classify highway construction and maintenance operations in three main categories, as presented in Table 2.16, according to the needed lightning levels. 
Table 2.16 Illumination Guidelines for Highway Construction (adapted from FHWA)

\begin{tabular}{|c|l|}
\hline Category & \multicolumn{1}{c|}{ Lighting Requirements } \\
\hline Category I & $\begin{array}{l}\text { - General illumination requirements for work zones. } \\
\text { - Recommended for large-scale visual tasks with comparatively low } \\
\text { need for accuracy. }\end{array}$ \\
\hline Category II & $\begin{array}{l}\text { - General illumination of tasks and around construction vehicles and } \\
\text { equipment. }\end{array}$ \\
& $\begin{array}{l}\text { - Recommended for tasks on and/or around construction equipment, } \\
\text { - } \begin{array}{l}\text { such as paving and milling. } \\
\text { presence of workers near machinery. }\end{array}\end{array}$ \\
\hline Category III & $\begin{array}{l}\text { - Specified for small-scale visual tasks that require high accuracy, } \\
\text { such as potholes and repairing cracks. }\end{array}$ \\
& $\begin{array}{l}\text { - Recommended for situations that require extreme caution and } \\
\text { attention, such as signaling and flagging. }\end{array}$ \\
\hline
\end{tabular}

El-Rayes and Hyari (2002) with the University of Illinois developed an automated decision support system for the design of temporary lighting arrangements for nighttime construction operations. The main objective of the system is to provide support to highway contractors and resident engineers in optimizing lighting design for nighttime construction. The performance criteria considered in the design of the lighting arrangement included the following:

- Maximization of average illuminance level

- Minimization of uniformity ratio in order to ensure that light evenly reaches all areas in the work zone

- Minimization of glare in order to limit the visual impairments and/or discomfort experienced by workers and motorists

\subsubsection{Strategies to Prevent Occupational Injuries resulting from "Worker Struck by Mobile Equipment in Work Zones"}

Recommendations to prevent the occurrence of occupational injuries in the event of worker struck by mobile equipment in work zones have been developed and published mainly by NIOSH. These recommendations have been formulated in the fatal accident reports published by the FACE program, and are intended for employers, government agencies, and equipment manufacturers. Table 2.17 and Table 2.18 list a series of recommendations gathered principally from NIOSH-FACE reports of accidents related solely to the event of worker struck by mobile equipment. Some of these 
recommendations are generic and can be applied as strategies to reduce injuries caused by other types of accident events.

Table 2.17 Recommendations based on safety policies to prevent occupational injuries resulting from "worker struck by mobile equipment"

\begin{tabular}{|c|c|}
\hline Safety Policy & Recommendation \\
\hline \multirow{7}{*}{ Safety program } & $\begin{array}{l}\text { Develop, Implement, and enforce a comprehensive program considering the } \\
\text { following parameters: }\end{array}$ \\
\hline & $\begin{array}{l}\text { - Promote the concept of team work in safety as part of the safety program } \\
\text { (FACE 2003c). }\end{array}$ \\
\hline & $\begin{array}{l}\text { - Training of workers on foot, and equipment operators in appropriate } \\
\text { communication methods (Pratt et al. 2001) }\end{array}$ \\
\hline & - Training must meet language and literacy levels of all workers (FACE \\
\hline & $\begin{array}{l}\text { - Implement specific training on equipment blind areas for workers and } \\
\text { drivers/operators (FACE 2006). }\end{array}$ \\
\hline & $\begin{array}{l}\text { - Train all personnel to understand any symbols, markers and colors used to } \\
\text { separated workers on foot from equipment (Pratt et al. 2001) }\end{array}$ \\
\hline & $\begin{array}{l}\text { Government agencies should offer work zone safety training for all municipal } \\
\text { officers who perform traffic control activities (FACE 2003b) }\end{array}$ \\
\hline \multirow{4}{*}{ Safety enforcement } & Ensure compliance with all aspects of the safety program \\
\hline & $\begin{array}{l}\text { Ensure that workers adhere to the provisions on traffic control, set forth in the } \\
\text { Manual on Uniform Traffic Control Devices (MUTCD) (FACE 2005a). }\end{array}$ \\
\hline & $\begin{array}{l}\text { Institute a progressive discipline program to reinforce the need for workers to } \\
\text { follow established safe work procedures (FACE 2005a). }\end{array}$ \\
\hline & Ensure the use of personal protective equipment (PPE) (FACE 2004b). \\
\hline \multirow{5}{*}{ Other safety policies } & $\begin{array}{l}\text { Notify the nearest OSHA office within } 8 \text { hours of a serious occupational } \\
\text { accident, to allow investigators to appropriately assess hazards and remove } \\
\text { other potential hazardous conditions (FACE 2005a). }\end{array}$ \\
\hline & $\begin{array}{l}\text { Contractor should have a policy that requires site supervisors be notified } \\
\text { before subcontractor's employees enter the work zone (FACE 2004b). }\end{array}$ \\
\hline & $\begin{array}{l}\text { Establish and maintain a safety committee and a written injury prevention plan } \\
\text { (FACE 2005b). }\end{array}$ \\
\hline & $\begin{array}{l}\text { Implement performance-based training that evaluates trainees' knowledge and } \\
\text { ability to perform the task for which they were trained (Pratt et al. 2001) }\end{array}$ \\
\hline & $\begin{array}{l}\text { OSHA should consider a rulemaking effort to improve safety regulations and } \\
\text { require new safeguards for employees on work zones (FACE 2006) }\end{array}$ \\
\hline
\end{tabular}

The recommendations in Table 2.17 are related to safety policies and are grouped in the following categories: safety program, safety enforcement, and other safety policies. Table 2.18 lists recommendations based on other strategies that are not included in the classification of safety policies. 
Table 2.18 Other recommendations to prevent occupational injuries resulting from "worker struck by mobile equipment"

\begin{tabular}{ll}
\hline \multicolumn{1}{c}{ Strategy } & \multicolumn{1}{c}{ Recommendation } \\
\hline \multirow{3}{*}{$\begin{array}{l}\text { To offset presence } \\
\text { of blind spots }\end{array}$} & $\begin{array}{l}\text { Consider the use of a spotter to direct reversing maneuvers (FACE 2004a). } \\
\text { Manufacturers of heavy equipment and employees should consider the installation of } \\
\text { collision avoidance systems, such as cameras, radars, sonar, and radio frequency } \\
\text { identification (RFID) systems (FACE 2006). }\end{array}$ \\
\hline & $\begin{array}{l}\text { Separate workers on foot from equipment as much as possible by: } \\
\text { - Scheduling work tasks to keep workers on foot out of areas where heavy equipment } \\
\text { is in use (Pratt et al. 2001). }\end{array}$ \\
- Implement an Internal Traffic Control Plan (TCP) (FACE 2004a). \\
$\begin{array}{l}\text { Planning of } \\
\text { construction or } \\
\text { maintenance tasks }\end{array}$ & $\begin{array}{l}\text { Conduct daily pre-work safety meetings to discuss the work to be performed, } \\
\text { potential hazards, and safety procedures (FACE 2003a). }\end{array}$ \\
\cline { 2 - 2 } & $\begin{array}{l}\text { Plan staging areas to minimize backing distances through work zones (FACE 2004a). } \\
\text { Schedule work in such a manner that workers are provided with enough rest periods } \\
\text { (FACE 2004a). }\end{array}$ \\
& $\begin{array}{l}\text { Change periodically the audible tones of the alarms. This will allow workers to } \\
\text { become less accustomed and respond better to the warnings emitted by alarms } \\
\text { (FACE 2004b). }\end{array}$ \\
\cline { 2 - 3 } Other & $\begin{array}{l}\text { Inspect daily construction vehicles/equipment; report and remove from service any } \\
\text { defective equipment until repairs have been made (FACE 2003a). }\end{array}$ \\
\hline
\end{tabular}

\subsubsection{Use of Technological Devices to Prevent Occupational Injuries Resulting from the Event}

"Worker Struck by Mobile Equipment"

In order to offset the hazardous effect on workers on foot resulting from mobile equipment blind spots, devices or systems based on different technologies have been designed and/or proposed as support for drivers and operators. Collision warning systems were developed initially for industries such as mining and the automotive industry, which later on, were adapted for other industries. Perhaps the most common and simple system that seeks to avoid collisions between mobile equipment and workers is the back-up alarm system. Other more complex collision warning systems have evolved in time, and currently there are different commercially available systems, such as cameras, radars, ultrasonic sensors, and radio frequency identification (RFID) systems.

The back-up alarm system consists of an alarm that is activated every time a vehicle or equipment is put in reverse gear. According to OSHA safety and health regulations for 
construction (Standards 1926.601 and 1926.602), it is mandatory for a driver or operator to use back-up alarm systems when the driver moves his vehicle or equipment backwards and has an obstructed view to the rear, unless another employee signals that is safe to move (OSHA 2005). Although back-up alarms systems are required in construction, they are not reliable.

Blackmon and Gramopadhye (1995) stated that one of the problems with conventional alarm systems is the decrease in vigilance of workers when alarms are in use. The attention to assigned tasks causes workers to exclude other distracting and annoying noises. In addition, after a prolonged exposure to alarm warning sounds, workers appeared to become habituated and their responses to those warnings were less effective (Kryter 1970, as cited in Blackmon and Gramopadhye 1995). Duchon and Laage (1986) described the conventional back-up alarm system as the "boy who cried wolf", due to the occurrence of false alarms, and that workers on foot can hear the alarm whether or not they are directly behind the mobile equipment, prompting them to stop responding to warnings. Table 2.19 lists cases where the back-up alarm systems proved to be ineffective. The cases were obtained from the NIOSH-FACE reports of accidents that occurred during 2001 to 2005.

To overcome the problems of conventional alarm systems, Duchon and Laage (1986) proposed the use of discriminated alarm systems for mining applications. These devices were based on object sensing systems utilizing technologies such as infrared light, ultrasonic waves, and Doppler radars (Duchon and Laage 1986). They stated that these systems would have the following advantages: (1) both the operator and the workers on foot are warned by the alarm; (2) the condition of habituation would not be present since the warning signal would sound only when it detects an object; and (3) there is less noise pollution.

Ruff (2001) tested numerous collision warning systems on a mining dump truck (Komatsu 210 M). The test was performed utilizing the following technologies: two Doppler-based radar systems, a pulse radar system, a frequency-modulated continuous wave (FMCW) radar system, an ultrawide band (UWB) radar system, an ultrasonic sensor system, and two radio frequency identification systems (RFID). The radar technologies transmit signals and measure any returns signals reflected from objects within the transmitted beam. The radar systems differ in how the 
signal is transmitted, and whether any motion from the object or vehicle is required for an object's detection. For instance, the pulsed radar tested in Ruff (2001) pulses a signal 40 times per second and does not require motion from any of the parties for detection. On the other hand, the Doppler radar system uses frequency modulation of microwave signals to determine the distance to the obstruction, which results in the need for motion from any of the parties. The performance for each of the systems is shown in Table 2.20.

Table 2.19 Accident cases where the back-up alarm system was not an effective tool to prevent fatal injuries in work zones (gathered from NIOSH-FACE Reports).

\begin{tabular}{|c|c|c|c|c|}
\hline $\begin{array}{l}\text { NIOSH- } \\
\text { FACE } \\
\text { Report }\end{array}$ & Date & Equipment & Observations & Inconvenience \\
\hline $\begin{array}{l}\text { (FACE } \\
2005 d) .\end{array}$ & $\begin{array}{l}\text { May } \\
2001\end{array}$ & $\begin{array}{l}\text { Motor } \\
\text { grader }\end{array}$ & $\begin{array}{l}\text { Alarm was working properly; another } \\
\text { laborer near to the victim stated he heard } \\
\text { the back-up alarm }\end{array}$ & $\begin{array}{l}\text { Victim did not hear or } \\
\text { ignored the alarm. }\end{array}$ \\
\hline $\begin{array}{l}\text { (FACE } \\
\text { 2004a). }\end{array}$ & $\begin{array}{c}\text { Jan } \\
2002\end{array}$ & Dump truck & $\begin{array}{l}\text { Alarm was tested and found to be in } \\
\text { working order. Sound level where the } \\
\text { victim was standing was } 89 \mathrm{~dB} \text { and was } \\
76 \mathrm{~dB} \text { at the rear of the truck. }\end{array}$ & $\begin{array}{l}\text { Environment sound leve } \\
\text { higher than the sound } \\
\text { level emitted by the } \\
\text { alarm. }\end{array}$ \\
\hline $\begin{array}{l}(\text { FACE } \\
2004 \mathrm{c}) .\end{array}$ & $\begin{array}{c}\text { Jun } \\
2003\end{array}$ & Dump truck & $\begin{array}{l}\text { Alarm was in full operation at } 97 \mathrm{~dB} \text {. At } \\
\text { least one person reported hearing the } \\
\text { alarm. }\end{array}$ & $\begin{array}{l}\text { Victim did not hear or } \\
\text { ignored the alarm. }\end{array}$ \\
\hline $\begin{array}{l}\text { (FACE } \\
2004 b) .\end{array}$ & $\begin{array}{l}\text { Apr } \\
2004\end{array}$ & Dump truck & $\begin{array}{l}\text { Alarm tested before and after the incident } \\
\text { and was working properly. }\end{array}$ & $\begin{array}{l}\text { Victim did not hear or } \\
\text { ignored the alarm. }\end{array}$ \\
\hline $\begin{array}{l}\text { (FACE } \\
\text { 2005b). }\end{array}$ & $\begin{array}{l}\text { Dec } \\
2004\end{array}$ & Dump truck & $\begin{array}{l}\text { Alarm tested before and after the incident } \\
\text { and was working properly. A witness also } \\
\text { verified she could hear it. }\end{array}$ & $\begin{array}{l}\text { Victim did not hear or } \\
\text { ignored the alarm. }\end{array}$ \\
\hline $\begin{array}{l}\text { (FACE } \\
2004 b) .\end{array}$ & $\begin{array}{l}\text { May } \\
2005\end{array}$ & Dump truck & $\begin{array}{l}\text { Alarm checked by police after incident } \\
\text { and was found operable. However, the } \\
\text { alarm was functioning below } \\
\text { manufacturer's rating level }(97 \mathrm{~dB}) \text {. }\end{array}$ & $\begin{array}{l}\text { Placement of the alarm } \\
\text { did not follow the } \\
\text { manufacturer's } \\
\text { installation instructions }\end{array}$ \\
\hline
\end{tabular}


Table 2.20 Summary of test results for collision warning systems on a Komatsu $210 \mathrm{M}$ mining dump truck (Ruff 2001)

\begin{tabular}{lcccccccc}
\hline \multicolumn{1}{c}{ System } & $\begin{array}{c}\text { RFI } \\
\text { D 1 }\end{array}$ & $\begin{array}{c}\text { RFI } \\
\text { D 2 }\end{array}$ & $\begin{array}{c}\text { Doppler } \\
\text { radar } \\
1\end{array}$ & $\begin{array}{c}\text { Doppler } \\
\text { radar } \\
2\end{array}$ & $\begin{array}{c}\text { Pulsed } \\
\text { radar }\end{array}$ & $\begin{array}{c}\text { FMCW } \\
\text { radar }\end{array}$ & $\begin{array}{c}\text { Ultrasonic } \\
\text { sensor }\end{array}$ & $\begin{array}{c}\text { UWB } \\
\text { radar }\end{array}$ \\
\hline $\begin{array}{l}\text { Meature } \\
\text { for detection required }\end{array}$ & No & No & Yes & Yes & No & Yes & No & No \\
\hline $\begin{array}{l}\text { Maximum length } \\
\text { for detection of a } \\
\text { person (ft) }\end{array}$ & 50 & 50 & 22.5 & 25 & 30 & 40 & 8 & 50 \\
$\begin{array}{l}\text { Total coverage } \\
\text { near bumper }\end{array}$ & Yes & Yes & Yes & Yes & No & Yes & No & No \\
\hline $\begin{array}{l}\text { Two-way alarming } \\
\text { Yes }\end{array}$ & No & No & No & No & No & No & No \\
\hline $\begin{array}{l}\text { False-alarm rate in } \\
\text { clear field }\end{array}$ & $\begin{array}{c}\text { No } \\
\text { ne }\end{array}$ & $\begin{array}{c}\text { No } \\
\text { ne }\end{array}$ & Infrequent & $\begin{array}{c}\text { Frequen } \\
\mathrm{t}\end{array}$ & None & None & Infrequent & None \\
\hline $\begin{array}{l}\text { Cost* } \\
\mathrm{h}\end{array}$ & $\begin{array}{c}\mathrm{Hig} \\
\mathrm{h}\end{array}$ & Low & Low & Low & Low & Low & Med. \\
\hline
\end{tabular}

* Cost categories: High $=$ above U\$ 8,000; Medium $=$ U\$ 2,000 - \$8,000; Low = below U\$2,000

RFID = Radio frequency identification; FMCW = Frequency-modulated continuous wave; UWB = Ultra wide band.

As a technology, RFID performed the best. Two RFID systems tested were obtained from different providers, and one of them had a two-way alarm warning feature, which enables both the equipment operator and the worker to receive individually a warning alarm. The driver receives an alarm from a device installed in the truck cab, and the worker receives an alarm from a device or tag that he uses on his belt. The RFID technology has two components: (1) a reader, which is a device used to communicate with the (2) tag. The reader has at least one antenna that emits radio waves and receives signals back from the tag. The tag is a microchip attached to an antenna that can be incorporated into a product, animal, person, etc. It contains a unique serial number and can be either a passive or an active tag. Active tags have their own internal power source, which is used to generate the outgoing signal, while passive tags reflect the radio waves coming from the reader antenna (RFID Journal 2007).

The RFID systems used for collision avoidance in mining do not produce false alarms since they detect only objects or individuals using the tag. In theory, the applicability of this system can be extended to construction and maintenance work zones. However, it is not economically feasible, because the cost of the devices for just one equipment or truck is close to U\$ 11,000 . In addition, each of the workers must use a tag which costs approximately U\$ 2,700 (quotes provided by Nautilus International, January 26, 2007). 


\subsubsection{Collision Avoidance Systems Tested to Prevent Backing Accidents in Construction and}

\section{Maintenance Activities}

NIOSH has conducted testing of different collision warning systems on dump trucks used for construction and highway maintenance activities. Purdue University and the Indiana Department of Transportation have also tested camera systems installed on highway maintenance vehicles. In the Purdue University study (McCullouch 2003), six camera (black and white) systems of the same model were acquired and tested in dump trucks with sander beds and in highway assistance vehicles (i.e., "Hoosier Helper vehicles"). The testing of camera systems was performed to evaluate the systems as tools for preventing backing accidents and assisting drivers in operational activities. In both studies, most of the systems were tested under summer and winter conditions. A summary of the systems tested in these two studies is presented in Table 2.21. The main feedback provided by drivers of the test vehicles was that the combination of camera systems and sensor systems based on either ultrasonic or radar technologies, was more effective than just the use of one single system.

Two main problems were encountered with the sensors in the NIOSH study (Ruff 2003 and Ruff 2004). First, the detection zone of a person varies according to the posture of the individual; namely, it is reduced significantly when the person is in a crouching position. This is a major concern due to the potential for a person to be in that position in highway construction or maintenance activities (Ruff 2004). A graphical representation of this concern is shown in Figure 2.8. The second problem pertained to one of the Doppler radars, which worked well when detecting a person moving towards the truck, but its performance was very poor when the person was stationary and the truck was in motion (Ruff 2003).

Three major concerns were identified during the testing of camera systems. First, the cameras are passive devices (McCullouch 2003); they do not provide an alarm if an object is present in the backing path of the vehicle (Ruff 2004). They rely solely on the driver's level of attention to them. The second problem encountered was view obstruction. Ruff (2004) found that the camera view was quickly obscured by snow and road grime. Similarly, during the testing done by McCullouch (2003), there were times when the camera vision became distorted by mist and 
moisture that rolled up behind the truck, especially during the winter season. The third problem was glare at night when the pavement was wet (McCullouch 2003).

Alternative solutions proposed by McCullouch (2003) and Ruff (2004) for the aforementioned problems with camera systems include: (1) a combined camera and sensor-based system; (2) a lens washing system and a device similar to a spoiler at the top of the camera to force air down across the camera lens; (3) the use of color camera systems (McCullouch 2003). The last recommendation was not tested.

Table 2.21 Summary of collision warning systems tested in highway construction and maintenance activities

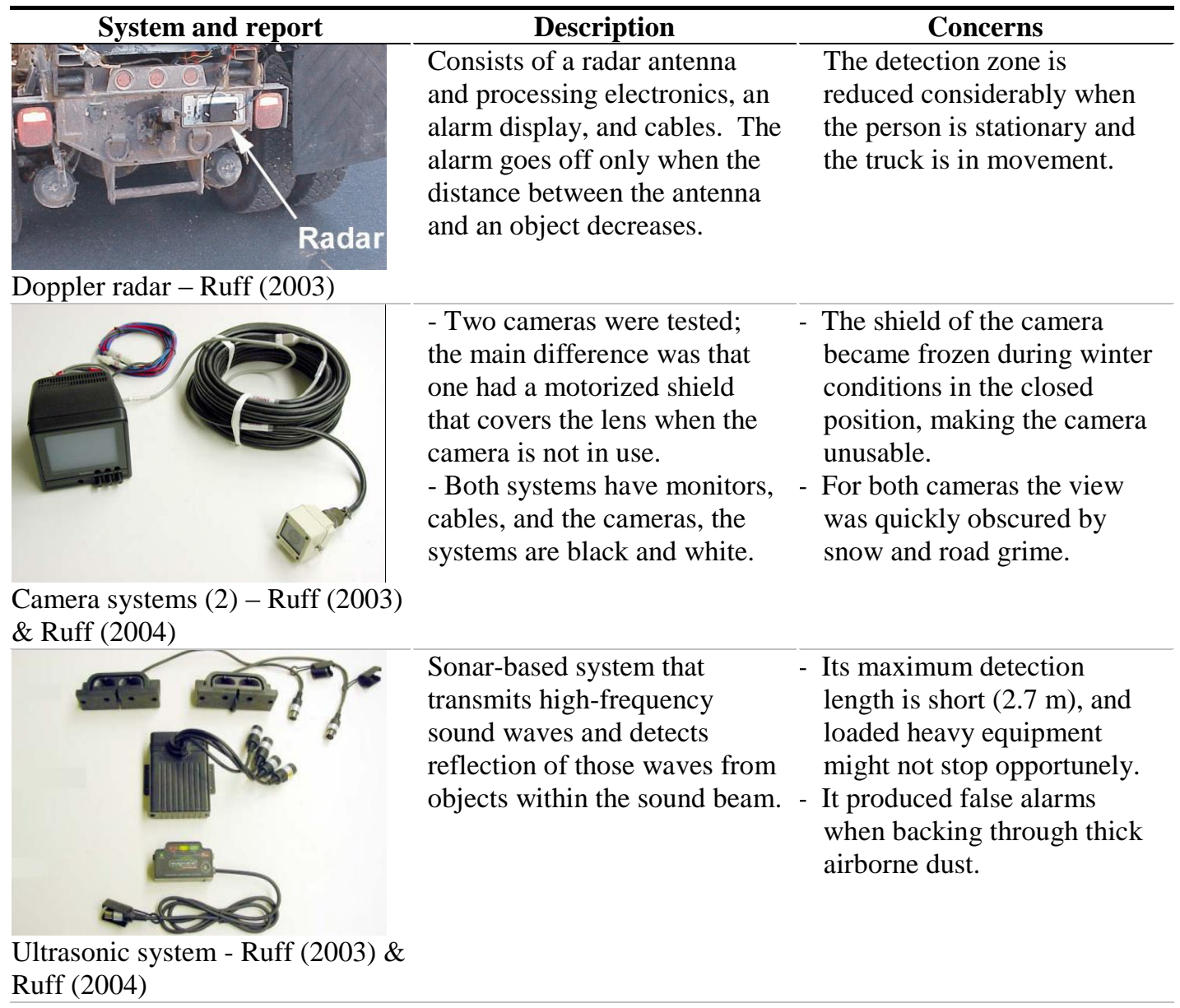




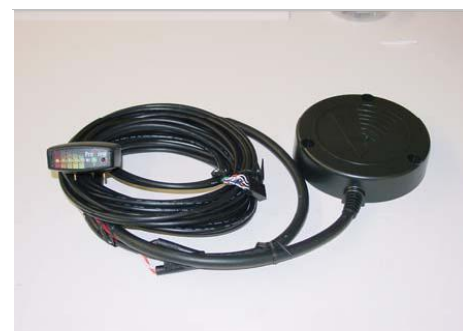

Pulse radar - Ruff (2003) \& Ruff (2004)

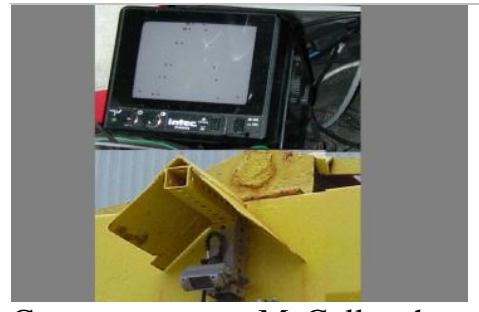

Camera system - McCullouch (2004)
Uses pulsed microwave signal techniques to detect an object within the radar beam.

Consists of a radar antenna and processing electronics, an alarm display, and cables.
- The detection zone of a person in a crouching position is poor.

- Nuisance alarms from nearby equipment or other non-hazardous objects were frequent in congested areas.
The system has monitors, cables, and the camera, which is a black and white system.
- The camera vision can become distorted by mist and moisture that rolls up behind the truck, especially during the winter season.

- There is glare at night when the pavement is wet.

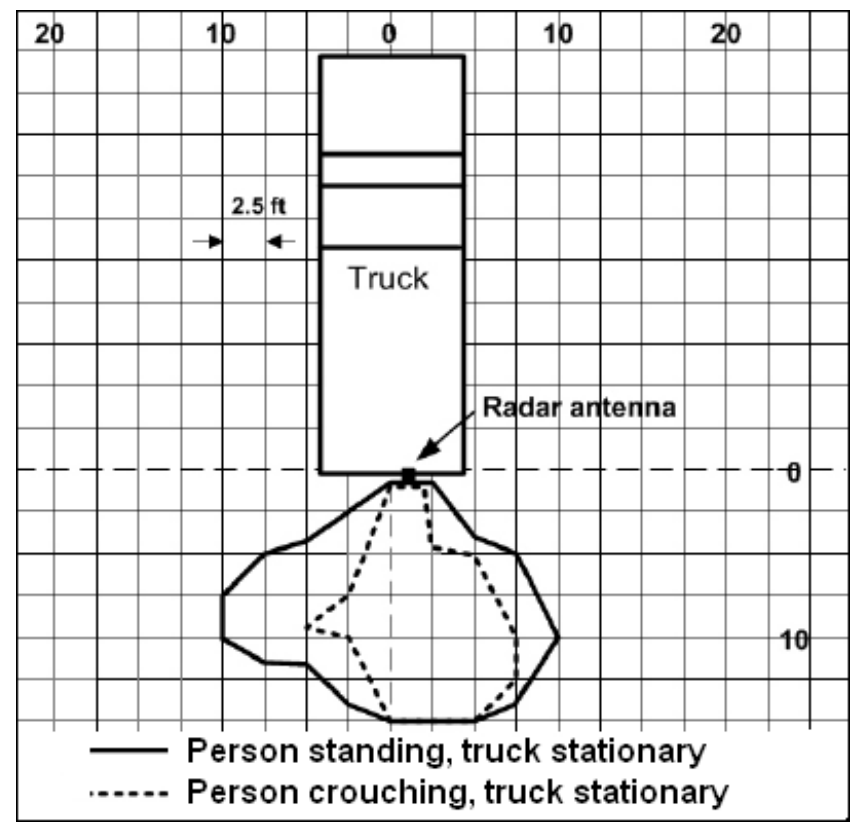

Figure 2.8 Detection zone for a person with a pulsed radar-based system (Ruff 2004)

Even though several technological devices have been tested as strategies to prevent serious injuries due to mobile equipment, further research related to the use of the systems in work zones is necessary to engage contractors and departments of transportation in the implementation of these technologies. None of the prior testing has evaluated the performance of combinations of cameras and sensors under the parameters of cost. Additionally, the performance of cameras 
under nighttime conditions and congested work zones are factors that need to be evaluated in greater detail.

\subsubsection{Identification of Factors Influencing Visibility of Workers in Nighttime Construction} Hyari (2004) conducted a survey of the Department of Transportation (DOT) in 17 states that focused on the amount of nighttime construction being performed in 2001. This survey revealed that an average of nearly 17 percent of construction projects, based on project value, were performed at night. A large amount of nighttime construction can be attributed to the advantages associated with performing construction projects at night. These advantages include reduced traffic congestion, reduced project duration, reduced impact on surrounding businesses, minimal economic effect due to delay, minimal air pollution from gases emitted by vehicles idling in traffic congestions, increased freedom to plan lane closures, enhanced work conditions at night, and faster delivery of material at night (Arditi et al. 2005).

Although there are advantages to planning construction project for nighttime, there are also disadvantages that are associated with nighttime construction operations as well. Reduced quality of work, staffing issues, and safety issues are among the disadvantages named by highway engineers, with safety listed at the top (Laws 2002). Visibility of workers and worker alertness are the main concerns of contractors when dealing with safety in nighttime construction. Practices that are used to improve worker visibility and alertness include the use of reflective apparel known as personal protection equipment (PPE), construction lighting equipment and techniques, and backup cameras mounted on mobile construction equipment. The type of PPE worn by a worker and the lighting equipment and techniques can vary from site to site and should be selected in such a way that the combination provides the most visibility of 
workers on site. Multiple combinations of these variables will be used to evaluate the use of rear-mounted cameras as instruments to increase the likelihood of a worker being identified in mobile equipment's blind spot. Increasing this likelihood will help to prevent injuries associated with workers being struck by mobile equipment in nighttime construction and maintenance operations.

\subsubsection{Personal Protection Equipment (PPE)}

Safety vests are worn by highway construction workers to increase the chance that they will be visible to others and that they will be identified as a worker, as opposed to a piece of equipment or traffic control device (i.e., barrels and cones) (Bacon 2002). Table 2.12 in section 2.3.4 provided a summary of design and recommended workers for each garment classification.

In addition to these safety vests already in use, other PPE assemblies may have a more positive impact on worker visibility in highway construction and maintenance work zones. For this reason, multiple safety vests should be investigated in order to identify the PPE with the least negative impact on worker visibility in highway work zones.

\subsubsection{Construction Lighting}

Hyari (2004) surveyed the participating DOTs and contractors with regards to the problems they encountered with the use of lighting in nighttime construction operations. The results of this survey concluded that a multitude of problems are associated with construction lighting including insufficient lighting levels, glare to workers, glare to road users, non-uniformity of 
lighting levels, light trespass to adjacent facilities, availability of suitable lighting equipment, reliability of lighting equipment, difficulty retrofitting construction equipment with additional lighting equipment, placement of lighting equipment, mobility of lighting equipment, lack of expertise in light design, lack of lighting design guidelines, and cost of lighting equipment. The most pressing of these issues were glare to workers, non-uniformity of lighting, glare to road users, insufficient lighting levels, and placement of lighting equipment, all of which were experienced by 65 percent of survey responses from contractors or greater (Hyari 2004).

El-Rayes and Hyari (2005) developed a lighting decision support system that could be used to generate near optimal and practical lighting arrangements for nighttime highway construction projects. The decision support system takes into consideration the lighting factors and variables, identified by Hyari (2004), and the lighting objectives to provide the user with a lighting arrangement that maximizes the average luminance on construction sites, maximizes lighting uniformity in construction zones, minimizes glare to workers and road users, and minimizes lighting costs. 
Table 2.22 Summary of factors and variables related to construction lighting that influence glare and the basis of their selection (Adapted from Hyari 2004).

\begin{tabular}{|l|l|l|}
\hline \multicolumn{1}{|c|}{ Factor } & \multicolumn{1}{|c|}{ Variables } & \multicolumn{1}{c|}{ Basis of Selection } \\
\hline Lamp Type & $\begin{array}{l}\text { Halogen, mercury vapor, high- } \\
\text { pressure sodium (HPS), incandescent, } \\
\text { fluorescent, low-pressure sodium } \\
\text { (LPS), metal halide. }\end{array}$ & $\begin{array}{l}\text { Selection of lamp type } \\
\text { based on availability } \\
\text { and contractor } \\
\text { preference. }\end{array}$ \\
\hline Lighting Position & $\begin{array}{l}\text { Horizontal position and height of } \\
\text { lamp(s) }\end{array}$ & $\begin{array}{l}\text { Construction } \\
\text { equipment movement, } \\
\text { road user movement, } \\
\text { lighting tower } \\
\text { mobility, light trespass, } \\
\text { and number of lamps. }\end{array}$ \\
\hline
\end{tabular}

Table 2.22 shows a summary of the factors and variables related to construction lighting that can influence the glare in nighttime construction work zones. Due to the many combinations of position and type of lighting used to illuminate highway construction and maintenance work zones, it is important to investigate which combination has the least negative impact on worker visibility. When using camera systems to view mobile equipment's blind spots, it is especially important to minimize the glare created by the lighting used to illuminate the work zone.

The Transportation Research Board (TRB) has published guidelines for the illumination of nighttime highway work with the National Cooperative Highway Research Program (NCHRP 2003). These guidelines cover three main areas: (1) illumination guidelines for nighttime highway work, (2) guidelines for work zone illumination design, and (3) guidelines for the use of temporary roadway lighting. 
According to the TRB, technical aspects of illumination guidelines for nighttime highway work are relatively new to contractor field personnel, making training appropriate. This training should cover areas such as glare control requirements and minimum levels of illumination. Adjustments will often need to be made to meet illumination requirements and allow the workers and equipment operators to see the tasks they are performing. These adjustments must be made on a task-by-task basis and should aim to reduce glare to workers. The TRB has found that the most effective glare control is the proper aiming of the light source along with the use of glare control shading hardware. The 2007 report published by the NCHRP (2007) adds that there are five factors that should be considered for task illumination. These factors are: (1) the importance and accuracy of the task, (2) background reflection, (3) speed associated with the task, (4) relative size of object(s) to be seen, and (5) distance of the object(s) from the observer.

\subsubsection{Productivity of Construction Equipment and Equipment Operators}

Cost is one of the most important factors in construction for every stakeholder in the construction process. The owner, contractor, and users all want the final cost of construction to be minimized. An effective way of minimizing cost is by increasing the productivity of workers and construction equipment. The analysis of productivity in construction operations reveals information about the current status of the project and operations and can also serve as a reference for the planning of future projects. Contractors and state DOTs can use information gathered by productivity analyses to help in planning and bidding of operations (Colbert 2003).

Productivity is generally defined as an amount of work scope that could be accomplished within a certain time period (i.e. linear feet per hour, square feet per minute, cubic yards per day, etc.). The equipment capacity is affected by the size of construction equipment, the operator efficiency 
is affected by human factors, and the total cycle time is affected by the type of construction equipment, site conditions, and human factors (Colbert 2003).

\subsubsection{Identification of Factors Influencing Productivity}

Many variables must be taken into consideration when determining the productivity of construction equipment, including haulers. These variables can be categorized as human factors, equipment factors, site condition factors, and time of day. Table 2.23 gives a brief list of variables that can affect the productivity of construction equipment.

In order to identify the significance of the time of day when work is performed, Colbert (2003) studied the productivity of earthwork and paving operations during nighttime and daytime. Through site visits, information was collected to determine the productivity of an excavator and a paver used in both daytime and nighttime operations. Using a T-Test to test the difference in the mean productivity, Colbert (2003) found that the increase in productivity and decrease in cycle times of operations performed at night was statistically significant when compared to operations performed during daytime. This can mostly be attributed to a decrease in motorist traffic congestion. 
Table 2.23 List of factors affecting productivity of construction operations (Adapted from Colbert 2003).

\begin{tabular}{|c|c|}
\hline Factor & Description \\
\hline Location & $\begin{array}{l}\text { The location determines the local governing body and } \\
\text { the rules and regulations that must be followed during } \\
\text { construction. Stringent regulations may decrease } \\
\text { productivity. }\end{array}$ \\
\hline \multirow{3}{*}{$\begin{array}{l}\text { Site Layout \& } \\
\text { Condition }\end{array}$} & Distance between cut and fill areas increases haul times. \\
\hline & $\begin{array}{l}\text { Poorly maintained haul roads can increase haul time as } \\
\text { well as limit number of vehicles passing at one time. }\end{array}$ \\
\hline & $\begin{array}{l}\text { Proper lighting is required during nighttime operations to } \\
\text { allow workers to see the tasks they are performing. }\end{array}$ \\
\hline \multirow{2}{*}{ Equipment } & $\begin{array}{l}\text { Track mounted equipment provides better traction, } \\
\text { increasing the load and speed that the equipment can } \\
\text { handle. }\end{array}$ \\
\hline & $\begin{array}{l}\text { The size of the equipment affects the volume of the load } \\
\text { that is carries in one cycle. }\end{array}$ \\
\hline Time of Day & $\begin{array}{l}\text { Nighttime operations typically experience higher } \\
\text { productivity and reduced cycle times due to decreased } \\
\text { interaction with motorists. }\end{array}$ \\
\hline
\end{tabular}

\subsubsection{Effective Planning of Construction Operations to Minimize Causes of Reduced Productivity}

Factors such as site layout and conditions, the equipment used for the project, and the time of day when the operations are performed can all be changed/modified to maximize productivity. Possible areas of consideration when planning any construction project would be providing proper training to the work force that will be performing the operations and the possible use of technology available for construction workers and construction equipment. 
The work force that is available to work on a construction site is dictated by the location of the project. The training that the work force has undergone may limit the type of equipment as well as particular practices that may be used on the construction site (Colbert 2003). Providing the work force the training specific to safety, equipment operation and practices that will maximize productivity of an operation. Proper training may also need to be provided for the use of new technologies available for use in construction.

Truck drivers involved in construction operations must often exit the cab of their truck to check the performance of their equipment (i.e., functionality of spreaders) and, when backing, the driver must be aware of people and objects in the path of the equipment. There are often false alarms when checking the blind spot of the mobile equipment. The time spent performing such checks adds to time spent on non-productive activities. By mounting a rear-facing camera on the mobile equipment, the functionality of the equipment could be monitored and the visibility of the equipment's blind spot from inside the cab could be improved, eliminating the need for the driver to exit the mobile equipment thus reducing time spent on non-productive activities (Ruff 2001). 


\section{CHAPTER 3. ANALYSIS OF ACCIDENT REPORTS AND PERSPECTIVES OF WORK ZONE PERSONNEL OF CAUSES OF ACCIDENTS}

This chapter provides a descriptive analysis for the fatal accident reports and the survey distributed to work zone personnel. A binomial logit model was also designed to explore worker perception regarding "lack of awareness" as a primary cause of accidents. Since some of the questions developed for the survey were based on the analysis of fatal accident of the available accident reports, the results from this model and the descriptive analysis will be compared.

\subsection{Data Collection Process}

The data collection process for the analysis of accident reports and perspectives of work zone personnel of causes of accidents is divided in two components. The first one consists of an accident reports database of work zone accidents that occurred in the United States from 2000 to 2006. The second component was achieved by the collection of data through a survey that was administered to different work zone personnel. The purpose of the survey was to obtain the perception of different parties about common causes of work zone accidents.

\subsubsection{Identification of Primary Causes of Serious Work Zone Injuries from Accident Reports}

A database with 230 fatal occupational incidents that reportedly occurred in work zones during the 2000-2006 time frame in the United States was obtained from the Occupational Safety and Health Administration (OSHA). After reviewing the database, 28 of the reports were removed because it was determined from the descriptions of these incidents that they were not construction or maintenance work zone occupational accidents.

The reports of fatal workplace incidents are based on second-level priority field inspections performed by OSHA, which are classified in the group of "fatality/catastrophe investigations." Each of the reports in the OSHA database includes the following information: date and time of the incident, incident location (state and street), accident event, demographic information of the 
injured worker, number of employees at the site, the number of total employees, the cost of the project, the identity of the employer, the employer's code for the Standard Industrial Classification (SIC) and the North American Industry Classification System (NAICS), an accident abstract, and a description of the accident. Unfortunately, not all the information had been completed for each report in the database.

For this research, fatal incident information was classified in two major groups: (a) the characteristics of the project and the injured worker and (b) the accident causes. The categories in the former group are described in Table 3.1. With the exception of the injured worker's occupation, the information in this group was already classified in the database file. The classification of the occupation of the injured worker and the second major group was performed according to the accident description provided in each report. The accident causes group had two main categories: (1) accident events and (2) behavioral causes of the accidents.

Table 3.1 Classification according to the characteristics of the project and the injured worker(s)

\begin{tabular}{|c|c|c|}
\hline & Category & Description \\
\hline \multirow{4}{*}{ Date and time } & Year (2001-2006) & \multirow{4}{*}{ Date and time of incident occurrence. } \\
\hline & Month & \\
\hline & Day of the week & \\
\hline & Time of the day & \\
\hline State & ----- & State where the incident took place. \\
\hline Project cost $*$ & $\begin{array}{l}\text { Under } 50 \mathrm{~K} ; 50-250 \mathrm{~K} ; 250- \\
500 \mathrm{~K} ; 500 \mathrm{~K}-1 \mathrm{M} ; 1-5 \mathrm{M} ; 5 \\
-20 \mathrm{M} \text {; over } 20 \mathrm{M}\end{array}$ & $\begin{array}{l}\text { Range of values for the projects where } \\
\text { incidents occurred. }\end{array}$ \\
\hline NAICS & ----- & $\begin{array}{l}\text { North American Classification System } \\
\text { (NAICS) for the employer of the injured } \\
\text { individual(s). }\end{array}$ \\
\hline $\begin{array}{l}\text { Number of workers } \\
\text { killed }\end{array}$ & $1 ; 2 ; 3$ & $\begin{array}{l}\text { Number of employees fatally injured in the } \\
\text { same incident. }\end{array}$ \\
\hline $\begin{array}{l}\text { Number of } \\
\text { employees at site }\end{array}$ & $\begin{array}{l}1-10 ; 11-19 ; 20-49 ; 50-99 ; 100- \\
249\end{array}$ & $\begin{array}{l}\text { Number of workers performing activities } \\
\text { when the accident occurred. }\end{array}$ \\
\hline Worker's age & 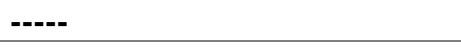 & Age in years of the fatally injured worker. \\
\hline $\begin{array}{l}\text { Worker's } \\
\text { occupation }\end{array}$ & ---- & $\begin{array}{l}\text { Occupation of the injured worker according } \\
\text { to the incident description. }\end{array}$ \\
\hline
\end{tabular}

- $\mathrm{K}=$ thousands of U.S. dollars; $\mathrm{M}=$ million of U.S dollars.

Table 3.2 and Table 3.3 describe the classification of the fatal incidents according to the accident events and the behavioral causes respectively. The accident events are the physical actions that ultimately caused the fatal injury of the workers. Behavioral causes of accidents relate to any 
inappropriate behavior by individuals involved. The Bureau of Labor Statistics (BLS) publishes the "Occupational Injury and Illness Classification Manual" in order to categorize accident events. However, these classifications are generally too basic and do not completely explain work zone accidents. In order to classify the fatal incidents in a better way, some of the BLS classifications were therefore modified and new classifications were proposed. Table 3.2 describes the categories used in this research for the accident events and indicates whether the category was created, adapted, or adopted from the BLS classification manual.

Table 3.2 Incident classification according to accident events

\begin{tabular}{|c|c|c|}
\hline Accident Event & $\begin{array}{l}\text { Existing, Adapted, } \\
\text { or Created }\end{array}$ & Description \\
\hline $\begin{array}{l}\text { Struck by vehicle not } \\
\text { part of the project }\end{array}$ & Adapted & $\begin{array}{l}\text { The injured worker was on foot in the work zone and } \\
\text { was struck by an intruder vehicle. It was adapted from } \\
\text { BLS classification "pedestrian struck by vehicle, } \\
\text { mobile equipment", which had no information about } \\
\text { the relationship of the vehicle to the project. }\end{array}$ \\
\hline $\begin{array}{l}\text { Struck by vehicle } \\
\text { which was part of the } \\
\text { project }\end{array}$ & Adapted & $\begin{array}{l}\text { The injured worker was on foot in the work zone and } \\
\text { was struck by mobile equipment or other vehicle } \\
\text { involved in the construction or maintenance project. It } \\
\text { was adapted from BLS classification "pedestrian } \\
\text { struck by vehicle, mobile equipment." }\end{array}$ \\
\hline $\begin{array}{l}\text { Collision between } \\
\text { intruder vehicle and } \\
\text { equipment }\end{array}$ & Adapted & $\begin{array}{l}\text { The worker was fatally injured from the crash of an } \\
\text { intruder vehicle and the equipment or vehicles used in } \\
\text { the project. It was adapted from BLS classification } \\
\text { "collision between vehicles, mobile equipment." }\end{array}$ \\
\hline $\begin{array}{l}\text { Fell from mobile } \\
\text { equipment }\end{array}$ & Existing & $\begin{array}{l}\text { The worker was positioned inside or over a } \\
\text { construction vehicle and fell from it. }\end{array}$ \\
\hline Struck by object & Existing & $\begin{array}{l}\text { The worker was hit or struck by an object (e.g., piece } \\
\text { of concrete, guardrail section). }\end{array}$ \\
\hline $\begin{array}{l}\text { Exposed to harmful } \\
\text { substances or } \\
\text { environments }\end{array}$ & Existing & $\begin{array}{l}\text { The worker died from his exposure to harmful } \\
\text { substances or environments (e.g., heat exposure, } \\
\text { exposure to chemical substances). }\end{array}$ \\
\hline $\begin{array}{l}\text { Equipment slid or } \\
\text { rolled over }\end{array}$ & Created & $\begin{array}{l}\text { Occurred when an employee (e.g., operator) rolled } \\
\text { over an embankment or slid and then fell to a lower } \\
\text { level while operating the equipment. }\end{array}$ \\
\hline Fell to a lower level & Existing & $\begin{array}{l}\text { The worker was injured by the impact between the } \\
\text { worker and the source of the injury, the motion } \\
\text { producing the contact being that of the person, and } \\
\text { was produced by gravity (BLS 2007). }\end{array}$ \\
\hline $\begin{array}{l}\text { Crush between parts } \\
\text { of equipment }\end{array}$ & Adapted & $\begin{array}{l}\text { The worker was caught between parts of the } \\
\text { construction equipment (e.g., backhoe bucket and rear } \\
\text { part of the backhoe). It was adapted from "caught in } \\
\text { or compressed by equipment or objects." }\end{array}$ \\
\hline $\begin{array}{l}\text { Contact with } \\
\text { equipment }\end{array}$ & Existing & $\begin{array}{l}\text { Worker was struck by a mobile part of the } \\
\text { construction equipment. It was adapted from "contact } \\
\text { with objects and equipment." }\end{array}$ \\
\hline
\end{tabular}


The incidents were classified according to seven behavioral causes groups according to the incident description. With the exception of "unsafe methods or sequencing" and "not using provided safety equipment" developed by Toole (2002), the other categories were created in this research. Table 3.3 describes each behavioral cause utilized to classify the data.

Table 3.3 Incident classification according to behavioral causes

Behavioral Cause

Description

\begin{tabular}{|c|c|}
\hline Negligence of a third party & $\begin{array}{l}\text { Associated with individuals not related to the } \\
\text { construction/maintenance project, including drivers/owners of } \\
\text { intruder vehicles (vehicles without brakes, drunken drivers, a } \\
\text { driver who does not follow the orders given by a traffic } \\
\text { controller). }\end{array}$ \\
\hline $\begin{array}{l}\text { Lack of awareness from injured } \\
\text { worker }\end{array}$ & $\begin{array}{l}\text { Accidents due to this factor occur when the worker is not aware } \\
\text { of possible hazards (e.g., distracted worker run over by a dump } \\
\text { truck backing up). }\end{array}$ \\
\hline Unsafe methods or sequencing & $\begin{array}{l}\text { The normal sequencing of construction activities does not occur, } \\
\text { resulting in an activity being more hazardous than it usually is } \\
\text { (Toole 2002); for instance, a worker installing traffic control } \\
\text { devices without the appropriate protection, the use of } \\
\text { malfunctioning equipment). }\end{array}$ \\
\hline $\begin{array}{l}\text { Worker misjudgment of a } \\
\text { hazardous situation }\end{array}$ & $\begin{array}{l}\text { When a worker does not consider the risk that some } \\
\text { circumstances represent (e.g., worker walking along a highway } \\
\text { median outside the protection zone, worker stepping into an } \\
\text { active lane). }\end{array}$ \\
\hline Lack of traffic control devices & $\begin{array}{l}\text { This behavioral cause is linked directly to the employer and } \\
\text { occurs when the employer (e.g., contractor) does not have in } \\
\text { place sufficient traffic control devices (e.g., when there are } \\
\text { insufficient signs, concrete barriers might be needed but they are } \\
\text { not in place). }\end{array}$ \\
\hline $\begin{array}{l}\text { Co-worker lack of awareness } \\
\text { and/or misjudgment of a } \\
\text { hazardous situation }\end{array}$ & $\begin{array}{l}\text { A worker who does not properly consider the risk that an activity } \\
\text { might represent to a fellow worker or is unaware of the presence } \\
\text { of other workers who might be injured while performing usual } \\
\text { activities (e.g., a dump truck driver who starts moving his/her } \\
\text { vehicle forward without noticing the presence of workers in front } \\
\text { of the truck) }\end{array}$ \\
\hline $\begin{array}{l}\text { Not using provided safety } \\
\text { equipment }\end{array}$ & $\begin{array}{l}\text { As described in Toole (2002), when a worker is provided with } \\
\text { safety equipment but does not use it appropriately or simply does } \\
\text { not make use of it (e.g., employee working in an elevated bucket } \\
\text { not using available fall protection). }\end{array}$ \\
\hline Not Classifiable & $\begin{array}{l}\text { This category is for incidents that could not be classified in any } \\
\text { of the above categories due mostly to insufficient description of } \\
\text { the events or because the incidents occurred due to isolated } \\
\text { circumstances (e.g., suicide) }\end{array}$ \\
\hline
\end{tabular}




\subsubsection{Surveys about Causes of Occupational Injuries in Work Zones}

Three different surveys were distributed to work zone personnel within State Departments of Transportation (DOT) and construction companies in the Midwest. The first survey was

specifically designed for workers in construction companies and DOTs. The second survey was geared towards personnel with safety managerial roles in DOTs, such as supervisors and project engineers. The third survey was designed for individuals with safety managerial roles in highway construction companies (e.g., supervisors and safety managers). The purpose of the surveys was to obtain the perception of different work zone personnel regarding the causes of serious and fatal occupational injuries as well as other safety issues encountered in construction and maintenance work zones. The worker survey and the survey for supervisory personnel in DOTs were also distributed to work zone personnel employed by the Tippecanoe County Highway Department in Lafayette, Indiana.

\subsubsection{Development of the Surveys Distributed to Work Zone Personnel}

The surveys were developed based on the literature review and the analysis of the available accident reports. Although three different surveys were designed, some of the questions were identical in all three surveys to address the perspectives of all relevant parties involved in a work zone project on certain subjects. For instance, each survey instrument included an evaluation of the likelihood of occurrence of different accident events. Other questions that were common in the three surveys were: the perception of the level of hazard exposure for different occupations, the perception of the occurrence likelihood of human behavioral causes of accidents, the satisfaction level with the training received (in the case of the workers) or provided (in the case of supervisors, safety managers, and safety officers) for different safety provisions. A copy of each the three surveys implemented can be found in Appendices A, B, and C. 


\subsubsection{Survey Administration and Sample Description}

The surveys were distributed between June and September 2007 through e-mail and site visits. Twelve site visits to projects and highway maintenance facilities located in Indiana were conducted. Table 3.4 lists the dates, locations, and projects for the site visits. The worker survey was distributed to highway construction and maintenance workers employed by the Indiana Department of Transportation (INDOT), construction company employees performing contracts for INDOT at the time of the survey implementation, and maintenance workers employed by the Tippecanoe County Highway Department, in Lafayette, Indiana.

Table 3.4 Site visits performed to administer the surveys

\begin{tabular}{lll}
\hline \multicolumn{1}{c}{ Date } & \multicolumn{1}{c}{ Project } \\
\hline $6 / 25 / 07$ & SR-43 Intersection SR-225 N & $\begin{array}{l}\text { SR-43 Added Travel Lanes \& Bridge } \\
\text { Replacement }\end{array}$ \\
\hline $7 / 13 / 07$ & SR-28 1.5 Miles East from I-65 & Clinton County SR-28 Pavement \\
\hline $7 / 23 / 07$ & US-6 Portage & US Highway 6 Reconstruction \\
\hline $7 / 23 / 07$ & US-6 1 Mile East SR-51 & US Highway 6 Reconstruction \\
\hline $7 / 23 / 07$ & I-80/94 & I-80/94 I-65 Interchange \\
\hline $7 / 23 / 07$ & Gary & INDOT Sub-district Unit \\
\hline $7 / 23 / 07$ & Wagner & Maintenance US-20 \\
\hline $8 / 13 / 07$ & SR-26 Intersection I-65 Lafayette & SR-26 Improvements \\
\hline $8 / 13 / 07$ & Main Street in Monticello & Main Street Improvements \\
\hline $8 / 13 / 07$ & SR-32 Fountain County & SR-32 Pavement \\
\hline $9 / 27 / 07$ & 3550 Brady Lane, Lafayette & Tippecanoe County Highway Department \\
\hline
\end{tabular}

The survey for DOT safety supervisory personnel was administered to INDOT supervisors and district safety officers for different DOTs in the Midwest (i.e., Indiana, Ohio, Pennsylvania, and Wisconsin). The survey for personnel with safety managerial roles at highway construction companies was administered to supervisors and safety managers for the companies where the worker surveys were also administered. Table 3.5 shows the rates of response to all the surveys. 
Table 3.5 Rate of response for surveys distributed among work zone personnel

\begin{tabular}{|c|c|c|c|c|}
\hline Survey & $\begin{array}{c}\text { Type of Work } \\
\text { Zone } \\
\text { Personnel }\end{array}$ & Sample Population & $\begin{array}{l}\text { Responses } \\
\text { Received }\end{array}$ & $\begin{array}{c}\text { Rate of } \\
\text { Response }\end{array}$ \\
\hline \multirow{3}{*}{1} & \multirow{3}{*}{ Workers } & Construction companies & 34 & $44 \%$ \\
\hline & & INDOT & 56 & $42 \%$ \\
\hline & & County Highway Department & 9 & $36 \%$ \\
\hline \multirow{6}{*}{2} & \multirow{4}{*}{$\begin{array}{c}\text { Safety } \\
\text { Directors }\end{array}$} & INDOT & 3 & $50 \%$ \\
\hline & & Wisconsin DOT & 2 & $22 \%$ \\
\hline & & Ohio DOT & 1 & $8 \%$ \\
\hline & & Pennsylvania DOT & 1 & $6 \%$ \\
\hline & Supervisors & INDOT & 6 & $67 \%$ \\
\hline & Supervisors & County Highway Department & 2 & $100 \%$ \\
\hline 3 & Supervisors & Construction companies & 9 & $60 \%$ \\
\hline
\end{tabular}

Survey 1: Worker

Survey 2: State supervisory personnel (DOT and County Highway Department)

Survey 3: Construction companies supervisory personnel

Thirteen surveys were completed by safety supervisory personnel within DOTs; fifty-four percent of the respondents were DOT regional safety directors and the remaining percentage were INDOT supervisors for different projects at the sites visited. A total of 99 worker surveys were completed as shown in Table 3.5, 56\% of which were INDOT workers. Most of the respondents in the worker survey were White or Caucasian (82\%), and $24 \%$ of the total had worked more than ten years in highway construction or maintenance projects.

Figure 3.1 illustrates the distribution of workers according to their ages and their work experience in highway construction or maintenance activities. Most of the workers who completed the survey were highway technicians, followed by construction laborers, with $45 \%$ and $15 \%$ respectively. Figure 3.2 shows the distribution of the workers according to their occupations. 


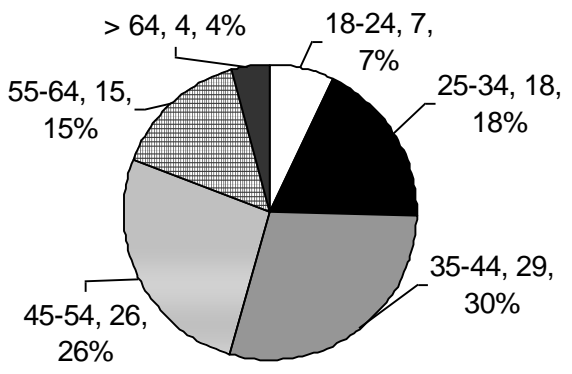

a) Age distribution of the workers

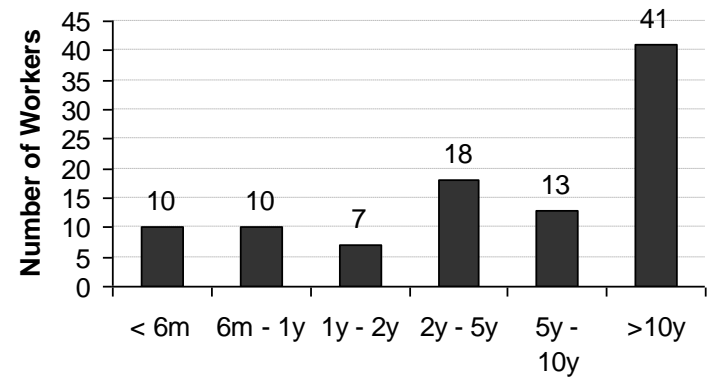

Time Working in Highway Construction/ Maintenance Activities

b) Distribution of the workers according to their tenure in highway construction/maintenance

Figure 3.1 Distribution of the workers by age and tenure working in highway construction/maintenance

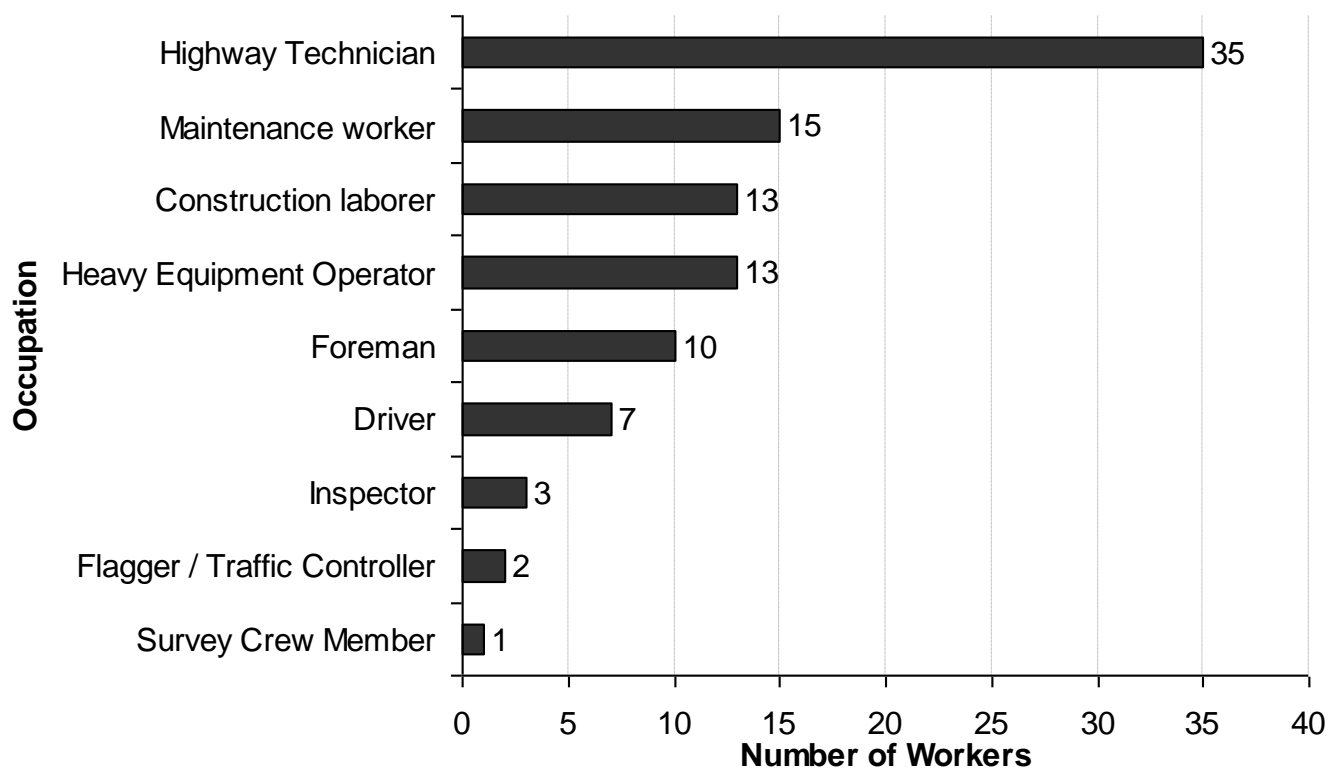

Figure 3.2 Distribution of the workers by occupation 


\subsection{Data Analysis}

The Data analysis for this chapter is divided in a descriptive analysis of the accident reports, and a descriptive analysis of the surveys distributed to work zone personnel. In this chapter, a binomial logit model is also presented. This model was developed to assess the perception of the workers regarding "lack of awareness" as a primary behavioral cause of accidents in work zones.

\subsubsection{Analysis of Accident Reports Database}

The analysis performed with the data from the database was divided in two sections: (1) the characteristics of the fatally injured workers and characteristics of the projects where the accidents occurred, and (2) the causes of the accidents. The number of fatalities was almost similarly distributed during the seven-year period with the exception of 2004, when there were 43 fatalities. The distribution for the incidents and fatalities for the seven-year period is illustrated in Figure 3.3.

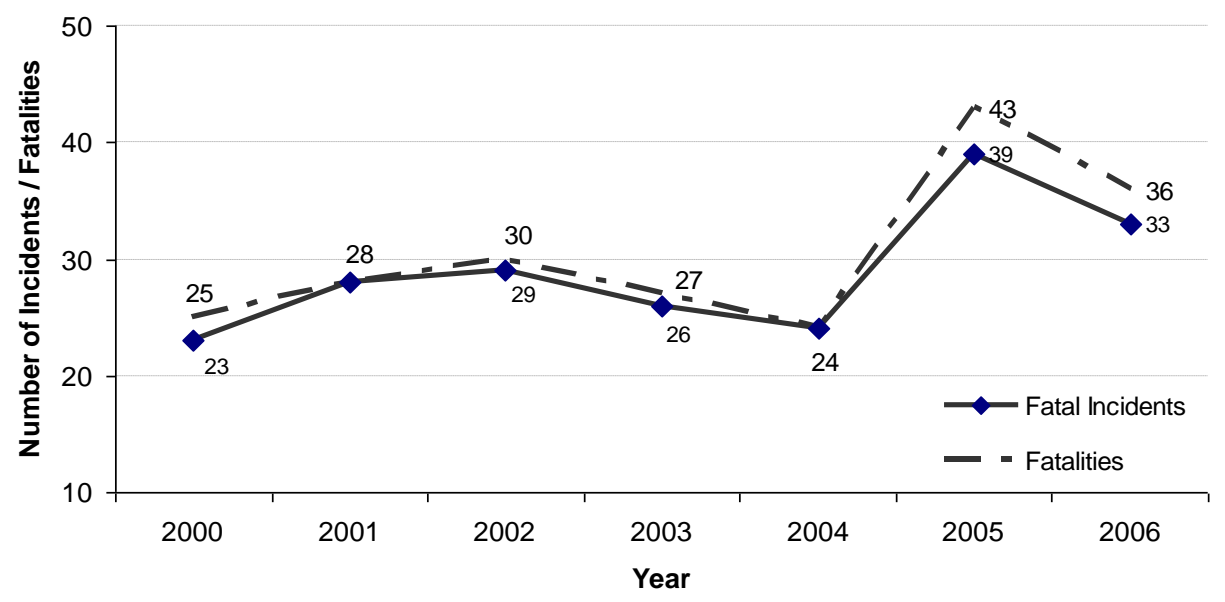

Figure 3.3 Work zone fatal incidents and injuries per year, all U.S., 2000-2006

The states with the largest numbers of fatalities were Florida, Texas, and California, Ohio, and Indiana tied with Maryland and North Carolina. The 10 states with the largest number of fatalities are illustrated in Figure 3.4. 


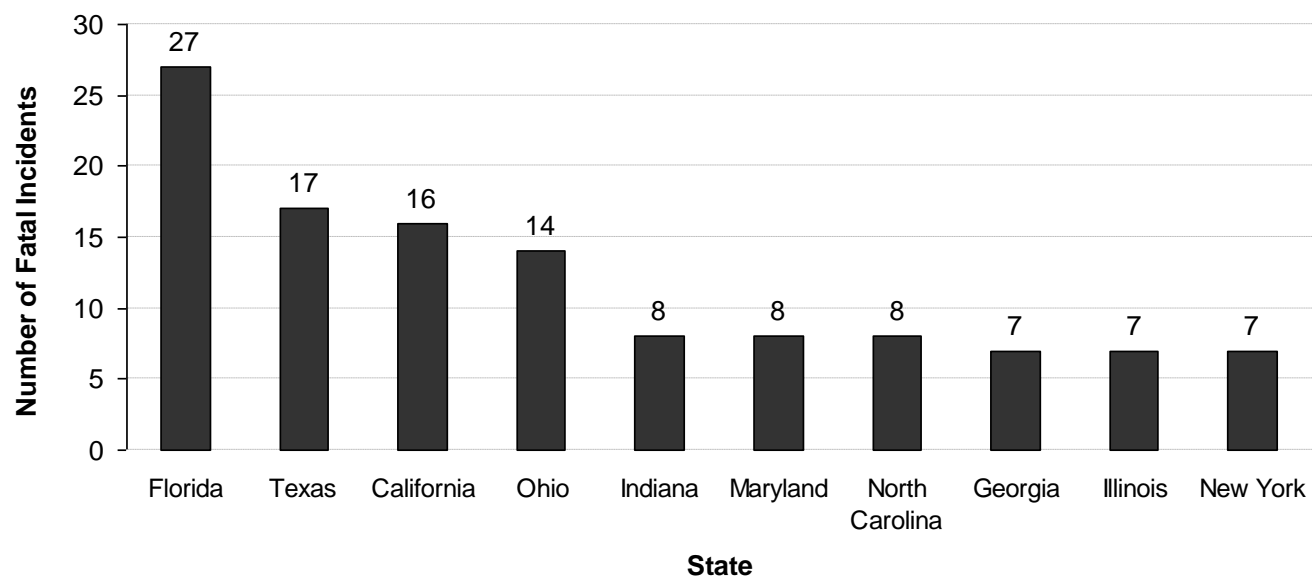

Figure 3.4 Top 10 states according to number of work zone fatal incidents, all U.S., 2000-2006

\subsubsection{Characteristics of the Fatally Injured Workers and Projects where the Incidents Occurred.}

Information about gender was available for 209 of the 213 victims reported in the database.

Ninety percent of the fatally injured workers were male. Twenty-seven percent of the victims were between 35 and 44 years old as shown in Figure 3.5. About 17\% of the accidents occurred in projects with a construction cost under $\$ 50,000$, closely followed by $15 \%$ of the accidents in projects costing between $\$ 1,000,000$ and $\$ 5,000,000$.

Figure 3.6 shows the distribution of the fatal incidents according to cost of the project.

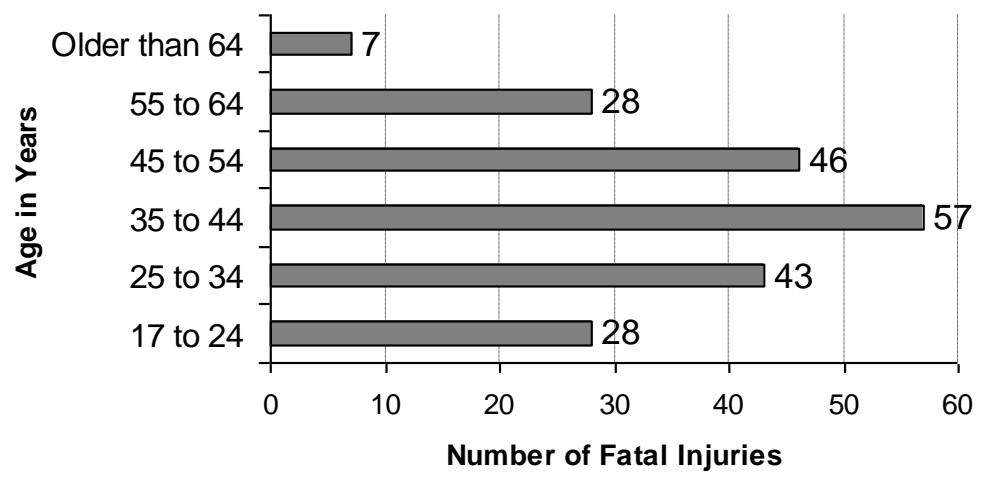


Figure 3.5 Distribution of work zone fatal incidents according to the age of the injured worker, all U.S., 2000-2006

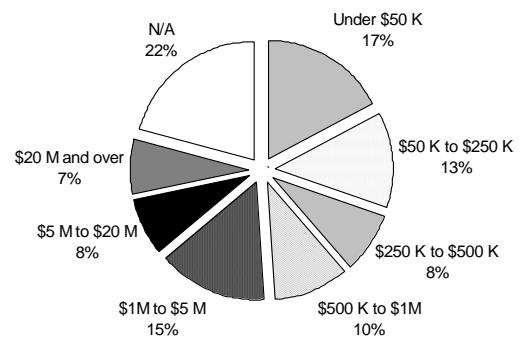

Figure 3.6 Distribution of work zone fatal incidents according to the cost of the project, all U.S., 2000-2006

Almost $64 \%$ of the victims were classified as laborers, followed by flaggers or traffic controllers with $21.8 \%$ of the injured workers. The number of flaggers killed (44) is significant considering the low percentage of the workers who are flaggers in regular work zone projects.

Table 3.6 shows the distribution of the injured workers according to occupation.

Table 3.6 Distribution of work zone fatal incidents according to occupation of the injured workers, all U.S., 2000-2006

\begin{tabular}{lcc}
\hline Worker Occupation & $\begin{array}{c}\text { Number of } \\
\text { Injuries }\end{array}$ & $\begin{array}{c}\text { \% of } \\
\text { Total }\end{array}$ \\
\hline Laborer & 129 & $63.9 \%$ \\
\hline Flagger & 44 & $21.8 \%$ \\
\hline Operator & 9 & $4.5 \%$ \\
\hline Foreman & 7 & $3.5 \%$ \\
\hline Survey crew member & 6 & $3.0 \%$ \\
\hline Inspector & 3 & $1.5 \%$ \\
\hline Superintendent & 3 & $1.5 \%$ \\
\hline Electrician & 2 & $1.0 \%$ \\
\hline Driver & 2 & $1.0 \%$ \\
\hline Highway technician & 2 & $1.0 \%$ \\
\hline Traffic control technician & 1 & $0.5 \%$ \\
\hline Engineering technician & 1 & $0.5 \%$ \\
\hline
\end{tabular}




\begin{tabular}{lll}
\hline Engineer & 1 & $0.5 \%$ \\
\hline Project manager & 1 & $0.5 \%$ \\
\hline Non-heavy equipment operator & 1 & $0.5 \%$ \\
\hline Not available & 1 & $0.5 \%$ \\
\hline
\end{tabular}

The incidents were also classified according to the time of the day when they occurred. Figure 3.7 indicates that the incidents that occurred during regular daytime work hours were almost equally distributed. It appears that the time has no influence at least during these work hours (8:00 a.m. to 4:00 p.m.). Twenty-two percent of the fatal incidents occurred from 10:00 p.m. to 6:00 a.m.

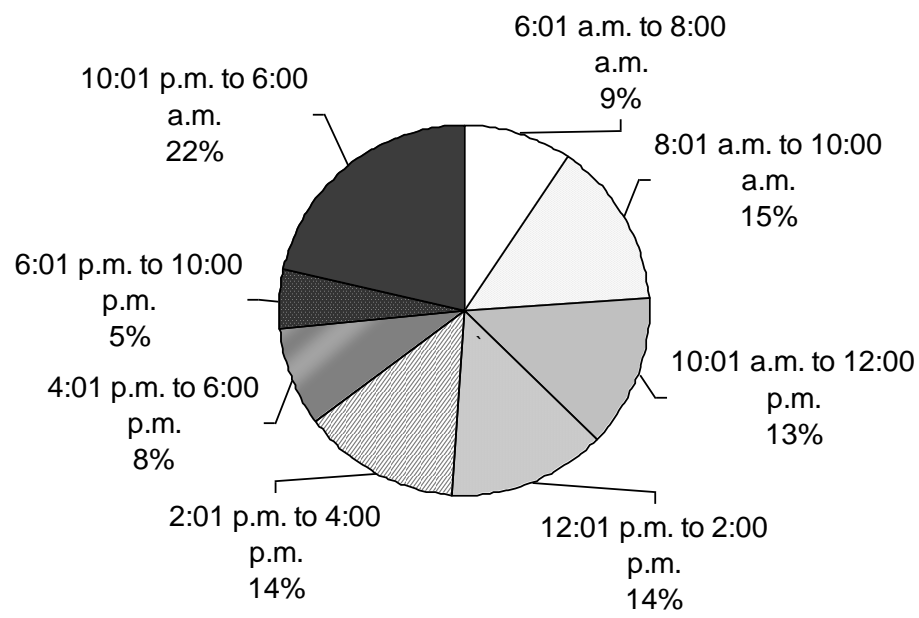

Figure 3.7 Distribution of work zone fatal incidents according to time of the day when the accidents occurred, all U.S., 2000-2006

About half of the employer companies involved in the incidents were classified as "highway, street, and bridge construction" according to the North American Industry Classification System (NAICS). Most of the other companies appear to be sub-contractors for different activities involved in highway construction and maintenance projects, such as electric contractors, site preparation contractors, water, sewer, pipeline, communications, and power line contractors. Table 3.7 shows the distribution of the incidents according to the industry classifications. Incidents that occurred before 2003 were classified according to the Standard Industrial Classification (SIC). The other ones (from 2003 to 2006) were classified according to NAICS. 
Table 3.7 Distribution of work zone fatal incidents according to industry classification for the employer company of the injured worker(s), all U.S., 2000-2006

\begin{tabular}{lcccc}
\hline \multicolumn{1}{c}{ Industry Classification } & $\begin{array}{c}\text { NAICS } \\
\text { Code }\end{array}$ & $\begin{array}{c}\text { SIC } \\
\text { Code }\end{array}$ & $\begin{array}{c}\text { Number of } \\
\text { Incidents }\end{array}$ & $\begin{array}{c}\text { \% of } \\
\text { Total }\end{array}$ \\
\hline Highway, street, and bridge construction & 237310 & ----- & 102 & $50.5 \%$ \\
\hline All other specialty trade contractors & 238990 & ----- & 7 & $3.5 \%$ \\
\hline Water and sewer line and related structures & 237110 & ----- & 6 & $3.0 \%$ \\
\hline Highway and street construction, except elevated highways & ----- & 1611 & 6 & $3.0 \%$ \\
\hline $\begin{array}{l}\text { Electrical contractors and other wiring installation } \\
\text { construction }\end{array}$ & 238210 & ----- & 5 & $2.5 \%$ \\
\hline Site preparation contractors & 238910 & ----- & 5 & $2.5 \%$ \\
\hline Landscaping services & 561730 & ----- & 5 & $2.5 \%$ \\
\hline Engineering services & 541330 & ----- & 4 & $2.0 \%$ \\
\hline $\begin{array}{l}\text { Water, sewer, pipeline, communications and power line } \\
\text { construction }\end{array}$ & ----- & 1623 & 4 & $2.0 \%$ \\
\hline Bridge, tunnel, and elevated highway construction & ----- & 1622 & 4 & $2.0 \%$ \\
\hline Other & ----- & ----- & 52 & $25.7 \%$ \\
\hline Not available & ----- & ----- & 2 & $1.0 \%$ \\
\hline
\end{tabular}

The month with the largest number of fatal incidents was October. This month was also found to be the most significant in number of fatalities by Hinze et al. (1998) and Arboleda (2002) in an analysis of general construction accidents and accidents in trenching construction respectively. Arboleda (2002) stated that a possible cause for this outcome, is "the pressure to complete projects before the onset of winter can lead to increased activity and, hence, the high level of fatalities during this month." Eighteen percent of the fatal incidents occurred while workers were setting up, retrieving, or removing traffic control devices (cones, barrels, concrete barriers).

\subsubsection{Causes of Work Zone Serious/Fatal Occupational Injuries}

The incidents were classified as to follows: (1) accident event and (2) behavioral causes of work zone accidents. The definitions for these two classifications and their sub-categories were explained in Chapter 3. Sixty-five percent (131) of the incidents occurred in the event "worker 
struck by vehicle not related to the project." This category is related only to passing motorist who do not have any direct affiliation with the road construction or maintenance project. The second most significant sub-category within accident events was "worker struck by vehicles related to the project" with $21.3 \%$ of the fatal incidents. This type of incident refers to those where workers were killed by mobile equipment within the work zones. The complete classification list of the incidents according to the accident event is shown in Table 3.8.

Table 3.8 Distribution of work zone fatal occupational incidents according to accident events, all U.S., 2000-2006

\begin{tabular}{lcc}
\hline \multicolumn{1}{c}{ Accident Event } & $\begin{array}{c}\text { Number of } \\
\text { Incidents }\end{array}$ & \% of Total \\
& 131 & $64.9 \%$ \\
\hline Struck by vehicle not related to the project & 43 & $21.3 \%$ \\
\hline Struck by vehicle which was part of the project & 32 & $15.8 \%$ \\
$\quad$ Moving backwards & 11 & $5.4 \%$ \\
$\quad$ Moving forward & 6 & $3.0 \%$ \\
\hline Collision between intruder vehicle and equipment & 3 & $1.5 \%$ \\
$\quad$ Intruder vehicle hit equipment, worker fell from it & 2 & $1.0 \%$ \\
$\quad$ Intruder vehicle hit equipment, equipment struck worker & 6 & $3.0 \%$ \\
\hline Fell from mobile equipment & 5 & $2.5 \%$ \\
$\quad$ Fell from mobile equipment while transporting TCD & 4 & $2.0 \%$ \\
\hline Struck by object & 3 & $1.5 \%$ \\
\hline Struck by falling object & 3 & $1.5 \%$ \\
\hline Exposed to harmful substances or environments & 2 & $1.0 \%$ \\
\hline Contact with electric current (overhead power lines) & 2 & $1.0 \%$ \\
\hline Equipment slid or roll over & 2 & $1.0 \%$ \\
\hline Fell to a lower level & 2 & $1.0 \%$ \\
\hline Crushed between parts of equipment & 2 & $1.0 \%$ \\
\hline Contact with equipment & 1 & $0.5 \%$ \\
\hline Heat exposure & & \\
\hline
\end{tabular}

The classification of the incidents according to the behavioral causes of accidents shows that most of the fatal incidents occurred due to "negligence of a third party." As explained in Chapter 3, this category refers to individuals not related to the construction/maintenance project, including drivers/owners of intruder vehicles (vehicles without brakes, drunk drivers, a driver who does not follow the orders given by a traffic controller). The second category with the largest number of fatal incidents and the first one involving just personnel of the construction or maintenance projects was "lack of awareness from the injured worker." Accidents due to this factor occur when the worker is not aware of possible hazards (e.g., distracted worker run over 
by a dump truck backing up). The complete classification of the fatal occupational incidents is shown in Table 3.9.

Table 3.9 Distribution of work zone fatal occupational incidents according to behavioral causes, all U.S., 2000-2006

\begin{tabular}{lcc}
\hline \multicolumn{1}{c}{ Behavioral Cause } & $\begin{array}{c}\text { Number of } \\
\text { Incidents }\end{array}$ & \% of Total \\
\hline Negligence of a third party & 52 & $25.7 \%$ \\
\hline Lack of awareness from injured worker & 36 & $17.8 \%$ \\
\hline Unsafe methods or sequencing & 26 & $12.9 \%$ \\
\hline Misjudgment of a hazardous situation from worker & 15 & $7.4 \%$ \\
\hline Lack of traffic control devices & 11 & $5.4 \%$ \\
\hline $\begin{array}{l}\text { Co-worker lack of awareness and/or misjudgment of a } \\
\text { hazardous situation }\end{array}$ & 10 & $5.0 \%$ \\
\hline Not using provided safety equipment & 7 & $3.5 \%$ \\
\hline Not Classifiable & 45 & $22.3 \%$ \\
\hline
\end{tabular}

\subsubsection{Causes of Work Zone Serious/Fatal Occupational Injuries Involving Mobile Equipment}

As described in Table 3.8, 43 of the 202 fatal incidents occurred due to workers being struck by mobile equipment. Thirty-two of the cases were the result of backing maneuvers by equipment in the work zones, and 23 of those involved dump trucks. The sources of injury for the fatal incidents involving mobile equipment are shown in Table 3.10. Regarding the distribution of the incidents according to behavioral causes of accidents, 19 occurred due to "lack of awareness from the injured worker", followed by "co-worker lack of awareness and/or misjudgment of a hazardous situation."

Table 3.11 shows the distribution of mobile equipment-related occupational incidents according to the behavioral causes of accidents classification.

Table 3.10 Distribution of mobile equipment related occupational incidents according to the source of injury, all U.S., 2000-2006

\begin{tabular}{cc}
\hline Source of Injury & Fatal Incidents \\
\hline Dump trucks & 25 \\
\hline Concrete trucks & 3 \\
\hline
\end{tabular}




\begin{tabular}{cl} 
Water trucks & 2 \\
\hline Fuel trucks & 2 \\
\hline Motor graders & 2 \\
\hline Other trucks & 7 \\
\hline Other equipment & 2 \\
\hline
\end{tabular}

Table 3.11 Distribution of mobile equipment related occupational incidents according to the behavioral causes, all U.S., 2000-2006

\begin{tabular}{lc}
\hline \multicolumn{1}{c}{ Behavioral Cause } & $\begin{array}{c}\text { Number of } \\
\text { Incidents }\end{array}$ \\
\hline Lack of awareness from injured worker & 19 \\
\hline $\begin{array}{l}\text { Co-worker lack of awareness and/or misjudgment of a hazardous } \\
\text { situation }\end{array}$ & 11 \\
\hline Misjudgment of a hazardous situation from worker & 5 \\
\hline Unsafe methods or sequencing & 5 \\
\hline Not using provided safety equipment & 1 \\
\hline Not classifiable & 2 \\
\hline
\end{tabular}

\subsubsection{Analysis of Perspectives of Work Zone Personnel about Causes of Accidents in Construction and Maintenance Activities}

Two type of statistical analysis were performed with the data obtained from the survey regarding the common causes of serious accidents in work zones. The first analysis involved descriptive statistics. The second was a statistical analysis of the perception of workers about relevant behavioral causes of accidents. The first step of the data analysis was achieved through graphic, tabular, and summary statistic descriptors. The analysis was structured according to the topics involved in the survey: general safety questions; perceptions of the level of hazard exposure for different occupations; perceptions of the occurrence likelihood of human behavioral causes of accidents; satisfaction level for the training received (in the case of the workers) or provided (in the case of supervisors, safety managers, and safety officers) for different safety aspects; and perceptions of the occurrence of accident events.

For the data analysis, all the observations gathered from the workers in construction companies, INDOT, and the Tippecanoe County Highway Department were grouped under the category 
"workers." In a similar manner, all the data from supervisors for the different entities and the safety directors in DOTs were grouped in the category "supervisors."

The questions in the survey for both the supervisors and the workers were divided into three categories: (1) general questions about the demographic characteristics of the respondents (e.g., age, gender); (2) questions about the safety training received and safety meetings; and (3) questions about the perception of the respondents about causes of work zone occupational accidents. Ninety-eight worker surveys and 24 supervisor surveys were finally used for the descriptive analysis of the perception of work zone personnel about different safety issues.

Overall, workers and supervisors seemed to be somewhat satisfied with the safety training received (in the case of the workers) and provided (in the case of supervisors) for different safety provisions. These two sets of individuals appeared to be the most satisfied with the training received and provided to properly use Personal Protective Equipment (PPE), and the least satisfied with the training received and provided to perform activities with exposure to health hazards such as silica dust, asphalt fumes, lead, solvents, etc. The score scale for the evaluation of each safety aspect varies from one to five, with one representing "completely unsatisfied", and five representing "totally satisfied." Table 3.12 shows the average scores for each one of the aspects that the workers and supervisors were asked to evaluate.

Table 3.12 Satisfaction level with the training received or provided for different safety provisions

\begin{tabular}{lcc}
\hline \multicolumn{1}{c}{ Safety Aspect } & $\begin{array}{c}\text { Average Score } \\
\text { for workers }\end{array}$ & $\begin{array}{c}\text { Average } \\
\text { Score for } \\
\text { supervisors }\end{array}$ \\
\hline To work near traffic & 3.79 & 4.08 \\
\hline To use adequate Personal Protective Equipment (PPE) & 4.06 & 4.29 \\
\hline $\begin{array}{l}\text { To set up, retrieve, or remove traffic control devices ( e.g., cones, barrels, } \\
\text { concrete barriers, rumble strips, signs) }\end{array}$ & 3.70 & 3.67 \\
\hline To work around mobile equipment & 3.92 & 3.96 \\
\hline To perform flagging activities & 3.74 & 4.04 \\
\hline To work during nighttime hours & 3.56 & 3.42 \\
\hline To perform trenching activities & 3.44 & 3.58 \\
\hline To work near overhead power lines & 3.48 & 3.79 \\
\hline $\begin{array}{l}\text { To work near underground electrical current or other buried utilities such as } \\
\text { gas lines }\end{array}$ & 3.44 & 3.58 \\
\hline
\end{tabular}


To perform activities in elevated structures such as bridges, formwork, elevated buckets, or near excavations

\begin{tabular}{llc}
\hline To recognize and work in environments with high level of noise & 3.78 & 3.54 \\
\hline $\begin{array}{l}\text { To perform activities with exposure to health hazards such as silica dust, } \\
\text { asphalt fumes, lead, solvents, etc. }\end{array}$ & 3.36 & 3.33 \\
\hline To work in harsh environments such as intense hot and cold weather. & 3.51 & 4.08 \\
\hline Total average score & 3.63 & 3.78 \\
\hline
\end{tabular}

The occurrence likelihood of five accidents events were evaluated by both workers and supervisory personnel. The scale for this evaluation was also from one to five, with one and five representing the events with the least and the most likelihood to occur. From the analysis of the accident reports, it was found that "workers struck by mobile equipment" was the accident event with the second largest number of fatalities. However, in the survey, workers provided a low average score (2.83) for the occurrence likelihood of this accident event. It appears that workers do not fully understand the risk involved when working near mobile equipment. The averages scores of workers and supervisors for the five accident event categories are shown in

Table 3.13.

Table 3.13 Average scores of workers and supervisory personnel for the occurrence of five major accident events

\begin{tabular}{lcc}
\hline \multicolumn{1}{c}{ Accident Event } & $\begin{array}{c}\text { Average } \\
\text { Score for } \\
\text { workers }\end{array}$ & $\begin{array}{c}\text { Average } \\
\text { Score for } \\
\text { Supervisors }\end{array}$ \\
\hline Worker struck by vehicle not related to the project & 3.58 & 3.71 \\
\hline Worker struck by mobile equipment (project vehicles) & 2.83 & 3.46 \\
\hline Contact with objects or equipment & 2.51 & 2.71 \\
\hline Worker exposed to harmful substances or environments & 2.91 & 3.08 \\
\hline Falls & 2.92 & 3.08 \\
\hline
\end{tabular}

The same criterion for evaluating the accident events was used to evaluate the likelihood of the occurrence of behavioral causes. The most remarkable finding was that workers rated "lack of awareness" as the least likely behavioral cause of accidents to occur, with an average score of 2.9. However, supervisory personnel rated it as the most likely to occur in a work zone tied with "negligence of a third party." Both classifications were rated with an average score of 4.0 by the supervisors. The low average score for the worker responses might reflect the "tough guy" 
mentality that is prevalent among construction workers (Toole 2002). Table 3.14 shows a comparison for the average scores provided by workers and supervisors when evaluating the likelihood of occurrence of the behavioral causes.

Table 3.14 Average scores provided by workers and supervisors for the occurrence likelihood of behavioral causes of accidents.

\begin{tabular}{llcc}
\hline \multicolumn{1}{c}{ Behavioral Cause } & $\begin{array}{c}\text { Average } \\
\text { Score for } \\
\text { Workers }\end{array}$ & $\begin{array}{c}\text { Average } \\
\text { Score for } \\
\text { Supervisors }\end{array}$ \\
\hline A & Lack of awareness by injured worker & 2.94 & 3.96 \\
\hline$\quad \begin{array}{l}\text { Misjudgment of a hazardous situation by injured } \\
\text { B }\end{array}$ & 3.24 & 3.88 \\
\hline$\quad$ Corker & Co-worker lack of awareness and/or misjudgment of a & 3.23 & 3.67 \\
C & hazardous situation & 2.94 & 2.75 \\
\hline D & Lack of traffic control devices & 3.98 & 4.00 \\
\hline E & Negligence of a third party & 3.14 & 2.96 \\
\hline F & Unsafe methods or sequencing & 3.01 & 3.17 \\
\hline G & Not using provided safety equipment & & \\
\hline
\end{tabular}

The perception of work zone personnel of hazardous occupations was also evaluated in the survey. Different work zone occupations were listed with the purpose of assessing the risk they involved. The results are analogous to those drawn from the analysis of work zone accident reports. The occupations rated in the first five places were: flaggers or traffic controllers, construction laborers, heavy equipment operator, highway technician, and survey crew members. Supervisory personnel were rated as having the least risky occupations. The roles of engineer, inspector, and foreman received the least scores with respect to risk from both, supervisor and workers.

The workers were asked to provide suggestions that might improve work zone safety. Most of the responses were focused on ways to control the traffic passing through the work zones. The following is a summary of the most frequent suggestion provided by the workers: 
- Police enforcement (10.1\%)

- Higher fines for speeders in work zones and implementation of fines for drivers talking on cell phones $(7.1 \%)$

- Lower speed limits in work zones $(6.1 \%)$

- Heat exposure measures, for example, reduce work hours on heat advisory days (3.1\%)

- Proper safety equipment should be provided by employer (2\%)

The supervisory personnel were asked to list possible weaknesses of the safety program provided by their companies, districts, or Departments of Transportation. The responses were related to lack of funds, resources, and equipment, as well as the attitude of the workers and the employee turnover. The following are recurring responses provided in the surveys:

- Budget restraints to provide and maintain necessary safety equipment (16.7\%)

- Lack of employee buy-in compliance (i.e., convincing employees to change their behaviors) $(12.5 \%)$

- High constant employee turnover (i.e., new employees are not as safety oriented as experienced employees) (12.5\%)

- Lack of personnel and/or equipment to perform the work activities (8.3\%)

\subsubsection{Model to Assess the Perception of Workers about "Lack of Awareness" as a Primary Behavioral Cause of Accidents}

The analysis of accident reports identified that "lack of awareness" was one of the primary behavioral causes of work zone accidents. When a descriptive analysis of the data obtained from the workers was performed, it was determined that on average, workers rated lack of awareness as one of the behavioral causes less likely to occur in work zones. A statistical analysis of worker perception of lack of awareness as one of the major causes of accidents subsequently was performed.

A binomial logit model, which is a discrete outcome model, was chosen to statistically find and represent the factors that influence the perception of workers of the likelihood of occurrence of 
lack of awareness as the primary cause, or one of the major behavioral causes of work zone accidents. The model was selected by considering different variables, and choosing those that were within a confidence interval of $90 \%$ and those in which the log-likelihood function was maximized as much as possible. Table 3.15 shows the independent variables considered in the development of the model. More data were obtained from the survey (e.g., perception of workers of the safety training received, accident events in work zones); however, these data points were not used since these data belong to opinion variables as in the case of the response variable. Endogeneity would result if any other opinion variable is included as one explanatory variable.

Table 3.15 Independent Variables considered in the development of the binomial logit model

\begin{tabular}{|c|}
\hline Characteristics of the Worker \\
\hline $\begin{array}{l}\text { Ethnicity } \\
\text { (1) White } \\
\begin{array}{ll}\text { (2) Black } & \text { (4) Asian } \\
\text { (3) Hispanic or Latino } & \end{array}\end{array}$ \\
\hline $\begin{array}{l}\text { Age } \\
\text { (1) } 18-24 \\
\text { (2) } 25-34 \\
\text { (3) } 35-44\end{array}$ \\
\hline$\frac{\text { Gender }}{\text { (1) Male }}$ \\
\hline $\begin{array}{l}\text { Occupation } \\
\text { (1) Construction laborer } \\
\text { (2) Flagger/traffic controller } \\
\text { (3) Heavy equipment operator } \\
\text { (4) Driver } \\
\text { (5) Maintenance worker } \\
\text { (6) Foreman } \\
\text { (7) Survey crew member } \\
\text { (8) Inspector } \\
\text { (9) Highway technician }\end{array}$ \\
\hline $\begin{array}{l}\text { Type of worker } \\
\text { (1) INDOT worker } \\
\text { (2) Construction company worker } \\
\text { (3) County highway department }\end{array}$ \\
\hline
\end{tabular}

Characteristics of safety orientation received by the worker

How long have you been working in highway construction or maintenance?
(1) $<6$ months
(4) 2 - 5 years
(2) 6 months -1 year
(5) 5 - 10 years
(3) 1 - 2 years
(6) $>10$ years

Do you know what a "Safety and Health" program is?
(1) Yes
(0) No

Has your employer or any of your supervisors ever asked your opinion about improving safety in your workplace?
(1) Yes
(0) No

Does your company regularly conduct safety meetings?

(1) Never

(3) Often (once or twice every

3 months)

(2) Rarely (once or twice

(4) Very often (at least one in a in the last year month)

Do any of your supervisors advise you about the hazards of your specific occupation, and how to avoid them?
(1) Never
(3) Sometimes (once or twice
(2) Rarely (once or twice in the last year) every $3 \mathrm{~m}$ (4) Often (at least once in a month)

Have you ever been assigned to perform activities for which you have not received safety training?
(1) Never
(3) Sometimes (once every 


\subsubsection{Description of a Binomial Logit Model}

The description of the binomial logit model presented in this section of the chapter is based on Washington et al. (2003). A binomial logit model is a discrete outcome model with two outcomes. Similar to the multinomial logit model (logit model with more than two outcomes), the binomial model assumes that the distribution of the disturbances is extreme, which means that the maximum randomly values drawn from the distribution of disturbances have the same distribution as the values from which they were drawn. Additionally, it is assumed that the maximums drawn from this distribution of maximums also have an extreme distribution. The probability density functions and the distribution functions for the distribution of disturbances with these properties are shown in Equations 3.1 and 3.2 respectively. In the equations $n$ represents a positive scale parameter, $w$ is a location parameter, and the mean is $w+0.5772 / n$

$$
\begin{array}{cc}
f(\varepsilon)=n E X P[-n(\varepsilon-w)] E X P(-E X P[-n(\varepsilon-w)]) & \text { Eq. } 3.1 \\
F(\varepsilon)=E X P(-E X P[-n(\varepsilon-w)] & \text { Eq. } 3.2
\end{array}
$$

The following procedure for calculating the probability of a multinomial logit model was adopted from Washington et al. (2003). The general probability for a discrete outcome model is modified resulting in Equation 3.3.

$$
P_{n}(i)=P\left(\beta_{i} X_{n}+\varepsilon_{i n} \geq \max \left(\beta_{I} X_{I n}+\varepsilon_{I n}\right)\right) \quad \text { Eq. } 3.3
$$

If the disturbances have the same variances, location parameters $w_{l n}$, and a common scale parameter $n$, the maximum in the Equation 3.3 becomes

$$
\begin{array}{ll}
\frac{1}{n} L N \sum E X P\left(n \beta_{I} X_{I n}\right) \quad \text { Eq. } 3.4
\end{array}
$$

With $\varepsilon_{n}{ }^{\prime}$ as the disturbance term with the maximum of all possible outcomes different than $i$, and $\beta^{\prime} X_{n}$ ' as the parameter and covariate product associated with the maximum of all possible discrete outcomes, then the equation takes the form (Washington et. al, 2003) 


$$
\beta^{\prime} X^{\prime}=\frac{1}{n} L N \sum E X P\left(n \beta_{I} X_{I n}\right)
$$

With the location parameter equal to zero and the scale parameter $n$, adding the scalar in Equation 3.4 results in an extreme value distributed variate with a location parameter ( $\left.\beta^{\prime} X n\right)$ equal to Equation 3.4 and scale parameter $n$, the equation 3.4 is

$$
P_{n}(i)=P\left(\beta_{i} X_{n}+\varepsilon_{i n} \geq \beta^{\prime} X^{\prime}{ }_{n}+\varepsilon^{\prime}{ }_{n}\right) \quad \text { Eq. } 3.6
$$

or

$$
P_{n}(i)=P\left(\beta^{\prime} X^{\prime}{ }_{n}+\varepsilon^{\prime}{ }_{n}-\beta_{i} X_{n}+\varepsilon_{i n}-\leq 0\right) \quad \text { Eq. } 3.7
$$

Now, since the difference between two independently distributed extreme values from the disturbances distribution is assumed, the variates with common scale parameter are logistically distributed, then,

$$
\operatorname{Pn}(\mathrm{i})=\frac{1}{1+\operatorname{EXP}\left[n\left(\beta^{\prime} X^{\prime}{ }_{n}-\beta^{\prime}{ }_{i} X^{\prime}{ }^{\prime}{ }\right)\right]}
$$

Substituting with Equation 3.5 and setting the scale parameter to one, the probability equation for a multinomial logit model results

$$
P_{n}(i)=\frac{E X P\left[\beta_{i} X_{i n}\right]}{\sum_{\forall I} \operatorname{EXP}\left(\beta_{I} X_{I n}\right)}
$$

In the case of this research, the probability had only two outcomes (binomial). So the probability equation is rearranged into

$$
P_{n}(1)=\frac{E X P[\beta 1 X]}{1+E X P[\beta 1 X]}
$$

Washington et al. (2003) states that for estimation of the parameters coefficients (betas), Equation 3.11 is solved by maximizing the value of the log likelihood function $(L L)$.

$$
L L=\sum_{n=1}^{N}\left(\sum_{i=1}^{I} \delta_{i n}\left[\beta_{i} X_{i n}-L N \sum_{\forall I} E X P\left(\beta_{I} X_{I n}\right)\right]\right)
$$




\subsubsection{Binomial Logit Model Developed with the Worker Survey Data}

A binomial logit model was developed to find the factors from the sample population that can influence the perception of workers about "lack of awareness" as a primary cause of accidents. To model this perception, the responses provided by the workers were adapted to fit into the model since a binomial logit model has only two outcomes. These responses were converted into ones or zeros. The observation was changed into one when the "lack of awareness" score provided by a worker was the highest or tied as the highest score among all behavioral causes of accidents. When this condition was not fulfilled, the observation data point was changed to zero.

Table 3.16 shows examples of the modification performed. The table also shows a summary of the question asked of the workers. In the actual question, explanations and examples for each behavioral cause were provided to the workers. In observation 1 of the table, the respondent rated "lack of awareness" with a score of 3 . Two other behavioral causes were rated with a score of 4 , therefore, the observation was modified to zero. In the case of observation 2, "lack of awareness" was rated with the highest score when compared to the other behavioral causes, consequently the observation was modified to one. The last observation shows a response from a worker, under the principle that all seven behavioral causes are equally likely to occur. In this case, the data point observation is also modified to one, given that it ties as the highest score. After the modification of the data for the dependent variable, 40 observations resulted in a one, and 58 were zero. 
Table 3.16 Example of the modifications performed to the data collected

\begin{tabular}{|c|c|c|c|c|c|c|c|c|}
\hline \multicolumn{8}{|c|}{$\begin{array}{l}\text { The behavior of individuals is sometimes the primary cause of } \\
\text { accidents in construction/maintenance activities. Evaluate the } \\
\text { following human behavioral causes according to their } \\
\text { likelihood of occurrence in construction/maintenance work } \\
\text { zones. }\end{array}$} & \multirow{3}{*}{$\begin{array}{l}\text { Modification of the } \\
\text { responses to fit into a } \\
\text { binomial logit model }\end{array}$} \\
\hline \multicolumn{8}{|c|}{$\begin{array}{l}\underline{\mathbf{A}} \text { - Lack of awareness of the injured worker } \\
\underline{\mathbf{B}} \text { - Worker misjudgment of a hazardous situation } \\
\underline{\mathbf{C}} \text { - Co-worker lack of awareness and/or misjudgment of a } \\
\text { hazardous situation } \\
\underline{\mathbf{D}} \text { - Lack of traffic control devices } \\
\underline{\mathbf{E}} \text { - Negligence of a third party } \\
\underline{\mathbf{F}} \text { - Unsafe methods or sequencing } \\
\underline{\mathbf{G}} \text { - Not using provided safety equipment } \\
\quad \text { Scale: } \mathbf{1}=\text { Least likely; } \mathbf{5}=\text { Most likely }\end{array}$} & \\
\hline Respondent & $\mathbf{A}$ & B & C & D & $\mathbf{E}$ & $\mathbf{F}$ & G & \\
\hline 1 & 3 & 4 & 3 & 3 & 4 & 3 & 2 & 0 \\
\hline 2 & 4 & 3 & 2 & 3 & 3 & 3 & 3 & 1 \\
\hline 3 & 5 & 5 & 5 & 5 & 5 & 5 & 5 & 1 \\
\hline
\end{tabular}

The model chosen has the form of Equation 3.12 with the utility factor $V(l a)$ with the form of Equation 3.13. The summary statistics for the independent variables are described in Table 3.17. The dependent variable is the perception of workers about the likelihood of "Lack of awareness as the primary, or one of the major behavioral causes of work zone accidents. Ninety-eight observations were used for the model, which model has a log-likelihood function of -57.69 and a chi-square equal to 17.16. This log-likelihood function value was the maximum for the models tried. The chi-square value shows that the goodness of fit for the data is appropriate with a more than $99 \%$ confidence interval. All the independent variables considered for the model are explained in Table 3.15 of this chapter. All variables included in the model decrease the probability that a worker chooses "lack of awareness" as the primary or one of the major behavioral causes of accidents.

$$
P(l a)=\frac{e^{V(l a)}}{1+e^{V(l a)}}
$$

$$
\mathrm{V}(\mathrm{la})=2.48-1.24(\mathrm{EXPER})-1.64(\mathrm{OFTSM})-1.88(\mathrm{HEODRIV})-0.99 \text { (ASSIG) } \quad \text { Eq. } 3.13
$$




\section{Description of the Explanatory Variables Included in the Binomial Logit Model}

Three of the variables in the model were found to be significant at a confidence level of $95 \%$, whereas the remaining variables were found to be significant at a confidence level of $90 \%$. The parameters estimates, the t-statistics, and the p-values for each independent variable are described in Table 3.17.

Table 3.17 Description and summary statistics for variables in the binomial logit model

\begin{tabular}{lcccc}
\hline \multicolumn{1}{c}{ Explanatory Variable } & $\begin{array}{c}\text { Variable } \\
\text { Mnemonic }\end{array}$ & $\begin{array}{c}\text { Estimated } \\
\text { Parameter }\end{array}$ & t-stat & P-value \\
\hline Constant & ONE & 2.48 & 2.81 & 0.0050 \\
\hline $\begin{array}{l}\text { Worker with more than two years of experience } \\
\text { in road construction or maintenance activities }\end{array}$ & EXPER & -1.24 & -2.46 & 0.0139 \\
\hline $\begin{array}{l}\text { Worker employed by a company or state entity } \\
\text { that always conducts at least one safety meeting } \\
\text { per month }\end{array}$ & OFTSM & -1.64 & -2.31 & 0.0210 \\
\hline $\begin{array}{l}\text { Driver or heavy equipment operator } \\
\text { Worker assigned to perform an activity without }\end{array}$ & HEODRIV & -1.88 & -2.42 & 0.0157 \\
\hline \begin{tabular}{l} 
receiving safety training for that activity \\
\hline
\end{tabular} & ASSIG & -0.99 & -1.88 & 0.0608 \\
\hline
\end{tabular}

The model presented two major groups of workers; safety oriented and non-safety oriented workers. The former consists of workers with two or more years of experience and workers that attend at least one safety meeting per month. The second group consists of workers that perform activities without the appropriate safety training for those activities. Both groups of workers had a decrease in the probability of choosing lack of awareness as a main behavioral cause of accidents in work zones.

The experience variable in the model reduces the likelihood for a worker to choose "lack of awareness" as the primary, or one of the major behavioral causes of accidents. Workers with more than two years of experience have had the opportunity of observing different situations involving workers at risk in work zones and might consider that other behavioral causes are more likely to result in occupational injuries for workers. Additionally, it could be the case that the better safety orientation that experienced workers have when compared with new employees, makes them more aware of potential hazards; therefore, they might think that they can be injured 
by other causes not related to their behaviors (e.g., negligence of a third party, contractor not providing enough traffic control devices)

Employees who attend at least one safety meeting per month have a decreased probability of ranking "lack of awareness" as the primary, or one of the main, causes of accidents in work zones. Most of the safety meetings are conducted to give guidance to workers about possible hazards in the work zone and ways to avoid them. Workers who regularly attend safety meetings are constantly advised to be alert in the work zones; as a result, they have this awareness issue in mind, and may believe that they are less likely to be injured by this cause.

Workers who have been assigned to perform activities without appropriate safety training also have a decreased probability of ranking "lack of awareness as the primary, or one of the main, causes of accidents in work zones. While performing those activities, they may have experienced situations that make them feel at risk of being injured by causes related to poor safety training (e.g., inadequate use of equipment, not knowing how to interact with hazardous substances, not knowing safety procedures for working in elevated structures, not knowing safety procedures to operate equipment). For instance, if a worker is regularly assigned to work in elevated structures without safety training for the use of falling protection, he might think that other factors not related to his awareness might increase his chances to be injured.

Drivers and heavy equipment operators also decreased the probability of ranking "lack of awareness" as the primary, or one of the main causes of accidents. This is a concern when they operate the equipment in the work zone, since from this perception, they would maneuver the equipment believing that workers on foot are aware of the risk involved in working in the vicinity of his equipment. This seems to be the case of a work zone accident occurred in 2002, in Virginia, where the driver relied on the awareness of the worker when backing through the work zone; "the driver reported that he made eye contact with the victim, thinking that he had alerted the victim that he would be backing into the work zone" NIOSH (2004a). 


\section{Interpretation of the Binomial Logit Model}

With Equations 3.12 and 3.13, the probability that a worker chose "lack of awareness" as the primary, or one of the major, behavioral causes of accidents can be calculated if the information contained in each variable is known for that worker. For instance, in the hypothetical case of a flagger with more than two years of experience in road construction or maintenance projects, who attends at least one safety meeting per month, and has never been assigned to perform an activity without receiving the proper safety training for that activity, the probability is calculated as follows:

$$
\begin{gathered}
V(l a)=2.48-1.24(1)-1.64(1)-1.88(0)-0.99(0)=-0.4 \\
P(a)=\frac{e^{-0.4}}{1+e^{-0.4}}=0.401
\end{gathered}
$$

The results indicate that a worker with the characteristics described, has a 0.4 probability of choosing "lack of awareness" as the primary, or one of the major behavioral causes of accident occurrence in work zones. The highest probability that a worker can have in this regard according to this model is 0.923 . This probability occurs when the worker does not fulfill any of the characteristics that are assigned to a determined variable. Therefore the utility function $V(l a)$ would take the parameter estimate value of the constant (i.e., 2.48).

\section{Marginal Effects for the Variables in the Binomial Logit Model}

In order to determine how influential or important a variable is, the marginal effects approach for the model was performed. The variable with the greatest effect on the dependent variable was "driver or heavy equipment operator." It presented a marginal effect of -0.44 , which means that workers with either of these two occupations will have on average a 0.44 decrease in the probability of ranking "lack of awareness" as the primary, or one of the major causes, of work zone accidents. Table 3.18 shows the marginal effect value for each variable in the model, as well as the t-statistics and p-values for the evaluation of the significance of the marginal effect test performed. 
Table 3.18 Marginal effects for variables in the binomial logit model

\begin{tabular}{|c|c|c|c|c|}
\hline Explanatory Variable & $\begin{array}{c}\text { Variable } \\
\text { Mnemonic }\end{array}$ & $\begin{array}{c}\text { Marginal } \\
\text { Effect }\end{array}$ & t-stat & P-value \\
\hline Constant & ONE & 0.58 & 2.76 & 0.0059 \\
\hline $\begin{array}{l}\text { Worker with more than two years of experience } \\
\text { in road construction or maintenance activities }\end{array}$ & EXPER & -0.29 & -2.47 & 0.0135 \\
\hline $\begin{array}{l}\text { A worker employed by a company or state entity } \\
\text { that always conducts at least one safety meeting } \\
\text { per month }\end{array}$ & OFTSM & -0.39 & -2.34 & 0.0195 \\
\hline Driver or heavy equipment operator & HEODRIV & -0.44 & -2.48 & 0.0130 \\
\hline $\begin{array}{l}\text { A worker that has been assigned to perform an } \\
\text { activity without having received the proper safety } \\
\text { training for that activity }\end{array}$ & ASSIG & -0.23 & -1.89 & 0.0587 \\
\hline
\end{tabular}

\subsection{Chapter Summary}

This chapter described the analysis of accident reports of fatalities that occurred in work zones in the United States in the 2000-2006 time frame. From the descriptive analysis it was found that most of the fatal occupational accidents in work zones occurred in the accident events "worker struck by passing motorist" and "worker struck by mobile equipment (which was part of the project)." Two relevant behavioral accident causes were found: "negligence of a third party" and "lack of awareness from the injured worker." These results were compared to those obtained from the survey responses provided by work zone workers surveyed Indiana. Workers rated the accident event involving mobile equipment as the second least likely to occur when compared with the other accident events, and the behavioral cause "lack of awareness" as the least likely to occur when compared with the other behavioral causes of accidents. A binomial logit model was developed to describe the likelihood of a worker choosing "lack of awareness" as the primary, or one of the major, causes of accidents in work zones. Through the model, the following factors were found to be significant for reducing the probability of workers to choose "lack of awareness" as the primary, or one of the major, behavioral causes of accidents: (1) workers with two or more years of experience in road construction or maintenance; (2) workers who attended to at least one safety meeting per month; (3) drivers and heavy equipment operators; and (4) workers that were assigned to perform an activity without receiving safety training for that activity. 


\subsubsection{Limitations of This Analysis}

The limitation for the analysis of accident reports was the lack of information in the some of the reports. The information provided in some cases was not good enough to identify the cause of the accidents as well to classify the incidents into the accident events classification. The limitations for the analysis of the perspectives of work zone personnel about causes of accidents were mainly related to the low participation in the research from different parties. It was difficult to engage construction companies and certain districts within the Indiana Department of Transportation (INDOT) to conduct the survey with their workers. Additionally, even when cooperation from these entities was provided, it was difficult to engage workers to complete the survey.

\subsubsection{Recommendations for Future Studies for Analyzing Causes of Construction Workzone Accidents, based on Worker Perceptions}

A more representative sample of workers is needed to effectively evaluate the factors that influence their perception of the common causes of accidents in work zones. In the same manner, more specific questions about the characteristics of the workers (e.g., activities they usually perform, work schedule) and the safety training received (e.g., activities for which worker has received safety training) should be included in the survey with the purpose of finding other significant factors affecting worker perception of accident causes that may not be considered in this research. The perception of other parties (e.g., supervisors) should be modeled as well to identify the factors affecting the perspectives of these parties about different causes of accidents. 


\section{CHAPTER 4. EVALUATION AND ASSESSMENT OF WORK ZONE SAFETY STRATEGIES}

The analysis process described in this chapter can be applied to understand highway construction and maintenance safety issues from the perspectives of the construction workers, the general contractors, and the owner (state DOTs). First, the sources of risk or safety hazards for workers and the currently used safety strategies and procedures were identified, and through a survey and field observations, data were gathered about these factors. Then analyses were performed for various purposes:

- To obtain the worker's perspective on safety risks and to evaluate currently used safety strategies from their perspective

- To obtain the contractor's perspective on safety risks and to evaluate currently used safety strategies from their perspective

- To obtain the owner's (state DOTs) perspective on safety risks and to evaluate currently used safety strategies based on their perspective.

\subsection{Data Collection Process}

The data collection process consisted of administering the surveys and gathering data about the different aspects of safety on highway construction and maintenance jobsites. Data were collected about currently used safety strategies and the on-site safety perceptions of the owner, contractor, and workers. The site visits to construction and maintenance work zones in Indiana also provided an insight on safety on the jobsite.

\subsubsection{Survey Design}

The main instruments used to gather information about work zone safety strategies and risks in highway construction and maintenance projects were three types of surveys administered to owners (state DOTs), general contractors, and construction workers. Two types of surveys were developed for the contractor entity, one specifically geared towards the general contractor at the management level and the other towards the construction workers. The general contractor's tasks include performing the project planning, supervising the construction operations, and monitoring 
safety on the project site. In addition, the contractor supervises the workers who perform the manual construction labor. The general contractor's perspective on safety is considered separately from the perspective of the construction workers due to the different tasks performed by each.

In order to establish the criteria used to evaluate the effectiveness of a safety strategy, the administered surveys include a section in which the owners, contractors, and workers were asked to rate the level of importance of nine given factors in evaluating the effectiveness of a strategy. The respondents were asked to rate each factor using a five-point scale (1 signifying that the factor is not important at all to 5 signifying that it is extremely important). An evaluation of the averages rates of the same factors was performed to compare the rates across the three groups.

The effectiveness of the currently used work zone safety strategies was evaluated by owners, contractors, and workers in the administered surveys. The respondents were asked to rate the safety strategies using a five-point scale of effectiveness (1 signifying a poor performance of the strategy to 5 signifying an excellent performance). A comparison of the obtained rates was made across the three groups by evaluating the average rates of the same safety strategy in each survey.

\subsubsection{Survey Administered to Owners}

The main objective of the owner survey was to assess the perspective of the owner on the safety risks faced by construction workers, as well as safety strategies that are currently being used on highway construction and maintenance projects. In this study, key personnel and safety officers from the midwest DOTs, (i.e., Indiana, Illinois, Michigan, Ohio, Wisconsin and Pennsylvania) were the participants in the owners surveys. Since the state DOTs take an active role in establishing work zone safety standards and regulations for highway construction and maintenance projects, the owner's survey was designed to include consideration of safety management and costs. The owner's survey is composed of eleven sections, which include the following: 1) general safety questions, 2) administrative safety strategies, 3) traffic control strategies, 4) measures to improve safety in work zones, 5) innovative technologies for traffic 
control, 6) nighttime traffic control, 7) overall evaluation of strategies, 8) relative ranking of safety strategies, 9) demographic information, 10) additional comments and suggestions, and 11) general information. A copy of the owner survey is attached in Appendix D.

\subsubsection{Survey Administered to General Contractors}

Construction safety is largely the responsibility of the contractor and other job site professionals. The success of a construction project depends on the appropriate planning and decisions made on site (Mroszcvyk, 2006). OSHA 1926.16 stipulates that the general contractor has the overall responsibility for job site safety. A study conducted by Lingard and Holmes (2001) concluded that more than 50 percent of construction workers believe that their safety is the responsibility of the general contractor or trade union. The general contractor highly influences job site safety because they direct, coordinate, and monitor the tasks performed by workers and subcontractors.

Construction companies have the ability and opportunity to effectively communicate, train and equip the workers. Also, they have the authority to enforce and promote compliance with established safety procedures. This was demonstrated on a study of the Kuwaiti construction industry performed by Kartam and Bouz (1998), where the construction industry lacks government regulations and there is little safety training outside construction companies. The researchers evaluated the injury and fatality data and found that pressure from upper management and competent construction managers played a significant role in reducing job site accidents.

A survey specifically geared towards the general contractors was developed in order to obtain their perspective on the work zone risks for workers, the currently used work zone safety strategies, and their safety program and planning. The contractor's survey is composed of the following sections: 1) company information, 2) project information, 3) general safety questions, 4) administrative safety strategies, 5) traffic control strategies, 6) measures to improve safety in work zones, 7) innovative technologies for traffic control, 8) nighttime traffic control, 9) relative ranking of safety strategies , 10) demographic information, 11) additional comments and 
suggestions, and 12) general information. A copy of the contractor's survey is attached in Appendix E.

\subsubsection{Survey Administered to Construction Workers}

Construction workers are exposed to work zone risks and hazards on a daily basis, and are the most adversely and directly affected by an accident. All highway construction and maintenance workers, regardless of their assigned task, frequently work in conditions of poor lighting, low visibility, inclement weather and congested traffic areas with exposure to high speeds and traffic volumes. The safety of workers is a main concern for state DOTs and general contractors. Construction workers are expected to follow and comply with the owner's and/or the general contractor's safety policies and regulations.

According to Abdelhamid and Everett (2000), the primary causes of work zone accidents are the following:

- Failure to identify an unsafe condition that existed before the activity started or that developed after the activity began.

- Proceeding with an activity after the worker identifies an existing unsafe condition.

- Deciding to perform an unsafe act regardless of the initial conditions of the work environment.

These three causes make the worker primarily responsible for safety, because he is the closer to the situation and most likely to detect an unsafe situation. When the worker has not received proper safety training, his supervisor and the construction company share the responsibility. In some cases, though, the worker performs his own risk assessment and chooses to continue performing the work knowing that an unsafe condition exists. Research done by Ellis and Warner (1999) indicated that as workers gain experience and confidence performing a certain task, they tend to develop a false sense of security. Holmes et al (1999) identified another method by which workers tend to weigh the costs and the benefits of a potentially unsafe situation. For instance, if performing the necessary safety measure is perceived by the worker to require an excessive level of effort it may be ignored. The key factor in safety compliance is the 
worker's perception which is often misjudged by the true weighted cost. Workers need to have some outside motivation factor that promotes the necessary discipline to keep them safe (Cattledge, et al. 1997).

The surveys were administered to workers on highway construction and maintenance projects, who were employed by INDOT, and the general contractor's workers. The main purpose of this survey is to assess the worker's perspective of safety practices and measures to improve the level of safety of construction activities. Safety training and demographical information was also obtained from workers. In addition, the workers were asked to indicate which three elements made them feel safer on the job site. Knowing the perception of the construction workers provides a better understanding of the risks in work zone daily activities and encountered risks. The worker survey is composed of the following sections: 1) general safety questions, 2) safety training, 3) administrative safety strategies, 4) traffic control strategies, 5) measures to improve safety in work zones, 6) innovative technologies for traffic control, 7) nighttime traffic control, 8) overall evaluation of strategies, 9) demographic information, 10) additional comments and suggestions, and 11) general information. A copy of the worker survey is included in Appendix F.

\subsubsection{Description of Survey Administration and Sample}

The workers surveyed included INDOT construction and maintenance crew workers and workers for general contractors in the state of Indiana. The surveys to the construction workers were administered between the months of May and August of 2007. The surveys were field tested by administering the questionnaires to 13 INDOT maintenance crew workers at the West Lafayette, Indiana Maintenance Unit. The main objective of the testing was to determine the workers' response level and to measure the average amount of time that it would take a worker to complete the survey.

The surveys to workers were administered directly on ten highway construction or maintenance sites in Indiana or in safety training sessions provided by the Indiana Local Technical Assistance Program (LTAP) in two INDOT subdistricts. A total of 257 worker surveys were distributed, of 
which 163 were completed, a response rate of $63 \%$. Seventy eight percent of the surveys were completed by INDOT workers and $22 \%$ by contractors' workers. Table 4.1 summarizes general information about the amount of implemented surveys.

Table 4.1 Worker Sample Distribution

\begin{tabular}{|c|c|c|c|c|}
\hline Activity & $\begin{array}{l}\text { Type of } \\
\text { Workers }\end{array}$ & $\begin{array}{l}\text { Distributed } \\
\text { Surveys }\end{array}$ & $\begin{array}{l}\text { Completed } \\
\text { Surveys }\end{array}$ & $\begin{array}{l}\text { Percent of } \\
\text { Response }\end{array}$ \\
\hline $\begin{array}{l}\text { Indiana LTAP Conference - } \\
\text { INDOT Sub-district A }\end{array}$ & INDOT & 47 & 47 & $100 \%$ \\
\hline $\begin{array}{l}\text { Indiana LTAP Conference - } \\
\text { INDOT Sub-district B }\end{array}$ & INDOT & 40 & 40 & $100 \%$ \\
\hline $\begin{array}{l}\text { Site Visit \# } 1 \text { - SR-43 Added } \\
\text { Travel Lanes \& Bridge } \\
\text { Replacement West Lafayette, IN }\end{array}$ & Contractor & 17 & 17 & $100 \%$ \\
\hline $\begin{array}{l}\text { Site Visit \# } 2 \text { - Clinton County } \\
\text { SR-28 Pavement, IN }\end{array}$ & Contractor & 10 & 10 & $100 \%$ \\
\hline $\begin{array}{l}\text { Site Visit \# } 3 \text { - US-6 } \\
\text { Reconstruction Portage, IN }\end{array}$ & Contractor & 4 & 0 & $0 \%$ \\
\hline $\begin{array}{l}\text { Site Visit \# } 4 \text { - US-6 east SR-51 } \\
\text { Reconstruction Portage, IN }\end{array}$ & Contractor & 3 & 0 & $0 \%$ \\
\hline $\begin{array}{l}\text { Site Visit \# } 5 \text { - I-80/94 \& I-65 } \\
\text { Interchange, IN }\end{array}$ & Contractor & 13 & 9 & $69.2 \%$ \\
\hline $\begin{array}{l}\text { Site Visit \# } 6 \text { - INDOT } \\
\text { Maintenance Site US-20 } \\
\text { Wagner, IN }\end{array}$ & INDOT & 50 & 12 & $24 \%$ \\
\hline $\begin{array}{l}\text { Site Visit \# } 7 \text { - INDOT Sub- } \\
\text { district Unit D }\end{array}$ & INDOT & 20 & 20 & $100 \%$ \\
\hline $\begin{array}{l}\text { Site Visit \# } 8 \text { - SR-26 } \\
\text { Improvements Lafayette, IN }\end{array}$ & Contractor & 21 & 5 & $23.8 \%$ \\
\hline $\begin{array}{l}\text { Site Visit \# } 9 \text { - Main Street } \\
\text { Improvements Monticello, IN }\end{array}$ & Contractor & 20 & 2 & $10 \%$ \\
\hline $\begin{array}{l}\text { Site Visit \# } 10-\text { SR-32 Pavement } \\
\text { Fountain County, IN }\end{array}$ & Contractor & 12 & 1 & $8.3 \%$ \\
\hline Total & & 257 & 163 & $63.4 \%$ \\
\hline
\end{tabular}


The general contractor surveys were distributed to contractors performing highway construction operations in Indiana. These surveys were implemented during site visits or scheduled interviews with managerial personnel from the construction companies. Safety directors, project managers, project engineers, and superintendents from the general contractor community participated in the survey. A total of 25 general contractor surveys were distributed; 17 surveys from four construction companies were completed, for a response rate of $68 \%$.Table 4.2 summarizes general information about the implemented surveys.

Table 4.2 General Contractor Sample Distribution

\begin{tabular}{|c|c|c|c|c|}
\hline Activity & $\begin{array}{l}\text { General } \\
\text { Contractor }\end{array}$ & $\begin{array}{l}\text { Distributed } \\
\text { Surveys }\end{array}$ & $\begin{array}{l}\text { Completed } \\
\text { Surveys }\end{array}$ & $\begin{array}{l}\text { Percent of } \\
\text { Response }\end{array}$ \\
\hline $\begin{array}{l}\text { Site Visit \# 1 - SR-43 } \\
\text { Added Travel Lanes \& } \\
\text { Bridge Replacement West } \\
\text { Lafayette, IN }\end{array}$ & Contractor A & 1 & 1 & $100 \%$ \\
\hline $\begin{array}{l}\text { Site Visit \# } 2 \text { - Clinton } \\
\text { County SR-28 Pavement, IN }\end{array}$ & Contractor A & 1 & 1 & $100 \%$ \\
\hline $\begin{array}{l}\text { Site Visit \# } 4 \text { - US-6 east } \\
\text { SR-51 Reconstruction } \\
\text { Portage, IN }\end{array}$ & Contractor B & 3 & 0 & $0 \%$ \\
\hline $\begin{array}{l}\text { Site Visit \# 5 - I-80/94 \& I- } \\
65 \text { Interchange, IN }\end{array}$ & Contractor C & 3 & 2 & $67 \%$ \\
\hline $\begin{array}{l}\text { Interview with Safety } \\
\text { Officer and Managerial } \\
\text { Personnel at General } \\
\text { Contractor Main Office, } \\
\text { Lafayette IN }\end{array}$ & Contractor A & 6 & 4 & $83.3 \%$ \\
\hline $\begin{array}{l}\text { Site Visit \# } 8 \text { - SR-26 } \\
\text { Improvements Lafayette, IN }\end{array}$ & Contractor C & 2 & 1 & $50 \%$ \\
\hline $\begin{array}{l}\text { Site Visit \# } 9 \text { - Main } \\
\text { Street Improvements } \\
\text { Monticello, IN }\end{array}$ & Contractor C & 3 & 2 & $67 \%$ \\
\hline $\begin{array}{l}\text { Site Visit \# } 10-\text { SR-32 } \\
\text { Pavement Fountain } \\
\text { County, IN }\end{array}$ & Contractor $\mathrm{C}$ & 1 & 1 & $100 \%$ \\
\hline
\end{tabular}




\begin{tabular}{|c|c|c|c|c|}
\hline \multicolumn{1}{|c|}{ Activity } & $\begin{array}{c}\text { General } \\
\text { Contractor }\end{array}$ & $\begin{array}{c}\text { Distributed } \\
\text { Surveys }\end{array}$ & $\begin{array}{c}\text { Completed } \\
\text { Surveys }\end{array}$ & $\begin{array}{c}\text { Percent of } \\
\text { Response }\end{array}$ \\
\hline $\begin{array}{l}\text { Interview with Safety } \\
\text { Director of Construction } \\
\text { Company Indianapolis, } \\
\text { IN }\end{array}$ & Contractor A & 2 & 2 & $100 \%$ \\
\hline $\begin{array}{l}\text { Interview with President } \\
\text { of Contractor D }\end{array}$ & Contractor D & 3 & 3 & $100 \%$ \\
\hline Total & & 25 & 17 & $68 \%$ \\
\hline
\end{tabular}

The owner survey was administered primarily to INDOT employees; however, $10 \%$ of the owner survey participants were Ohio Department of Transportation (ODOT) safety directors. The remaining $90 \%$ of the owner survey participants were INDOT safety directors, project managers, and inspectors.

\subsubsection{Site Visits and On-Site Observations}

Field observations obtained through site visits served as a valuable tool for understanding the relationship between unique construction factors and safety on construction jobsites. Site visits were conducted during June and August of 2007 at jobsites in Indiana. Surveys were administered to workers, general contractors, and owners at these sites. The safety strategies in place, the work zone set-up, and the safety equipment worn and used by the workers were observed and recorded by completing the site visit protocol form shown in Appendix E. The form summarizes project information and the safety measures in place on a construction jobsite.

The main advantage of visiting nine construction jobsites was to observe the differences, as well as the similarities, in the implemented safety strategies. The observed construction activities and safety strategies are summarized in Table 4.3. 
Table 4.3 Site Visit Summary

\begin{tabular}{|c|c|c|c|}
\hline Project Name & $\begin{array}{l}\text { Date of Data } \\
\text { Collection }\end{array}$ & $\begin{array}{l}\text { Construction } \\
\text { Activities }\end{array}$ & Safety Strategies \\
\hline $\begin{array}{l}\text { SR-43 Added Travel } \\
\text { Lanes \& Bridge } \\
\text { Replacement } \\
\text { (West Lafayette, IN) }\end{array}$ & June 2007 & $\begin{array}{l}\text { - Earthwork } \\
\text { - Paving of roadway } \\
\text { - Construction of } \\
\text { new bridge } \\
\text { structure }\end{array}$ & $\begin{array}{l}\text { - Traffic zone of two lanes } \\
\text { defined by barrels } \\
\text { - Worker safety apparel } \\
\text { - Warning signs } \\
\text { - Flashing arrows } \\
\text { - Flaggers }\end{array}$ \\
\hline $\begin{array}{l}\text { SR- } 28 \\
\text { Re-pavement (Clinton } \\
\text { County, IN) }\end{array}$ & July 2007 & - Paving operations & $\begin{array}{l}\text { - Traffic zone of two lanes } \\
\text { defined by barrels and } \\
\text { cones } \\
\text { - Worker safety apparel } \\
\text { - Traffic signs } \\
\text { - Lane closure } \\
\text { - Flaggers }\end{array}$ \\
\hline $\begin{array}{l}\text { US-6 Reconstruction } \\
\text { (Portage, IN) }\end{array}$ & July 2007 & $\begin{array}{l}\text { - Bridge } \\
\text { replacement } \\
\text { - Earthwork } \\
\text { - Road widening } \\
\text { from } 2 \text { lanes to } 4 \\
\text { lanes }\end{array}$ & $\begin{array}{l}\text { - Traffic zone of one lane } \\
\text { defined by barrels and } \\
\text { cones } \\
\text { - Flashing arrows } \\
\text { - Warning signs } \\
\text { - Flaggers }\end{array}$ \\
\hline $\begin{array}{l}\text { US-6 east SR-51 } \\
\text { Reconstruction } \\
\text { (Portage, IN) }\end{array}$ & July 2007 & $\begin{array}{l}\text { - Concrete Works } \\
\text { on Sidewalks and } \\
\text { Curbs } \\
\text { - Storm Sewer } \\
\text { Installation }\end{array}$ & $\begin{array}{l}\text { - Traffic zone of two lanes } \\
\text { defined by barrels and } \\
\text { cones } \\
\text { - Warning signs } \\
\text { - Flaggers }\end{array}$ \\
\hline $\begin{array}{l}\text { I- } 80 / 94 \& \text { I- } 65 \\
\text { Interchange }\end{array}$ & July 2007 & - Earthwork & $\begin{array}{l}\text { - Traffic zone of two lanes } \\
\text { defined by concrete } \\
\text { barriers } \\
\text { - Driver Information } \\
\text { Displays } \\
\text { - INDOT Special Police } \\
\text { Enforcement Patrol } \\
\end{array}$ \\
\hline $\begin{array}{l}\text { US- } 20 \text { Maintenance } \\
\text { Operations } \\
\text { (Wagner, IN) }\end{array}$ & July 2007 & - Grinding surfaces & $\begin{array}{l}\text { - Truck-mounted attenuator } \\
\text { - Warning vehicles } \\
\text { - Flaggers } \\
\text { - Worker safety Apparel- } \\
\text { safety vests }\end{array}$ \\
\hline $\begin{array}{l}\text { SR-26 Improvements } \\
\text { (Lafayette, IN) }\end{array}$ & August 2007 & $\begin{array}{l}\text { - Asphalt paving } \\
\text { - Storm sewer } \\
\text { installation } \\
\text { - Earthwork }\end{array}$ & $\begin{array}{l}\text { - Traffic zone of one lane } \\
\text { defined by barrels } \\
\text { - Flashing arrows } \\
\text { - Warning signs } \\
\text { - Flaggers } \\
\text { - Worker safety apparel- } \\
\text { retro-reflective t-shirts }\end{array}$ \\
\hline
\end{tabular}




\begin{tabular}{|l|l|l|l|}
\hline \multicolumn{1}{|c|}{ Project Name } & $\begin{array}{c}\text { Date of Data } \\
\text { Collection }\end{array}$ & $\begin{array}{c}\text { Construction } \\
\text { Activities }\end{array}$ & \multicolumn{1}{c|}{ Safety Strategies } \\
\hline $\begin{array}{l}\text { Main Street } \\
\text { Improvements } \\
\text { (Monticello, IN) }\end{array}$ & August 2007 & $\begin{array}{l}\text { - Asphalt paving } \\
\text { - Concrete works on } \\
\text { curbs and } \\
\text { sidewalks }\end{array}$ & $\begin{array}{l}\text { - Traffic zone of one lane } \\
\text { defined by barrels } \\
\text { - Flaggers } \\
\text { - Warning signs } \\
\text { - Worker safety apparel - } \\
\text { retro-reflective t-shirts }\end{array}$ \\
\hline $\begin{array}{l}\text { SR-32 Repaving } \\
\text { (Fountain County, IN) }\end{array}$ & August 2007 & $\begin{array}{l}\text { - Cold-milling } \\
\text { - Asphalt paving }\end{array}$ & $\begin{array}{l}\text { - Flaggers } \\
\text { - Worker safety apparel - } \\
\text { retro-reflective t-shirts }\end{array}$ \\
\hline
\end{tabular}

\subsection{Data Analysis}

After the data were collected, the descriptive statistics of each safety strategy included in the survey were developed to illustrate the trends of the effectiveness ratings and the factors that affect their evaluation. The highest rated safety strategies in each of the five categories (administrative, traffic control, measures to improve safety in the work zone, innovative technologies for hazard control and nighttime traffic control) were chosen to create five statistical models to predict which factors affect the effectiveness ratings of the safety strategies. A Binary Logit Model was chosen to predict which factors affect the effectiveness ratings of the analyzed safety strategies. This type of model is used to analyze discrete data with the objective of estimating a function to determine the outcome probabilities (Washington et al. 2003).

\subsubsection{Results from the Administered Surveys}

In order to assess the perception of the effectiveness of safety strategies and identify the factors that influence this perception, a survey was conducted among workers, general contractors, and owners. This section discusses the results obtained from the administered surveys and compares the perception of the main stakeholders involved in the study. 


\subsubsection{General Safety and Training Perspective of Workers}

The survey administered to construction and maintenance workers includes two sections which address general safety issues and safety training. Seventy nine percent of the respondents indicated that the staffing of their projects includes the designation of a person (i.e., safety officer) who is responsible for ensuring that safety procedures are followed. The most common type of safety training attended by the workers was the OSHA 10-hour, followed by the OSHA 30-hour training. The OSHA 10-hour General Outreach Training Program covers topics related to hazard communication, machine guarding, personal protective equipment, and safety and health programs. The OSHA 30-hour General Industry Training Course includes more specific sections on basic electrical safety, fall protection, scaffolding, excavations, tools, and heavy equipment safety. From the workers who participated in the survey, 33\% indicated that they have received other types of safety training from several organizations, such as the Indiana Local Technical Assistance Program (LTAP), the American Traffic Safety Services Association (ATSSA) and worker trade unions. However, $30 \%$ of the workers who participated in the survey indicated that they had not received any type of safety training. Figure 4.1 shows the number of responses corresponding to each type of safety training.

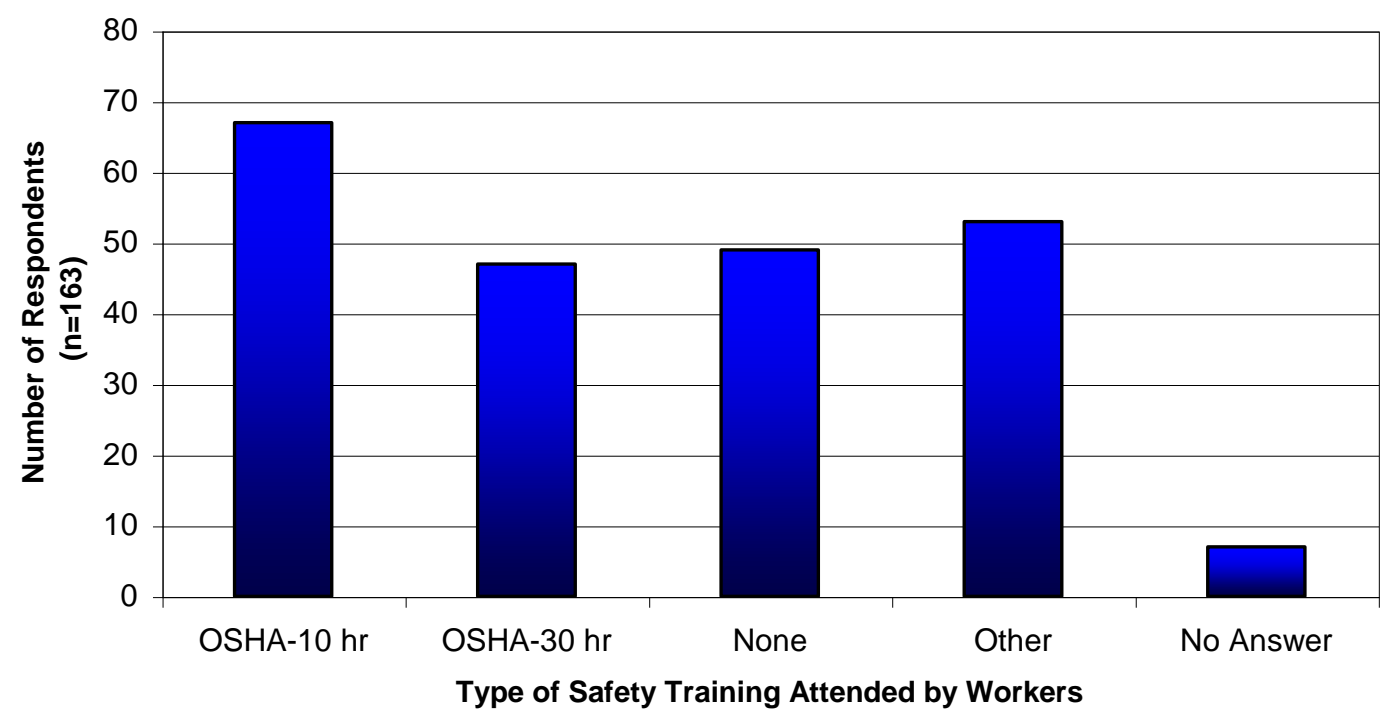

Figure 4.1 Safety Training Undertaken by Construction and Maintenance Workers 
From the workers' perspective, the three elements in the work zone that made them feel safe are barriers, followed by worker safety apparel and police enforcement, as shown in Figure 4.2. This finding may indicate that these elements would be the essential safety strategies that should be implemented in work zones to improve the workers' perception of safety and protect them from the hazards to which they are directly exposed on a daily basis.

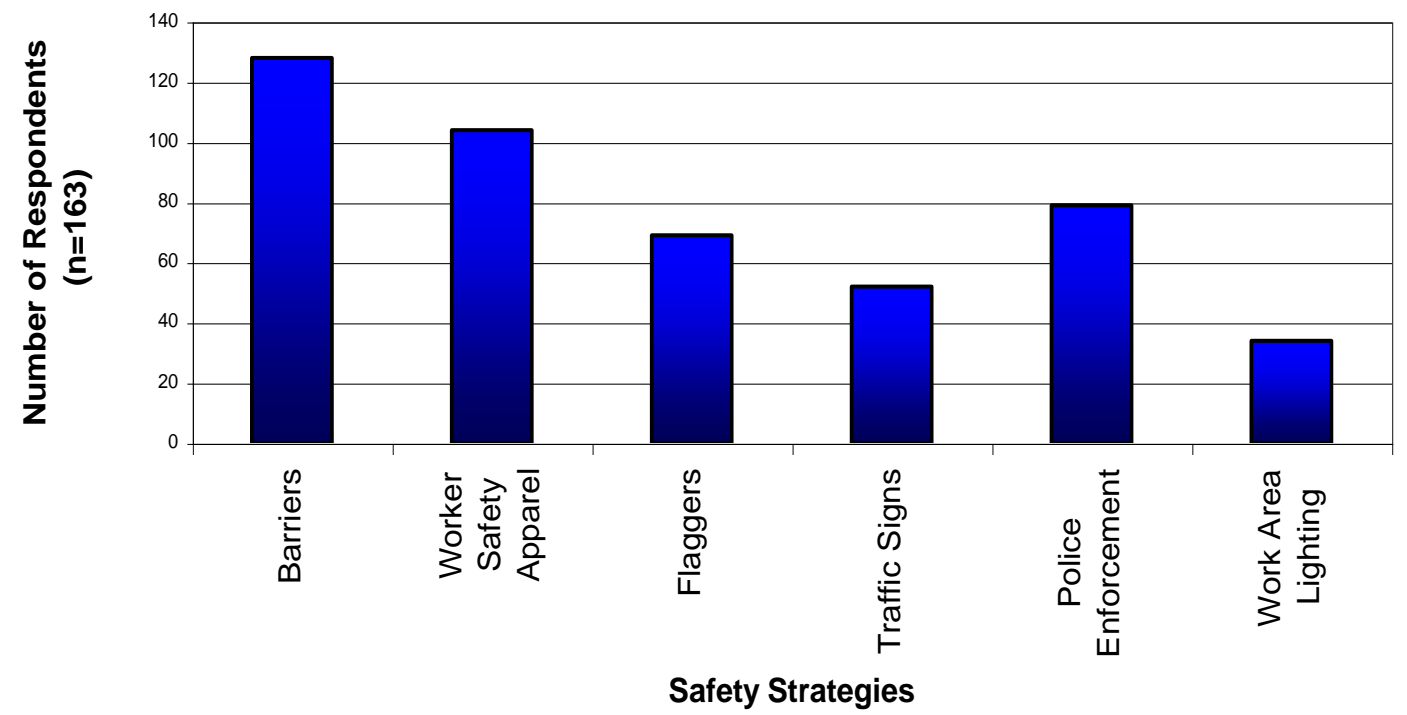

Figure 4.2 Elements in the Work Zone that Make Workers Feel Safe

The respondents were asked how frequently they attended safety meetings; $28 \%$ answered that they attended safety meetings on a daily-basis and $23 \%$ attended weekly. Seventeen percent of the workers answered that they attended safety meetings once a month, $7 \%$ attended bi-weekly and the other 7\% never attended, as shown in Figure 4.3. 


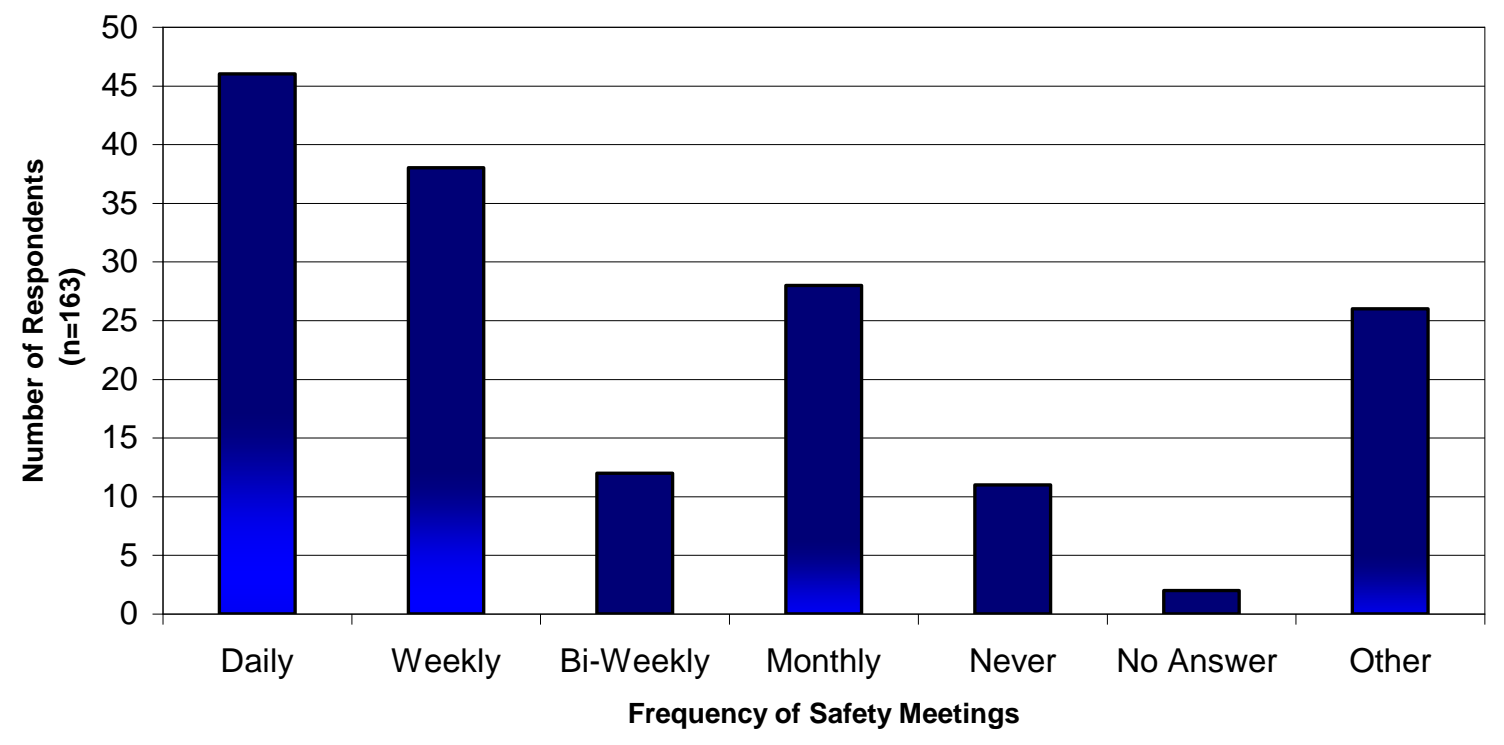

Figure 4.3 Frequency of Worker Attendance at Safety Meetings

Eighty five percent of the respondents indicated that they received training on safety practices to prevent injuries when they were hired; the other 15\% indicated that they did not receive the training. As shown in Figure 4.4, the most common safety topics covered in the training were the use of personal protective equipment, how to minimize exposure to risk, and the limitations of safety equipment and strategies.

The general safety and training information discussed in this section will be used as independent variables in the development of the statistical models. These models will be related to the effectiveness ratings of various safety strategies to predict the factors that affect the workers' perception of their effectiveness. 


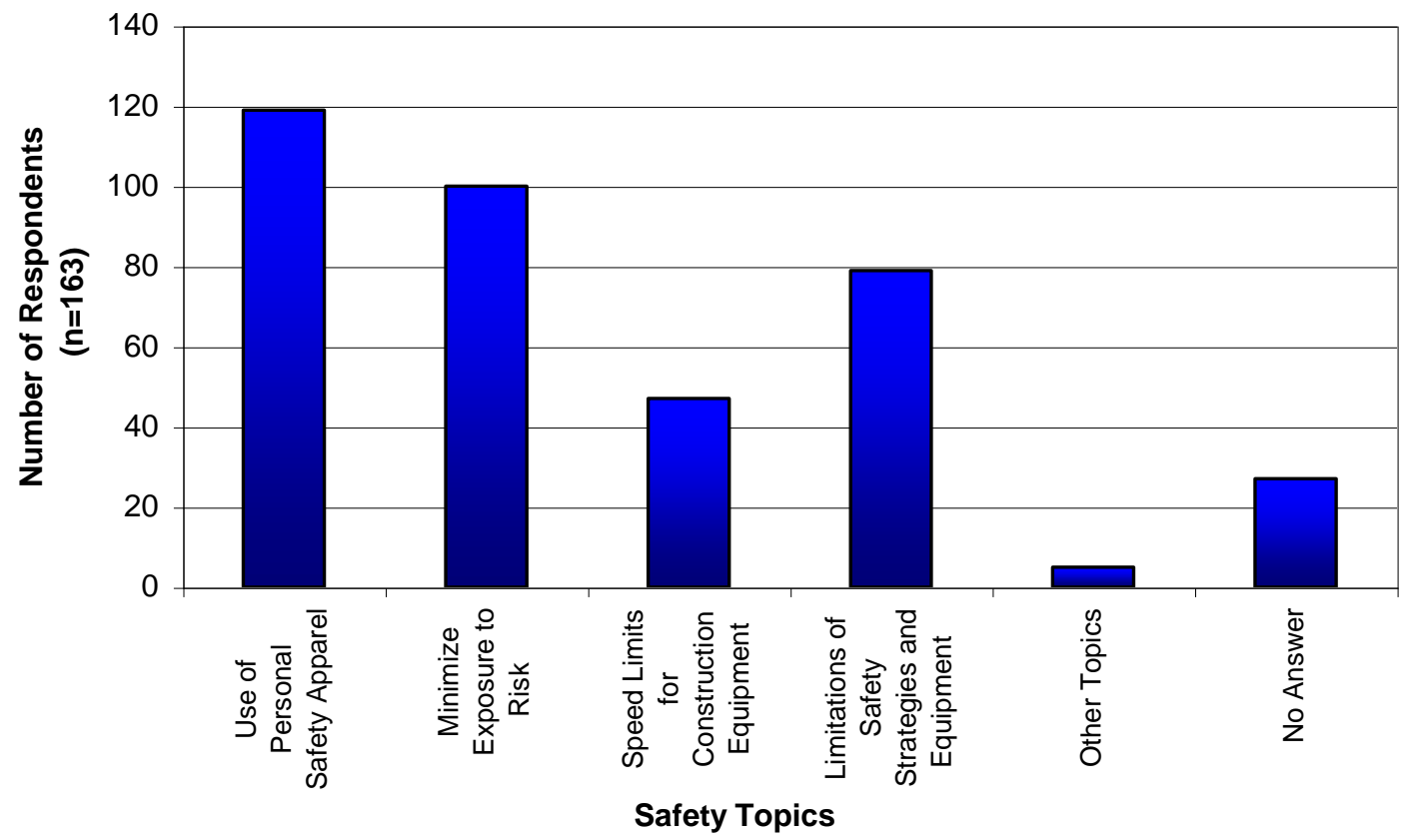

Figure 4.4 Commonly Covered Topics on Safety Trainings

\subsubsection{Factors Affecting the Effectiveness of Safety Strategies}

The respondents were asked to rate the importance of several factors in the evaluation of the effectiveness of a safety strategy. These ratings were based on a five-point scale of importance (1 signifying not important at all, to 5 signifying extremely important). The average score for each factor is shown in Figure 4.5.

According to the perception of the three stakeholder groups who participated in this study (workers, contractors, and owners), the most important factor in evaluating the effectiveness of a safety strategy is the success in injury prevention, with average scores between 4.60 and 4.82 . These average scores are between the "somewhat important" and the "extremely important" choices in the scale of importance presented in the survey. In this case, the worker and owner average scores were very similar, while the contractor assigned this factor the highest score. This may indicate that a major concern of construction companies and contracting agencies is 
implementing safety strategies that have proven to be successful in preventing injuries and fatalities.

The cost of these strategies was the least important factor in the evaluation of their effectiveness. The scores assigned for this factor by the three groups were between 3.18 and 3.40, which are between the "no opinion" and the "somewhat important" choices presented in the survey. By comparing the scores across the three groups it was observed that this factor appeared to be less important to the contractors than to the workers and the owners. This result may indicate that contractors and contracting agencies are not giving the same priority to economic factors in the implementation of safety strategies as they are in prioritizing other factors such as protecting workers from intruding vehicles and hazards that arise from construction operations, implementation time and ease, and success in injury prevention to improve worker safety.

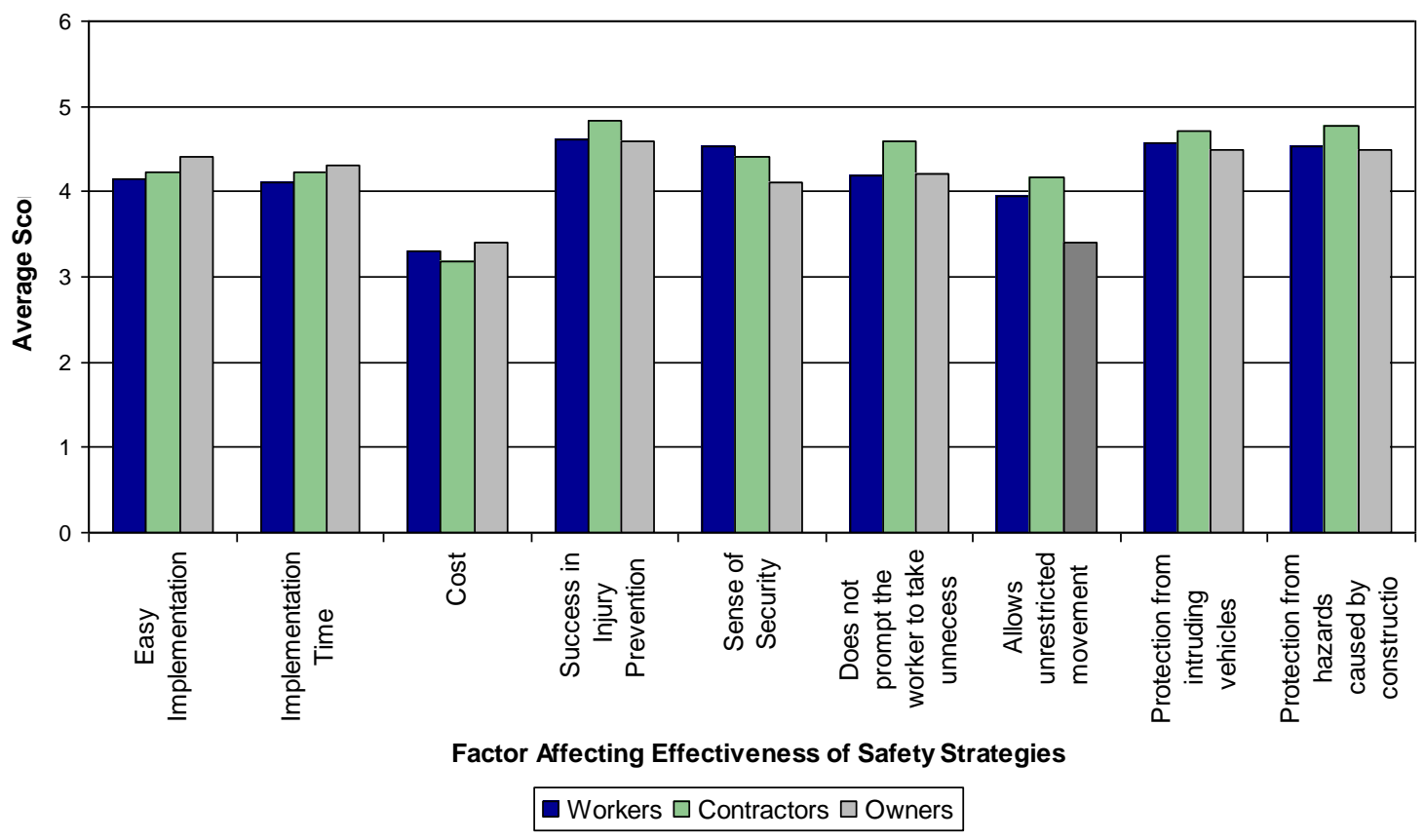

Figure 4.5 Importance of Factors Affecting the Evaluation of the Effectiveness of Safety Strategies

The scores obtained from the workers' perception were used as independent variables in the development of the statistical models for each of the highest rated safety strategies in each 
category. These factors that affect the evaluation of the effectiveness of a safety strategy will be related to the effectiveness ratings given by the workers for the five analyzed safety strategies.

\subsubsection{Level of Risk and Occurrence of Safety Hazards}

The surveys included a section in which respondents were asked to rate the level of risk and probability of occurrence of the work zone safety hazards identified through the literature review. The perspective of workers was measured using a three-point scale (1 signifying low level of risk or occurrence, to 3 signifying high level of risk or occurrence). Figure 4.6 shows the average score for the level of risk of different safety hazards, while Figure 4.7 shows the probability of occurrence of the different safety hazards from three different perspectives - those of the workers, those of contractors and those of owners.

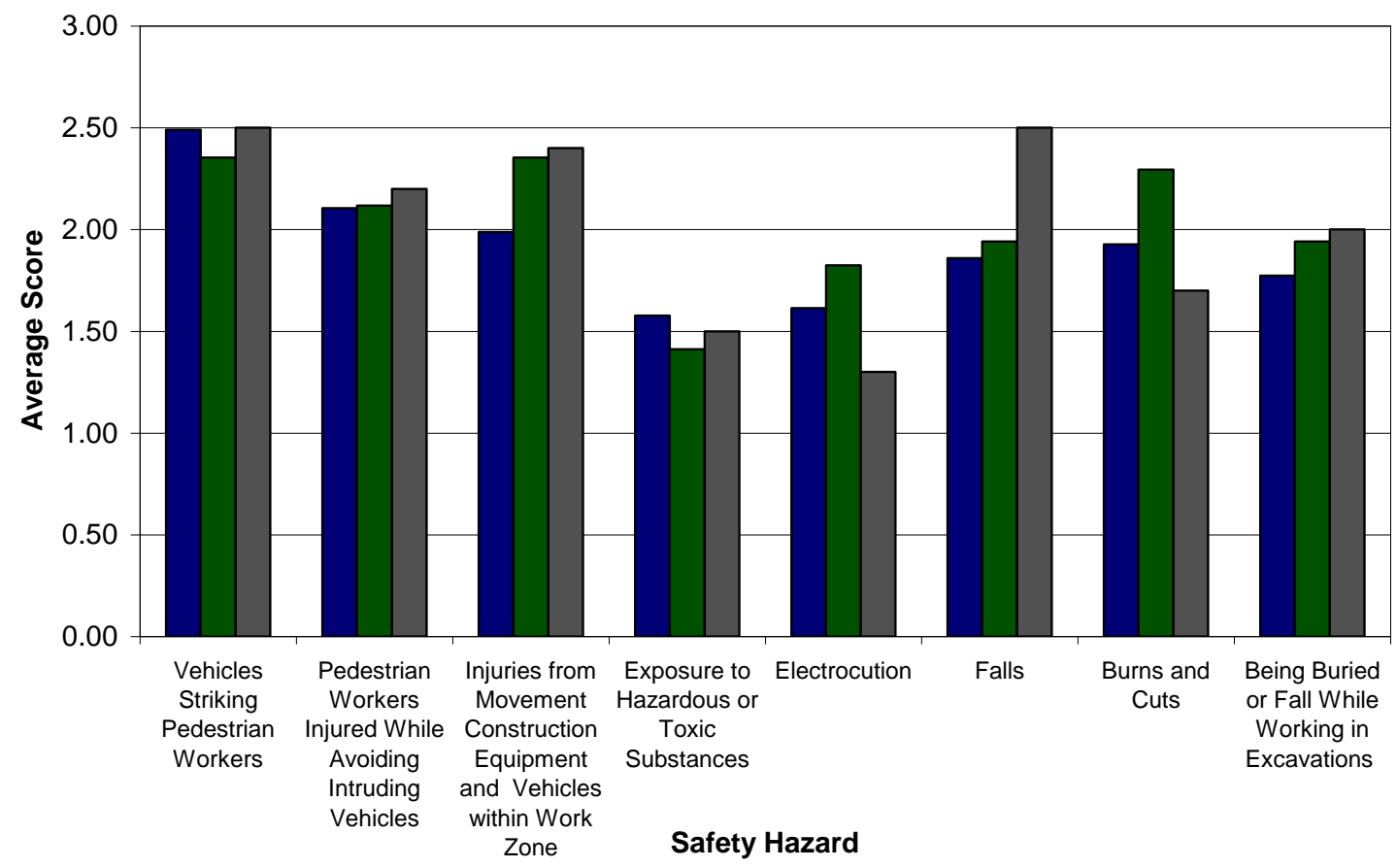

Worker $\square$ Contractor $\square$ Owner

Figure 4.6 Level of Risk of Safety Hazards in Highway Construction and Maintenance Work Zones.

Based on the three stakeholders' perspectives the hazard with the highest level of risk appeared to be vehicles striking pedestrian workers. This hazard obtained averages scores between 2.35 and 2.50, which are between the "moderate" and "high" choices in the scale of risk presented in 
the survey. This indicates that workers, as well as contractors and owners are aware of the high risk that intruding vehicles represent to workers in the work zone. Another hazard, according to the perception of the contractors, which has the same level of risk as the vehicles striking pedestrian workers, is injuries from the movement of construction equipment and vehicles within the work zone. Contractors perceive both hazards as equally dangerous for the workers, which may suggest that they would implement safety strategies with the main purpose of avoiding and minimizing both hazards.

According to the owner's perspective, another hazard that also has the same level of risk is injury from falls. This hazard showed a significantly different average score for the owner when compared with the scores of both the worker and the contractor. From the owner's perspective, the level of risk of this hazard (2.50) can be classified between "high" and "moderate." In contrast, the workers and contractors classified the level of risk for this hazard (1.86) as "moderate" and "low." This may imply that the personnel who are more directly exposed to the work zone hazards, like workers and contractors, do not perceive the risk of injury from falls as significant as the risk of injury caused by vehicles striking pedestrian workers, pedestrian workers injured while avoiding intruding vehicles, and the risk of injury from the movement of construction equipment or vehicles within the work zone.

The exposure to hazardous or toxic substances presented the lowest level of risk according to the worker and contractor. Both average scores given by these two groups showed a "moderate" to "low" level of risk for this hazard. This finding may indicate that the majority of highway construction and maintenance projects do not include tasks that would expose workers to hazardous substances. Therefore, the level of risk is perceived as lower than for other hazards. Based on the perception of the owner, the hazard with the lowest level of risk is electrocution, which showed the lowest average score (1.30) of all the safety hazards included in the survey. These findings indicate that the perspectives of the three stakeholders groups did not vary significantly when identifying the safety hazard that represents the highest level of risk for the worker. However, the perception can vary when identifying the hazard with lowest level of risk, particularly when comparing both the worker and contractor perspectives with that of the owner. 
Vehicles striking pedestrian workers was rated at the highest level of risk by all three groups that participated in this study. This hazard was also perceived as having the highest occurrence by workers and the contractors. This finding matches the statistics for the fatalities caused by mobile equipment, which indicates that the highest number of fatalities in work zones are caused by vehicle intrusions. However, based on the perception of the owner, falls have highest occurrence, which the owner also believed presents one of the highest levels of risk for the worker. This result indicates that in this case there is also a difference between the perception of the owner and the worker and contractor. The average scores for the occurrence of each safety hazard, based on the worker, contractor, and owner perspectives are shown in Figure 4.7.

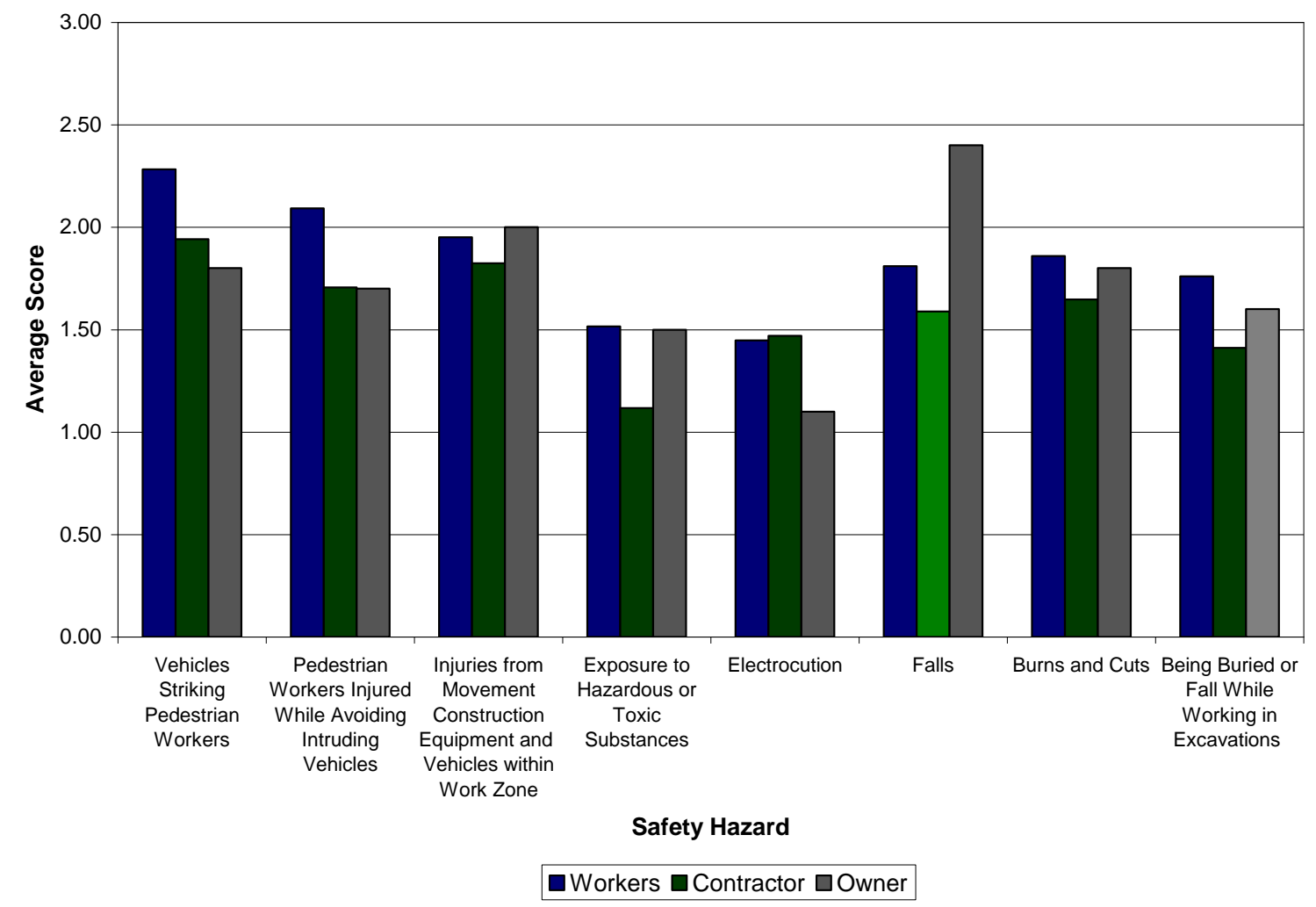

Figure 4.7 Occurrence of Safety Hazards in Highway Construction and Maintenance Work Zones.

The hazard of electrocution was perceived by both the worker and the owner as having the least occurrence. The average scores for this hazard were close to the "low" level of risk category presented in the survey. On the other hand, the contractor perceived the hazard caused by the 
exposure to hazardous or toxic substances as having both the lowest occurrence, as well as, the lowest level of risk.

\subsubsection{Effectiveness of Administrative Safety Strategies}

As discussed in Section 2.3, work zone safety strategies were divided into five main categories: administrative (initiated by the owner), traffic control, measures to improve safety in the work zone, innovative technologies for hazard control, and nighttime traffic control. The workers, contractors, and owners were asked in the surveys to assess the effectiveness of the currently used safety strategies by rating them on a five-point scale (1 signifying a poor level of effectiveness, to 5 signifying an excellent level of effectiveness). The average scores for each of the analyzed safety strategies in this category are shown in Figure 4.8.

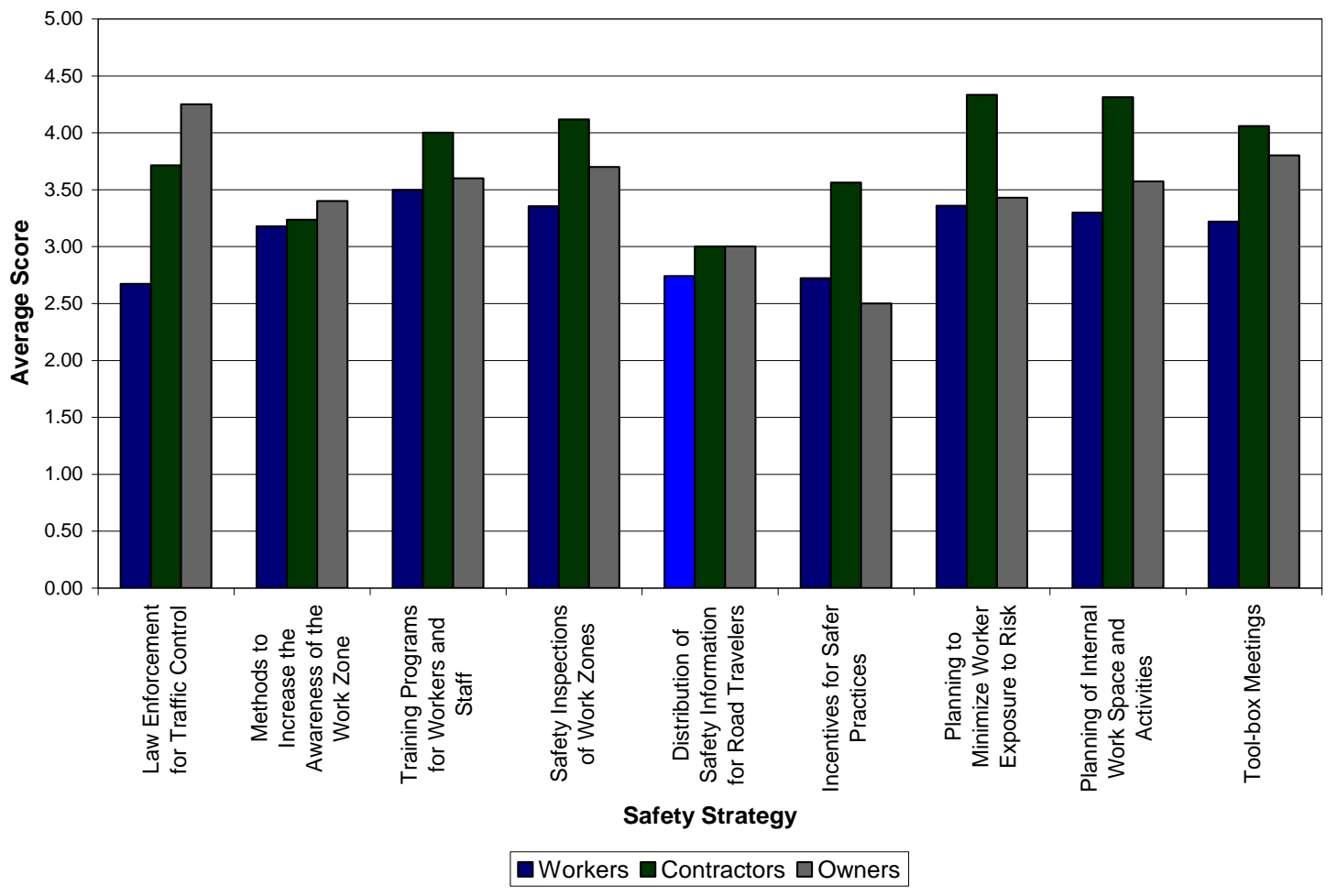

Figure 4.8 Effectiveness Ratings of Administrative Safety Strategies 
The training for workers and staff from the worker perspective is the most effective safety strategy in this category. This strategy obtained an average score of 3.50, which is between the "average" and "good" choices presented in the survey.

According to the contractors, the most effective safety strategy in this category is the planning to minimize worker exposure to risk. This strategy obtained the highest effectiveness ratings (4.33) across all the strategies analyzed in this category. This finding may indicate that contractors are implementing this type of planning on their projects and are obtaining successful results in the prevention of worker injuries and fatalities.

As shown in various previous studies (Burgess 2006, Miller 2007) the use of law enforcement was perceived by the owners as the most effective administrative strategy. In contrast, workers perceived this strategy as the least effective one in this category. Although in previous studies this strategy was considered as highly effective by workers and owners, in this survey many respondents (workers and contractors) commented that it is not frequently or never used, and is therefore not as effective. Some contractors also commented that contracting agencies should increase the use of law enforcement, especially on projects with high traffic flow. The lowest rated administrative strategy according to the contractor is the distribution of safety information to road travelers, with an average score of 3 . However, the owner indicated that the least effective safety strategy is the use of incentives for safer practices, which are used by $88 \%$ of the contractors that participated in this study. Typically, construction personnel who have worked on projects which have used law enforcement for traffic control, report that this administrative strategy is very effective. However, law enforcement is not used on all work zone projects. Hence, some construction personnel (who have not experienced the use of this strategy) would have ranked this strategy not as 'high' in effectiveness as some of the other strategies (for instance, tool-box meetings, training programs).

When comparing the effectiveness ratings given by the three groups, we observe that the average scores given by the workers are significantly lower (between 3.50 and 2.67) than the scores based on the contractors and owners perspective. This means that workers do not consider the effectiveness of any of these strategies as "good" or "excellent". 


\subsubsection{Effectiveness of Traffic Control Strategies}

The effectiveness of several traffic control strategies identified through the site visits and literature review was assessed in a similar way to the administrative safety strategies. Figure 4.9 shows the effectiveness ratings for the safety strategies included in this category according to the perception of the workers, contractors, and owners.

The perception of the effectiveness of the strategies included in this category varies among the groups that participated in this study. For instance, the workers perceived the most effective traffic control measure is the use of warning signs with an average score of 3.49. The use of flaggers is the most effective strategy according to the contractors with a higher effectiveness rating (3.82) than the warning signs. However, the highest effectiveness rating (4.00) was given for the use of signals, which according to the owners is the most effective strategy in this category.

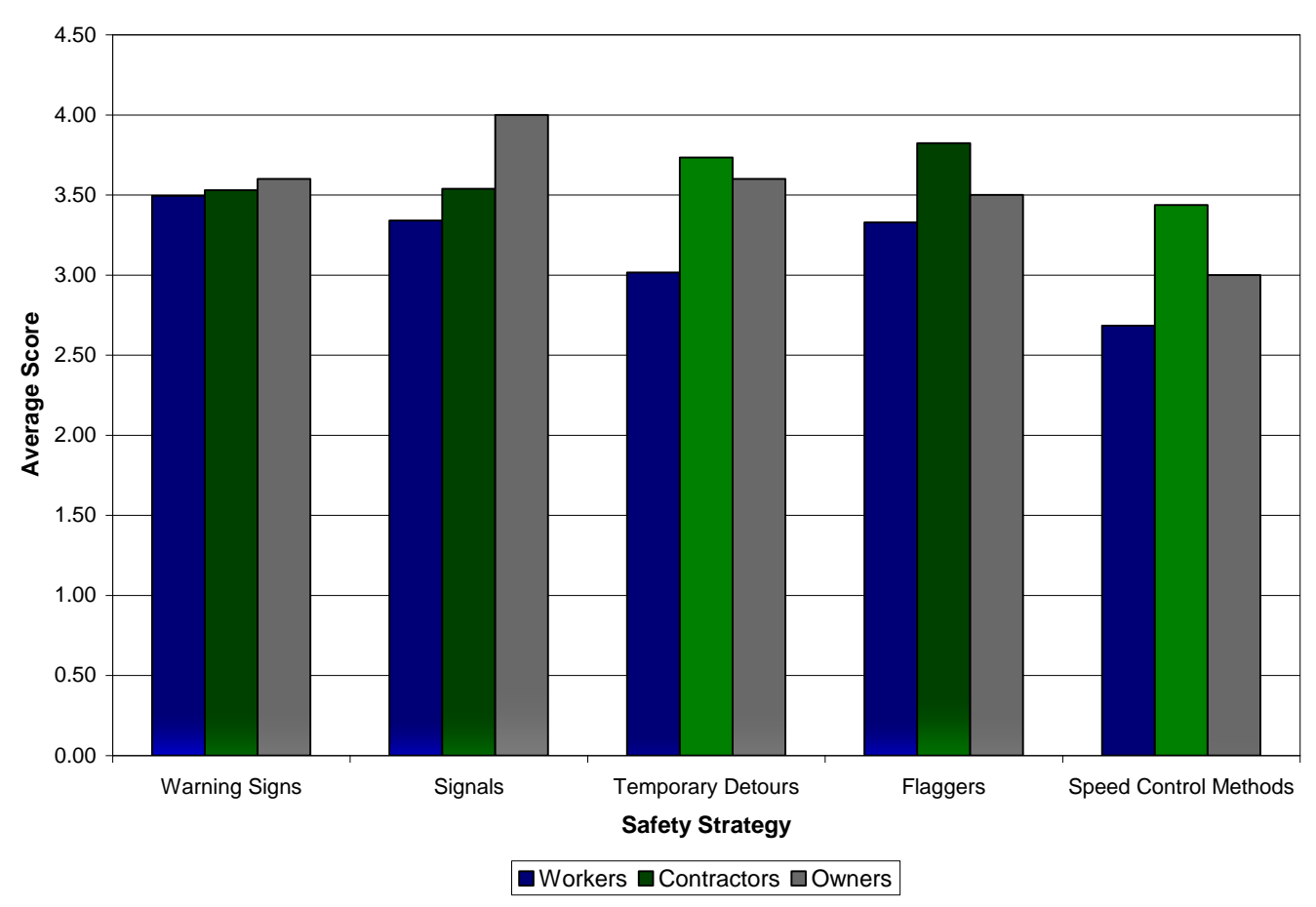

Figure 4.9 Effectiveness Ratings of Traffic Control Strategies

The use of speed control methods was considered by workers and owners as the least effective strategy for traffic control. The use of warning signs, which as previously mentioned was the 
most effective strategy according to the workers, appears to be the least effective according to the contractors. Although it was the lowest rated by this group, its average score was higher than the score given by the workers, which was the highest for this group. As in the administrative strategies category, in this case the effectiveness ratings given by the workers were lower than those given by either the contractors or owners. In addition, similar to the administrative strategies category, the contractors gave highest overall effectiveness ratings in this category. This indicates that contractors and owners rely more on both, administrative and traffic control safety strategies than the workers. This also may indicate that the workers constant exposure to safety hazards on the work zone, may affect their perception of effectiveness of the safety strategies in the administrative and traffic control categories.

In addition to the effectiveness ratings for the traffic control strategies, the workers were asked to indicate which are the most commonly-used type of warnings signs. As shown in Figure 4.10, these include arrow panels, followed by state regulation signs and warning vehicles.

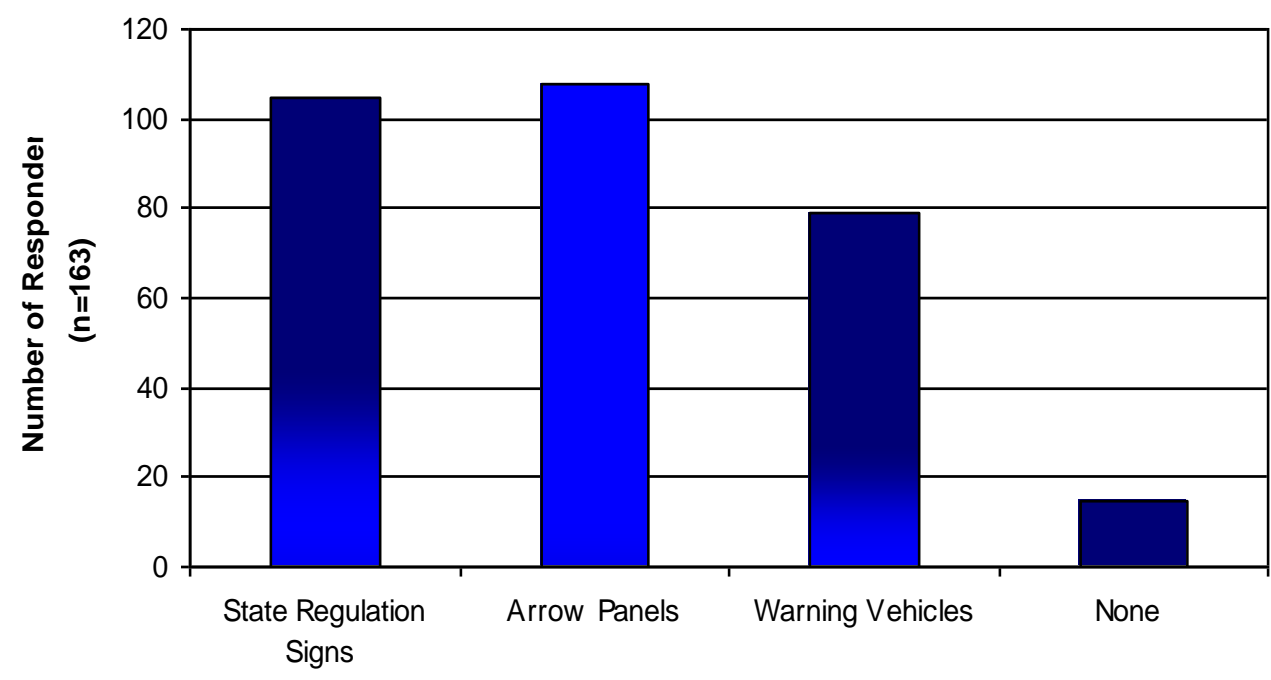

Type of Warning Signs

Figure 4.10 Currently-Used Speed Warning Signs in Construction and Maintenance Projects

\subsubsection{Effectiveness of Measures to Improve Safety in the Work Zone}

The effectiveness ratings of the measures to improve safety in the work zone were based on the same five-point scale (1 signifying a poor level of effectiveness, to 5 signifying an excellent level 
of effectiveness) used in the previously discussed categories. Figure 4.11 shows the strategies included in this category and their effectiveness ratings.

The majority of the workers stated that the use of worker safety apparel was the most effective strategy in this category. Worker safety apparel was found to be the most widely-used safety strategy on construction and maintenance job sites. Ninety eight percent of the workers indicated that they use safety vests, which appear to be the most commonly-used type of worker safety apparel, followed by hardhats, which were used by $91 \%$ of the workers who participated in the survey. Eye protection and hand protection, were used by $87 \%$ and $82 \%$, respectively. In addition, $74 \%$ of the respondents indicated that they use steel-toe boots, and only six percent reported the use of high visibility pants. The number of responses for each type of worker safety apparel is shown in Figure 4.12.

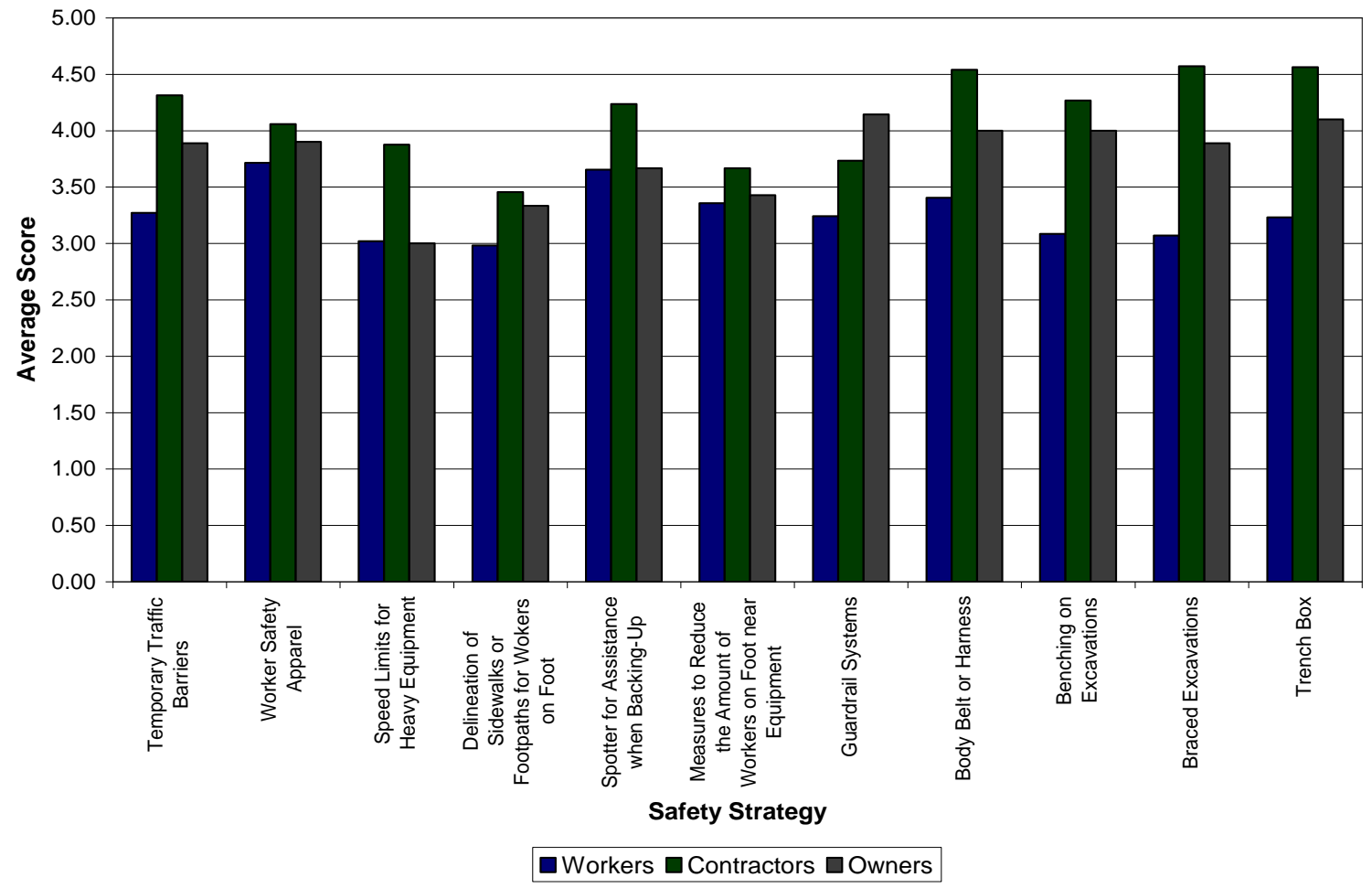

Figure 4.11 Effectiveness Ratings of Measures to Improve Safety in the Work Zone 


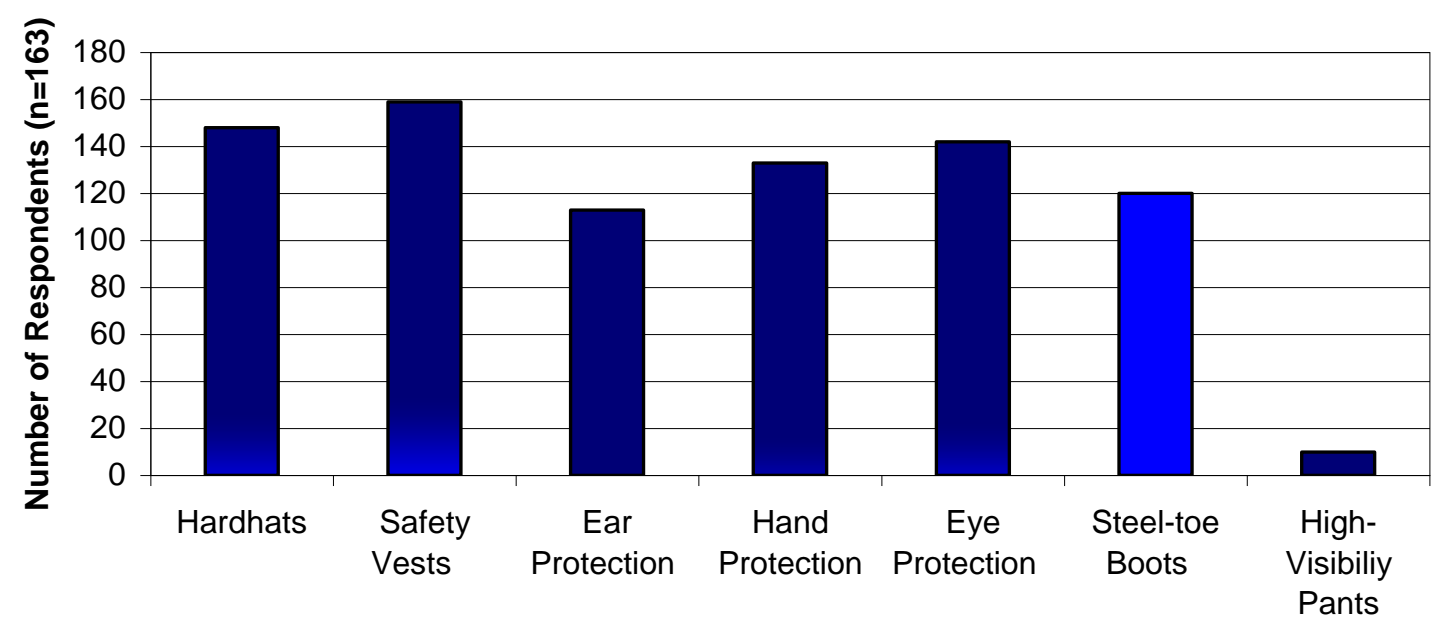

Type of Worker Safety Apparel

Figure 4.12 Currently-Used Types of Worker Safety Apparel in Construction and Maintenance Projects

Contractors believe that the most effective measure to improve safety in the work zones is the used of bracings in excavations. This strategy obtained effectiveness ratings (4.57) between "good" and excellent" which may indicate that contractors believe that the use of effective safety measures on excavations can improve the fatality and injury prevention in the work zone. This can also be observed through the effectiveness ratings of the trench boxes on excavations, which similar to the use of bracings on excavations, obtained the highest overall effectiveness ratings in this category.

The use of guardrail systems was the highest rated strategy in this category by the owners. This effectiveness rating can be related to the safety hazards ratings of injury by falls given by owners. According to the hazards ratings the owners appear to be concerned about high level of risk and occurrence of the hazard of injury by falls, which could be prevented or reduced by the use of guardrail systems.

The delineation of sidewalks or footpaths for pedestrian workers is, according to both the workers and the contractors, the least effective strategy in this category. However, the majority of the respondents indicated that this strategy is not currently being used on their projects. The 
owners' lowest rated strategy was the use of speed limits for heavy equipment, which also obtained one of the lowest scores for the workers survey.

This category shows the same trend observed in the previous two categories; namely, the effectiveness ratings given by the workers are the lowest among the three groups while the contractors' ratings are the highest ones. This result may indicate that the overall level of satisfaction with the effectiveness of safety strategies is lower for the workers than for the other two groups. As in the previous two categories, the direct exposure of the workers to the safety hazards can generate an inverse impact on their perception of effectiveness.

\subsubsection{Effectiveness of Innovative Technologies for Hazard Control}

The respondents of the survey were also asked to assess the effectiveness of various innovative technologies for hazard control identified through the literature review. These technologies were rated using the same five-point effectiveness scale used on all the previously discussed categories. The average scores for each of the analyzed technologies in this category are shown in Figure 4.13.

The effectiveness perception for this category varied among the groups of respondents. Certain innovative technologies (such as removable rumble strips, and light guard raised pavement markers) are not used on all work zone projects and hence workers may not be as familiar with their use and/or effectiveness. This may be reflected in the lower ratings for some of the innovative technologies, and may have influenced the workers' perceptions of their effectiveness The use of alert systems was identified by the workers as the most effective technology in this category, which we note is the most widely used innovative technology in this category. 


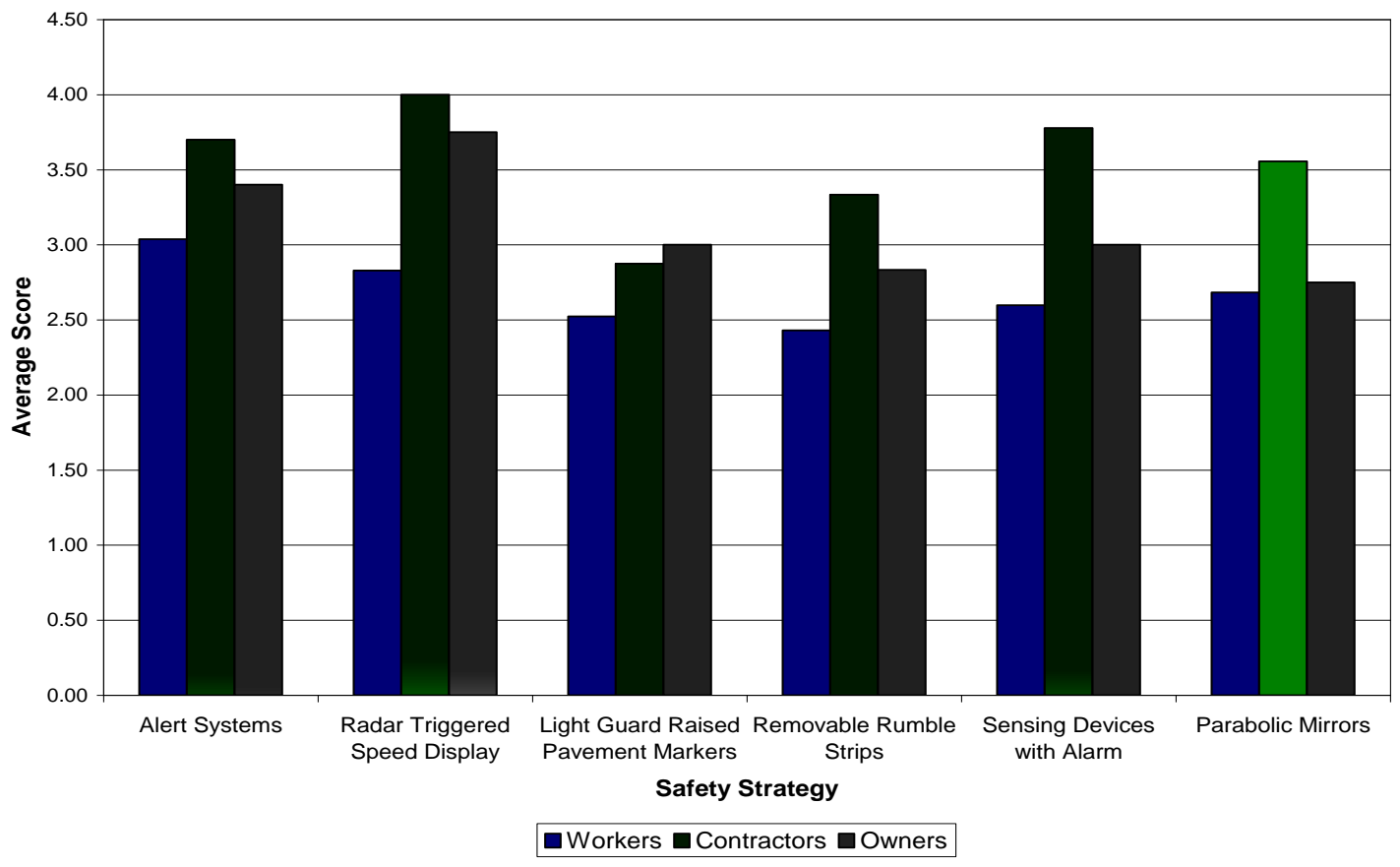

Figure 4.13 Effectiveness Ratings of Innovative Technologies for Hazard Control

Although the owners and contractors indicated that the radar triggered speed display it is not commonly used, it was ranked as the most effective technology for hazard control according to the perception of both, owners and contractors. In this same category, the strategy with the lowest effectiveness ratings according to the workers was the use of removable rumble strips, which like most of the innovative technologies included in this section, is not commonly used on the job site. The use of light guard raised pavement markers was the lowest rated technology by the contractors. The owners chose the use of parabolic mirrors as the least effective technology, although the indicated that they are not currently being used on their projects. It appears that the effectiveness ratings of these technologies were affected by whether they are currently implemented on the job site, which may indicate that if these technologies were implemented it could generate an effect on their perceived effectiveness. This category shows the same trend of the mean score observed for each group in the previous categories, where the contractor perspective always had the highest effectiveness ratings, followed by the owners and then the workers. 


\subsubsection{Effectiveness of Nighttime Traffic Control Strategies}

The last category included in the implemented survey addresses the effectiveness of nighttime traffic control strategies. As with the previous categories, these were also evaluated by the workers, contractors and owners of the construction and maintenance projects. The effectiveness ratings are shown in Figure 4.14.

According to the three stakeholder groups the most commonly-used safety strategy in this category is the use of retro-reflective clothing. Ninety-three percent of the workers, $94 \%$ of the contractors, and $90 \%$ of the owners indicated that this strategy is currently being used on their projects. This was also the most effective strategy according to all the respondents of the survey. Although their effectiveness ratings are different, this is the only category where the workers, contractors, and owners perceived the same strategy as the most effective one. The same result occurred for the lowest rated strategy, where the use of flashing lights on the body or clothing was chosen as the least effective strategy by all three groups and also as the least commonlyused. These findings may indicate that the current use of the safety strategy on the work zone may affect the perception of effectiveness.

Similar to the other four categories included in the survey, the contractors had the highest effectiveness ratings. However, in this specific case, the workers perspective showed higher effectiveness ratings than the owners, which may indicate that workers rely more on the overall effectiveness of the strategies included in this category than the owners. 


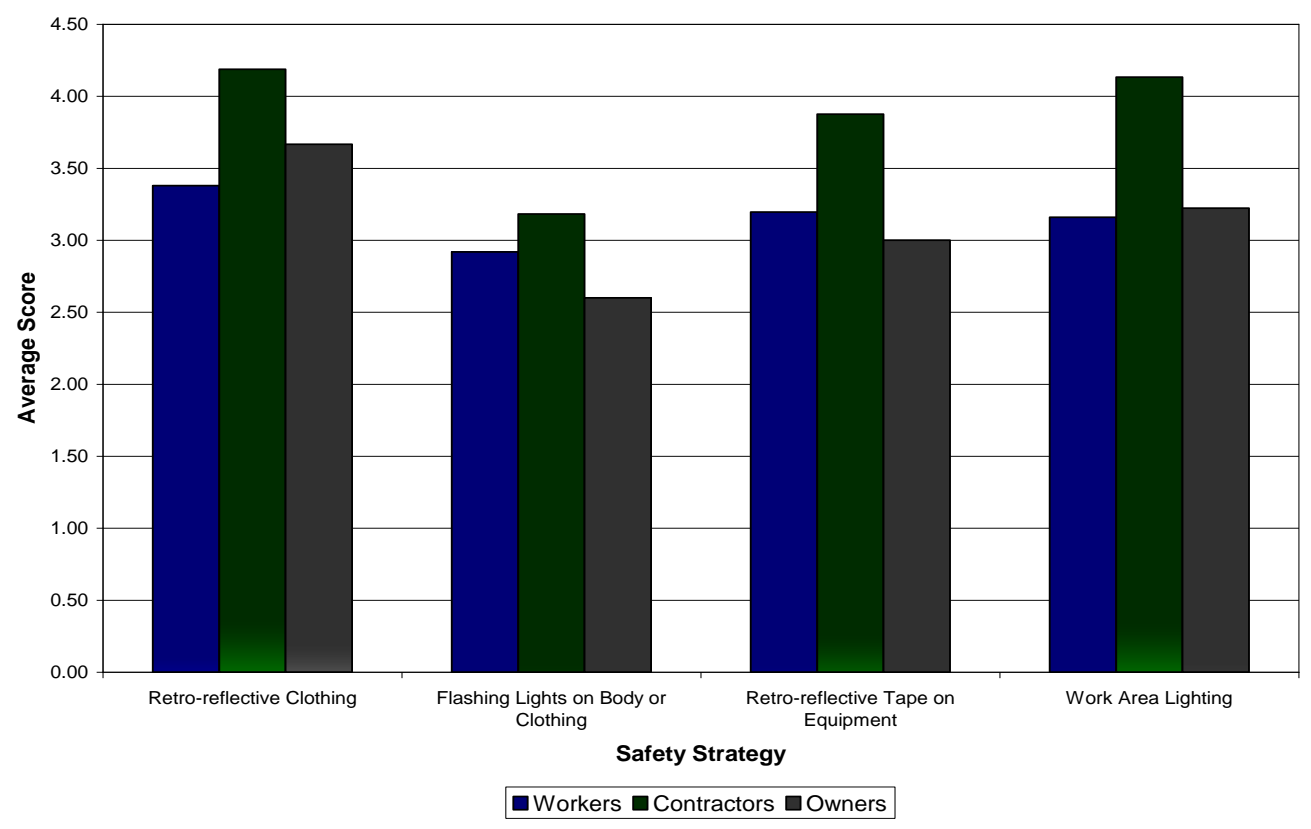

Figure 4.14 Effectiveness Ratings of Nighttime Traffic Control Strategies

\subsubsection{Summary of Results - Preliminary Analysis of Data}

Preliminary data related to the types of currently-used safety strategies and recommendations from the owners and contractors, were gathered during interviews and site visits to highway construction and maintenance job sites in the state of Indiana. This data and the literature review process led to the development of the surveys. The surveys that were implemented to the owners, contractors, and workers served as the main instrument to gather detailed data about work zone safety strategies and risks in highway construction and maintenance projects.

The surveys included various sections in which the respondents were asked provide general safety information about training, common safety hazards, and risks. The survey also included a section in which the respondents assessed the effectiveness of various safety strategies identified through the literature review and site visits. The analyzed safety strategies were classified in five main categories, which include administrative strategies, traffic control, measures to improve safety in work zones, innovative technologies for hazard control, and nighttime traffic control. These safety strategies were evaluated based on a five-point scale (1 signifying a poor level or 
effectiveness, to 5 signifying an excellent level of effectiveness). The effectiveness ratings for each of the evaluated safety strategies are shown in Table 4.4.

Table 4.4 Effectiveness Ratings for Safety Strategies Evaluated in Administered Surveys

\begin{tabular}{|c|c|c|c|c|}
\hline \multirow[b]{2}{*}{ Category } & \multirow[b]{2}{*}{ Safety Strategy } & \multicolumn{3}{|c|}{ Average Score } \\
\hline & & Worker & $\begin{array}{c}\text { General } \\
\text { Contractor }\end{array}$ & Owner \\
\hline \multirow{9}{*}{$\begin{array}{l}\text { Administrative } \\
\text { Safety Strategies }\end{array}$} & $\begin{array}{l}\text { Law Enforcement for Traffic } \\
\text { Control }\end{array}$ & 2.67 & 3.71 & 4.25 \\
\hline & $\begin{array}{l}\text { Methods to Increase the Awareness } \\
\text { of the Work Zone }\end{array}$ & 3.18 & 3.24 & 3.40 \\
\hline & $\begin{array}{l}\text { Training Programs for Workers and } \\
\text { Staff }\end{array}$ & 3.50 & 4.00 & 3.60 \\
\hline & Safety Inspections of Work Zones & 3.35 & 4.12 & 3.70 \\
\hline & $\begin{array}{l}\text { Distribution of Safety Information } \\
\text { for Road Travelers }\end{array}$ & 2.74 & 3.00 & 3.00 \\
\hline & Incentives for Safer Practices & 2.72 & 3.56 & 2.50 \\
\hline & $\begin{array}{l}\text { Planning to Minimize Worker } \\
\text { Exposure to Risk }\end{array}$ & 3.36 & 4.33 & 3.43 \\
\hline & $\begin{array}{l}\text { Planning of Internal Work Space and } \\
\text { Activities }\end{array}$ & 3.30 & 4.31 & 3.57 \\
\hline & Tool-Box Meetings & 3.22 & 4.06 & 3.80 \\
\hline \multicolumn{2}{|l|}{ Mean Score } & 3.12 & 3.81 & 3.47 \\
\hline \multirow[b]{2}{*}{ Category } & \multirow[b]{2}{*}{ Safety Strategy } & & Average Scol & \\
\hline & & Worker & $\begin{array}{c}\text { General } \\
\text { Contractor }\end{array}$ & Owner \\
\hline \multirow{5}{*}{$\begin{array}{l}\text { Traffic Control } \\
\text { Strategies }\end{array}$} & Warning Signs & 3.49 & 3.53 & 3.60 \\
\hline & Signals & 3.34 & 3.54 & 4.00 \\
\hline & Temporary Detours & 3.02 & 3.73 & 3.60 \\
\hline & Flaggers & 3.33 & 3.82 & 3.50 \\
\hline & Speed Control Methods & 2.68 & 3.44 & 3.00 \\
\hline \multicolumn{2}{|l|}{ Mean Score } & 3.17 & 3.61 & 3.54 \\
\hline
\end{tabular}




\begin{tabular}{|c|c|c|c|c|}
\hline \multirow[b]{2}{*}{ Category } & \multirow[b]{2}{*}{ Safety Strategy } & \multicolumn{3}{|c|}{ Average Score } \\
\hline & & Worker & $\begin{array}{c}\text { General } \\
\text { Contractor }\end{array}$ & Owner \\
\hline \multirow{11}{*}{$\begin{array}{l}\text { Measures to } \\
\text { Improve Safety } \\
\text { in Work Zones }\end{array}$} & Temporary Traffic Barriers & 3.27 & 4.31 & 3.89 \\
\hline & Worker Safety Apparel & 3.71 & 4.06 & 3.90 \\
\hline & Speed Limits for Heavy Equipment & 3.02 & 3.88 & 3.00 \\
\hline & $\begin{array}{l}\text { Delineation of Sidewalks or } \\
\text { Footpaths for Pedestrian Workers }\end{array}$ & 2.98 & 3.45 & 3.33 \\
\hline & Spotter for Backing-Up Assistance & 3.65 & 4.24 & 3.67 \\
\hline & $\begin{array}{l}\text { Measures to Reduce the Amount of } \\
\text { Workers on Foot Near Equipment }\end{array}$ & 3.36 & 3.67 & 3.43 \\
\hline & Guardrail Systems & 3.24 & 3.73 & 4.14 \\
\hline & Body Belt or Harness & 3.40 & 4.54 & 4.00 \\
\hline & Benching on Excavations & 3.08 & 4.27 & 4.00 \\
\hline & Braced Excavations & 3.07 & 4.57 & 3.89 \\
\hline & Trench Box for Excavations & 3.23 & 4.56 & 4.10 \\
\hline \multicolumn{2}{|l|}{ Mean Score } & 3.27 & 4.12 & 3.76 \\
\hline \multirow{6}{*}{$\begin{array}{c}\text { Innovative } \\
\text { Technologies for } \\
\text { Hazard Control }\end{array}$} & Alert Systems & 3.04 & 3.70 & 3.40 \\
\hline & Radar Triggered Speed Display & 2.83 & 4.00 & 3.75 \\
\hline & $\begin{array}{l}\text { Light Guard Raised Pavement } \\
\text { Markers }\end{array}$ & 2.52 & 2.88 & 3.00 \\
\hline & Removable Rumble Strips & 2.43 & 3.33 & 2.83 \\
\hline & Sensing Devices with Alarm & 2.60 & 3.78 & 3.00 \\
\hline & Parabolic Mirrors & 2.68 & 3.56 & 2.75 \\
\hline \multicolumn{2}{|l|}{ Mean Score } & 2.68 & 3.54 & 3.12 \\
\hline \multirow{4}{*}{$\begin{array}{c}\text { Nighttime } \\
\text { Traffic Control }\end{array}$} & Retro-Reflective Clothing & 3.38 & 4.19 & 3.67 \\
\hline & Flashing Lights on Body or Clothing & 2.92 & 3.18 & 2.60 \\
\hline & Retro-Reflective Tape on Equipment & 3.20 & 3.88 & 3.00 \\
\hline & Work Area Lighting & 3.16 & 4.13 & 3.22 \\
\hline \multicolumn{2}{|l|}{ Mean Score } & 3.16 & 3.84 & 3.12 \\
\hline
\end{tabular}

\subsubsection{Binary Logit Models with Marginal Effects}

Five Binary Logit Models were developed in order to predict the likelihood of a highway construction or maintenance worker to perceive a safety strategy as effective. This type of model is used to estimate a function that will determine the probability of a certain effectiveness rating. In the developed models, the effectiveness ratings for the safety strategies indicated by the workers were chosen as the dependent variable. The obtained data related to general safety, safety training, and demographical characteristics were used as independent variables in the models. 
For the development of the models the effectiveness scale presented in the surveys was grouped in two categories; the first category includes the effectiveness ratings from one to three (signifying poor effectiveness to average effectiveness) and from four to five (signifying good effectiveness to excellent effectiveness), as shown in Figure 4.15. The model considered two discrete outcomes denoted as (0) and (1); where (0) signifies that the effectiveness of the safety strategy was rated between poor and average, and (1) signifying that the effectiveness of the safety strategy was rated as good or excellent.

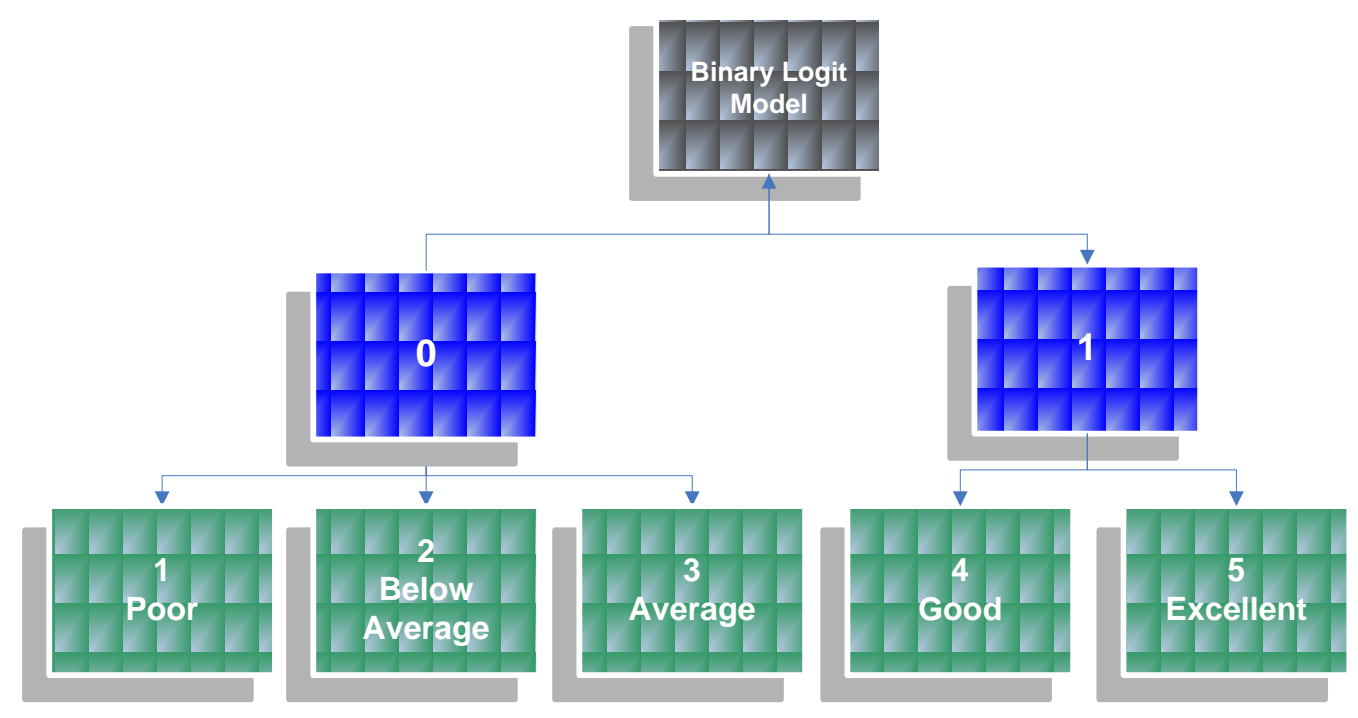

Figure 4.15 Binary Logit Model Discrete Outcomes

The choice probabilities for the two effectiveness ratings considered in this model for $n$ workers can be calculated using the following equations (Washington et al. 2003):

$$
\begin{gathered}
P(1,2,3)=\frac{e^{V_{1,2,3}}}{e^{V_{1,2,3}}+e^{V_{4,5}}} \\
P(4,5)=\frac{e^{V_{4,5}}}{e^{V_{1,2,3}}+e^{V_{4,5}}}
\end{gathered}
$$


where $\mathrm{P}(1,2,3)$ and $\mathrm{P}(4,5)$ are the probabilities that worker $n$ selects the poor to average effectiveness rating (1 to 3), and the good to excellent effectiveness rating (4 or 5), respectively, and $\mathrm{V}_{1,2,3}$ and $\mathrm{V}_{4,5}$ are the corresponding utility functions. The utility functions for equations 4.1 and 4.2 are defined as:

$$
\mathrm{V}_{i}=\beta_{i} \mathrm{X}_{\text {in }}
$$

Where $\beta_{i}$ is the vector of estimable parameters corresponding to outcome specific variables, and $\mathrm{X}_{\text {in }}$ are vectors of variables that will vary across the choices outcomes as experienced by worker n.

For the developed models this equation was simplified as shown in equations 4.4 and 4.5.

$$
\begin{aligned}
& P(4,5)=\frac{e^{\beta X}}{e^{0}+e^{\beta X}} \\
& P(4,5)=\frac{1}{1+e^{-\beta X}}
\end{aligned}
$$

The statistical models developed using Limdep software included the marginal effects for each significant independent variable. Marginal effects refer to an economic term used to measure the effect that a unit change in an independent variable has on the response variable of interest. These are indicators of how influential or significant a variable is in a particular data-generating process (Washington et al. 2003).

The data corresponding to the variables included in the analysis were collected through the distribution of surveys. The effectiveness rates for the analyzed safety strategies were used as the dependent variable for the creation of the statistical models. Other variables that include general safety information, safety training information, and demographic information for the respondents were used as independent variables. Table 4.5 shows the variables considered in the development of the Binary Logit Models for each category of safety strategies. 
Table 4.5 Variables Considered in the Statistical Model Development

\begin{tabular}{|c|c|c|c|c|}
\hline Variable & Symbol & Mean & $\begin{array}{l}\text { Standard } \\
\text { Deviation }\end{array}$ & $\begin{array}{l}\operatorname{Max} / \\
\text { Min }\end{array}$ \\
\hline \multicolumn{5}{|l|}{ Dependent Variables } \\
\hline $\begin{array}{l}\text { Effectiveness ratings for training for workers and } \\
\text { staff }\end{array}$ & eftrain & 3.50 & 1.11 & $5 / 1$ \\
\hline Effectiveness ratings for warning signs & efwarn & 3.49 & 1.11 & $5 / 1$ \\
\hline Effectiveness ratings for worker safety apparel & efworap & 3.71 & 0.99 & $5 / 1$ \\
\hline Effectiveness ratings for alert systems & efalert & 3.04 & 1.20 & $5 / 1$ \\
\hline Effectiveness ratings for retro-reflective clothing & efretro & 3.38 & 1.19 & $5 / 1$ \\
\hline \multicolumn{5}{|l|}{ Independent Variables } \\
\hline \multicolumn{5}{|l|}{$\begin{array}{l}\text { If the strategy is currently-used on the project } \\
\text { ( } 1 \text { if yes, } 0 \text { otherwise })\end{array}$} \\
\hline a. Training for workers and staff & ustrain & 0.91 & 0.28 & $1 / 0$ \\
\hline b. Warning signs & uswran & 0.96 & 0.19 & $1 / 0$ \\
\hline c. Worker safety apparel & usworap & 0.99 & 0.11 & $1 / 0$ \\
\hline d. Alert systems & usalert & 0.46 & 0.50 & $1 / 0$ \\
\hline e. Retro-reflective clothing & usretro & 0.94 & 0.23 & $1 / 0$ \\
\hline $\begin{array}{l}\text { Staffing of the project includes a person } \\
\text { responsible for project safety aspects } \\
\text { ( } 1 \text { if yes, } 0 \text { otherwise })\end{array}$ & safepers & 0.79 & 0.41 & $1 / 0$ \\
\hline $\begin{array}{l}\text { Safety training activities undertaken by worker } \\
\text { (10= OSHA- } 10 \mathrm{hr}, 30=\text { OSHA- } 30 \mathrm{hr}, 1=\text { None, } 2= \\
\text { Other) }\end{array}$ & train & 6.48 & 7.80 & $30 / 1$ \\
\hline \multicolumn{5}{|l|}{$\begin{array}{l}\text { Factors in evaluating the effectiveness of a safety } \\
\text { strategy } \\
\text { ( } 1=\text { poor, } 2=\text { below average, } 3=\text { average, } 4= \\
\text { good, and } 5=\text { excellent) }\end{array}$} \\
\hline a. Easy implementation & easy & 4.15 & 1.01 & $5 / 1$ \\
\hline b. Implementation time & time & 4.10 & 1.02 & $5 / 1$ \\
\hline c. Cost & cost & 3.31 & 1.38 & $5 / 1$ \\
\hline d. Success in injury prevention & injprev & 4.61 & 0.78 & $5 / 1$ \\
\hline e. Sense of security & secsen & 4.54 & 0.79 & $5 / 1$ \\
\hline $\begin{array}{l}\text { f. Does not prompt the worker to take } \\
\text { unnecessary risks }\end{array}$ & norisk & 4.19 & 1.17 & $5 / 1$ \\
\hline
\end{tabular}




\begin{tabular}{|c|c|c|c|c|}
\hline g. Allows unrestricted movement & movem & 3.95 & 1.13 & $5 / 1$ \\
\hline Variable & Symbol & Mean & $\begin{array}{l}\text { Standard } \\
\text { Deviation }\end{array}$ & $\begin{array}{l}\text { Max/ } \\
\text { Min }\end{array}$ \\
\hline h. Protection from intruding vehicle & intveh & 4.56 & 0.86 & $5 / 1$ \\
\hline $\begin{array}{l}\text { i. Protection from hazards that arise from } \\
\text { construction operations }\end{array}$ & prothaz & 4.54 & 0.83 & $5 / 1$ \\
\hline $\begin{array}{l}\text { Frequency of safety meetings } \\
(1=\text { daily, } 2=\text { weekly, } 3=\text { bi-weekly, } \\
\text { monthly, } 5=\text { never, } 6=\text { other })\end{array}$ & freqmet & 2.95 & 1.84 & $6 / 1$ \\
\hline $\begin{array}{l}\text { If the worker received safety training when hired } \\
\text { ( } 1 \text { if yes, } 0 \text { otherwise) }\end{array}$ & trhired & 0.85 & 0.36 & $1 / 0$ \\
\hline $\begin{array}{l}\text { If the worker receives on-going training on safety } \\
\text { strategies } \\
\text { otherwise) }\end{array}$ & ongtrain & 0.83 & 0.38 & $1 / 0$ \\
\hline $\begin{array}{l}\text { Frequency of on-going training on safety } \\
\text { strategies } \\
(1=\text { daily, } 2=\text { weekly, } 3=\text { bi-weekly, } \\
\text { monthly, } 5=\text { never, } 6=\text { other })\end{array}$ & freqtrain & 1.54 & 2.04 & $6 / 1$ \\
\hline $\begin{array}{l}\text { Age of worker } \\
(1=\text { younger than } 18,2=18-30,3=31-40,4=41- \\
50,5=51-60,6=\text { older than } 60)\end{array}$ & agework & 3.45 & 1.21 & $6 / 1$ \\
\hline $\begin{array}{l}\text { Gender of worker } \\
(1=\text { male, } 0=\text { female })\end{array}$ & gender & 0.92 & 0.27 & $1 / 0$ \\
\hline Years of experience & yexp & 12.58 & 9.66 & $40 / 0$ \\
\hline $\begin{array}{l}\text { Number of highway projects that the worker has } \\
\text { worked }\end{array}$ & numproj & 11.33 & 15.24 & $100 / 1$ \\
\hline $\begin{array}{l}\text { Type of project in which worker works most } \\
\text { frequently } \\
\text { ( } 1=\text { construction, } 0=\text { maintenance })\end{array}$ & proj & 0.32 & 0.47 & $1 / 0$ \\
\hline $\begin{array}{l}\text { Type of worker } \\
(1=\text { INDOT, } 0=\text { Contractor })\end{array}$ & worker & 0.79 & 0.41 & $1 / 0$ \\
\hline
\end{tabular}

The statistical significance of the variables used in the Binary Logit Models will be approximated using a one-tailed t-test. The t-statistic is calculated in order to determine if the estimated parameter is significantly different from zero (Washington et al. 2003):

$$
t=\frac{\beta-0}{S E(\beta)}
$$


Where S.E. $(\beta)$ is the standard error of the parameter, and $\beta$ is the vector of estimable parameters corresponding to outcome specific variables. Critical values for the t-statistic can be found in Table C.2 in Statistical and Econometric Methods for Transportation Data Analysis by Washington, Karlaftis, and Mannering (2003). Using the calculated t-statistic, the confidence level for a one-tailed t-test for each variable can be obtained from Table C.2, where a value higher than 1.282 will indicate that the variable is over the $90 \%$ confidence level for a one-tailed t-test. If the obtained t-statistic for the variable is above this value there is a $90 \%$ confidence that the estimated parameter should be included in the model due to its statistical significance.

The likelihood ratio test will be used to evaluate the overall significance of the five developed models. The likelihood ratio test statistic is (Washington et. al 2003):

$$
X^{2}=2 L L\left(\beta_{R}\right)-L L\left(\beta_{U}\right)
$$

where $\operatorname{LL}\left(\beta_{R}\right)$ is the log likelihood at convergence of the restricted model $\left(\beta_{R}=0\right)$, and $\operatorname{LL}\left(\beta_{U}\right)$ is the log likelihood at convergence of the unrestricted model $\left(\beta_{U}=\beta\right)$. The $X^{2}$ is distributed with degrees of freedom equal to the difference in the number of parameters between the restricted and unrestricted models. Critical values of $X^{2}$, to determine the overall significance level of the models can be found in Table C.3 in the text Statistical and Econometric Methods for Transportation Data Analysis by Washington, Karlaftis, and Mannering (2003).

\subsubsection{Binary Logit Model for Administrative Safety Strategies}

The highest rated administrative safety strategy according to the perception of the construction and maintenance workers who participated in the study was the use of training programs for workers and staff. In the development of the Binary Logit model for this strategy, variables such as the type of project on which the respondent works most frequently, the type of worker, whether or not the staffing of the project includes a person who is responsible for safety, the years of experience and age of the worker were found to significantly affect the effectiveness ratings given by the workers. According to the one-tailed t-test, each of the variables included in 
this model are significantly different from zero and over the $90 \%$ confidence level. The Binary Logit Model results are presented in Table 4.6.

Table 4.6 Effectiveness of Training for Workers and Staff: Binary Logit Model

\begin{tabular}{lccc}
\hline \multicolumn{1}{c}{ Variable } & Symbol & $\begin{array}{c}\text { Estimated } \\
\text { Coefficient }(\boldsymbol{\beta})\end{array}$ & t-Statistic $^{\mathbf{1}}$ \\
\hline Constant & & -0.0233 & -0.038 \\
Staffing of the project includes a person & safepers & 0.5385 & $1.296^{*}$ \\
$\begin{array}{l}\text { responsible for project safety aspects } \\
\text { (1 if yes, 0 if no) }\end{array}$ & & & \\
Years of experience of worker & expwork & 0.0465 & $2.315^{*}$ \\
Age of worker & agework & -0.2099 & $-1.345^{*}$ \\
Construction worker & conwork & -0.6982 & $-1.448^{*}$ \\
Construction company worker & contract & 0.7370 & $1.315^{*}$ \\
\hline Number of observations & & & 163 \\
Log-likelihood function LL(0) & & & -112.4640 \\
Restricted Log-likelihood LL( $\beta)$ & & & -107.6656 \\
Chi-squared & & & 9.5969 \\
\hline
\end{tabular}

${ }^{1}$ One-tailed t-test results: * significantly different from zero at more than $90 \%$ confidence level

The likelihood ratio test of the overall significance of the model was determined to be over the $90 \%$ confidence level, which essentially confirms that the estimated parameters in the model affect the effectiveness ratings in a significant way. This model shows that the variable safepers, which represents the project on which the staffing includes the designation of a person who is in charge of the safety aspects in the project, generates an increment in the amount of workers that rate the safety training as highly effective ( 4 or 5 on the effectiveness scale). This finding may indicate that the presence of a person who is in charge of safety in the project can enforce and improve the effectiveness of the current training programs for workers and staff. The estimated marginal effects of this parameter, shown in Table 4.7, indicate that the presence of a person responsible for safety in a project would generate a 0.13 increment in the probability of a worker perceiving the training programs as highly effective.

The most significant variable in this model due to its strong t-statistic (2.315) appeared to be expwork, which represents the years of experience of the worker. This model predicted that workers with more experience level, probably have undertaken more training are more likely to recognize their effectiveness. The obtained marginal effects for this parameter indicate that a 
one-year increase in the experience of the worker would cause a 0.011 increment in the probability of a worker perceiving the training programs as highly effective.

Another variable that appeared to be directly related to the probability of a worker perceiving the training for workers and staff as highly effective was contract, which represents the worker from a construction company. This finding may indicate that the training programs for workers and staff used by construction companies may be more effective than the training programs used by INDOT. It may be beneficial to INDOT to explore the content of the safety training materials used by contractors, and the frequency of the training, to determine if good practices could be adopted and/or adapted into INDOT safety training programs. This model predicted that the contractors' workers with more years of work experience on projects where the staffing included the designation of a person responsible for safety were more likely to perceive the training programs as highly effective.

Other parameters estimated in the model include agework and conwork, which represent the age of the worker and the workers who work most frequently on construction projects, respectively. These two parameters showed an inverse relationship with the effectiveness perceived by the workers of the safety training programs. This model predicted that as workers age and work more frequently in construction projects, they tend to perceive training programs as less effective. This finding may indicate that some older construction workers may become accustomed to the safety measures used on a job site and believe they do not need additional training, creating the perception that it will not improve safety in the work zone.

Table 4.7 Marginal Effects for the Effectiveness of Training for Workers and Staff: Binary Logit Model

\begin{tabular}{lcc}
\hline & Symbol & Marginal Effects \\
\hline Constant & -0.0058 \\
safepers & 0.1337 \\
expwork & 0.0115 \\
agework & -0.0521 \\
conwork & -0.1733 \\
contract & 0.1830 \\
\hline
\end{tabular}


The choice probability for the high effectiveness rating (4 or 5 on the effectiveness scale) considered in this model for 163 workers is shown in the following equation:

$$
P(4,5)=\frac{1}{1+e^{0.023-0.539(\text { safepers })-0.047(\text { exp work })+0.220(\text { agework })+0.700(\text { conwork })-0.737(\text { contract })}}
$$

The probability of the workers rating the training for workers and staff as average or below (between the 1 and 3 choices on the scale of effectiveness) can be obtained by subtracting one minus the probability for the high effectiveness rating $(\mathrm{P}(4,5))$.

\subsubsection{Binary Logit Model for Traffic Control Strategies}

A Binary Logit Model was developed to predict which factors significantly affect the perceived effectiveness of warning signs, as well as the probability of a worker perceiving this strategy as highly effective. The estimated parameters included in this model, shown in Table 4.8, appeared to be significant at more than an $85 \%$ confidence level. The chi-squared for this model of 8.0629 obtained from the likelihood ratio test was over the $90 \%$ confidence level, which confirms that the estimated parameters in the model affect the effectiveness ratings of the warning signs in a significant way.

Table 4.8 Effectiveness of Warning Signs: Binary Logit Model

\begin{tabular}{|c|c|c|c|}
\hline Variable & Symbol & $\begin{array}{c}\text { Estimated } \\
\text { Coefficient } \\
(\beta)\end{array}$ & t-Statistic ${ }^{1}$ \\
\hline Constant & & -0.0567 & -0.086 \\
\hline $\begin{array}{l}\text { Currently- used safety strategy } \\
\text { ( } 1 \text { if yes, } 0 \text { if no) }\end{array}$ & used & -0.6980 & $-1.168 * *$ \\
\hline Workers who received training when hired & trhired & 0.6558 & $1.387^{*}$ \\
\hline Construction worker & conwork & 0.9903 & $2.005^{*}$ \\
\hline Construction company worker & contract & -0.7209 & $-1.275^{*}$ \\
\hline Number of observations & & & 163 \\
\hline Log-likelihood function LL(0) & & & -112.9063 \\
\hline Restricted Log-likelihood LL $(\beta)$ & & & -108.8748 \\
\hline Chi-squared & & & 8.0629 \\
\hline
\end{tabular}


The variable used, represents the projects on which the warning signs are currently being used. This parameter showed that on projects where warning signs are currently used, the workers were found to be less likely to rate its use as highly effective. This finding may indicate that the more the warning signs are used in the project site, their effectiveness tends to be underestimated by the workers. The predicted marginal effects of this parameter, shown in Table 4.9, indicate that when warning signs are used, there is a 0.17 decrease in the probability of a worker perceiving them as highly effective. Contrary to previous perceptions (initial surveys conducted in this study), in general, workers may not regard warning signs as being highly effective in improving safety awareness. However, the workers who had received safety training were able to better comprehend the role of warning signs and their limitations, and hence considered them to be highly effective when used appropriately. This points to the need for early and continuous safety training for workers to more effectively educate them on the role of different safety strategies.

Other estimated parameters in this model were, trhired and conwork, which represent the workers who received safety training when hired and the workers who work in construction projects most frequently, respectively. Both variables showed a direct relationship with the effectiveness of warning signs based on the worker's perception. These finding may indicate that the training that workers are provided when hired gives the workers information that can lead them to understand the effectiveness of the warning signs. Also, it may indicate that construction workers, who typically work on the same project site for greater time periods than maintenance workers, may perceive the warning signs' long-term effectiveness by warning the drivers of unusual or potentially hazardous roadway conditions. The marginal effects for these two parameters are shown in Table 4.5, where the most significant effect is the increase of 0.25 in the probability of a worker perceiving the warning signs as highly effective. This model predicted that construction workers who received safety training when hired are more likely to perceive the use of warning signs as a highly effective safety strategy.

The last variable included in this model is contract, which similar to the model for the training for workers and staff, represents the worker from a construction company. In contrast to the previous model, this parameter shows an inverse relationship with the effectiveness ratings, 
which means that the contractors' workers are less likely to perceive the use of warning signs as highly effective. This finding may indicate that construction companies may be using more traffic control strategies than INDOT, which can be perceived by the workers as more effective. The surveys included both maintenance and construction workers: a few maintenance workers had also worked for contractors who provided traffic control for INDOT. Thus, the responses reflect not just the perceptions based on their experience as INDOT maintenance workers, but also their experiences with contractors. For maintenance projects undertaken by INDOT, traffic control is provided by INDOT. For construction projects undertaken by INDOT, traffic control is provided by the contractor. Since maintenance work is temporary and is typically mobile, extensive traffic control setups are not required, making maintenance operations inherently less safe. These factors could also have contributed to the results obtained in the analysis.

Table 4.9 Marginal Effects for the Effectiveness of Warning Signs: Binary Logit Model

\begin{tabular}{|c|c|}
\hline Symbol & Marginal Effects \\
\hline $\begin{array}{l}\text { Constant } \\
\text { used } \\
\text { trhired } \\
\text { conwork } \\
\text { contract }\end{array}$ & $\begin{array}{r}-0.0142 \\
-0.1743 \\
0.1637 \\
0.2473 \\
-0.1800\end{array}$ \\
\hline
\end{tabular}

The equation to calculate the choice probability for the high effectiveness rating ( 4 or 5 choices on the effectiveness scale) for this strategy for 163 workers is the following:

$$
P(4,5)=\frac{1}{1+e^{0.057+0.698(\text { used })-0.656(\text { trhired })-0.990(\text { conwork })+0.721(\text { contract })}}
$$

\subsubsection{Binary Logit Model for Measures to Improve Safety in the Work Zone}

As previously discussed the highest rated safety strategy by the workers in the category that includes the measures to improve safety within the work zone was the use of worker safety apparel. The results of the statistical model developed for this strategy, as well as the significant estimated parameters are shown in Table 4.10. As in the previous models, the estimated parameters included in this model were proven by the one-tailed t-test to have a significant effect 
on the effectiveness ratings of the worker safety apparel. Similar to other models, the loglikelihood ratio test was also performed, obtaining a $99.95 \%$ confidence level of the overall significance, which is the highest of all five models.

Table 4.10 Effectiveness of Worker Safety Apparel: Binary Logit Model

\begin{tabular}{|c|c|c|c|}
\hline Variable & Symbol & $\begin{array}{c}\text { Estimated } \\
\text { Coefficient } \\
(\beta)\end{array}$ & t-Statistic ${ }^{1}$ \\
\hline Constant & & -1.3280 & $-2.742 *$ \\
\hline $\begin{array}{l}\text { Staffing of the project includes a person } \\
\text { responsible for project safety aspects } \\
(1 \text { if yes, } 0 \text { if no) }\end{array}$ & safepers & 0.6297 & $1.386^{*}$ \\
\hline $\begin{array}{l}\text { Worker who received OSHA-10 hr or } \\
\text { OSHA-30 hr training }\end{array}$ & train & 0.4677 & $1.284 *$ \\
\hline $\begin{array}{l}\text { Worker who receive on-going training on safety } \\
\text { practices }\end{array}$ & ongtrain & 0.9652 & $1.962 *$ \\
\hline $\begin{array}{l}\text { Worker who have worked in more than } 10 \\
\text { highway projects }\end{array}$ & highnum & 0.7652 & $1.451 *$ \\
\hline Construction worker & conwork & 0.5358 & $1.428 *$ \\
\hline Number of observations & & & 163 \\
\hline Log-likelihood function LL(0) & & & -109.3446 \\
\hline Restricted Log-likelihood LL $(\beta)$ & & & -98.5236 \\
\hline Chi-squared & & & 21.3446 \\
\hline
\end{tabular}

The saferpers variable included in the model was also estimated in the previous model developed for the training for workers and staff. This variable showed a direct relationship with the effectiveness ratings of the worker safety apparel, which essentially means that on projects where the staffing included a person responsible for safety, workers were more likely to perceive the analyzed strategy as highly effective. The marginal effects, shown in Table 4.11, of this parameter in this model were higher than the effects observed for the same parameter in the model developed for the training for workers and staff. This result shows that the presence of a person responsible for safety on the job site can have a greater impact on the probability of a worker perceiving the safety apparel as highly effective than on the same probability for the training programs. This finding may indicate that the presence of a person in charge of the safety aspects of the project can serve as enforcement, as well as communicate to the workers the importance of the use of the safety apparel and how effective they can be when properly used. 
The train variable, which represents the worker who had undertaken OSHA-10 hr or OSHA-30 hr safety training, has a direct relationship with the effectiveness ratings of the safety apparel based on worker perception. The most significant variable in this model (t-stat 1.962) that also shows a direct relationship with the dependent variable is ongtrain, which represents the worker who received on-going training on safety practices. Other variables that had a direct relationship with the effectiveness ratings of the worker safety apparel are highnum and conwork, which represent the worker who has worked in more than ten highway projects and those who worked most frequently in construction projects, respectively. The conwork variable was also included in the two previous models (training for workers and staff and warning signs models); however, in contrast with the first model and similar to the second one, this model shows that the variable increased the effectiveness ratings of the safety strategy. The model predicted that construction workers who have worked on more than ten highway projects, worked on projects where the staffing included a person responsible for safety, received on-going training on safety practices, and had undertaken OSHA-10 hr or OSHA-30 hr training were more likely to perceive the use of safety apparel as highly effective. This finding may indicate that the on-going safety training, as well as the OSHA-10 hr or OSHA-30 hr training can promote worker understanding of the importance of the use of safety apparel and its effectiveness. Also, as workers work on more highway projects, they may better understand how the safety apparel protects them, changing their perception about its effectiveness.

Table 4.11 Marginal Effects for the Effectiveness of Worker Safety Apparel: Binary Logit Model

\begin{tabular}{|c|c|}
\hline Symbol & Marginal Effects \\
\hline $\begin{array}{l}\text { Constant } \\
\text { safepers } \\
\text { train } \\
\text { ongtrain } \\
\text { highnum } \\
\text { conwork }\end{array}$ & $\begin{array}{c}-0.3137 \\
0.1487 \\
0.1105 \\
0.2280 \\
0.1807 \\
0.1265\end{array}$ \\
\hline
\end{tabular}

The equation to calculate the choice probability for the high effectiveness ratings ( 4 or 5 choices in the effectiveness scale) for this strategy was developed from Equation 4.5. 


$$
P(4,5)=\frac{1}{1+e^{1.328-0.630(\text { safepers })-0.468(\text { train })-0.965(\text { ongtrain })-0.765(\text { highnum })-0.536(\text { conwork })}}
$$

\subsubsection{Binary Logit Model for Innovative Technologies for Hazard Control}

Another Binary Logit Model was developed to predict the factors that affect the effectiveness ratings of alert systems on highway construction and maintenance work zones. Table 4.12 shows the results and the estimated parameters for this model. Some of the significant variables in this model, such as trhire, ongtrain, and conwork also proved to have a significant effect on the previous models. The likelihood ratio test of the overall significance of the model was determined to be between the $97.5 \%$ and $99 \%$ confidence level.

Table 4.12 Effectiveness of Alert Systems: Binary Logit Model

\begin{tabular}{|c|c|c|c|}
\hline Variable & Symbol & $\begin{array}{c}\text { Estimated } \\
\text { Coefficient } \\
(\beta) \\
\end{array}$ & t-Statistic ${ }^{1}$ \\
\hline Constant & & 0.3273 & 0.413 \\
\hline Workers who received training when hired & trhired & -1.1211 & $-2.232 *$ \\
\hline $\begin{array}{l}\text { Worker who receive on-going training on } \\
\text { safety practices }\end{array}$ & ongtrain & 1.0996 & $2.006^{*}$ \\
\hline Male worker & male & -1.2711 & $-2.039 *$ \\
\hline Construction worker & conwork & 0.7886 & $2.173 *$ \\
\hline $\begin{array}{l}\text { Number of highway projects that the worker } \\
\text { has worked }\end{array}$ & numproj & -0.0143 & $-1.051 * *$ \\
\hline Number of observations & & & 163 \\
\hline Log-likelihood function LL(0) & & & -105.5028 \\
\hline Restricted Log-likelihood LL $(\beta)$ & & & -98.3847 \\
\hline Chi-squared & & & 14.2361 \\
\hline
\end{tabular}

The trhired variable that appeared to be significant in the warning signs model is present again in this model, yet with an inverse effect to that predicted in the previous model. This model shows that the workers who received training when hired were less likely to perceive the use of alert systems as highly effective. The marginal effects, shown in Table 4.13, are opposite, yet the effects generated by this variable in this model $(-0.25)$ are higher than in the warning signs model (0.16). This result implies that the effects of this variable on the probability of a worker 
perceiving the alert systems as highly effective would be greater than that for the warning signs. This finding may indicate that the training that workers receive when hired does not necessarily address the use of innovative technologies in the same way as other safety practices, thereby affecting their perception.

Another variable included in this model that was also significant in the worker safety apparel model is ongtrain. This variable shows the same direct effect as the previous model. The marginal effects presented by this variable are similar to the ones in the worker safety apparel model. Both trhired and ongtrain appeared to be more significant in this model than in the warning signs model due to its stronger t-statistic values. The conwork variable included in this model was also significant in all three previously developed models. In contrast to the training for workers and staff model, this variable had a direct effect on the effectiveness ratings in this model. By comparing the marginal effects of this variable with the other models, it becomes apparent that the effect that a construction worker has on the probability of perceiving the alert systems as highly effective is very similar in magnitude (0.17) to the decrease it causes on the training for workers and staff model. The marginal effects of the conwork variable in this model (0.17) are lower than the effects presented in the warning signs model (0.24) and higher than the effects in the worker safety apparel model (0.13).

Other significant variables in this model that were not significant in the previous models are male and numproj. These variables represent the male worker in the highway project and the number of highway projects on which the workers has worked, respectively. Both variables showed an inverse relationship with the effectiveness ratings of the alert systems. Although, only seven percent of the respondents were female, the main cause of this impact could have been the presence of unobserved factors among the respondents not considered in this study. This finding may suggest that as the worker works in more highway projects they can get become comfortable with the commonly-used safety strategies and believe that other innovative technologies will not be as effective as the ones that are used.

This model predicted that construction workers who receive on-going training on safety practices are more likely to perceive the alert systems are highly effective. Further, these findings may 
indicate that it is possible that innovative hazard control technologies, such as alert systems, were addressed in the on-going training given to workers, which can influence their perception of its effectiveness. Also, construction workers may be more likely to rate this strategy as highly effective because contrary to maintenance workers, they are able to observe the performance of a safety strategy on the job site for longer time periods, which can also generate an effect on their perception.

Table 4.13 Marginal Effects for the Effectiveness of Alert Systems: Binary Logit Model

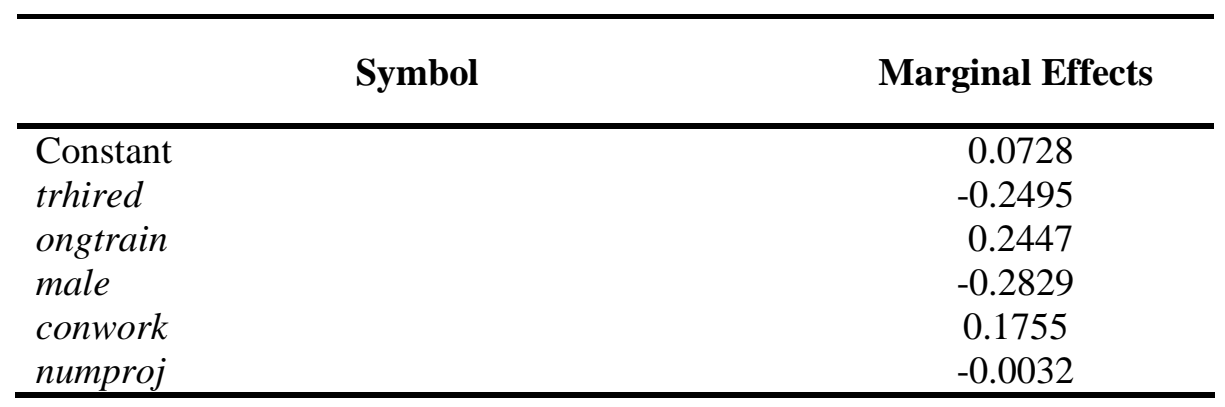

As in the previously developed models, the choice probability for the high effectiveness ratings ( 4 or 5 choices in the effectiveness scale) of the alert systems can be obtained from the following equation.

$$
P(4,5)=\frac{1}{1+e^{-0.327+1.121(\text { trhired })-1.100(\text { ongtrain })+1.271(\text { male })-0.789(\text { conwork })+0.0114(\text { numproj })}}
$$

\subsubsection{Binary Logit Model for Nighttime Traffic Control}

The final model that was developed was the retro-reflective clothing model, which was the highest rated safety strategy by the workers in the nighttime traffic control category. The results and the significant estimated parameters for this model are shown in Table 4.14. As in the previous models, the one-tailed t-test was performed to show that the significance of each variable included in this model was over the $80 \%$ confidence level. The results for the log likelihood ratio test for this model indicated a 95\% confidence level of the overall significance of the model. 
Table 4.14 Effectiveness of Retro-reflective Clothing: Binary Logit Model

\begin{tabular}{|c|c|c|c|}
\hline Variable & Symbol & $\begin{array}{c}\text { Estimated } \\
\text { Coefficient } \\
(\beta)\end{array}$ & t-Statistic ${ }^{1}$ \\
\hline Constant & & -0.6986 & $-2.590 *$ \\
\hline $\begin{array}{l}\text { Worker who attends safety meetings bi-weekly, } \\
\text { weekly or daily }\end{array}$ & freqmet & 0.7567 & $2.117 *$ \\
\hline $\begin{array}{l}\text { Worker who has worked in more than } 20 \text { highway } \\
\text { projects }\end{array}$ & hnumpro & 0.9852 & $1.322 *$ \\
\hline Construction company worker & contract & 0.4609 & $1.093 * *$ \\
\hline Number of observations & & & 163 \\
\hline Log-likelihood function LL(0) & & & -112.8326 \\
\hline Restricted Log-likelihood LL $(\beta)$ & & & -107.8327 \\
\hline Chi-squared & & & 9.9998 \\
\hline
\end{tabular}

Only one of the parameters estimated in this model, the contract variable appeared to be significant in two of the previously developed models. As in the training for workers and staff model, this variable shows a direct effect on the effectiveness ratings in this model. The presence of this variable in the warning signs model shows an inverse effect to that predicted in this model. By comparing the t-statistic value of the contract variable (1.093) with the t-statistic values in the other two models, it appears that this variable was more significant for both previous models than in the model for retro-reflective clothing. The marginal effects for this variable, shown in Table 4.15, were compared to the ones presented by the variable in the other two models. The effect on the probability of perceiving this strategy as highly effective by a construction company worker appears to be higher for both the training for workers and staff and the warning signs models than for this model.

The other variables included in the model are freqmet, and hnumpro, which represent the workers who attends safety meetings on a bi-weekly, weekly, or daily basis, and the worker who has worked in more than 20 highway projects, respectively. Both variables had a direct relationship with the effectiveness ratings for the retro-reflective clothing. This finding may imply that when safety meetings are performed bi-weekly or more frequently they can include more safety topics than others performed less frequently, making the workers more aware of the potential effectiveness of various safety strategies, including the use of retro-reflective clothing. Also, after a worker has worked on more than 20 highway projects, they may have experienced 
the use of various safety strategies in different types of projects, including nighttime conditions allowing them to have a broader perception of the effectiveness of strategies such as retroreflective clothing. This model predicted that construction company workers who attend safety meetings bi-weekly or more frequently and have worked in more than 20 highway projects are more likely to perceive the use of retro-reflective clothing for nighttime traffic control as highly effective.

Table 4.15 Marginal Effects for the Effectiveness of Retro-reflective Clothing: Binary Logit Model

\begin{tabular}{lcc}
\hline & Symbol & Marginal Effects \\
\hline Constant & -0.1743 \\
freqmet & 0.1888 \\
hnumpro & 0.2458 \\
contract & 0.1150 \\
\hline
\end{tabular}

The equation to calculate the choice probability for the high effectiveness ratings ( 4 or 5 choices in the effectiveness scale) of the retro-reflective clothing is the following:

$$
P(4,5)=\frac{1}{1+e^{0.699-0.757(\text { freqmet })-0.985(\text { hnumpro })-0.461(\text { contract })}}
$$

\subsection{Chapter Summary}

The results obtained from the administered surveys provide an assessment of various currently used safety strategies and safety hazards in construction and maintenance work zones based on three different perspectives (owners, contractors, and workers). The three stakeholders seemed to agree on the importance of the factors involved in the evaluation of a safety strategy. The most important factor to all three groups of stakeholders in evaluating the effectiveness of a safety strategy was the success in injury prevention. The cost of these strategies was considered as the least important factor in evaluating their effectiveness. The three stakeholders who participated in this study showed a common concern about the risk generated by the intrusion of vehicles in the work zone. According to these groups, the safety hazard with the highest level of risk and probability of occurrence appeared to be vehicles striking pedestrian workers. 
The perception of the effectiveness of different safety strategies varied considerably among the stakeholders involved in this study. For instance, in the administrative strategies category, law enforcement for traffic control was perceived as the most effective strategy by the owner. However, according to the workers' perception, law enforcement was the least effective in this category. Workers tend to rely more on the effectiveness of the training programs for workers and staff than on any other strategy included in this category.

Other categories that showed high variability in the perception of their effectiveness were the traffic control strategies and the measures to improve safety in the work zones. However, other categories did not show significant variability among the stakeholders. For instance, within the category of innovative technologies for hazard control, the use of radar triggered speed displays was perceived by both contractors and owners as the most effective of the innovative technologies. The use of alert systems, which appeared to be the most commonly used strategy in this category, was perceived as the most effective by the workers. The category that includes the nighttime traffic control strategies did not show variability in the respondents' perception. The use of retro-reflective clothing was chosen as the most effective strategy and the flashing lights on body or clothing as the least effective by all the stakeholders. The mean effectiveness scores for each category indicated that contractors appear to be more satisfied with the effectiveness of currently used safety strategies than owners. The workers seemed to be the least satisfied group of the three stakeholders. These results may indicate that the perceived effectiveness of a safety strategy may appear to be lower when the respondent is directly exposed to the safety hazards than when the respondent is performing an assessment from a different perspective.

The Binary Logit Models predicted the factors that affect workers perception of the effectiveness of various safety strategies. In addition, the five developed models estimated the probability of a worker perceiving the analyzed safety strategies as highly effective. The developed model for the training for workers and staff predicted that contractors' workers with more years of work experience working on projects, where a designated staff was responsible for safety, were more likely to perceive this strategy as highly effective. The parameter that generates the highest impact on the probability of workers perceiving the use of training programs for workers and 
staff as highly effective is whether the respondent was a worker from a contracted construction company or from INDOT. If the respondent was a contractor's worker there was a 0.18 increase in the probability of perceiving this strategy as highly effective.

Construction workers who received safety training when hired were more likely to perceive the use of warning signs as a highly effective safety strategy. The parameter that had the highest impact on the warning signs effectiveness ratings was the type of projects in which the worker is most frequently involved. If the worker was more frequently involved in construction projects, there was a 0.25 increase in the probability of perceiving the warning signs as highly effective.

The worker safety apparel model predicted that construction workers who have worked on more than ten highway projects, worked on projects where the staffing included a person responsible for safety, received on-going training on safety practices, and had taken OSHA-10 hr or OSHA$30 \mathrm{hr}$ training were more likely to perceive this strategy as highly effective. The estimated parameter that generated the highest impact on the probability of perceiving the use of worker safety apparel as highly effective was on-going training for safety strategies, which generated a 0.22 increase in this probability.

The model for the alert systems predicted that construction workers who received on-going safety training were more likely to perceive this strategy as highly effective. The gender of the worker produced the highest impact on the probability of a worker perceiving this strategy as highly effective. This model showed that if the worker was a male, there was a 0.29 decrease in the probability of the worker perceiving this strategy as highly effective. Although, there were only a few female respondents, the main cause of this impact could have been the presence of unobserved factors among the survey respondents.

The model for the retro-reflective clothing predicted that contractor workers who attended safety meetings bi-weekly or more frequently and had worked on more than 20 highway projects were more likely to perceive the use retro-reflective clothing for nighttime traffic control as highly effective. The highest impact in the probability that a worker perceived the use of retro-reflective clothing as highly effective was the number of projects in which the worker had been involved. 
There was a 0.25 increase in the probability of a worker perceiving the use of retro-reflective clothing as highly effective when the worker had been involved in more than 20 highway projects.

\subsubsection{Research Limitations}

There are some limitations in this section of the study:

- Since the majority of the highway construction projects in Indiana are generally performed by the same construction companies, the sample poll does not include variety of contractors. Four general contractors participated in the study, were three general contractors in Indiana and another 15 in the Midwest who perform highway construction declined to participate in the study. Therefore, the sample of data does not have the sufficient number or respondents to develop a statistical model.

- Only the INDOT and ODOT safety officers responded to the surveys that were distributed to owners of the highway construction and maintenance projects. Other state DOTs in the Midwest were contacted on various occasions, however no responses were obtained. Therefore, the conclusions of this study relevant to owners may be only applicable to INDOT and ODOT.

- The cost information from the general contractors. Information obtained about the cost of different safety strategies was not available in a common format among the general contractors. Generally, construction companies are not willing to share cost information. This lack of information prevented the development of a cost analysis of the various safety strategies.

- The sample population for the surveys was primarily from the state of Indiana. Therefore, the gathered information may not include important safety factors that may be relevant or unique for other regions in the United States, such as weather conditions, communication issues, and construction technologies. In addition, the majority of the survey respondents were male; there were only a few female respondents in the sample population.

- There was no information gathered from drivers on their perception of the effectiveness of work zone safety strategies. This is an important perspective since the intrusion of vehicles in the work zone is one of the main causes of worker injuries and fatalities. 
- The respondents to the surveys had the opportunity to provide equal ranking for different safety strategies. However, most chose not to do so (even when the choices were 'equally the same'). The findings and conclusions could have been different, had responses been different. Nonetheless, such biases cannot be fully eliminated when human responses are requested.

\subsubsection{Recommendations for Future Analysis of Safety Strategies}

The intrusion of vehicles in the work zone was identified in the literature review as one of the main causes of worker injuries and fatalities. The hazard of vehicles striking pedestrian workers generated by the intrusion of vehicles in the work zone was identified by all three stakeholders groups who participated in this study as presenting the highest level of risk for workers, as well as having the highest probability of occurrence in a highway work zone. Therefore, the safety perspective of the drivers also needs further examination to determine their perception of work zone safety strategies and their level of awareness of the risks and hazard for workers that their driving behavior generates.

The low level of response from the majority of the contacted state DOTs does not allow the conclusion of this study to be applicable to a wide range of states and geographical locations. Therefore, another recommendation would be to include more state DOTs from other geographical areas as part of the sample of a survey. The main purpose of this would be to compare their safety perception, and identify which factors are related to geographical location, weather conditions and the type of construction technologies and techniques they utilize. Also, construction and maintenance workers from other geographical locations could be included in the sample data to observe and compare their safety perception, with the perception of the workers from Indiana. This comparison would allow the identification of geographical and workenvironment-related factors that may have an effect on worker safety perception.

The limited amount of survey responses from the owners and the general contractors did not allow the creation of similar statistical models to the ones developed for the workers perspective. Therefore, by increasing the sample data of these two groups it may be possible to analyze and 
compare which factors affect their perceptions of the effectiveness of safety strategies. In addition, this would allow the comparison among the three groups (worker, general contractor, owner) of the quantitative impact of each factor on the probability of perceiving the performance of a safety strategy as highly effective. 


\section{CHAPTER 5. USE OF CAMERA AND RADAR SYSTEMS TO PREVENT WORKERS INJURED BY MOBILE EQUIPMENT}

The analysis of the work zone fatal occupational accident reports for 2000 to 2006 indicated that the most common event of fatal occupational injuries not involving the public (i.e., intruder vehicles), was workers being struck by dump trucks moving backwards. Thirty fatal incidents occurred under these circumstances in work zones; most of these accidents occurred due to lack of awareness of workers on foot and the lack of visibility by the driver when performing backing maneuvers. Existing technological devices, such as cameras and radar-based systems, might help to overcome the visibility problem that drivers encounter when backing through work zones.

\subsection{Data Collection Process}

In order to evaluate the performance of camera systems and radar-based systems as a measure to prevent dump truck backing incidents, three color cameras systems and three radar-based systems were acquired and installed on three dump trucks operated by the Tippecanoe Highway Department in Lafayette, Indiana. Three different combinations of radar and camera systems were installed in each of the dump trucks.

The cost of each device was a factor in the evaluation since one of the objectives of this study was also to evaluate the cost and benefits of the systems. Table 5.1 describes the camera systems installed on the dump trucks. A camera system enables a driver a rear view of his truck through a monitor located in the cab of the vehicle. The two types of radar systems selected had different features. As shown in Table 5.2, systems 1 and 3 are based on pulse radar technology and system 2 utilizes microwave radar technology. For the purpose of simplicity, from this point forward in this report, both the camera and radar systems will be identified by the numbers provided in Table 5.1 and Table 5.2 respectively. 
Table 5.1 Cameras systems evaluated during the testing

$\begin{aligned} & \text { System } \\ & \text { Number }\end{aligned}$
Description*

* Description of features from specifications obtained by providers

Another difference between the radar systems is the detection range. According to the providers, radar 1 and 3 detect objects up to $20 \mathrm{ft}$ away. Alternatively, radar 2 has a maximum detection range of $12 \mathrm{ft}$. In both cases, the range represents the maximum perpendicular distance from the face of the antenna or sensor to the object to be detected. The object detection capability of the radar systems is affected by the size, shape, and composition material of the object. 
Table 5.2 Radar systems evaluated during the testing

System
Number

* Description of features from specifications obtained by providers

\subsubsection{Installation of the Systems}

Dump truck vehicles performing activities in highway construction or maintenance projects are exposed to harsh conditions. DOTs or county highway departments (e.g., the Tippecanoe County Highway Department) perform paving activities and hauling activities of materials such as gravel, sand, asphalt concrete, soil, etc. These trucks are also used for sanding and plowing activities during the winter. All possible truck activities were considered when installing the cameras and radar antennae. For instance, for paving activities, the trucks must back up to the point of making contact with the paving machine, which can cause damage to the radar antennas if they are improperly installed. Other factors altering the mounting position of the devices are the physical structure of the truck; the capability of the technological system (e.g., field of view 
for the cameras); and the system manufacturer's specifications (e.g., the antennae for radars 1 and 3 should be placed on the rear center of the vehicle at roughly $1 \mathrm{~m}(36$ ") $+/-0.30 \mathrm{~m}(12$ ”) above the ground). The system combinations for each truck, as well as the characteristics of the trucks, are illustrated in Table 5.3. Figure 5.1 shows camera 2 and radar antenna 1 installed in truck 1 .

Table 5.3 Truck characteristics and combination of the systems installed in each truck.

\begin{tabular}{ccccc}
\hline Truck & Model and Make & $\begin{array}{c}\text { Capacity } \\
\text { (Tons) }\end{array}$ & Camera System & Radar System \\
\hline 1 & 1997-International & 15 & 2 & 1 \\
\hline 2 & 1999-International & 15 & 1 & 2 \\
\hline 3 & 1999-International & 15 & 3 & 3 \\
\hline
\end{tabular}

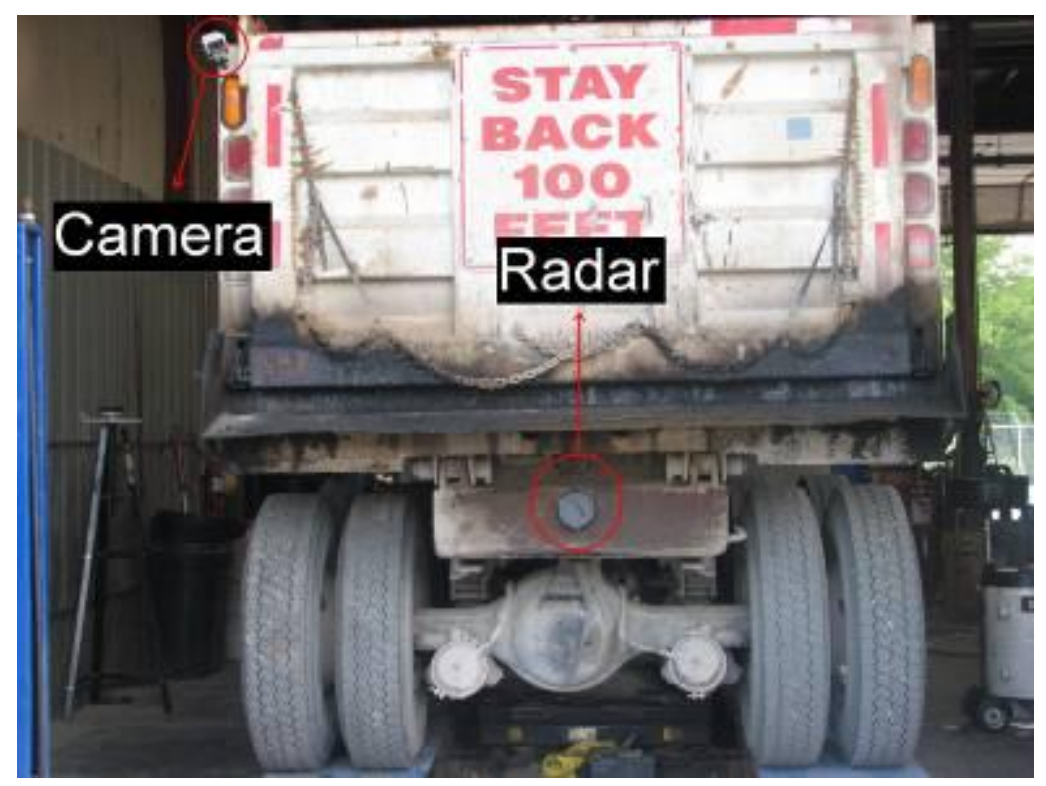

Figure 5.1 Camera 1 and radar antenna 2 installed in truck 1

The cameras were installed near the top of the dump box. Initially, all the cameras were positioned at the left side of the dump trucks pointing to the right to cover the larger blind spot to the right of the trucks, as suggested by Ruff (2004). This suggestion was also found to be acceptable to the drivers working for the Tippecanoe County Highway Department. Camera 3 was placed at the top center of the dump box. These mounting positions and the pointing directions of the cameras provided the maximum depth view possible while covering enough area just behind the truck so that a person in a crouching position could be identified. The 
devices were also protected in the best possible manner from other construction equipment and materials. The radar antennae were mounted taking into account a balance between the specifications of the manufacturers and the best possible protection for other construction equipment and materials. Due to the physical characteristics of the trucks, brackets for the radar antennae in trucks 2 and 3 were made as shown in Figure 5.2.

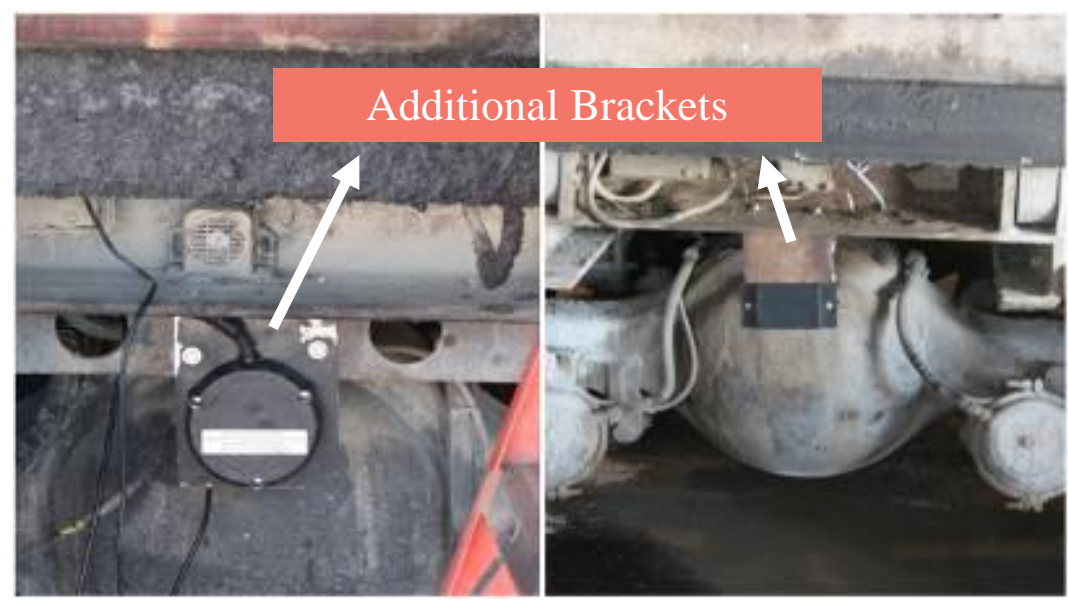

Figure 5.2 Additional brackets needed for installation of radar antennae in trucks 1 (left) and 2 (right)

\subsubsection{Final Mounting Position of the Systems}

The final mounting positions for the systems placed in trucks 1, 2, and 3 are illustrated in Figures 5.3, 5.4, and 5.5 respectively. The figures show the height of both the cameras and radar antennae and the pointing direction of the cameras. Cameras 1 and 2 were placed at an approximately $40^{\circ}$ angle to the bottom and $30^{\circ}$ to the right of the truck. Camera 3 was placed at an approximately $70^{\circ}$ angle to the bottom of the truck, mounted in the middle of the dump box. 


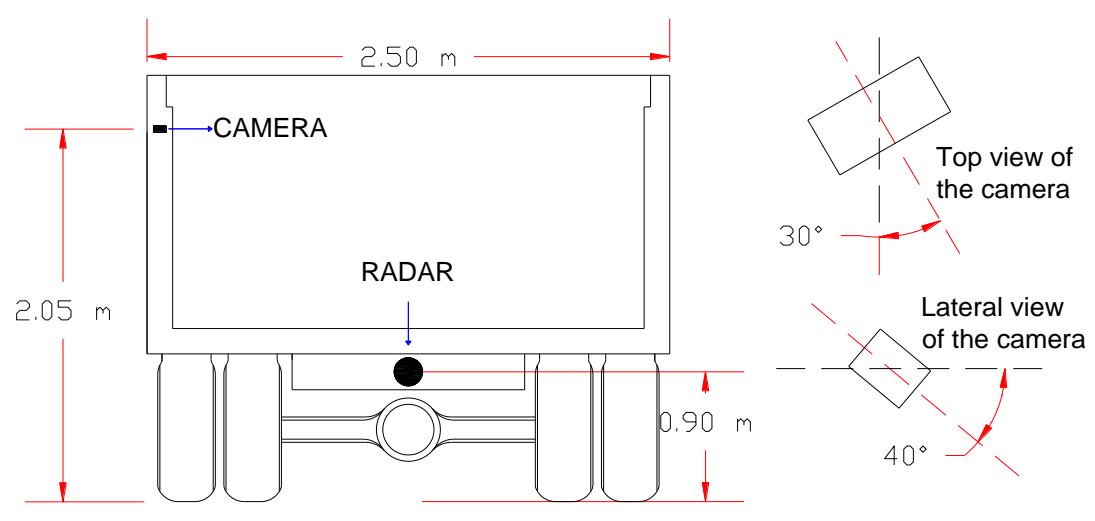

Figure 5.3 Final mounting position for camera and radar antenna on truck 1

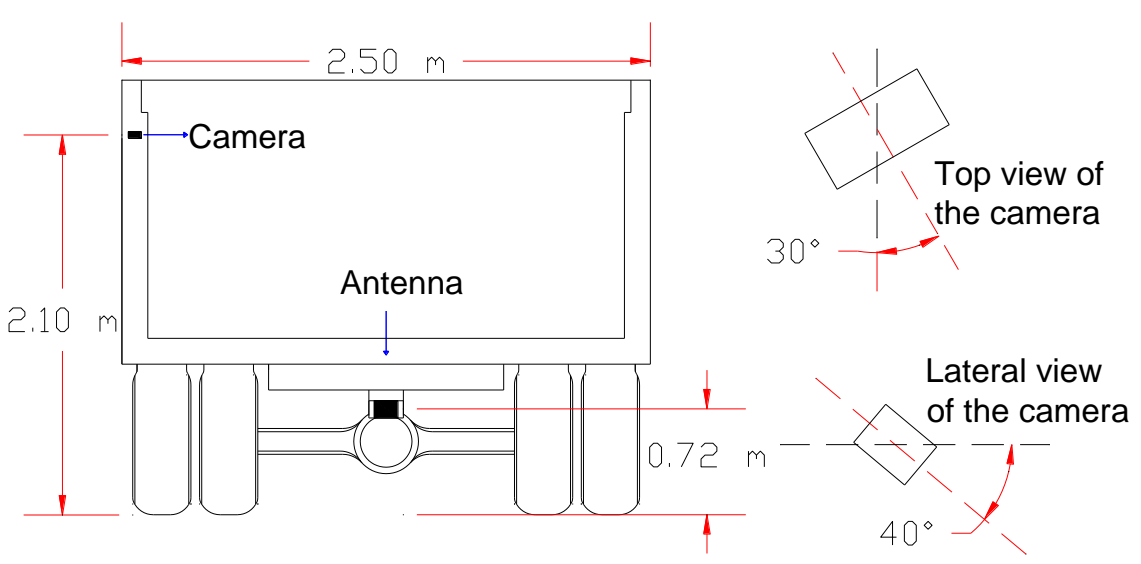

Figure 5.4 Final mounting position for camera and radar antenna on truck 2

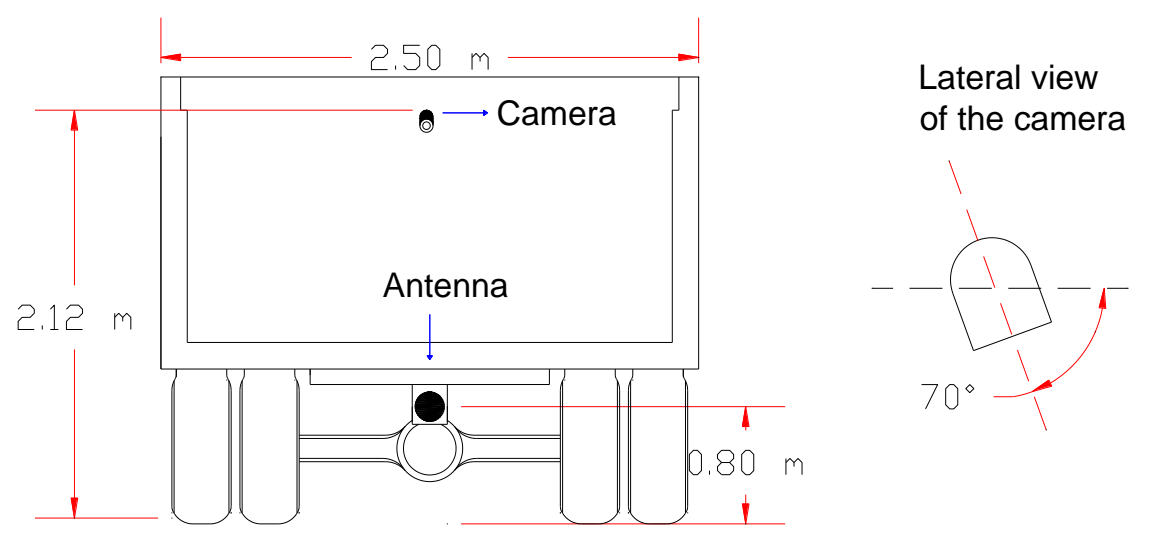

Figure 5.5 Final mounting position for camera and radar antenna on truck 3 


\subsubsection{Camera Field of View and Radar Detection Zone}

One of the most important characteristics of backing camera systems is the extent of the field of view. The greater the field of view, the greater the area covered by the camera system behind the truck. The equivalent of the field of view for the radar systems is the detection zone with one exception. If the radar has a wide detection zone to the sides of the vehicle, it would detect objects that are not in the path of the vehicle, such as trees, passing vehicles, etc. In such cases, a driver's alertness would be reduced, as the warning would sound constantly even when there are no workers in danger.

A procedure similar to Ruff (2003) was used to measure the detection zone of the radar for a person. First, the truck was stationary and a 5 feet 7 inches $(1.70 \mathrm{~m})$ tall person walked towards the truck, parallel to the longitudinal axis of the truck. The perpendicular dimensions from the edge of the truck and its longitudinal axis were measured when the radar was activated as illustrated in

Figure 5.6 (a). The procedure was performed repetitively until a detection zone diagram could be drawn.

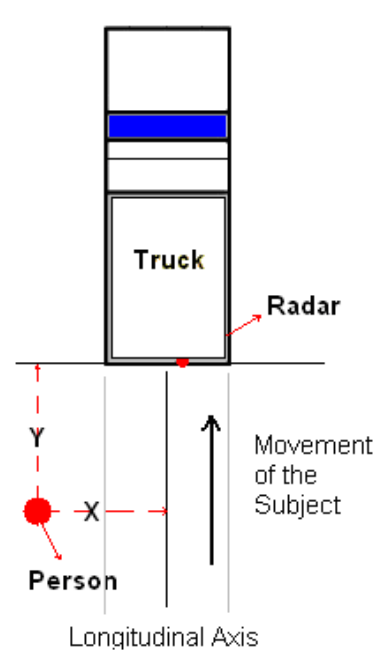

(a)

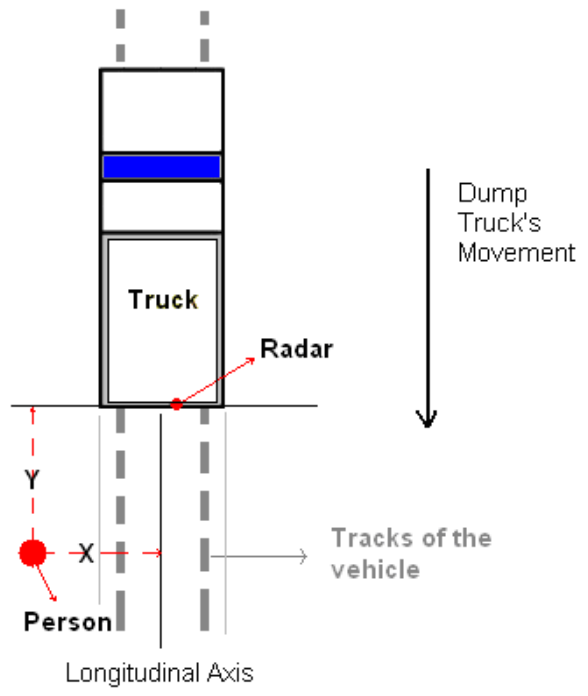

(b) 
Figure 5.6 Steps in measuring the detection zone of the radar systems (drawing not to scale)

The second step is illustrated in

Figure 5.6 (b). The measurements taken during the first step were verified as suggested in Ruff (2003). During this phase, the truck moved backwards towards the stationary subject. If after checking some of the measurements randomly, they did not match those found in the first step, all measurements were repeated since in real incidents the second approach is the most likely to occur. The detection zone was also measured for a person in a crouching position given that the performance of the radar systems is affected by the size of the objects.

The procedure for estimating the field of view of the cameras was less complicated than the procedure described for the radar systems. The dump truck was stationary and the person moved away from the rear of the truck until the most distant position to the sides of the truck where the 5 feet 7 inches $(1.70 \mathrm{~m})$ tall individual could be identified was found. Figure 5.7 shows the field of view for camera 2 and the detection zone for the radar. The figure also illustrates the area that is covered by the driver when using the mirrors of the truck. The detection zone for radar 1 as shown in the figure, varied according to the position of the individual. When the individual was in a crouching position, the detection zone was reduced.

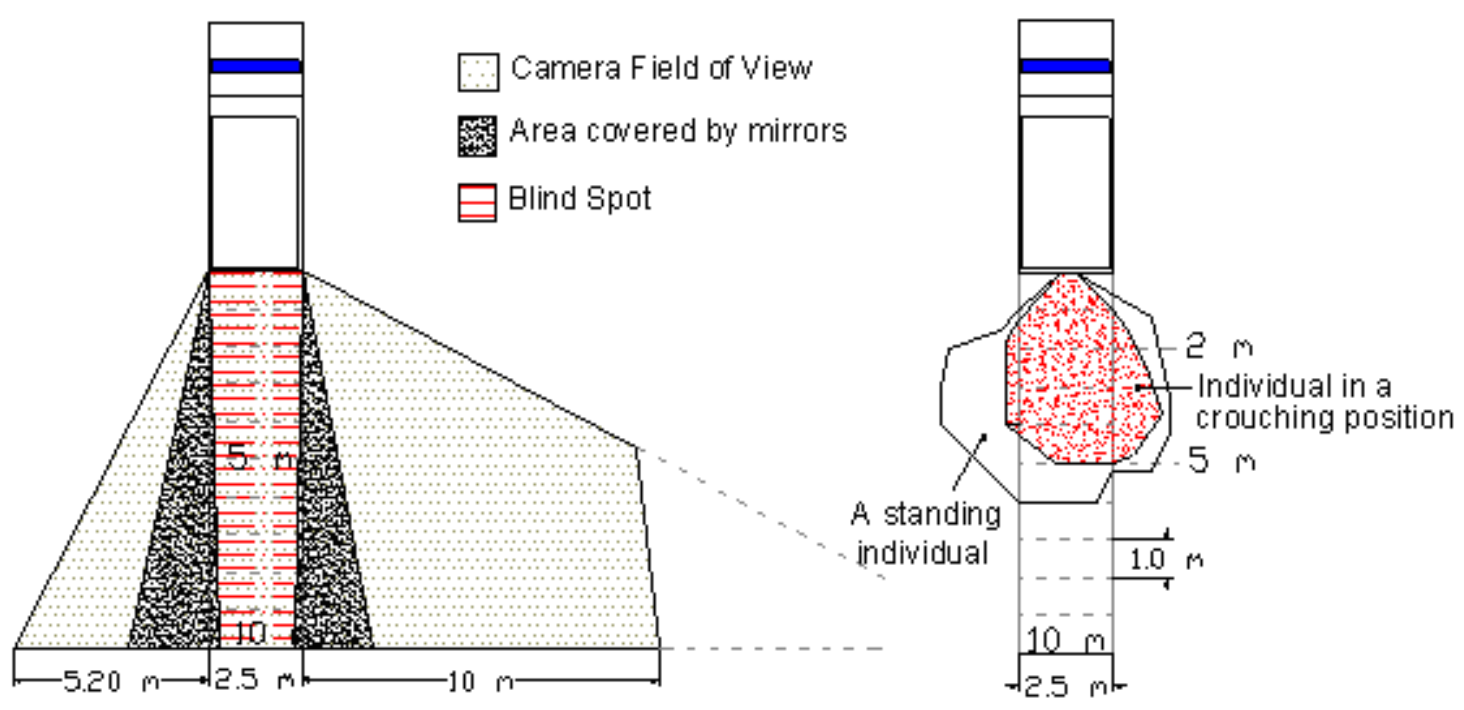


Figure 5.7 Field of view of camera 2 and radar 1 detection zone for a 5 feet 7 inches tall person in a standing and a crouching position

Figure 5.8 shows the field of view for camera 1 and the detection zone for radar 2 mounted on truck 2. Camera 1 had the greater field of view, however, the radar mounted in the same truck recorded the smallest detection zone. This radar system appears to be unreliable since it was not consistent in emitting the warnings in a specific area; as shown in the figure, the radar sometimes detected the individual walking towards the truck near the $8 \mathrm{~m}$ boundary and at other times near the $4 \mathrm{~m}$ boundary.

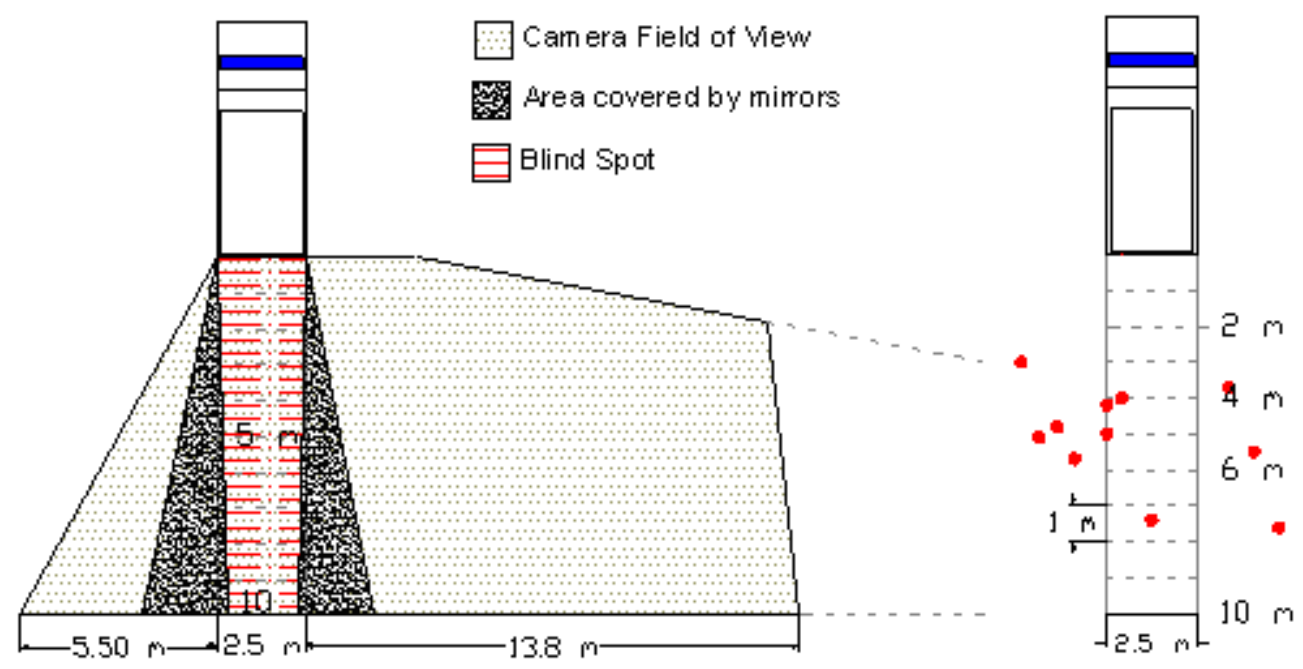

Figure 5.8 Field of view for camera 1 and instances at which radar 2 detected a 5 feet 7 inches tall person in a standing position

The field of view for camera 3 and the detection zone for radar 3 mounted on truck 3 are shown in Figure 5.9. The camera on this truck presented the shortest field of view. This camera system was only able to cover a standing person up to $2 \mathrm{~m}$ away from the truck. Radar system 3 is the same type as radar system 1, however, their detection zones differed due to different mounting positions (i.e., height and depth) and the physical structure of the truck. 


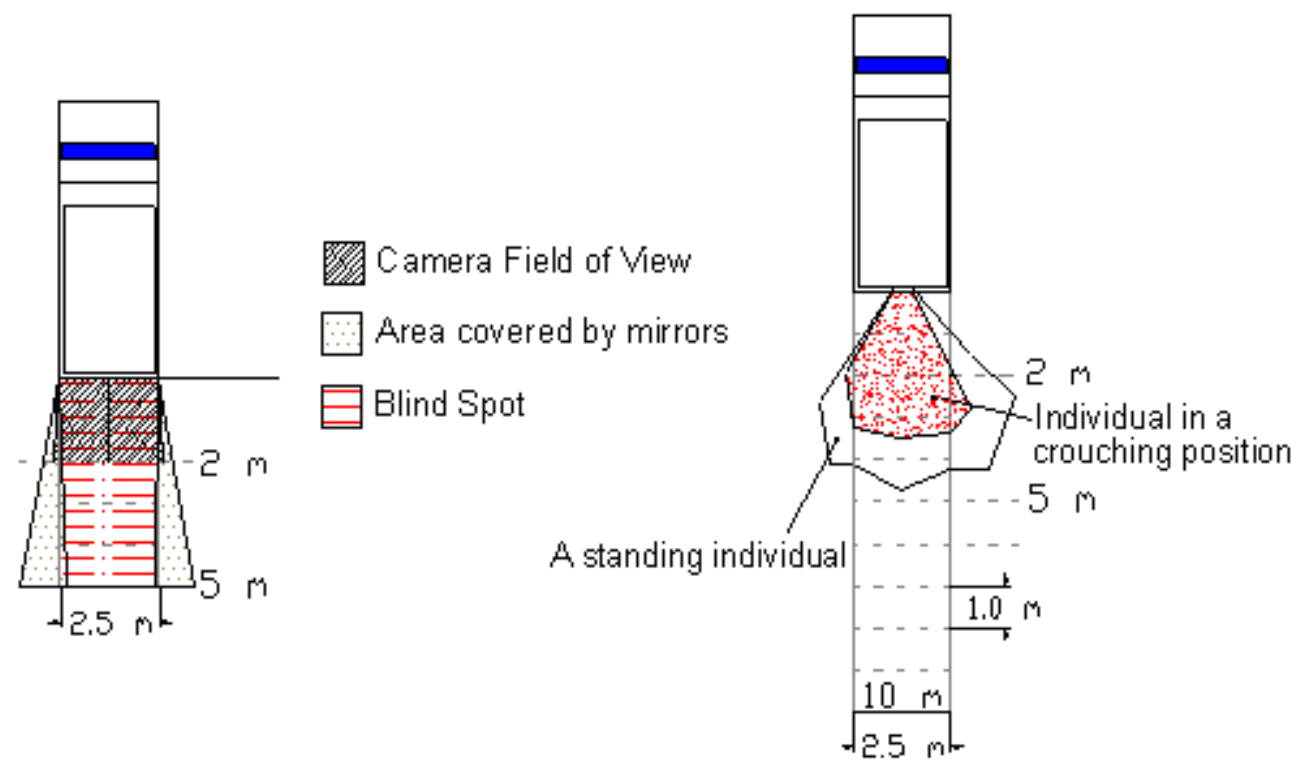

Figure 5.9 Field of view of camera 3 and radar 3 detection zone for a 5 feet 7 inches tall person in a standing and a crouching position

\subsubsection{Testing to Evaluate the Performance of Camera Systems}

A testing program was designed to assess the available distance for a driver to stop a backing dump truck once a mannequin (simulating a worker) was identified in the path of the vehicle through the use of the camera systems. Videos were recorded along a three-lane simulated work zone, which were then shown to different sets of individuals who were asked to assess different characteristics of the images in the videos, as well as the time when the mannequin was identified in the path of the vehicle.

\subsubsection{Development of the Videos Used in the Experiments}

A three-lane simulated work zone was set up in a garage facility of the Tippecanoe Highway Department in Lafayette, Indiana. Figure 5.10 illustrates the diagram of the simulated work zone set-up. Five major components were part the standard set-up used during the testing: a mannequin simulating a worker; a backing dump truck; a vehicle in motion simulating a passing motorist; highway construction equipment (i.e., a roller and a paving machine); and barrels 
separating the work site from the traffic lane. Due to the location of the construction equipment and the direction of the backing dump truck, the standard set-up did not simulate an actual paving activity. However, the set-up used did not affect the intended purposes of the testing which were to evaluate the camera systems and the potential factors that could affect the identification of a worker in the path of a backing dump truck through the use of camera systems.

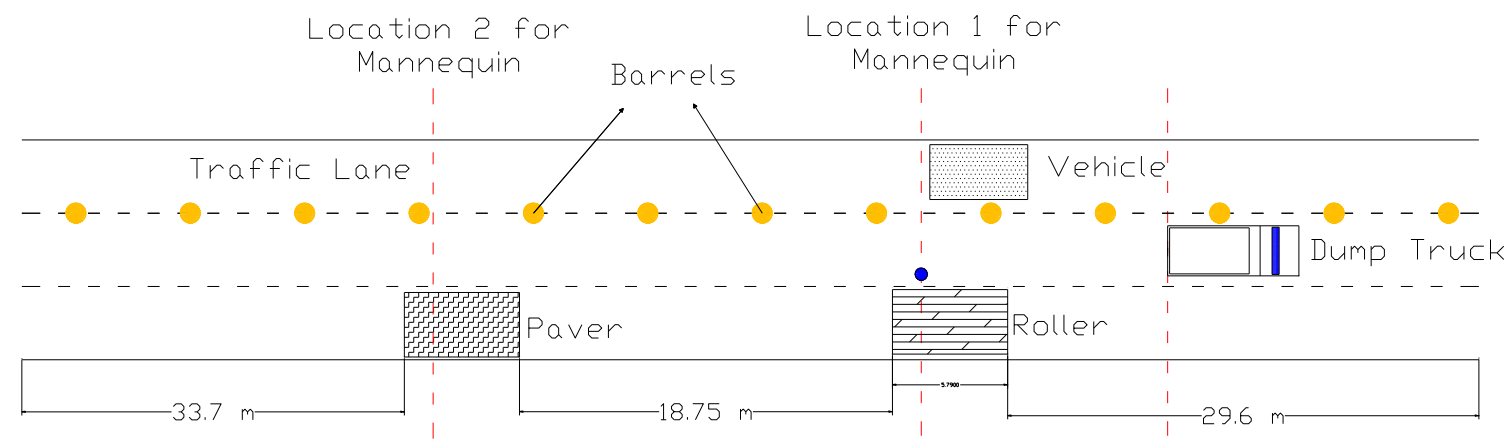

Figure 5.10 Simulated work zone set-up

The videos were recorded using each camera and using different combination of the following parameters: mannequin position, mannequin location within the work zone, safety vest on the mannequin, and speed of the dump truck. Figure 5.11 shows the combination of videos recorded for each of the cameras. Fourteen videos in total were recorded during the first stage of the testing. Since the purpose of this stage was to record the videos for further evaluation by different sets of people, video 14 and the videos with the mannequin in location $1 \mathrm{~b}$ (i.e., 6,7, and 8) were recorded to reduce the respondents' expectations of always finding the mannequin in the work zone and also at the same side of the dump truck lane respectively. Only three videos were recorded with the mannequin situated in location $1 \mathrm{~b}$ (near the roller at the left side of the backing dump truck) since it is more critical to have a worker positioned on the side opposite to the location of the camera. 


\begin{tabular}{|c|c|c|c|c|c|}
\hline Camera & Speed & Position & Safety Vest & & Location \\
\hline \multirow{14}{*}{ Camera X } & \multirow{8}{*}{$5 \mathrm{mph}$} & \multirow{2}{*}{ Standing } & INDOT & \multirow{5}{*}{\multicolumn{2}{|c|}{\begin{tabular}{l|c} 
& \\
2 & Location 1a: \\
3 & Roller, right side of \\
4 & backing dump truck
\end{tabular}}} \\
\hline & & & Class III & & \\
\hline & & \multirow{3}{*}{ Crouching } & INDOT & & \\
\hline & & & Class III & & \\
\hline & & & No Vest & & \\
\hline & & \multirow{2}{*}{ Standing } & INDOT & \multirow{3}{*}{\multicolumn{2}{|c|}{\begin{tabular}{|c|c}
6 & Location $1 \mathrm{~b}:$ \\
7 & Roller, left side of \\
8 & backing dump truck
\end{tabular}}} \\
\hline & & & Class III & & \\
\hline & & Crouching & INDOT & & \\
\hline & \multirow{5}{*}{$10 \mathrm{mph}$} & \multirow{2}{*}{ Standing } & INDOT & 9 & \multirow{5}{*}{$\begin{array}{c}\text { Location 2: } \\
\text { Paver, right side of } \\
\text { backing dump truck }\end{array}$} \\
\hline & & & Class III & 10 & \\
\hline & & \multirow{3}{*}{ Crouching } & INDOT & 11 & \\
\hline & & & Class III & 12 & \\
\hline & & & No Vest & 13 & \\
\hline & & & No Worker & 14 & \\
\hline
\end{tabular}

Figure 5.11 Combination of videos recorded from each camera

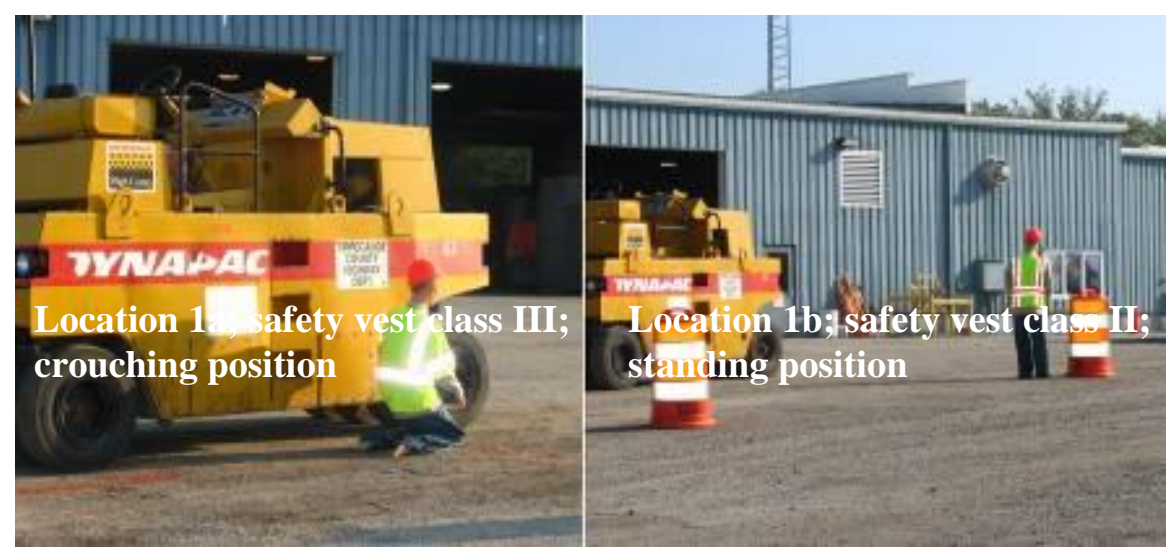

(a)

(b)

Figure 5.12 Comparison of different parameters with mannequin situated in location 1

(a)

Figure 5.12 shows a comparison of locations 1a and 1b. In Figure 5.12 (a), the mannequin is in a crouching position, wearing safety vest class III, and situated in location 1a. In Figure 5.12 (b), the mannequin is in a standing position, wearing an INDOT regular safety vest, and situated in location $1 b$. 


\subsubsection{Development and Implementation of the Survey for the Videos Recorded}

The survey design to evaluate the performance of the camera systems included questions about the characteristics of the respondent, such as ethnicity, age, gender, affiliation with Purdue University (e.g., undergraduate student, faculty member, no affiliation), and whether the respondent wore glasses or contact lenses. The second section of the survey consisted of questions to evaluate the images shown in the videos as well as the time when the mannequin was identified in the path of the vehicle. Each video image had a timer at the bottom of the image display that was used by the respondents to assess the time when the mannequin was identified. Figure 5.13 shows an example frame for one of the videos displayed during the survey implementation. The respondents were also asked to evaluate on a scale of one to five the following three characteristics of the images: the field of view, glare, and overall quality of the video. Twenty-one videos were shown one by one during each session where the survey was conducted.

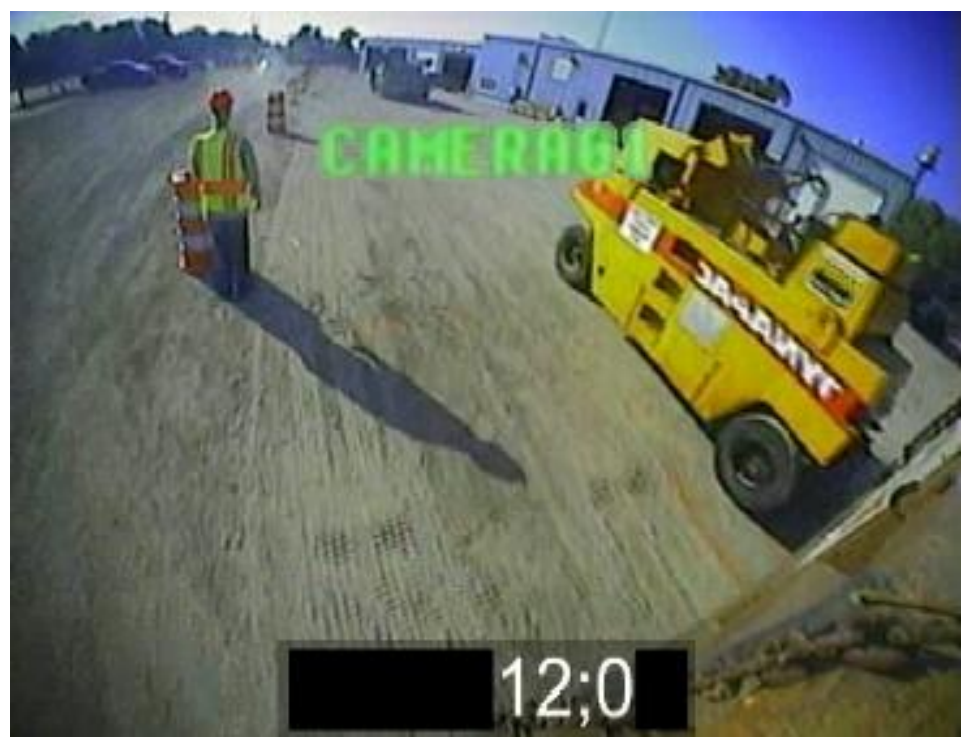

Figure 5.13 Example frame for one of the videos evaluated through the survey

The first two digits on the timer displayed with the videos provided the number of seconds since the start of the video. The last digit is related to the number of frames for a specific number of seconds. The videos were recorded at a rate of 30 frames per second. Originally, the timer 
displayed two digits in representation of the frames per second, however, this second digit was removed since it was considered to be distracting for the respondents. In the case of the example frame shown in Figure 5.13, the number in the timer is 12;0, which infers that this frame can be any of the first ten frames at second thirteen. The last digit of the time numbers provided by the survey participants was rounded to 5,15 , and 25 frames per second if the digit was 0,1 , or 2 respectively. Then these numbers where converted to $0.2,0.5$ and 0.8 seconds for the development of the statistical model.

The survey was conducted with five groups of civil engineering and construction engineering and management students at Purdue University. A total of 150 students participated in the evaluation of the videos. Table 5.4 describes the sample population for each video session (group), and the rate of response. Although same videos were not shown to all the groups of students, if a video with certain characteristics (mannequin's location and position, safety vest, and speed) was shown for camera 1, the videos with the same characteristics for camera 3 and 4 were shown during the same session when the survey was conducted.

Table 5.5 shows a combination of the videos displayed during one video session. In the table, three videos with the same characteristics for the three cameras are highlighted as an example. Overall, for each group of students, seven sets of three videos (three cameras) that had the same characteristics were shown. A copy of the survey distributed to the students is shown in Appendix G.

Table 5.4 Sample population and rate of response of the survey

\begin{tabular}{cccccc}
\hline Group & $\begin{array}{c}\text { Number of } \\
\text { respondents }\end{array}$ & $\begin{array}{c}\text { Response } \\
\text { rate }\end{array}$ & $\begin{array}{c}\text { Average } \\
\text { age }\end{array}$ & $\begin{array}{c}\text { Males } \\
(\boldsymbol{\%})\end{array}$ & $\begin{array}{c}\text { Females } \\
(\boldsymbol{\%})\end{array}$ \\
\hline 1 & 65 & $83 \%$ & 20 & $77 \%$ & $23 \%$ \\
\hline 2 & 16 & $36 \%$ & 21 & $75 \%$ & $25 \%$ \\
\hline 3 & 10 & $91 \%$ & 25 & $80 \%$ & $20 \%$ \\
\hline 4 & 20 & $95 \%$ & 28 & $70 \%$ & $30 \%$ \\
\hline 5 & 39 & $87 \%$ & 22 & $90 \%$ & $10 \%$ \\
\hline
\end{tabular}


Table 5.5 Videos evaluated by group 1

\begin{tabular}{ccccccc}
\hline $\begin{array}{c}\text { Video } \\
\text { Order }\end{array}$ & Video & Camera & Speed & Position & Safety Vest & Location \\
\hline 1 & Video1 & 1 & 5 & S & Class III & Roller \\
\hline 2 & Video17 & 2 & 5 & NA & NA & NA \\
\hline 3 & Video24 & 3 & 10 & S & INDOT & Paver \\
\hline 4 & Video7 & 1 & 5 & C & Class III & Roller \\
\hline 5 & Video36 & 3 & 5 & S & INDOT & Barrel-Roller \\
\hline 6 & Video26 & 2 & 10 & C & Class III & Paver \\
\hline 7 & Video13 & 1 & 5 & C & No Vest & Roller \\
\hline 8 & Video2 & 2 & 5 & S & Class III & Roller \\
\hline 9 & Video18 & 3 & 5 & NA & NA & NA \\
\hline 10 & Video22 & 1 & 10 & S & INDOT & Paver \\
\hline 11 & Video8 & 2 & 5 & C & Class III & Roller \\
\hline 12 & Video34 & 1 & 5 & S & INDOT & Barrel-Roller \\
\hline 13 & Video27 & 3 & 10 & C & Class III & Paver \\
\hline 14 & Video14 & 2 & 5 & C & No Vest & Roller \\
\hline 15 & Video3 & 3 & 5 & S & Class III & Roller \\
\hline 16 & Video16 & 1 & 5 & NA & NA & NA \\
\hline 17 & Video23 & 2 & 10 & S & INDOT & Paver \\
\hline 18 & Video9 & 3 & 5 & C & Class III & Roller \\
\hline 19 & Video35 & 2 & 5 & S & INDOT & Barrel-Roller \\
\hline 20 & Video25 & 1 & 10 & C & Class III & Paver \\
\hline 21 & Video15 & 3 & 5 & C & No Vest & Roller \\
\hline
\end{tabular}

* These speeds were requested to the dump truck drivers before recording each of the videos. For the statistical model, actual speeds were calculated based on length measurements taken on the site and the time codes of the videos.

5.2 Data Analysis

The first step of the analysis of the data was achieved through graphic, tabular, and summary statistic descriptors. The statistical analysis was performed by the use of an ordered probit model with random effects. As in the case of the binomial logit model, the significance of different variables was tested and the log-likelihood function was maximized as much as possible. The distance (categorized in five ranges) between the mannequin and the dump truck at any given time chosen by a respondent was the dependent variable of the model. The marginal effects test was also performed to evaluate the influence of the independent variables over the response variable. 
Table 5.6 shows the variables considered in the development of the model.

Table 5.6 Independent variables considered in the development of the ordered probit model with random effects

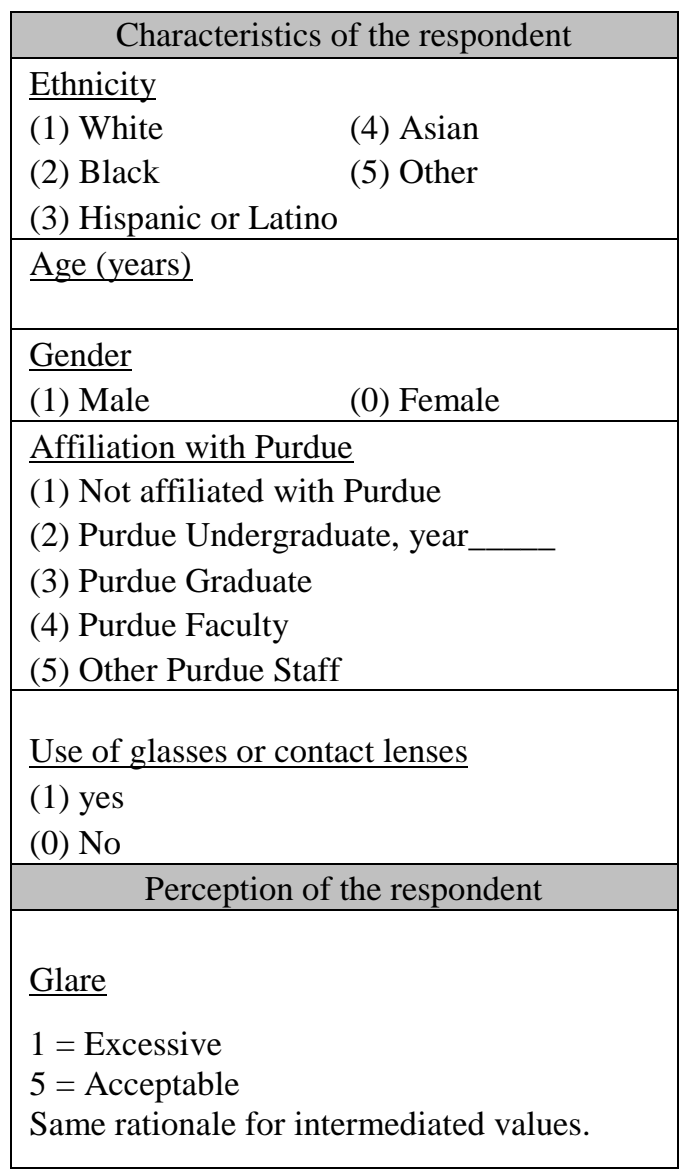

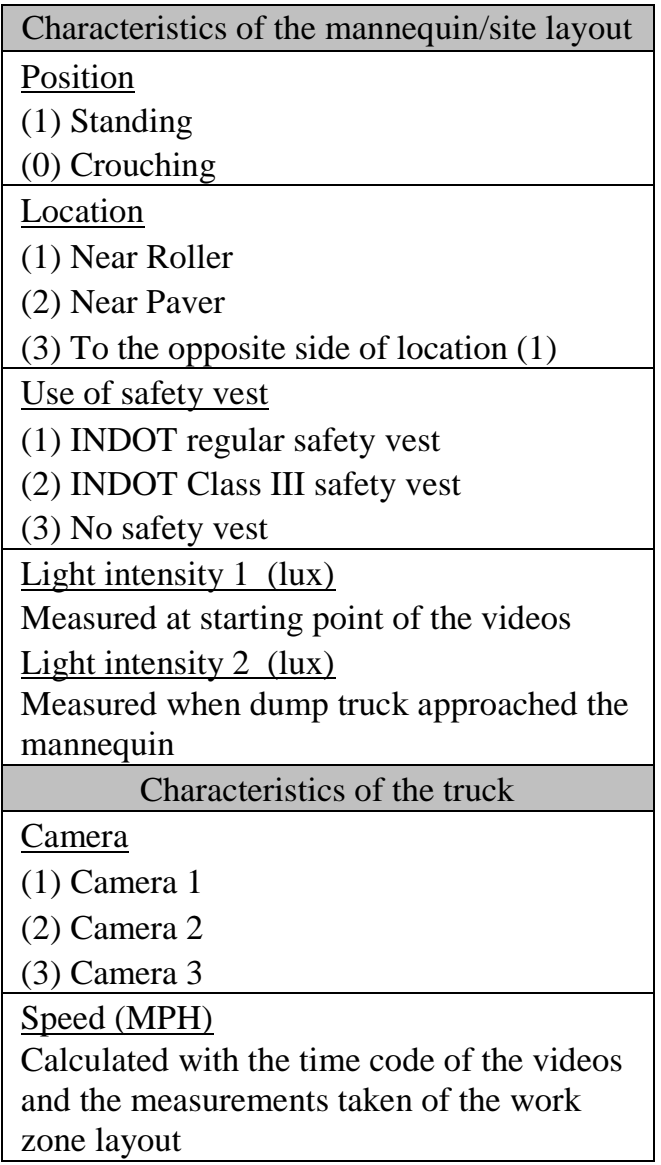

\subsubsection{Descriptive Analysis of the Survey for the Evaluation of the Videos}

The survey was conducted with five groups of civil engineering students at Purdue University, West Lafayette, Indiana. A total of 150 surveys were used to develop the analysis of the data. The average age of the participants was 22 years old. Figure 5.14 shows the distribution histogram for the ages of the respondents. Seventy-five percent of the respondents were White, followed by Asians (14\%), Black (4\%), Hispanic or Latino (3\%), and other ethnicities not classified in the previous categories (4\%). Seventy-nine percent of the respondents were male. 
Seventy-nine percent were undergraduate students, $20 \%$ were graduate students, and the remaining $1 \%$ was a faculty member. The academic year distribution of the undergraduate students is shown Figure 5.15. About 50\% of the survey respondents wore glasses or contact lenses.

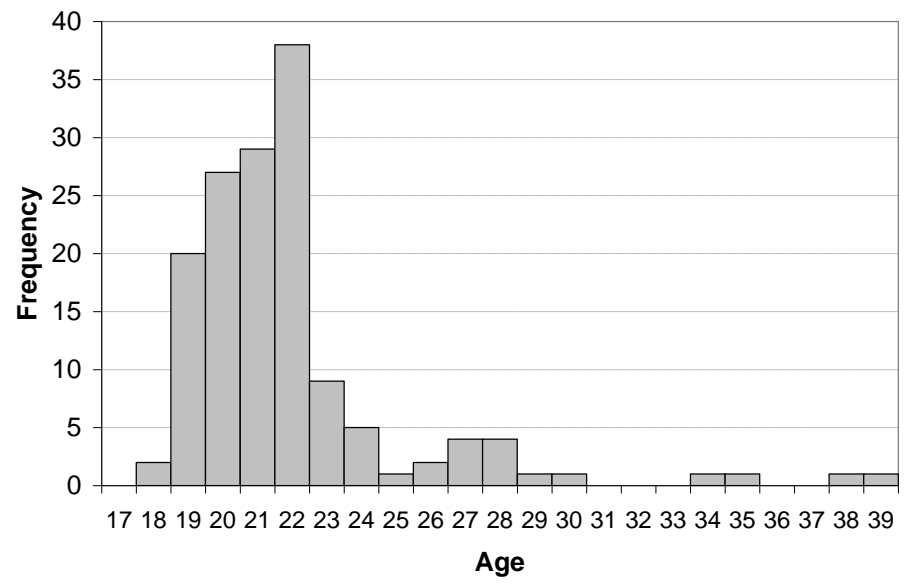

Figure 5.14 Age distribution of the respondents

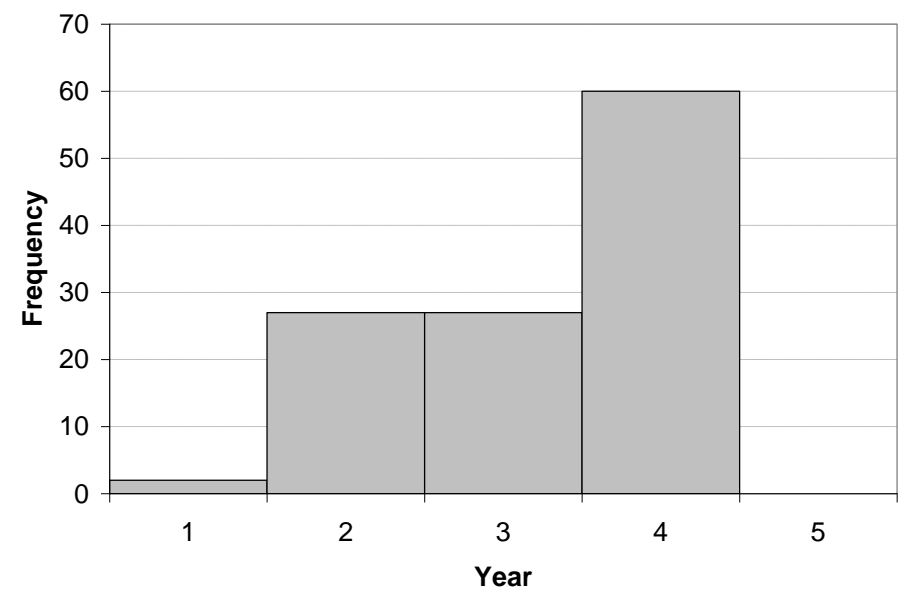

Figure 5.15 Academic-year distribution for undergraduate students

The characteristics of the images (field of view, glare acceptance, and overall image quality), of camera 1 were the highest rated. As shown in Figure 5.16, camera 1 received the highest ratings regarding the size of the field of view (FOV). The survey respondents were asked to evaluate this characteristic from 1 to 5, one being "small," and five "large." About $90 \%$ of the individuals gave camera 1 a rating of 4 or 5 . About $50 \%$ of the respondents gave camera 2 a rating of 3 . According to the perception of the individuals, camera 3 had the worst FOV; approximately $60 \%$ gave this camera the lowest score. The results obtained from the respondents were equivalent to 
the FOV measurements taken on the trucks (Section 5.1.), where camera 1 and 3 had the best and the worst field of view respectively.

Regarding the glare acceptance, camera 1 and camera 3 tied with an average score of 3.52 .

Camera 2 was rated with an average score of 2.46. As in the case of the FOV, the glare acceptance was rated from 1 to 5 or from excessive to acceptable. Even though camera 3 had a good score in glare acceptance, the lens of this camera was not exposed directly to the sun light. This was caused by the short field of view of the camera and the mounting position pointing to the floor in order to cover a worker just behind to the rear of the truck. Figure 5.16 also shows the scores for glare acceptance provided by the respondents for each camera. Camera 1 received the highest rating for the image quality, followed by camera 3. It seems that the glare on camera 2 caused the respondents to rate it as the camera with the lowest image quality.

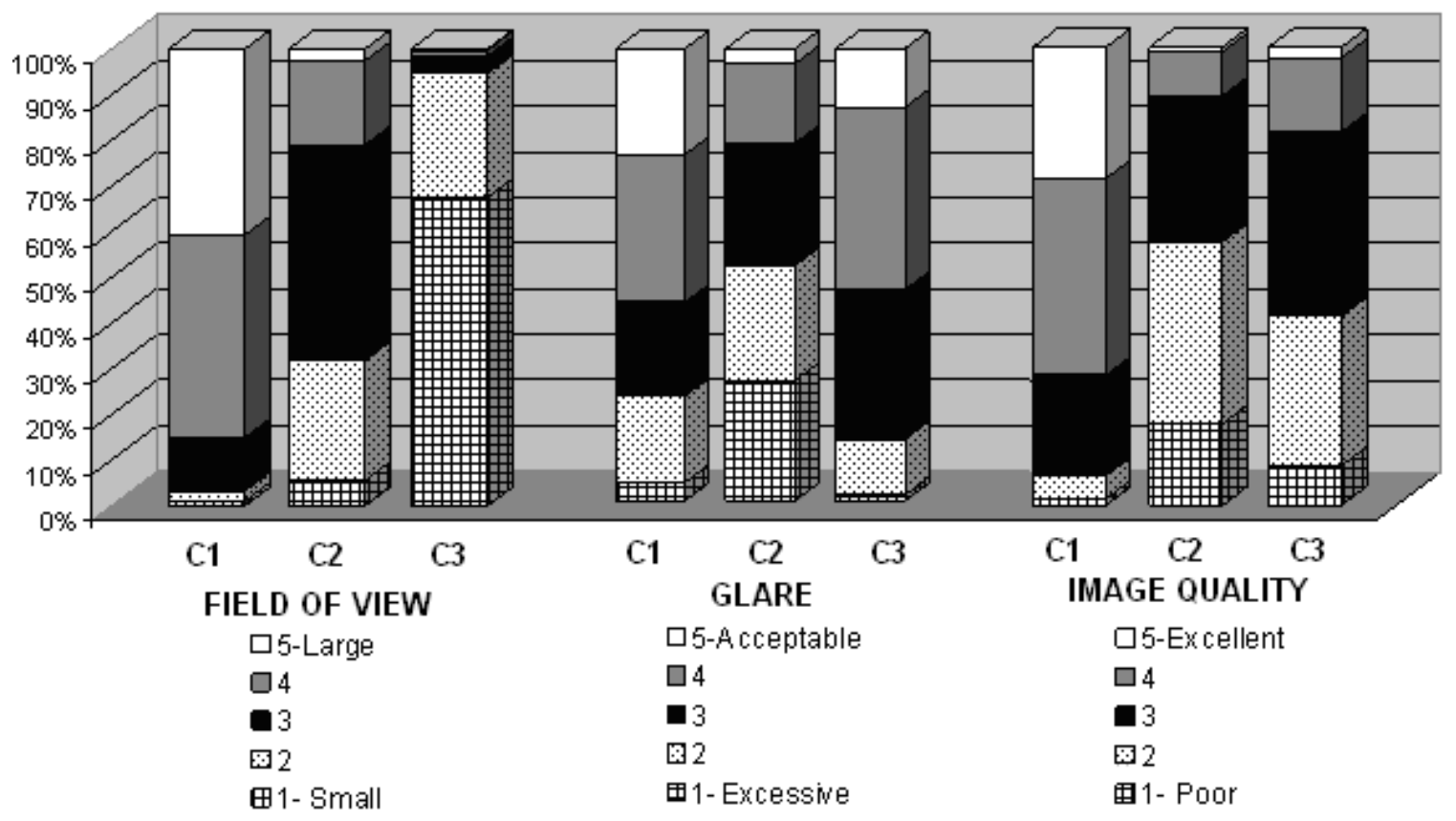

Figure 5.16 Field of view, glare, and image quality of each camera provided by the respondents

To test the consistency of the responses of the individuals, each variable characteristic of the mannequin (location, position, use of safety vest), and the field of view (FOV) responses were plotted. Since FOV is a characteristic of the camera, it was treated as independent of the characteristics of the mannequin as were the characteristics of the environment conditions 
surrounding the testing (e.g., direct sun light exposure of the camera lenses). Thereby, the FOV evaluation for each characteristic of the mannequin should be similar. The comparison of the field of view ratings for all cameras and for each variable characteristic of the mannequin is shown in Figure 5.17, which indicates that the responses were consistent.

Camera 1 presented the shortest distance traveled by the truck before a respondent identified the mannequin in the path of the vehicle. In $85 \%$ percent of the videos, the camera 1 truck recorded the shortest distance traveled when compared with the other cameras under the same characteristics of the video (mannequin's position and location, and use of safety vest). Camera 2 mounted on truck 1 had the shortest traveled distance in $12.5 \%$ of the videos, and the remaining $2.5 \%$ of the videos camera 3 had the shortest traveled distance.

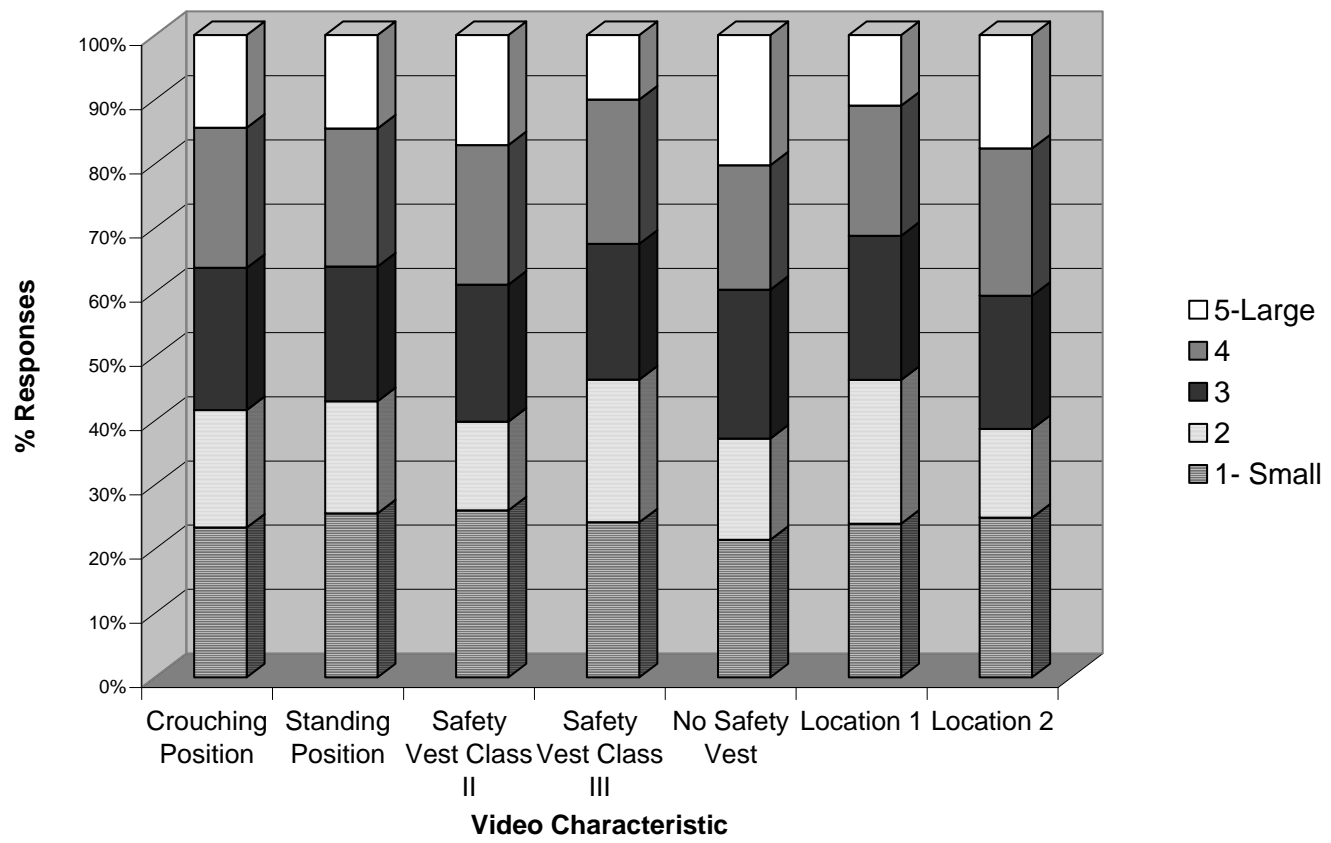

Figure 5.17 Comparison of the field of view scores for the cameras under different mannequin characteristics

Each characteristic of the mannequin (position, location, and use of safety vest) and the same combinations for those characteristics were evaluated the same number of times by the respondents. Table 5.7 shows the different times each characteristic of the mannequin was evaluated, and Figure 5.8 shows a comparison of the safety vests used during the testing. 
Table 5.7 Number of times each characteristic related to the mannequin/site was evaluated

\begin{tabular}{ccccccccc}
\hline \multirow{2}{*}{ Camera } & \multicolumn{2}{c}{ Position } & \multicolumn{3}{c}{ Location } & \multicolumn{3}{c}{ Safety vest } \\
& Crouching & Standing & 1a & $\mathbf{1 b}$ & $\mathbf{2}$ & Class II & Class III & $\begin{array}{c}\text { No } \\
\text { vest }\end{array}$ \\
\hline $\mathbf{1}$ & 476 & 424 & 424 & 150 & 326 & 352 & 398 & 150 \\
\hline $\mathbf{2}$ & 476 & 424 & 424 & 150 & 326 & 352 & 398 & 150 \\
\hline $\mathbf{3}$ & 476 & 424 & 424 & 150 & 326 & 352 & 398 & 150 \\
\hline
\end{tabular}
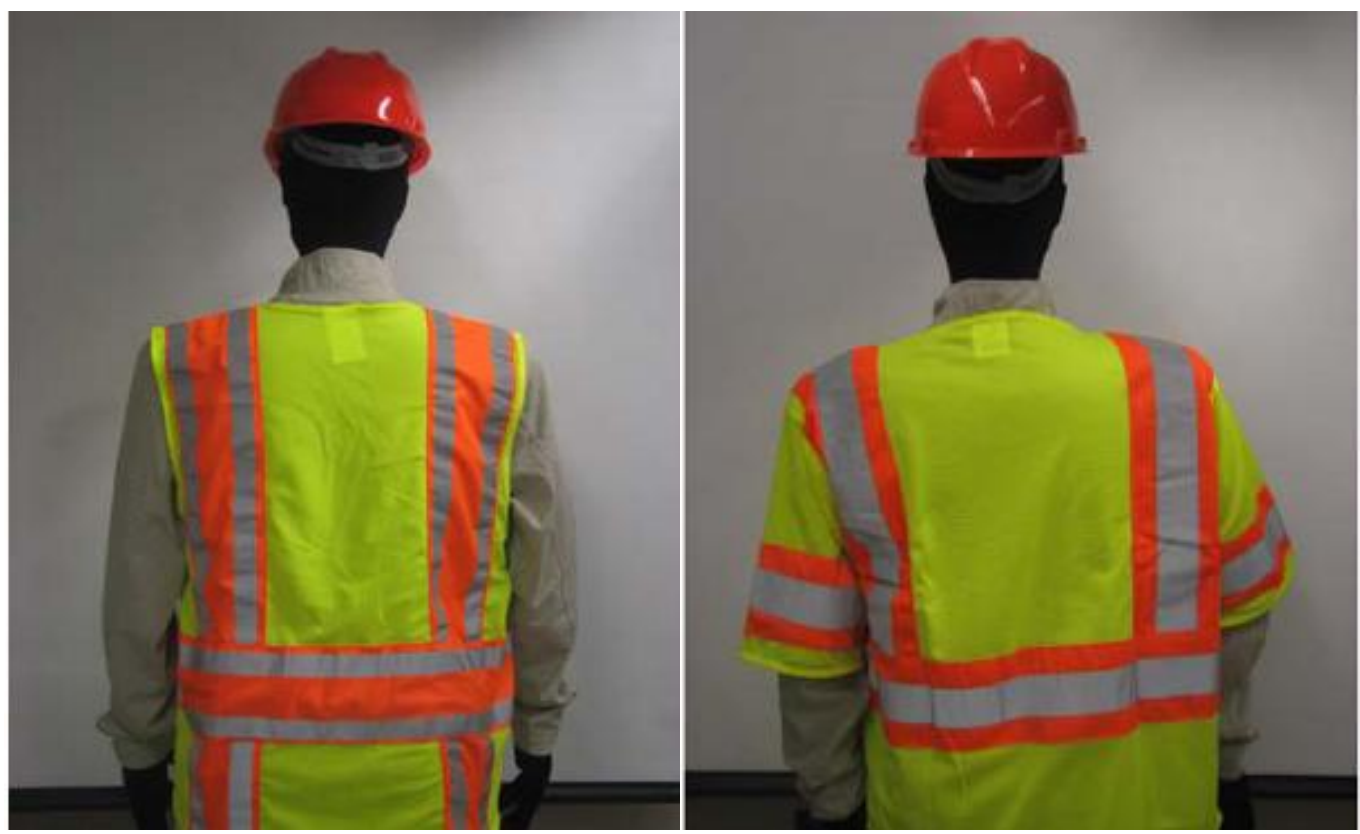

a) Safety vest class II; sleeveless vest b) Safety vest class III; short sleeves vest with 132 in2/front face retroreflective material with 149 in2/front face retroreflective material

Figure 5.18 Comparison of the safety vests used for the developing of the videos (Valentín 2007)

\subsubsection{Ordered Probit Models with Random Effects}

In order to evaluate the performance of the three camera systems and the factors that influence the identification of the mannequin in the path of the backing dump truck, ordered probit models with random effects were performed. This section presents a description of ordered probit models and the results obtained with the data collected through the analysis of the surveys that were administrated to students at Purdue University. 


\subsubsection{Description of Ordered Probit Models}

In ordered discrete data, the order of the data matters and represents values of importance on a given scale. For instance, in the case of the question asked of the respondents about the quality of the images in the videos recorded from the backing cameras, the choices ranged on a scale from one to five, with one representing "poor" and five representing "excellent".

Models of ordered discrete data are derived from an unobserved variable $(q)$ with the form of Equation 5.1. In the equation, $X$ represents a vector of variables determining the discrete order for any given observation $(n), \beta$ is a vector of the parameters estimates, and $\varepsilon$ is the error or disturbance (Washington et al. 2003).

$$
q=\beta X+\varepsilon
$$

In the case of this study, the dependent variable was classified into five categories. For calculating the probability that an observation is in any of the five categories, the thresholds $(\mu)$ had to be defined:

$$
\begin{aligned}
y=1 & \text { if } q \leq \mu_{0} \\
y=2 & \text { if } \mu_{0}<q \leq \mu_{1} \\
y=3 & \text { if } \mu_{1<}<\leq \mu_{2} \\
y=4 & \text { if } \mu_{2}<q \leq \mu_{3} \\
y=5 & \text { if } q \leq \mu_{3}
\end{aligned}
$$

Washington et al. (2003) state that the parameters $\mu$ and $\beta$ are estimated jointly and the probability of each observation $n$ is determined by assuming that the distribution of the disturbances is normal with the mean equal to zero, and the variance equal to one. Therefore, the ordered selection probabilities are:

$$
\begin{gathered}
\mathrm{P}(\mathrm{y}=1)=\boldsymbol{\Phi}(-\beta X) \\
\mathrm{P}(\mathrm{y}=2)=\boldsymbol{\Phi}\left(\mu_{1}-\beta X\right)-\boldsymbol{\Phi}(\beta X) \\
\mathrm{P}(\mathrm{y}=3)=\boldsymbol{\Phi}\left(\mu_{2^{-}} \beta X\right)-\boldsymbol{\Phi}\left(\mu_{1}-\beta X\right) \\
\mathrm{P}(\mathrm{y}=4)=\boldsymbol{\Phi}\left(\mu_{3^{-}} \beta X\right)-\boldsymbol{\Phi}\left(\mu_{2^{-}} \beta X\right) \\
\mathrm{P}(\mathrm{y}=5)=1-\boldsymbol{\Phi}\left(\mu_{3^{-}} \beta X\right)
\end{gathered}
$$


In Equation 5.3, $\Phi$ represents the cumulative distribution function with the form of Equation 5.4. According to Washington et al. (2003), the threshold $\mu_{0}$ is set equal to zero without loss of generality, therefore, only three thresholds are needed to be estimated.

$$
\Phi(\mu)=\frac{1}{\sqrt{2 \pi}} \int_{-\infty}^{\mu} E X P\left(-\frac{1}{2} w^{2}\right) d w
$$

Based on Washington et al. (2003), the log likelihood function that will be maximized to find the parameter estimates for a population of $N$ observations and five discrete outcomes, as in the case of this research, is explained in Equation 5.5. Maximizing this log likelihood function is subject to the constraint $\mu_{1} \leq \mu_{2} \leq \mu_{3}$.

$$
L L=\sum_{n=1}^{N} \sum_{1}^{5} \operatorname{din} L N \mid \mathbf{p}\left(\mu_{i}-\beta X_{n}\right)-\Phi\left(\mu_{i}-\beta X_{n}\right)_{-}^{-}
$$

\section{$\underline{\text { Random Effects }}$}

In the case of the survey to assess the performance of the camera systems, 21 videos were presented for evaluation to the respondents. Three of the videos did not have a mannequin; no time was recorded for those videos, hence, no distance was calculated. Therefore, at most, 18 observations from each individual were taken into account to calculate the distance from the back of the truck to the mannequin at any given time chosen by a respondent. Those 18 observations by any given respondent have unobserved effects provided by the individual, which underestimate the disturbances of the model's parameters. This unobserved heterogeneity of sampled units (respondents) should represent a random sample of effects from a larger population of interest, then the effects are thought to be random. In this type of model, there is no desire to model the effects of the sampled units (Washington et. al, 2003). Shafizadeh and Mannering (2006) state that the unobserved effects provided by the individuals can be addressed by adding a normally distributed individual specific error term (one for each respondent). 


\title{
5.2.4.2 Ordered Probit Model with Random Effects for the Analysis of the Data Collected from
}

\author{
the Video Survey
}

With the purpose of evaluating the factors that influence the identification of the mannequin in the path of the backing dump truck, the distance from the truck to the mannequin when the latter was identified by the respondent was modeled with an ordered probit model with random effects. The distance was calculated with the time provided by the respondents and the truck speed for each of the videos displayed. The average speed for the trucks was $7.02 \mathrm{mph}$, with a standard deviation of $1.737 \mathrm{mph}$. The maximum value of the speed achieved by a truck was $11.88 \mathrm{mph}$ and the minimum was $4.90 \mathrm{mph}$.

In ordered discrete data, the order of the data is significant and has values of importance on a given scale. For instance, in the case of the question about glare acceptance of the images in the videos, respondents could choose any number on a scale from one to five, with one representing "excessive" glare and five representing "acceptable glare". To use a continuous variable such as distance, the data were classified into five categories. The categories represent the level of danger for the worker (mannequin) due to his proximity to the backing dump truck. The category with the greatest risk of danger for the worker is category one (imminent danger), which involves distances below or equal to six feet. Distances from 6 to 12 feet were coded as two; from 12 to 25 feet were coded as three; from 25 to 50 feet were coded as four; and distances greater than 50 feet (minor level of danger) were coded as five. Figure 5.19 shows graphically the categorization of the distance (continuous data) into discrete data.

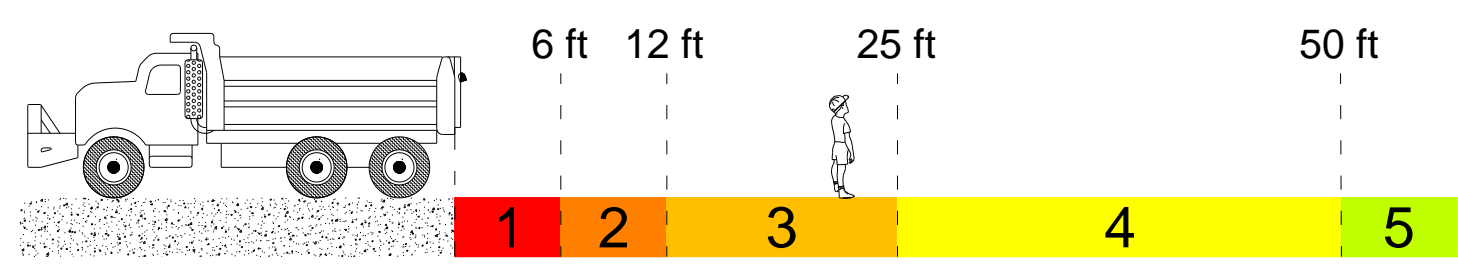

Figure 5.19 Categorization of the distance from the dump truck to the mannequin into discrete ordered data 
Two thousand six hundred and forty five $(2,445)$ observations were used for developing the model. The model has seven explanatory variables that were found to be significant. Table 5.8 and

Table 5.9 show the descriptive statistics for each variable and the estimation results for the model respectively. All variables in the model were significant at more than $90 \%$ of confidence level.

The positive and negative signs of the estimated parameters of the independent variable in Table 5.9 represent whether a variable increases or decreases respectively the probability of the dependent variable (distance) to be in the last category (minor level of danger). For instance, if the mannequin is standing (estimated parameter equal to 3.82), the probability that the mannequin is identified more than 50 feet (category 5) away from the dump truck increases. Similarly, the probability that the mannequin is identified at less than or equal to six feet decreases. With the estimated parameters it is not possible to know the behavior of the probabilities for the intermediate categories. In order to evaluate the effect of each variable across all categories, a marginal effects approach was needed.

Table 5.8 Mean and standard deviations for independent variables in the ordered probit model with random effects

\begin{tabular}{|c|c|c|c|}
\hline Explanatory Variable & $\begin{array}{l}\text { Variable } \\
\text { Mnemonic }\end{array}$ & Mean & $\begin{array}{l}\text { Stand. } \\
\text { Deviation }\end{array}$ \\
\hline \multicolumn{4}{|l|}{ Variables related to the mannequin/site layout } \\
\hline Mannequin's position ( 1 if standing, 0 crouching) & Stand & 0.50 & 0.072 \\
\hline $\begin{array}{l}\text { Mannequin positioned at location } 1 \mathrm{~b} \text { (beside the line of } \\
\text { barrels, opposite to the roller machine) }\end{array}$ & OppSide & 0.17 & 0.092 \\
\hline $\begin{array}{l}\text { Mannequin positioned at location } 1 \text { a (beside the roller } \\
\text { machine) and using any safety vest (Class II or Class III) }\end{array}$ & RollVest & 0.33 & 0.079 \\
\hline \multicolumn{4}{|l|}{ Variables related to the survey respondents } \\
\hline Individuals younger than 22 years old & Young & 0.54 & 0.120 \\
\hline \multicolumn{4}{|l|}{ Variables related to the respondents' perception } \\
\hline $\begin{array}{l}\text { Glare acceptance (from } 1 \text { to } 5,1 \text { if excessive and } 5 \text { if } \\
\text { acceptable, same rationale for intermediate values) }\end{array}$ & GAccep & 3.18 & 0.030 \\
\hline \multicolumn{4}{|l|}{ Variables related to the dump trucks } \\
\hline $\begin{array}{l}\text { Camera } 2 \\
\text { Camera } 3\end{array}$ & $\begin{array}{l}\text { Camera2 } \\
\text { Camera3 }\end{array}$ & $\begin{array}{l}0.33 \\
0.33\end{array}$ & $\begin{array}{l}0.063 \\
0.067\end{array}$ \\
\hline
\end{tabular}


Each of the respondents made a maximum of 18 observations, since 21 videos were presented for evaluation to the respondents, three of which did not contain a mannequin, and therefore no time was recorded, thereby no distance was calculated. The test for the significance of the random effects addition (i.e., Hausman test) presented a t-statistic of 14.22 (greater than 1.6), which strongly suggests the use of an ordered probit model with random effects over the simple ordered probit model.

Table 5.9 Ordered probit model with random effects of the distance from the backing dump truck to the mannequin.

\begin{tabular}{|c|c|c|c|c|}
\hline Explanatory Variable & $\begin{array}{l}\text { Variable } \\
\text { Mnemonic }\end{array}$ & $\begin{array}{l}\text { Estimated } \\
\text { Parameter }\end{array}$ & t-stat & P-value \\
\hline Constant & One & 2.66 & 24.32 & 0.0001 \\
\hline \multicolumn{5}{|l|}{ Variables related to the mannequin/site layout } \\
\hline $\begin{array}{l}\text { Mannequin's position ( } 1 \text { if standing, } 0 \\
\text { crouching) }\end{array}$ & Stand & 0.274 & 3.82 & $<0.0001$ \\
\hline $\begin{array}{l}\text { Mannequin positioned at location } 1 \mathrm{~b} \text { (beside the } \\
\text { line of barrels, opposite to the roller machine) }\end{array}$ & OppSide & -1.422 & -15.43 & $<0.0001$ \\
\hline $\begin{array}{l}\text { Mannequin positioned at location 1a (beside the } \\
\text { roller machine) and wearing any safety vest } \\
\text { (Class II or Class III) }\end{array}$ & RollVest & -1.067 & -13.54 & $<0.0001$ \\
\hline \multicolumn{5}{|l|}{ Variables related to the survey respondents } \\
\hline Individuals younger than 22 years old & Young & 0.228 & 1.90 & 0.0569 \\
\hline \multicolumn{5}{|l|}{ Variables related to the respondents' perception } \\
\hline $\begin{array}{l}\text { Glare acceptance (from } 1 \text { to } 5,1 \text { if excessive and } \\
5 \text { if acceptable, same rationale for intermediate } \\
\text { values) }\end{array}$ & GAccep & 0.180 & 6.04 & $<0.0001$ \\
\hline \multicolumn{5}{|l|}{ Variables related to the dump trucks } \\
\hline $\begin{array}{l}\text { Camera } 2 \\
\text { Camera } 3\end{array}$ & $\begin{array}{l}\text { Camera2 } \\
\text { Camera3 }\end{array}$ & $\begin{array}{l}-1.38 \\
-2.49\end{array}$ & $\begin{array}{l}-21.83 \\
-37.45\end{array}$ & $\begin{array}{l}<0.0001 \\
<0.0001\end{array}$ \\
\hline Random effect parameter $\sigma$ (Hausman test) & $\varphi i$ & 0.48 & 14.22 & $<0.0001$ \\
\hline \multicolumn{5}{|l|}{ Model Characteristics } \\
\hline$\overline{\text { Number of observations }}$ & 2,645 & & & \\
\hline Initial log-likelihood & $-4,156.45$ & & & \\
\hline Log-likelihood at convergence & $-3,141.08$ & & & \\
\hline
\end{tabular}




\section{Discussion of the Variables Included in the Model}

\section{Mannequin's position ( 1 if standing, 0 crouching)}

When the mannequin was in a standing position, the probability that the mannequin is identified more than 50 feet away from the dump truck increases. This result seems obvious given that the greater the size of an object, the greater its visibility.

\section{Mannequin positioned at location $1 \mathrm{~b}$}

When the mannequin was located beside the line of barrels opposite to the roller machine, the probability that an individual identifies the mannequin more than 50 feet away deceases. The probability that an individual identifies the mannequin at a distance less or equal to six feet away from the truck increases. The videos for those cases were analyzed in detail and the mannequin appeared to be as visible as if it was located at the right side of the video display (location 1a beside the roller machine). This outcome occurred because the respondents were expected to identify the mannequin at locations $1 \mathrm{a}$ or 2 , since most of the videos (15) shown to the respondents had the mannequin at those locations.

Figure 5.20 Shows a comparison when the mannequin was placed at location 1a and location $1 \mathrm{~b}$.
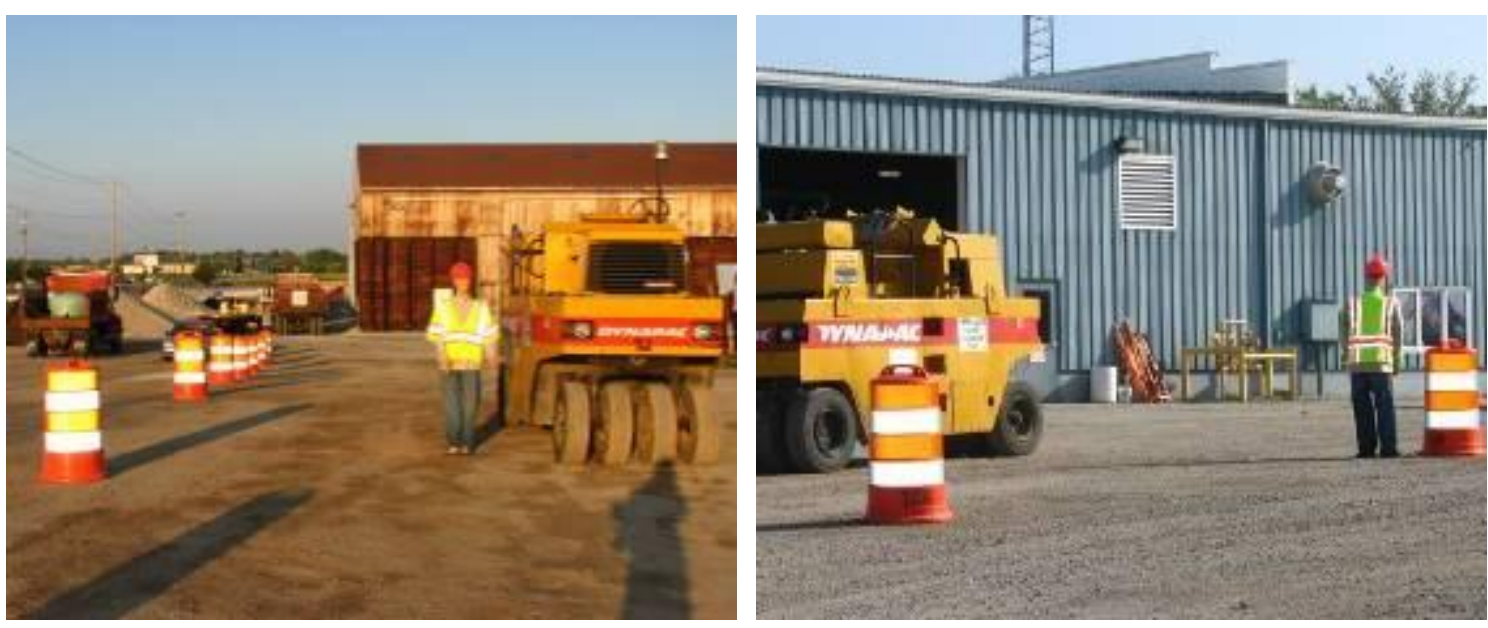
Figure 5.20 Comparison between locations $1 \mathrm{a}$ and $1 \mathrm{~b}$

Mannequin positioned at location 1a and wearing a safety vest

The probability of identifying the mannequin more than 50 feet away from the dump truck decreases, when the mannequin is positioned at location 1a (besides the roller machine) and wears a safety vest. Initially, it seems contradictory that the use of a safety vest whose purpose is to increase the visibility of a worker, resulted in a negative impact on the visibility of the mannequin. This outcome was caused mainly by the "yellow" roller machine as the background of the mannequin, which resulted in a camouflage effect for the mannequin. Figure 5.21 shows a comparison of two frames from two videos that were recorded from camera 1 when the mannequin was and was not wearing a safety vest, and positioned beside the roller machine.

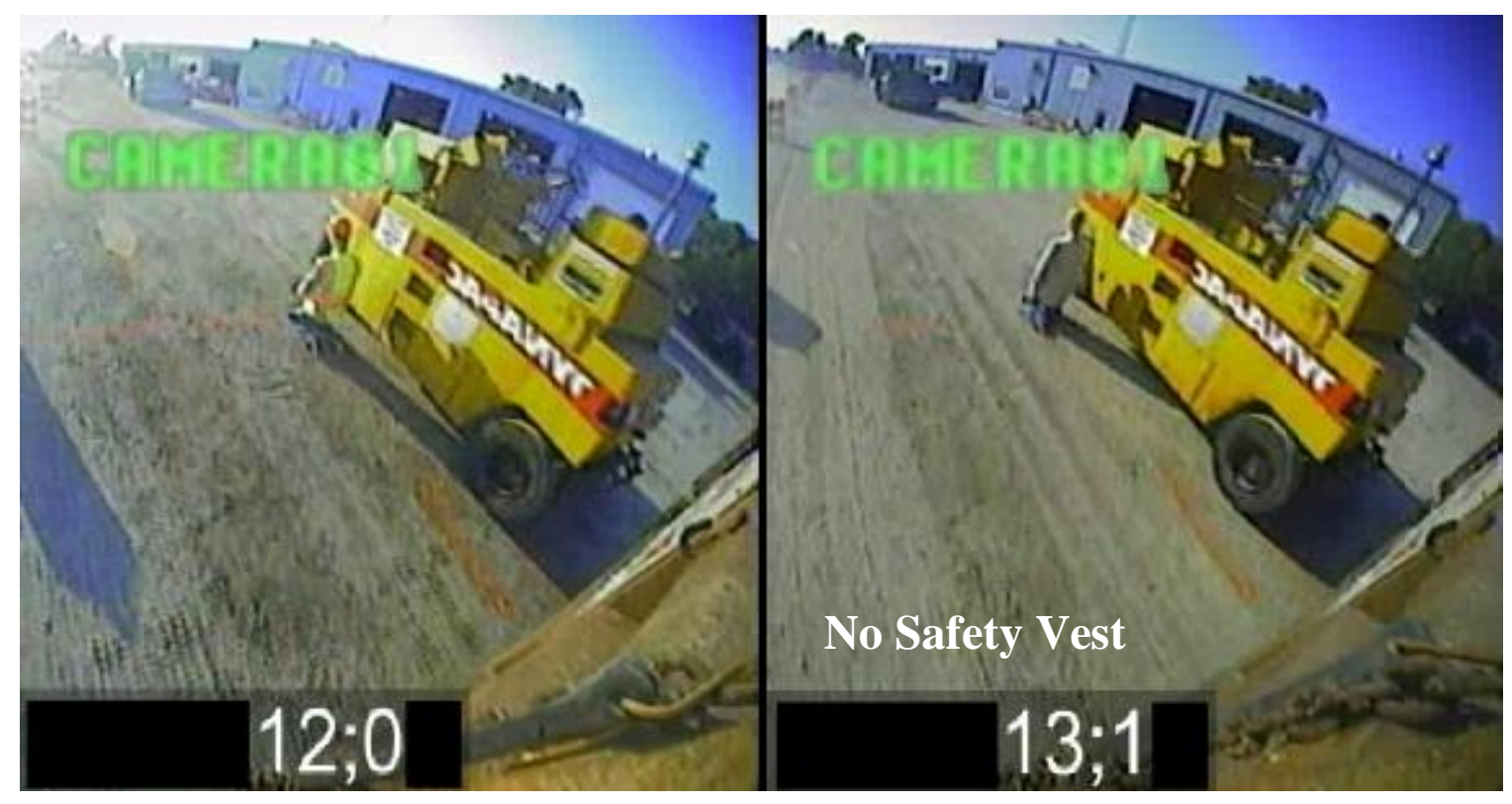

Figure 5.21 Comparison between video frames when mannequin was wearing a safety vest class II, and when the mannequin was not wearing a safety vest.

\section{Glare acceptance}

For this characteristic, the respondents gave a score on a scale from 1 to 5 . The images of a video were evaluated as " 1 " when the respondents perceived to be the glare in the video as excessive. A " 5 " was given when the respondents considered the glare in the images to be acceptable. The same rationale was used for intermediate values. The results showed that the 
greater the acceptance level for the glare, the larger the probability that the mannequin was identified at a distance greater than 50 feet.

\section{Camera 2 and Camera 3}

When a camera of the characteristics of cameras 2 or 3 is used, the probability that the mannequin is identified more than $50 \mathrm{ft}$ away from the truck decreases, and the probability of identifying the mannequin in the first category (less than 6 feet) increases. The negative influence of camera 3 is more significant than camera 2 since the magnitude of the t-statistic as well as the estimated parameter for camera 3 were greater than those for camera 2 . The influence of both cameras in each interval of distance (category) is explained with the marginal effects in the following section. Only one of these variables (cameras 2 and 3) can be considered at any time, therefore the other one must be zero. When both variables are equal to zero (not considered), then camera 1 is considered by the model, and no negative influence is caused by this camera on the probability of identifying the mannequin in the last interval of distance (more than 50 feet).

\section{Discussion of the Marginal Effects for the Ordered Probit Model with Random Effects}

A marginal effect represents the average change in the probability caused by a change in one unit of an explanatory variable. When there is a zero-one variable, the marginal effects measure the average change in the probability that the inclusion of the variable has (when the variable is equal to one). Table 5.10 shows the marginal effects for the variables in each of the categories. In the case of the Stand variable (1 if mannequin is standing, 0 if it is in a crouching position), the inclusion of the variable has on average a 0.049 decrease in the probability of identifying the mannequin in the second distance segment (6 to 12 feet). Similarly, it has on average, a 0.609 increase in the probability of identifying the mannequin more than 50 feet away from the truck. With ordered probit models, it is not possible to know the exact moment when a variable stops having a positive or negative influence and starts influencing negatively or positively the probability of the model. 
Table 5.10 Marginal effects for the ordered probit model with random effects

\begin{tabular}{cccccc}
\hline \multirow{2}{*}{$\begin{array}{c}\text { Variable } \\
\text { Mnemonic }\end{array}$} & $\mathbf{1}$ & $\mathbf{2}$ & $\mathbf{3}$ & $\mathbf{4}$ & $\mathbf{5}$ \\
\cline { 2 - 6 } & $\mathbf{d} \leq \mathbf{6} \mathbf{f t}$ & $\mathbf{6}<\mathbf{d} \leq \mathbf{1 2} \mathbf{f t}$ & $\mathbf{1 2}<\mathbf{d} \leq \mathbf{2 5} \mathbf{f t}$ & $\mathbf{2 5}<\mathbf{d} \leq \mathbf{5 0} \mathbf{f t}$ & $>\mathbf{5 0} \mathbf{f t}$ \\
\hline Stand & -0.0179 & -0.0487 & -0.4260 & 0.0445 & 0.4481 \\
\hline OppSide & 0.0928 & 0.2522 & 0.2208 & -0.2309 & -0.3349 \\
\hline RollVest & 0.0696 & 0.1892 & 0.1656 & -0.1732 & -0.2512 \\
\hline Young & -0.0149 & -0.0404 & -0.0354 & 0.0370 & 0.0537 \\
\hline GAccep & -0.0118 & -0.0320 & -0.0280 & 0.0293 & 0.0425 \\
\hline Camera2 & 0.0901 & 0.2449 & 0.2144 & -0.2243 & -0.3251 \\
\hline Camera3 & 0.1623 & 0.4412 & 0.3862 & -0.4040 & -0.5857 \\
\hline
\end{tabular}

The marginal effects represent an average change in the probability caused by a modification of a unit in the score is performed. For instance, if a score for an individual in the glare acceptance (GAccep) characteristic is modified from 3 to 4 on average, that increment has a 0.0118 decrease in the probability that the distance chosen is less or equal to six feet; a 0.032 decrease in the probability that the distance is between 6 and 12 feet; a 0.0280 decrease in the probability that the distance is between 12 and 25 feet; a 0.0293 increase in the probability that the distance is between 25 and 50 feet; and a 0.0425 increase in the probability that the distance is greater than 50 feet. This indicates that as the glare acceptance level increases, the probability of identifying a mannequin at larger distances (greater than $50 \mathrm{ft}$ ) increases. A glare acceptance value of "1" indicates that glare is excessive, and a value of " 5 " indicates that glare is acceptable. As expected, when glare is reduced, visibility is improved.

\subsubsection{Ordered Probit Model with Random Effects to Compare the Difference between the Use of Class II and Class III Safety Vests.}

An ordered probit model with random effects was performed rejecting the data for the no use of a safety vest in order to compare the visibility of Class II and Class III safety vests (refer to 
Figure 5.18 for the comparison of the safety vests). The result showed that an individual has an increased probability of identifying the mannequin when it is wearing a Class III safety vest within at a greater distance than when the mannequin is wearing a Class II safety vest. The new variable included in this model was ClassII (1 if the mannequin wears a Class II safety vest, 0 otherwise). The t-statistic for the ClassII variable was -1.65 , indicating that when the safety vest Class II is worn, the probability of identifying the mannequin more than 50 feet away from the truck decreases. Safety vest Class II is the one regularly use by INDOT workers. The one used for the testing was a sleeveless vest with $132 \mathrm{in}^{2} /$ front face of retroreflective material. Safety vest Class III is a short sleeves garment with $149 \mathrm{in}^{2} /$ front face of retroreflective material 
Table 5.11 Ordered probit model with random effects for comparing the difference between Class II and Class III safety vests

\begin{tabular}{|c|c|c|c|c|}
\hline Explanatory Variable & $\begin{array}{l}\text { Variable } \\
\text { Mnemonic }\end{array}$ & $\begin{array}{l}\text { Estimated } \\
\text { Parameter }\end{array}$ & t-stat & P-value \\
\hline Constant & One & 1.817 & 13.623 & $<0.0001$ \\
\hline \multicolumn{5}{|l|}{ Variables related to the mannequin/site layout } \\
\hline $\begin{array}{l}\text { Mannequin's position ( } 1 \text { if standing, } 0 \\
\text { crouching) }\end{array}$ & Stand & 0.315 & 3.93 & 0.0001 \\
\hline $\begin{array}{l}\text { Mannequin positioned at location } 1 \mathrm{~b} \text { (beside the } \\
\text { line of barrels, opposite to the roller machine) }\end{array}$ & OppSide & -0.322 & -2.88 & 0.0039 \\
\hline $\begin{array}{l}\text { Mannequin positioned at location } 2 \text { (beside the } \\
\text { paving machine) }\end{array}$ & Paver & 1.06 & 12.30 & \\
\hline Mannequin wearing a Class II safety vest & ClassII & -0.142 & -1.61 & 0.1084 \\
\hline \multicolumn{5}{|l|}{ Variables related to the survey respondents } \\
\hline Individuals younger than 22 years old & Young & 0.186 & 1.90 & 0.0990 \\
\hline \multicolumn{5}{|l|}{ Variables related to the respondents' perception } \\
\hline $\begin{array}{l}\text { Glare acceptance (from } 1 \text { to } 5,1 \text { if excessive and } \\
5 \text { if acceptable, same rationale for intermediate } \\
\text { values) }\end{array}$ & GAccep & 0.223 & 6.60 & $<0.0001$ \\
\hline \multicolumn{5}{|l|}{ Variables related to the dump trucks } \\
\hline $\begin{array}{l}\text { Camera } 2 \\
\text { Camera } 3\end{array}$ & $\begin{array}{l}\text { Camera2 } \\
\text { Camera3 }\end{array}$ & $\begin{array}{l}-1.345 \\
-2.535\end{array}$ & $\begin{array}{l}-18.531 \\
-34.21\end{array}$ & $\begin{array}{l}<0.0001 \\
<0.0001\end{array}$ \\
\hline Random effect parameter $\sigma$ (Hausman test) & $\varphi i$ & 0.454 & 13.04 & $<0.0001$ \\
\hline \multicolumn{5}{|l|}{ Model Characteristics } \\
\hline $\begin{array}{l}\text { Number of observations } \\
\text { Initial log-likelihood } \\
\text { Log-likelihood at convergence }\end{array}$ & $\begin{array}{c}2,211 \\
-3486.49 \\
-2643.61 \\
\end{array}$ & & & \\
\hline
\end{tabular}

Table 5.11 shows the estimation results for the model. The test for the significance of the random effects addition presented a t-statistic of 13.04, which again strongly suggests the use of an ordered probit model with random effects over the simple ordered probit model. When developing the safety vest comparison model, a new variable not included in the general model was found to be significant for the safety vest comparison model. The variable is Paver, and represents when the mannequin is located besides the paving machine. This variable had a tstatistic of 12.30, indicating that when the mannequin is located near the paving machine (the location farthest away from the starting point of the of the videos), the probability of identifying 
the mannequin more than 50 feet away from the truck increased, and the probability of identifying the mannequin in the imminent danger interval (less than 6 feet) decreased. Since the data for the mannequin not wearing a safety vest was removed so was the RollVest variable

\subsubsection{Ordered Probit Model with Random Effects Using Only Data for the Camera System with the Best Performance}

The performance of camera system 1 was better than the performance of the other two camera systems. In order to determine the factors that influence the available distance for a driver to stop a dump truck after identifying the mannequin through the use of a good performance camera system, an ordered probit model with random effects was performed. This model was developed including only data collected from the videos recorded from camera 1 . In this model, the variable Paver was also found to be significant. However, the variable Young, which was included in both previous models, was not found to be significant for this model so it was removed. It appears that with this camera system, the age of the individuals made no difference when identifying the mannequin in the path of the backing dump truck. The estimation results for this model are shown in Table 5.12.

For the camera 1 ordered probit model with random effects, 884 observations were used. The test for the significance of the random effects addition presented a t-statistic of 11.79, which again was in favor of the inclusion of the random effects. For this model the log-likelihood function was lower than the other two models. All the variables included in this model were significant with a confidence level of at least $95 \%$. Similarly, all the variables included in this model were included in at least one of the previous two models, and presented the same behavior influencing the probability of identifying the mannequin in the path of the vehicle.

After developing all three models, it can be concluded that the general model is a good representation of the data collected for the testing. The only aspect that cannot be addressed with this model is the significance of the use of safety vest Class III over the use of safety vest Class II. 
Table 5.12 Ordered probit model with random effects, using data collected for Camera 1 only.

\begin{tabular}{|c|c|c|c|c|}
\hline Explanatory Variable & $\begin{array}{c}\text { Variable } \\
\text { Mnemonic }\end{array}$ & $\begin{array}{l}\text { Estimated } \\
\text { Parameter }\end{array}$ & t-stat & P-value \\
\hline Constant & One & 1.817 & 13.623 & $<0.0001$ \\
\hline \multicolumn{5}{|l|}{ Variables related to the mannequin/site layout } \\
\hline $\begin{array}{l}\text { Mannequin's position ( } 1 \text { if standing, } 0 \\
\text { crouching) }\end{array}$ & Stand & 0.127 & 4.294 & $<0.0001$ \\
\hline $\begin{array}{l}\text { Mannequin positioned at location 1a (beside the } \\
\text { roller machine) and wearing Class II or Class III } \\
\text { safety vest }\end{array}$ & OppSide & -1.157 & -4.97 & $<0.0001$ \\
\hline $\begin{array}{l}\text { Mannequin positioned at location } 1 \mathrm{~b} \text { (beside the } \\
\text { line of barrels, opposite to the roller machine) }\end{array}$ & RollVest & -0.664 & -3.475 & 0.0005 \\
\hline $\begin{array}{l}\text { Mannequin positioned at location } 2 \text { (beside the } \\
\text { paving machine) }\end{array}$ & Paver & 0.422 & 2.465 & 0.0137 \\
\hline \multicolumn{5}{|l|}{ Variables related to the respondents' perception } \\
\hline $\begin{array}{l}\text { Glare acceptance (from } 1 \text { to } 5,1 \text { if excessive and } \\
5 \text { if acceptable, same rationale for intermediate } \\
\text { values) }\end{array}$ & GAccep & 0.133 & 2.30 & 0.0217 \\
\hline Random effect parameter $\sigma$ (Hausman test) & $\varphi i$ & 0.95 & 11.79 & $<0.0001$ \\
\hline \multicolumn{5}{|l|}{ Model Characteristics } \\
\hline $\begin{array}{l}\text { Number of observations } \\
\text { Initial log-likelihood }\end{array}$ & $\begin{array}{c}884 \\
-904.80\end{array}$ & & & \\
\hline Log-likelihood at convergence & -761.57 & & & \\
\hline
\end{tabular}

\subsubsection{Summary of Key Findings from the Models to Evaluate Effectiveness of Camera Systems} to Assist in Backing Operations

The variables found to be significant for each model are summarized in Table 5.13. The table also presents recommendations for the use of backing camera systems in work zones according to the conclusions drawn from the variable results. The recommendations seek to mitigate the influence of the factors that reduce the probability that a worker (represented by a mannequin) is identified at relative safe distance from the backing dump truck. 
Table 5.13 Summary of the models performed and recommendations on the use of camera backing systems in work zones.

\begin{tabular}{|c|c|c|c|c|}
\hline Variable & $\begin{array}{l}\text { General } \\
\text { model }\end{array}$ & $\begin{array}{l}\text { Safety vest } \\
\text { comparison } \\
\text { model }\end{array}$ & $\begin{array}{c}\text { Camera } 1 \\
\text { model }\end{array}$ & Recommendations \\
\hline $\begin{array}{l}\text { Mannequin's position ( } 1 \text { if } \\
\text { standing, } 0 \text { crouching) }\end{array}$ & $\square$ & $\square$ & $\square$ & $\begin{array}{l}\text { Advise workers to avoid as } \\
\text { much as possible crouching } \\
\text { positions }\end{array}$ \\
\hline $\begin{array}{l}\text { Mannequin positioned at } \\
\text { location } 1 \mathrm{~b} \text { (beside the } \\
\text { line of barrels, opposite to } \\
\text { the roller machine) }\end{array}$ & $\square$ & $\square$ & $\square$ & $\begin{array}{l}\text { Instill in drivers the concept } \\
\text { that identifying a worker } \\
\text { positioned at an uncommon } \\
\text { location is more difficult, } \\
\text { since it would not be expected }\end{array}$ \\
\hline $\begin{array}{l}\text { Mannequin positioned at } \\
\text { location 1a (beside the } \\
\text { roller machine) and } \\
\text { wearing Class II or Class } \\
\text { III safety vest }\end{array}$ & $\square$ & N.A. & $\square$ & $\begin{array}{l}\text { Train workers and supervisors } \\
\text { to identify and to avoid } \\
\text { potential camouflage } \\
\text { circumstances }\end{array}$ \\
\hline $\begin{array}{l}\text { Mannequin positioned at } \\
\text { location } 2 \text { (beside the } \\
\text { paving machine }\end{array}$ & $\begin{array}{l}\text { Not } \\
\text { significant }\end{array}$ & Not significant & $\square$ & \\
\hline $\begin{array}{l}\text { Mannequin wearing Class } \\
\text { II safety vest }\end{array}$ & & $\square$ & $\square$ & $\begin{array}{l}\text { Provide workers on foot with a } \\
\text { safety vest class III }\end{array}$ \\
\hline $\begin{array}{l}\text { Respondents younger } \\
\text { than } 22 \text { years old }\end{array}$ & $\square$ & $\square$ & $\begin{array}{c}\text { Not } \\
\text { significant }\end{array}$ & \\
\hline $\begin{array}{l}\text { Glare acceptance (from } 1 \\
\text { to } 5,1 \text { if excessive and } 5 \\
\text { if acceptable, same } \\
\text { rationale for intermediate } \\
\text { values) }\end{array}$ & $\square$ & $\square$ & $\square$ & $\begin{array}{l}\text { Train drivers to increase their } \\
\text { alertness to identify a worker } \\
\text { when there is glare in the } \\
\text { image displayed by the } \\
\text { system. Additionally, drivers } \\
\text { should be trained to configure } \\
\text { the brightness of the monitor } \\
\text { according to existing light } \\
\text { conditions. }\end{array}$ \\
\hline Camera 2 & $\square$ & $\square$ & N.A. & $\begin{array}{l}\text { Reduce the effect of glare } \\
\text { through the use of a protective } \\
\text { case over the lenses of the } \\
\text { camera. This case must have a } \\
\text { coated lens designed for glare } \\
\text { reduction. }\end{array}$ \\
\hline Camera 3 & $\square$ & $\square$ & N.A. & $\begin{array}{l}\text { The camera system to be used } \\
\text { should have a FOV similar to } \\
\text { cameras } 1 \text { and } 2 \text {. }\end{array}$ \\
\hline
\end{tabular}




\subsection{Chapter Summary}

The analysis of the ordered probit model with random effects provided the factors that have a positive impact on the likelihood of a person identifying the mannequin at a relatively safe distance from the truck (more than 50 feet). These factors were the use of camera 1, the mannequin in a standing position, and an acceptable level of glare in the images displayed by the camera system. Other factors, such as (1) the location of the mannequin near the roller machine while wearing a safety vest, (2) the location of the mannequin in the opposite side of the heavy equipment, and (3) the use of cameras 2 and 3, decrease the same probability. Additionally, the use of safety vest Class III had a positive impact on this probability over the use of safety vest Class II. If DOTs plan to use cameras on dump trucks performing activities in a specific work zone, workers on foot and drivers should be trained to avoid the factors that decrease the probability of a worker being identified within a relative safe distance (more than 50 feet). For instance, workers wearing a safety vest that might have a camouflage effect with any equipment or object in the work zone should not be positioned near that equipment or object. Similarly, drivers should be more cautious when backing and using the camera system if the sun or any other source of light provokes glare in the image displayed by the camera. The recommendations in Table 5.13 should be followed if camera systems are implemented on dump trucks performing activities in work zones.

\subsubsection{Limitations of the Study related to Analysis of Effectiveness of Camera Systems in Backing Operations}

The first limitation for the evaluation of camera systems was the use of only one environment when recording the videos. Work zone activities are also performed at night and under different environmental conditions (e.g., cloudy days, presence of fog). These environment features can influence the factors found to be significant in the detection zone of the mannequin in the path of the vehicle. For instance, it was found that when the mannequin was standing near the roller machine and a safety vest was not used, then it was easier to identify the mannequin within a safer distance than when the mannequin wore a safety vest. This occurred because of the camouflage effect of the safety vest with the background provided by the (yellow) color of the 
equipment. During nighttime conditions the camouflage effect would not exist due to the retroreflectivity of the safety vest that is not evident in daylight sunny conditions.

The other limitation of the evaluation of the camera systems was the implementation of the survey to only college students. The average age of the respondents was 22 years old. Through the site visits performed to work zones in this research project, it was observed that most of the individuals operating equipment or driving dump trucks were considerably older than 22 years old. This age aspect and other unobserved differences in the characteristics of dump truck drivers and college students may impact the detection times of a worker (represented by a mannequin).

\subsubsection{Recommendations for Future Studies to Enhance the Evaluation of Camera Systems}

For the evaluation of the factors that influence the detection of a worker in the path of a backing vehicle through the use of camera systems, the effect of different work environment conditions (e.g., nighttime activities) should be investigated. A different evaluation procedure that involves real construction or maintenance work zones should also be considered since the presence of various workers and their movements in the work zones might be other factors that influence the effectiveness of a camera system as a measure to reduce accidents involving backing equipment.

Additionally, the effect that the use of a camera system has on the use of the mirrors should be evaluated. Drivers should use both the mirrors and the camera system while backing. The use of a camera system should be viewed as a complement, not as a replacement of the use of the mirrors. Finally, the surveys for the evaluation of the videos should be conducted with dump truck drivers and equipment operators and the factors encountered to be significant should be validated since these drivers and operators are the individuals who will ultimately use the backing camera systems. 


\section{CHAPTER 6. USE OF CAMERA SYSTEMS TO PREVENT WORKERS INJURED BY MOBILE EQUIPMENT IN NIGHTTIME OPERATIONS}

As discussed in Chapter 5, the analysis of the use of camera systems to prevent workers injured by mobile equipment identified a number of factors that have a positive impact on the likelihood of a person identifying the mannequin at a relatively safe distance from the truck (more than 50 feet). Conditions during nighttime operations may lead to the identification of different factors having a positive impact on this likelihood.

\subsection{Data Collection Process}

Due to the poor performance of camera system 3 and a limited budget it was decided to assess the performance of camera systems 1 and 2 during nighttime operations. Final mounting positions and field of view for both cameras were the same as described in Chapter 5. A similar process was used to develop videos and administer surveys to stakeholders to collect data regarding the use of camera systems to prevent workers injured by mobile equipment in nighttime operations.

\subsubsection{Video Development}

A three-lane simulated work zone was developed and set up outside of the Tippecanoe County Highway Maintenance garage in Lafayette, Indiana. Five (5) major components to the simulated work zone were included to test the camera systems. These components included: (1) a mannequin simulating a worker, (2) a backing dump truck, (3) a dump truck passing in the opposing lane of traffic, (4) construction equipment (i.e. front end loader), and (5) barrels separating the work zone from the opposing lane of traffic. Figure 6.1 provides a diagram of the layout of the simulated work zone. 


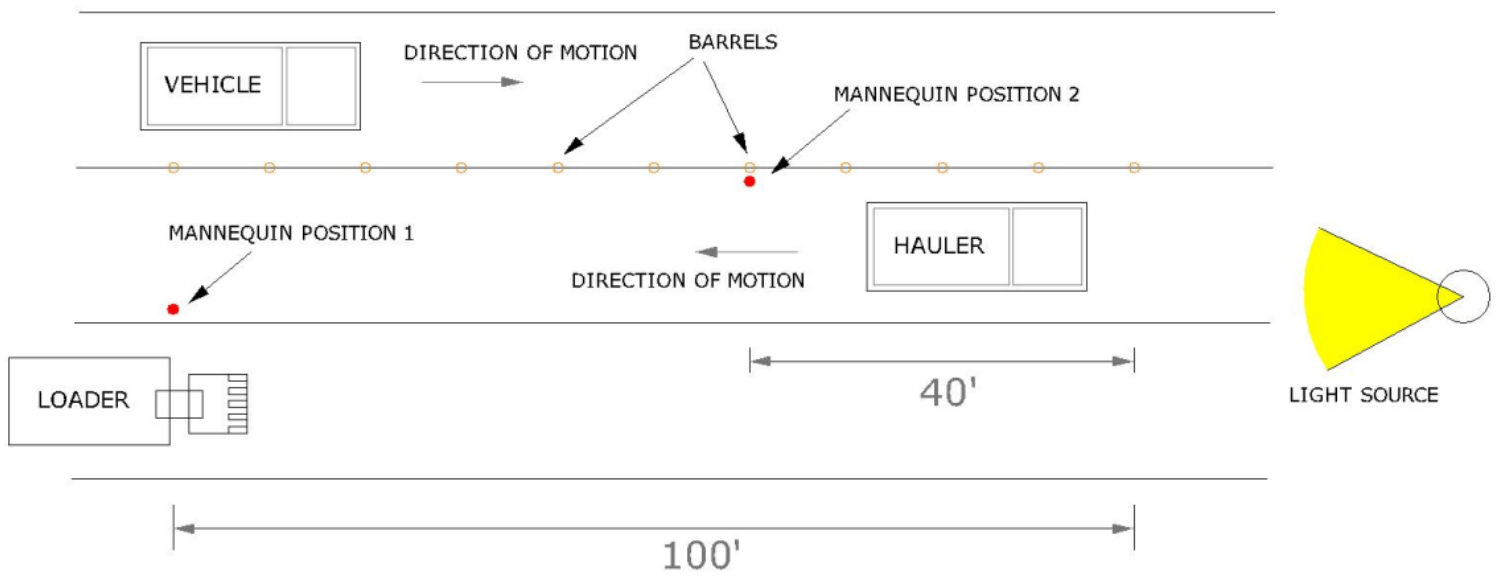

Figure 6.1 Setup of simulated work zone used to test camera system performance in assisting equipment operators in viewing equipment blind spot.

The set-up used was intended to incorporate objects, equipment, and personnel typical to a construction work site and may not be a set-up used for real construction operations. However, this does not affect the intended purpose of the testing site, which was to test the camera systems and the potential factors that could affect the ability of the camera system to be used in identifying a working in the path of the backing equipment.

Videos were recorded using both cameras and different combinations of the following variables: (1) mannequin location, (2) truck speed, (3) safety vest, and (4) lighting. Table 6.1 provides the combination of variables used in each video recorded by the cameras. Eighteen (18) videos were recorded for each camera. Videos 10 and 20 were developed such that no worker was present in the work zone in order to reduce the expectation of the respondents to always identify a worker. The location of the mannequin was varied to reduce the respondents' expectation to always find the mannequin in the same location. The truck speed, safety vest type, and lighting used were varied in order to identify various combinations of factors that are typical of nighttime highway 
construction and maintenance operations. A description of the physical characteristics of the safety vests used in this research can be found in Table 6.2.

Table 6.1 Combination of videos recorded for each camera system

\begin{tabular}{|c|c|c|c|c|c|}
\hline Camera & Lighting & $\underline{\text { PPE }}$ & Location & $\underline{\text { Speed }}$ & $\underline{\text { Run\# }}$ \\
\hline \multirow{20}{*}{ Camera X } & \multirow{10}{*}{$\begin{array}{c}\text { Rear Lights } \\
\text { On }\end{array}$} & \multirow{3}{*}{ Class II } & \multirow{2}{*}{ Driver's Side } & $5 \mathrm{mph}$ & 1 \\
\hline & & & & $10 \mathrm{mph}$ & 2 \\
\hline & & & Passenger's Side & $5 \mathrm{mph}$ & 3 \\
\hline & & \multirow{2}{*}{ Class III } & Driver's Side & $10 \mathrm{mph}$ & 4 \\
\hline & & & Passenger's Side & $10 \mathrm{mph}$ & 5 \\
\hline & & \multirow{2}{*}{ Assembly K } & \multirow{2}{*}{ Driver's Side } & $5 \mathrm{mph}$ & 6 \\
\hline & & & & $10 \mathrm{mph}$ & 7 \\
\hline & & \multirow{2}{*}{ No Vest } & Driver's Side & $5 \mathrm{mph}$ & 8 \\
\hline & & & Passenger's Side & $10 \mathrm{mph}$ & 9 \\
\hline & & \multicolumn{2}{|c|}{ No Worker } & $10 \mathrm{mph}$ & 10 \\
\hline & \multirow{10}{*}{$\begin{array}{c}\text { Rear Lights } \\
\text { Off }\end{array}$} & \multirow{2}{*}{ Class II } & \multirow{2}{*}{ Passenger's Side } & $5 \mathrm{mph}$ & 11 \\
\hline & & & & $10 \mathrm{mph}$ & 12 \\
\hline & & \multirow{3}{*}{ Class III } & \multirow{2}{*}{ Driver's Side } & $5 \mathrm{mph}$ & 13 \\
\hline & & & & $10 \mathrm{mph}$ & 14 \\
\hline & & & Passenger's Side & $5 \mathrm{mph}$ & 15 \\
\hline & & \multirow{2}{*}{ Assembly K } & Passenger's Side & $5 \mathrm{mph}$ & 16 \\
\hline & & & Driver's Side & $10 \mathrm{mph}$ & 17 \\
\hline & & \multirow{2}{*}{ No Vest } & \multirow{2}{*}{ Driver's Side } & $5 \mathrm{mph}$ & 18 \\
\hline & & & & $10 \mathrm{mph}$ & 19 \\
\hline & & \multicolumn{2}{|c|}{ No Worker } & $5 \mathrm{mph}$ & 20 \\
\hline
\end{tabular}

Table 6.2 Characteristics of safety garments used in this research

\begin{tabular}{|c|c|c|c|}
\hline $\begin{array}{c}\text { Safety Garment } \\
\text { Classification }\end{array}$ & Background Material & $\begin{array}{c}\text { Retroreflective } \\
\text { Material }\end{array}$ & $\begin{array}{c}\text { Retroreflective Band } \\
\text { Width }\end{array}$ \\
\hline Class 3 & $543 \mathrm{in}^{2}$ & $149 \mathrm{in}^{2}$ & 2 in \\
\hline Class 2 & $538 \mathrm{in}^{2}$ & $112 \mathrm{in}^{2}$ & 2 in \\
\hline Assembly K & $974 \mathrm{in}^{2}$ & $205 \mathrm{in}^{2}$ & 2 in \\
\hline
\end{tabular}

\subsubsection{Survey Development and Implementation}

The survey designed for the evaluation of the camera systems included two sections. The first section included questions pertaining to the respondent's demographics, including ethnicity, age, gender, use of corrective lenses, whether the respondent was color blind or not, whether there 
was a history of color blindness in the respondent's family or not, and the respondent's occupation or affiliation with Purdue University. The second section of the survey included the evaluation of the images in the videos shown during the survey. For each video, the respondent was asked to write the time at which they were able to identify the mannequin in the path of the backing vehicle. They were also asked to assess the field of view, glare, and overall image quality of the image provided by the camera. Each of these three image characteristics was assessed on a scale of one to five, one being the worst and five being the best. An additional section was included in the survey administered to highway construction workers. In this section, the respondent was asked to rank six characteristics associated with the camera systems from one to six, one being the least important and six being the most important. The six characteristics to be ranked by the respondent were: (1) cost, (2) visibility of object in camera's view, (3) sufficient distance provided for equipment to stop once worker is identified, (4) field of view, (5) glare, and (6) overall image quality.

The total number of videos was divided into two separate surveys containing eighteen and nineteen videos, respectively, in order to reduce the time required to implement the survey and to reduce the chance of respondents becoming bored after viewing many videos and providing input that might skew the survey results. Both of these surveys were shown to respondents with the original order of the videos and with the order of videos reversed in order to eliminate any effects of a video always being viewed in a certain place (i.e., first or last). At each session the videos were presented one by one to the respondents to the survey. 


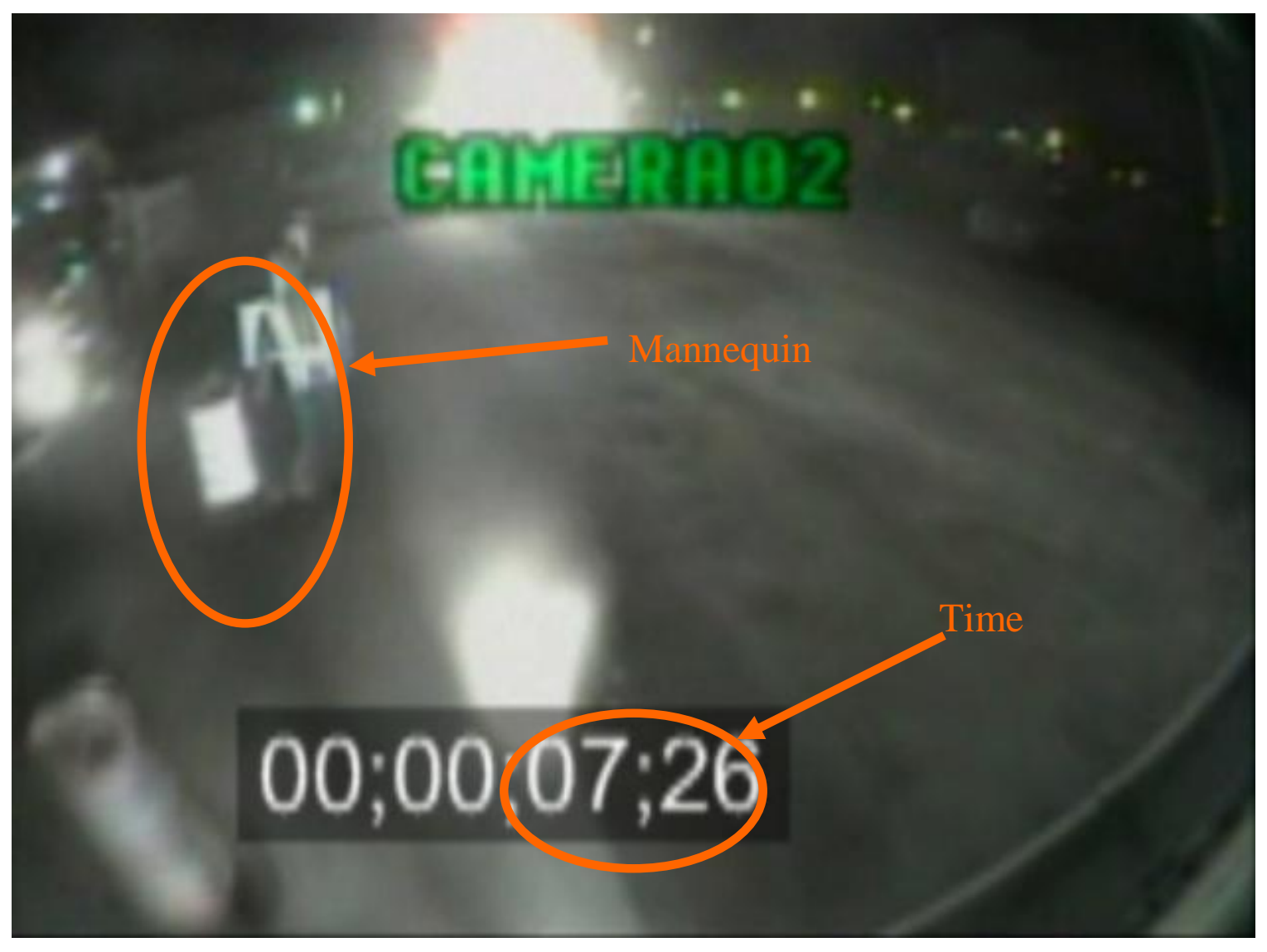

Figure 6.2 Sample frame from video used during survey

Figure 6.2 shows a sample frame from one of the videos presented during one of the sessions. The first two digits in the image represent the number of seconds that have passed since the start of the video. The second two digits represent the number of frames that have passed in a given second. Each video was recorded at 30 frames per second; therefore the last two digits can range from 00 to 29 . The respondent was only asked to identify the second and the first digit of the number of frames that had passed since the second digit changed quickly and was difficult to identify. For the sample frame shown in Figure 6.2 the respondent would identify a time of 07;2. The last digit provided by the respondent was rounded to frame 5,15 , or 25 if the digit was 0,1 , or 2 , respectively. These frames correlate to $0.2,0.5$, and 0.8 seconds, respectively. This 
fraction of a second was added to the number of seconds identified by the first two digits of the response.

Table 6.3 Sample population and Response Rate of the Survey

\begin{tabular}{cccccc}
\hline Group & $\begin{array}{c}\text { Number of } \\
\text { Respondents }\end{array}$ & $\begin{array}{c}\text { Response Rate } \\
\text { Average Age }\end{array}$ & $\begin{array}{c}\text { Male } \\
82 \%\end{array}$ & Female \\
Students & 112 & $75 \%$ & 22 & $18 \%$ \\
\hline Workers & 103 & $100 \%$ & 41 & $92 \%$ & $8 \%$ \\
\hline Total & 215 & $84 \%$ & 31 & $87 \%$ & $13 \%$ \\
\hline
\end{tabular}

Table 6.4 Combination of videos evaluated by group 1

\begin{tabular}{cccccc}
\hline $\begin{array}{c}\text { Video } \\
\text { Order }\end{array}$ & Camera & $\begin{array}{c}\text { Rear Lights } \\
(\text { On/Off })\end{array}$ & Safety Vest & Location* & $\begin{array}{c}\text { Speed } \\
(\mathbf{m p h})\end{array}$ \\
\hline 1 & 2 & On & Class 2 & D & 10 \\
\hline 2 & 1 & On & Class 2 & P & 5 \\
\hline 3 & 2 & On & Class 3 & D & 10 \\
\hline 4 & 1 & On & Class 3 & P & 10 \\
\hline 5 & 2 & On & Assembly K & D & 5 \\
\hline 6 & 1 & On & Assembly K & D & 10 \\
\hline 7 & 2 & On & No Vest & D & 5 \\
\hline 8 & 1 & On & No Vest & P & 10 \\
\hline 9 & 2 & On & No Worker & N/A & 10 \\
\hline 10 & 1 & Off & Class 2 & P & 5 \\
\hline 11 & 1 & Off & Class 2 & P & 10 \\
\hline 12 & 2 & Off & Class 3 & D & 5 \\
\hline 13 & 1 & Off & Class 3 & D & 10 \\
\hline 14 & 2 & Off & Class 3 & P & 5 \\
\hline 15 & 1 & Off & Assembly K & P & 5 \\
\hline 16 & 2 & Off & Assembly K & D & 10 \\
\hline 17 & 1 & Off & No Vest & D & 5 \\
\hline 18 & 2 & Off & No Vest & D & 10 \\
\hline 19 & 1 & Off & No Worker & N/A & 5 \\
\hline
\end{tabular}

* D refers to driver's side of truck next to barrel placed 40' from starting point. P refers to passenger's side of truck next to loader 100' from starting point.

The survey was administered to 4 groups of students in Purdue University's School of Civil Engineering as well as 7 groups of contractors, equipment operators, and construction workers. A total of 112 students and 103 contractors, equipment operators, and construction workers 
participated in the survey. Table 6.3 describes the sample population for each group of stakeholders who took part in the survey. Table 6.4 shows the combination of videos shown to a group during one particular survey session. A copy of the survey distributed to the students and contractors, equipment operators, and construction workers is located in Appendix A and B, respectively.

\subsubsection{Measurement of Safe Stopping Distance}

In order to identify the stopping distance required for the trucks used in this research, an average of the actual stopping distances for both trucks was used. Each truck was driven in reverse at speeds of 5,10, and $15 \mathrm{mph}$ and brought to an immediate stop. The length of the tire marks left by the truck at each speed was measured. This process was repeated three times for each speed for both trucks to obtain an average stopping distance required for each truck. Using the average speed of the truck as the video was recorded; the stopping distance was interpolated using these average stopping distances. Table 6.5 lists the weight of the empty truck, the truck capacity, and the stopping distance required at 5,10 , and $15 \mathrm{mph}$.

Table 6.5 Truck weights and stopping distance required

Stopping Distance Required at

\begin{tabular}{cccccc} 
Truck & Weight (ton) & Capacity (ton) & $\mathbf{5} \mathbf{~ m p h}$ & $\mathbf{1 0} \mathbf{~ m p h}$ & $\mathbf{1 5} \mathbf{~ m p h}$ \\
\hline 38 & 23.5 & 15 & $3^{\prime} 2^{\prime \prime}$ & $7^{\prime}$ & $13^{\prime} 9^{\prime \prime}$ \\
\hline 46 & 22.5 & 15 & $3^{\prime}$ & $5^{\prime}$ & $11^{\prime}$ \\
\hline
\end{tabular}

\subsection{Data Analysis}

The results from the survey were first analyzed using hypothesis testing. The process for obtaining the required stopping distance of the dump trucks is described in Chapter 5. The hypothesis that the distance between a worker and the backing dump truck at the time the worker 
can be identified using the rear-mounted camera is sufficient stopping distance was tested at $90 \%$ confidence. Next, the confidence required to state that the distance between truck and worker is sufficient to stop was calculated. Once this confidence was determined, the Analytical Hierarchy Process (AHP) was used to evaluate both camera systems based on six camera characteristics: (1) the level of confidence required to state that the mobile equipment has sufficient distance to stop before striking a worker, (2) the cost of the camera system, (3) the probability that a worker will be identified in the image provided by the camera system, and the survey respondents' perception of the (4) field of view, (5) glare, and (6) overall image quality. The survey respondents ranked these six criteria.

\subsubsection{Descriptive Analysis of the Data Collected from Video Surveys}

The survey was conducted using four groups of civil engineering students at Purdue University, West Lafayette, Indiana and seven groups of contractors, equipment operators, and construction workers. A total of 112 students and 103 workers participated in the survey. The student and worker responses were then analyzed. Figure 6.3 shows the distribution histogram for the age of the student and worker respondents.
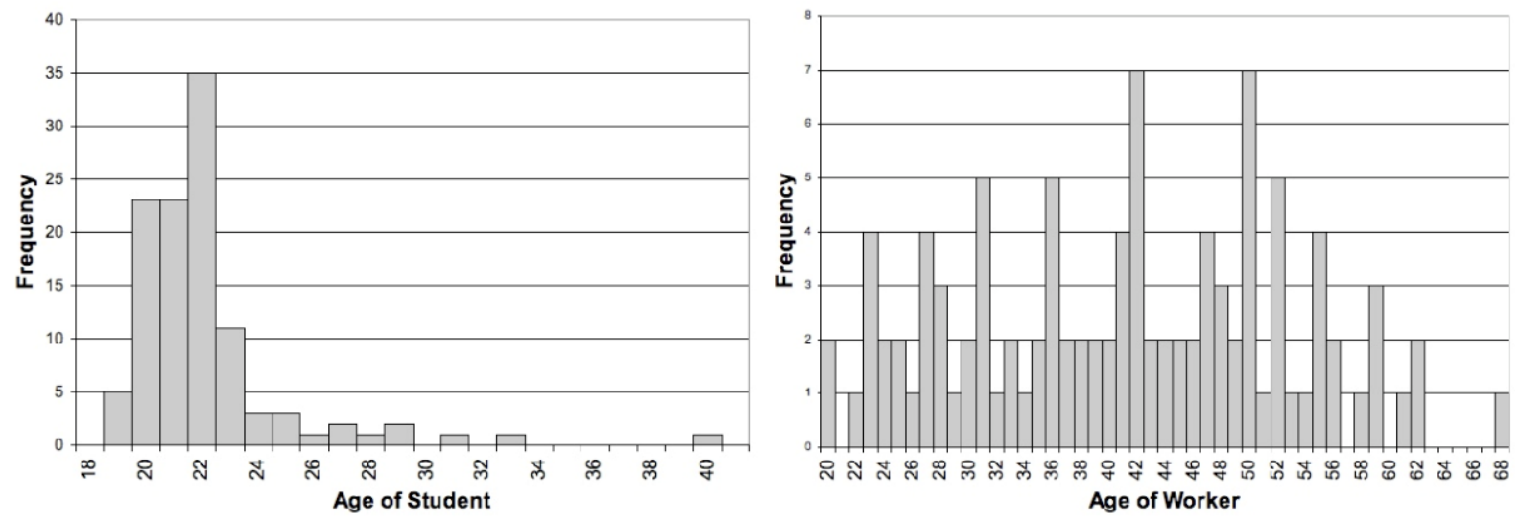

Figure 6.3 Age distributions of student and worker respondents 
For student respondents, 75\% were White, followed by Asian (18\%), Hispanic of Latino (5\%), and Black (1\%). Two percent of the respondents were of ethnicities not classified in the previously mentioned categories. Eighty-two percent of student respondents were male. Eightyseven percent were undergraduate students, followed by graduate students (13\%), and faculty (1\%). Forty-seven percent of student respondents wore corrective lenses, $10 \%$ have a history of color blindness in their family, and $4 \%$ of the respondents are color blind.

For worker respondents, $75 \%$ were White, followed by Black (17\%), and Hispanic of Latino (4\%). None of the worker respondents were Asian. Two percent of the respondents were of ethnicities not classified in the previously mentioned categories. Ninety-two percent of worker respondents were male. Fifty-one percent were highway technicians, followed by maintenance workers (39\%), drivers (14\%), foremen (7\%), heavy equipment operators (6\%), flaggers (6\%), and inspectors (1\%). Eight percent of respondents held occupations not classified in the previously mentioned categories. Forty-four percent of worker respondents wore corrective lenses, $4 \%$ have a history of color blindness in their family, and $4 \%$ of the respondents are color blind. 


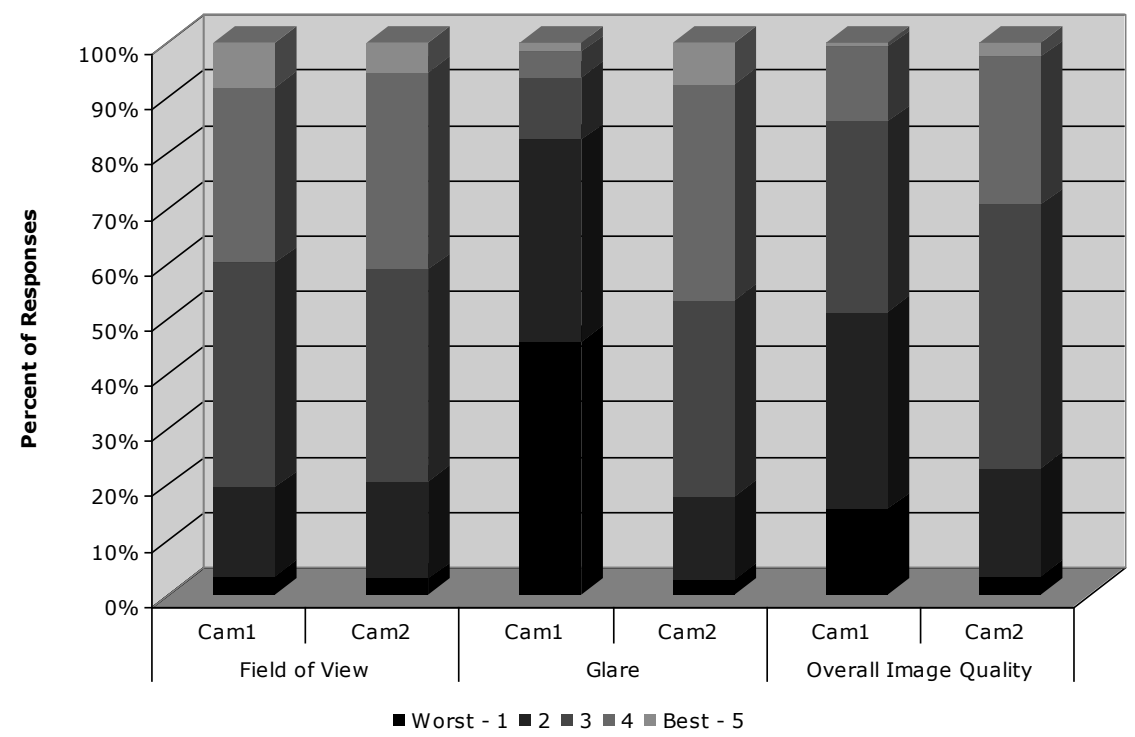

Figure 6.4 Summary of student ratings of camera characteristics

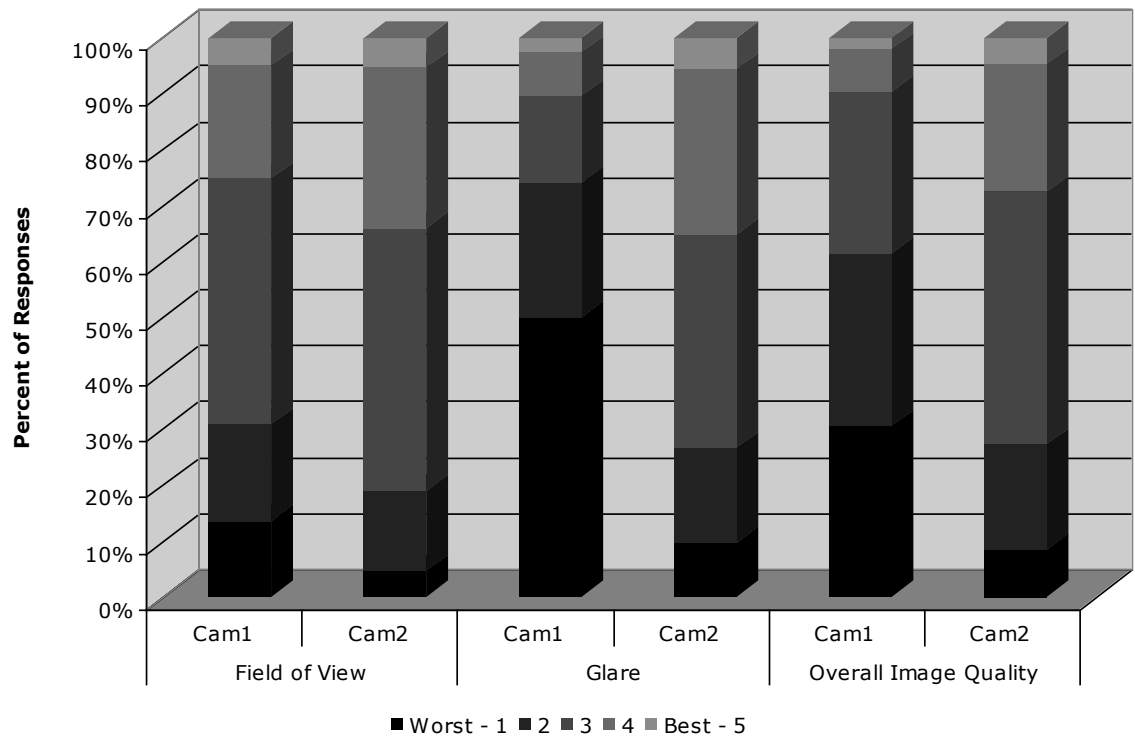

Figure 6.5 Summary of worker ratings of camera characteristics

Respondents were asked to rate the field of view, glare, and overall image quality of the image provided by the camera system on a relative scale ranging from one to five, one being the worst 
and five being the best. Figure 6.4 and Figure 6.5 show a summary the ratings for these three characteristics of cameras 1 and 2 given by students and workers, respectively. The figure shows that about $40 \%$ of students and $45 \%$ of workers gave camera 1 the lowest ranking possible for glare, compared to camera 2 , which had about $1 \%$ and $5 \%$ of student and workers giving it the lowest rating possible. Table 6.6 shows the average rating for all three characteristics of cameras 1 and 2 given by students, workers, and both groups combined. This table shows that camera 2 received a average ranking greater than camera 1 in all three areas of camera characteristics with the exception of the field of view as ranked by student respondents where camera one receives an average score of 3.25 , slightly higher than 3.23 for camera 2 . Due to the low number of colorblind respondents in both groups of stakeholders, it is difficult to conclude whether or not colorblindness has an effect on perception of these three image characteristics.

Table 6.6 Combination of videos evaluated by group 1

\begin{tabular}{|c|c|c|c|c|}
\cline { 3 - 5 } \multicolumn{2}{c|}{} & Field of View & Glare & $\begin{array}{c}\text { Overall Image } \\
\text { Quality }\end{array}$ \\
\hline \multirow{2}{*}{ Students } & Cam1 & 3.25 & 1.80 & 2.48 \\
\cline { 2 - 5 } & Cam2 & 3.23 & 3.34 & 3.06 \\
\hline \multirow{2}{*}{ Workers } & Cam1 & 2.86 & 1.89 & 2.19 \\
\cline { 2 - 5 } & Cam2 & 3.16 & 3.05 & 2.96 \\
\hline \multirow{2}{*}{ All } & Cam1 & 3.10 & 1.84 & 2.35 \\
\cline { 2 - 5 } & Cam2 & 3.19 & 3.20 & 3.01 \\
\hline
\end{tabular}

\subsubsection{Results of Hypothesis Testing}

Earlier in this study, the distance between truck and mannequin at the time of identifying the mannequin in the image provided by the camera, was investigation. However, at that time, the stopping distance required by the truck at a given speed, was not considered. Stopping distances for trucks 1 and 2 were measured by the length of the skid mark made when the driver applied 
the brakes at 5, 10, and $15 \mathrm{mph}$, as previously described with results summarized in Table 6.5. This study attempts to identify whether or not there is sufficient stopping distance to stop before striking a worker when the worker is identified in the image provided by the camera and the driver applies the brakes. This has been done through hypothesis testing.

The null hypothesis $\left(\mathrm{H}_{0}\right)$ that the distance between the dump truck and the mannequin was equal to the stopping distance required by the dump truck on dry gravel was tested a $90 \%$ confidence level. The alternative hypothesis $\left(\mathrm{H}_{\mathrm{a}}\right)$ tested was that the distance between the truck and mannequin is greater than the required stopping distance of the truck. The alternative hypothesis is the desired result; therefore a rejected null hypothesis is desired. The null hypothesis was tested for each video shown during the survey sessions. Table 6.7 summarizes the results of the hypothesis testing done for both cameras using responses from students, workers, and the combination of both groups. The left-hand side of the table shows the combination of variables used in each video while the right-hand side answers the question "Is the data sufficient enough to reject the null hypothesis?" Since the desired result is the rejection of the null hypothesis, "yes" is a favorable response.

Unfortunately, the majority of the variable combinations resulted in not rejecting the null hypothesis, indicating that one cannot state with $90 \%$ confidence that the distance between truck and worker is sufficient for the truck to stop before striking the worker in its path. There are a number of observations that can be made by inspection of the results to the hypothesis testing. It can be seen that there are more instances of the null hypothesis being rejected with the use of camera 2 than there are when using camera 1. 
Table 6.7 Results of hypothesis testing for cameras 1 and 2

\begin{tabular}{|c|c|c|c|c|c|c|c|c|c|}
\hline \multirow[b]{3}{*}{ 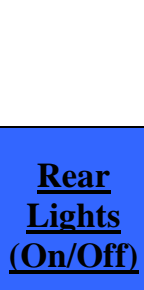 } & \multirow[b]{3}{*}{$\underline{\text { Vest }}$} & \multirow[b]{3}{*}{ Location* } & \multirow[b]{3}{*}{$\frac{\text { Speed }}{\underline{(\mathrm{mph})}}$} & \multicolumn{6}{|c|}{ Reject $\mathrm{H}_{0}$ ? } \\
\hline & & & & \multicolumn{3}{|c|}{ Camera 1} & \multicolumn{3}{|c|}{ Camera 2} \\
\hline & & & & 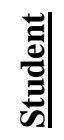 & 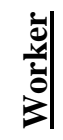 & $\equiv$ & 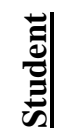 & 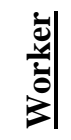 & $\equiv$ \\
\hline \multirow{7}{*}{ On } & \multirow{2}{*}{ Class II } & $\mathrm{D}$ & 5 & No & No & No & No & No & No \\
\hline & & $\mathrm{P}$ & 5 & No & No & No & Yes & Yes & Yes \\
\hline & Class III & $\mathrm{D}$ & 10 & No & No & No & No & No & No \\
\hline & Assembly K & $\mathrm{D}$ & 5 & No & No & No & No & No & No \\
\hline & \multirow{2}{*}{ No Vest } & $\mathrm{D}$ & 5 & No & No & No & Yes & No & No \\
\hline & & $\mathrm{P}$ & 10 & No & No & No & No & No & No \\
\hline & \multicolumn{2}{|c|}{ No Worker } & 10 & \multicolumn{6}{|c|}{ N/A } \\
\hline \multirow{10}{*}{ Off } & \multirow{2}{*}{ Class II } & \multirow{2}{*}{$\mathrm{P}$} & 5 & Yes & Yes & Yes & Yes & Yes & Yes \\
\hline & & & 10 & No & No & No & No & No & No \\
\hline & \multirow{3}{*}{ Class III } & \multirow{2}{*}{$\mathrm{D}$} & 5 & No & No & No & No & No & No \\
\hline & & & 10 & No & No & No & No & No & No \\
\hline & & $\mathrm{P}$ & 5 & No & No & No & Yes & Yes & Yes \\
\hline & \multirow{2}{*}{ Assembly K } & $\mathrm{P}$ & 5 & No & Yes & Yes & Yes & Yes & Yes \\
\hline & & $\mathrm{D}$ & 10 & No & No & No & No & No & No \\
\hline & \multirow{2}{*}{ No Vest } & \multirow{2}{*}{ D } & 5 & No & No & No & No & No & No \\
\hline & & & 10 & No & No & No & No & No & No \\
\hline & \multicolumn{2}{|c|}{ No Worker } & 5 & \multicolumn{6}{|c|}{ N/A } \\
\hline
\end{tabular}

* D refers to driver's side of truck. P refers to passenger's side of truck.

It can also be seen that the null hypothesis was only rejected in cases when the truck was backing at $5 \mathrm{mph}$. With the exception of one case, the null hypothesis was only rejected when the mannequin was located on the passenger side of the truck and was wearing some form of safety vest, however it is difficult to conclude that one type of safety vest was better than another. It is also difficult to conclude whether or not colorblindness significantly impacts the viewer's ability to identify a worker in the image due to the low number of colorblind respondents. Some of 
these results may have been influenced by the experimental setup. For instance, when the mannequin was placed on the passenger's side of the truck, it was between the headlights of the loader and the camera on the back of the dump truck. This may have caused the mannequin to be more visible, not just that the mannequin was located on the passenger side of the truck.

\subsubsection{Results of Confidence Analysis}

Due to the low occurrence of the null hypothesis being rejected for the alternative hypothesis, it was decided to calculate the level of confidence required to state that the distance between the truck and mannequin is sufficient to stop the backing truck before striking a worker. For all cases, if the null hypothesis was not rejected, the confidence level was calculated as $0 \%$ and when the null hypothesis was rejected for the alternative hypothesis, the confidence was calculated as $100 \%$. For this reason it was decided to calculate the average confidence level required to reject the null hypothesis for each camera, not for each case.

Table 6.8 Results of confidence analysis for cameras 1 and 2

\begin{tabular}{|l|r|r|r|}
\cline { 2 - 4 } \multicolumn{1}{c|}{} & \multicolumn{1}{c|}{ Student } & Worker & \multicolumn{1}{c|}{ All } \\
\hline Camera 1 & $5.88 \%$ & $17.65 \%$ & $11.76 \%$ \\
\hline Camera 2 & $31.25 \%$ & $25.00 \%$ & $25.00 \%$ \\
\hline
\end{tabular}

Table 6.8 shows the average confidence required to reject the null hypothesis in favor of the alternative hypothesis for both cameras using responses from students, workers, and the combination of both groups. The analysis of the data collected when using camera 1 shows that the null hypothesis is rejected at a lower confidence level, regardless of the group surveyed. This implies that one can be more confident that a worker will be identified with sufficient distance for the truck to stop before the worker is struck when using camera 2 rather than camera 1. 


\subsubsection{Results of the Analytical Hierarchy Process}

Using the survey responses of students and worker's perception of the field of view, glare, and overall image quality of the image provided by each camera system as well as the rate at which respondents were able to identify a worker in the video, the confidence level required to reject the null hypothesis, and the cost of the camera system, the analytical hierarchy process (AHP) was used to provide a subjective ranking of the two camera systems investigated in this research. The workers who completed the survey were asked to rank these six characteristics of the camera systems in order from lowest to highest importance. A pair-wise matrix was constructed using these responses in order to calculate relative weights to assign each characteristic. The resulting weights are shown in Table 6.9.

Table 6.9 Weights of camera characteristics based on responses given by workers

\begin{tabular}{|r|l|}
\hline Distance & 0.1610 \\
\hline Cost & 0.0839 \\
\hline Visibility & 0.2245 \\
\hline Field of View & 0.1791 \\
\hline Glare & 0.1531 \\
\hline Image Quality & 0.1984 \\
\hline
\end{tabular}

The resulting weights show that the cost of the system is the least important characteristic and visibility, which was defined as the probability of a worker being visible in the image provided by the camera system, as the most important characteristic when considering the use of camera systems in mobile equipment.

Relative scores for both camera systems were calculated for the field of view, glare, and overall image quality using a similar method of constructing pair-wise matrices. For the objective data used in the AHP, the results were normalized to provide relative scores for each characteristic. These scores can be seen in Table 6.10, which provides the scores for both camera systems with 
regards to each of the six camera characteristics considered in this research. The table provides the results for student and worker responses as well as the combination of both groups.

Table 6.10 Scores of camera characteristics based on responses given by students, workers, and the combination of both groups

\begin{tabular}{|c|c|c|c|c|c|c|c|}
\hline & & Distance & Cost & Visibility & $\begin{array}{c}\text { Field of } \\
\text { View } \\
\end{array}$ & Glare & $\begin{array}{l}\text { Image } \\
\text { Quality }\end{array}$ \\
\hline \multirow{2}{*}{ 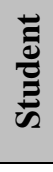 } & Camera 1 & 0.1584 & 0.7250 & 0.4473 & 0.4998 & 0.3467 & 0.4442 \\
\hline & Camera 2 & 0.8416 & 0.2750 & 0.5527 & 0.5002 & 0.6533 & 0.5558 \\
\hline \multirow{2}{*}{ 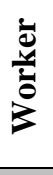 } & Camera 1 & 0.3200 & 0.7250 & 0.4456 & 0.4752 & 0.4273 & 0.4256 \\
\hline & Camera 2 & 0.6800 & 0.2750 & 0.5544 & 0.5248 & 0.5727 & 0.5744 \\
\hline \multirow{2}{*}{$\bar{z}$} & Camera 1 & 0.4138 & 0.7250 & 0.4532 & 0.4919 & 0.3650 & 0.4374 \\
\hline & Camera 2 & 0.5862 & 0.2750 & 0.5468 & 0.5081 & 0.6350 & 0.5626 \\
\hline
\end{tabular}

It can be seen that camera 2 received a higher score for all characteristics regardless of the group surveyed, with the exception of the cost of the camera system. These scores shown in Table 6.10 were assembled into a matrix and the weights of the camera characteristics were assembled into a vector. These were multiplied as shown in Eq. 6.1, Eq. 6.2, and Eq. 6.3 to give the final ranking for each camera based on student, worker, and all responses, respectively.

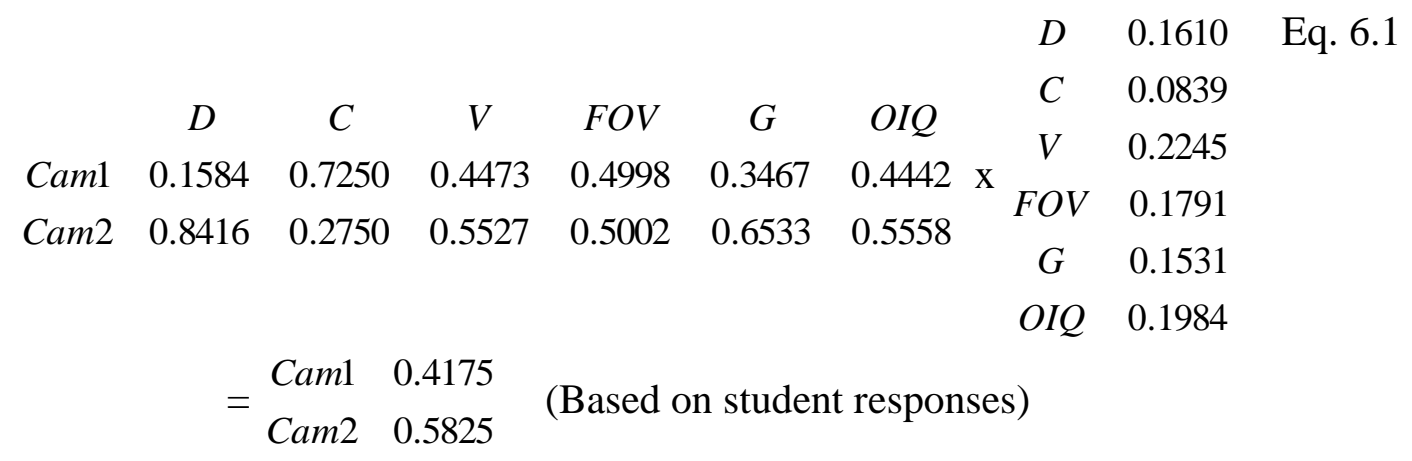




\begin{tabular}{|c|c|c|c|c|c|c|c|c|c|}
\hline \multirow{4}{*}{ Cam1 } & \multirow{3}{*}{$D$} & \multirow{3}{*}{$C$} & \multirow{3}{*}{$V$} & \multirow{3}{*}{$F O V$} & \multirow{3}{*}{$G$} & \multirow{3}{*}{$O I Q$} & $D$ & 0.1610 & \multirow[t]{3}{*}{ Eq. 6.2} \\
\hline & & & & & & & $C$ & 0.0839 & \\
\hline & & & & & & & $V$ & 0.2245 & \\
\hline & 0.3200 & 0.7250 & 0.4456 & 0.4752 & 0.4273 & $0.4256 \mathrm{x}$ & FOV & 0.1791 & \\
\hline \multirow{4}{*}{$\operatorname{Cam} 2$} & 0.6800 & 0.2750 & 0.5544 & 0.5248 & 0.5727 & 0.5744 & $G$ & 0.1531 & \\
\hline & & & & & & & $O I Q$ & 0.1984 & \\
\hline & & Caml & 0.4474 & (Based & $n$ worke & r resnonses & & & \\
\hline & & Cam2 & 0.5526 & & & & & & \\
\hline \multirow{8}{*}{$\begin{array}{l}\text { Cam1 } \\
\text { Cam2 }\end{array}$} & & & & & & & $D$ & 0.1610 & Eq. 6.3 \\
\hline & $D$ & $C$ & $V$ & EOV & $C$ & OIO & $C$ & 0.0839 & \\
\hline & 04120 & 07050 & 01520 & FOV & 02650 & OIQ & $V$ & 0.2245 & \\
\hline & 0.4138 & 0.7250 & 0.4532 & 0.4919 & 0.3650 & $0.43 / 4 x$ & $F O V$ & 0.1791 & \\
\hline & 0.5862 & 0.2750 & 0.5468 & 0.5081 & 0.6350 & 0.5626 & $G$ & 0.1531 & \\
\hline & & & & & & & $O I Q$ & 0.1984 & \\
\hline & & $=C a m 1$ & 0.4600 & \multirow{2}{*}{\multicolumn{3}{|c|}{ (Based on all responses) }} & & & \\
\hline & & Cam 2 & 0.5400 & & & & & & \\
\hline
\end{tabular}

The results from AHP show that camera 2 is ranked to be a better alternative when considering these six characteristics: (1) the level of confidence required to state that the mobile equipment has sufficient distance to stop before striking a worker, (2) the cost of the camera system, (3) the probability that a worker will be identified in the image provided by the camera system, and the survey respondents' perception of the (4) field of view, (5) glare, and (6) overall image quality.

This result is the same, regardless of the group surveyed. This result differs from that found by Ferreira (2007), which determined camera 1 to be the better camera for identifying a worker in the path of a backing dump truck. This difference can be attributed to a number of differences in the research. First, the research by Ferreira was performed for daytime operations where this research was performed for nighttime operations. The use of headlights for the nighttime operations significantly increased the glare in the images produced by the cameras. Ferreira (2007) describes a camouflage effect in his work where a worker wearing a fluorescent colored safety vest standing near a similarly colored piece of machinery is camouflaged by the similar 
background, making the worker more difficult to identify. This effect is reduced in this research due to the retroreflective material on the safety garments.

\subsection{Chapter Summary}

This research explored the relationship between technologies available to monitor blind spots in mobile equipment and safety. This study specifically evaluated the use of rear-mounted camera systems to improve visibility of workers in blind spots associated with mobile construction

equipment. As a result it should prevent workers from being struck by dump trucks used in nighttime highway construction and maintenance operations.

\subsubsection{Research Limitations}

The research done for this study has a number of limitations associated with the manner in which the experiments were conducted to gather data for either of the two objectives. The first limitation of the evaluation of the use of camera systems is related to the set up of the simulated work zone. The Tippecanoe County Highway Maintenance office does not typically perform nighttime work and therefore did not have various lighting towers available for use in the simulated work zone. The original experiment was designed to incorporate these various light sources in the simulated work zone, however, due to the lack of these light sources, the only lighting provided was that of a lamppost, vehicle headlights, and rear-mounted lights on the dump trucks. The second limitation was the use of headlights in the simulated work zone. After the videos were recorded it was discovered that the equipment operators typically operate the equipment without headlights while in the work zone in order to reduce glare to workers. The dump trucks and front-end loader in the simulated work zone were operating with headlights on in order to simulate the light intruding into the work zone from passing traffic. 


\subsubsection{Recommendations for Future Research}

An econometric model should be used to evaluate the data collected through this research. With the results of an econometric model, factors that increase the likelihood of a worker being identified in the path of backing mobile equipment can be identified. These factors can then be used while planning construction operations.

Highway construction and maintenance operations are performed in multiple environmental conditions that may influence the identification of a worker in the path of backing mobile equipment. Operations performed in conditions such as rain, snow, and fog should be investigated. Tests should also include multiple workers in the work zone and the motions of workers as well as different tasks (i.e., earthwork, paving, snow removal, etc.).

Different types of mobile equipment (i.e., loaders and scrapers) that perform backing operations should be considered when using rear-mounted cameras. All large construction equipments have blind spots that must be considered when mounting the cameras. The preferred mounting position should be one that reduces the size of the blind spot as much as possible. Similar testing procedures may be able to be used to evaluate the performance of these camera systems and identify factors influencing the identification of a worker in the mobile equipment's blind spot. 


\section{CHAPTER 7. USE OF CAMERA SYSTEMS TO INCREASE PRODUCTIVITY OF MOBILE EQUIPMENT IN NIGHTTIME OPERATIONS}

\subsection{Data Collection Process}

A method was developed to assess the difference in spotting time required by a dump truck backing into a simulated loading zone. A simulated loading site was developed so that both dump trucks with rear-mounted cameras could back into the zone with and without the use of the camera system. The time was recorded for a number of attempts at backing into the simulated loading zone with and without the assistance of the camera system. These times were then used to evaluate the influence of the rear-mounted camera system on the spotting time required to load a dump truck

A simulated loading zone was constructed by marking the area occupied by a stationary dump truck. Barrels were placed around this area, providing two feet of clearance to the rear and to either side of the dump truck. The front side of the area was marked with a line so that the dump truck was able to enter and exit the simulated loading area. A front loader was placed to the side of the loading zone with its bucket in the raised position, simulating a loader ready to load the dump truck. A line was drawn fifty feet from the front side of the loading zone to identify the starting position of the dump truck. Figure 7.1 provides a diagram of the layout of the simulated loading zone.

The truck driver was asked to start with the front tires of the truck on the starting line. The driver would then back the truck into the loading zone without the help of the rear-mounted camera system. The time, in seconds, was measured from the start of the truck's motion to the point when the truck came to rest with the front tires in the loading zone. This time represented the spotting time required for the loading of a dump truck. The procedure was repeated 20 times for 
both trucks. Next, the truck driver was asked to perform the same backing task with the assistance of the rear-mounted camera system. Both trucks performed the task 20 times with the use of the cameras. The number of trials did not reduce the spotting time - in fact, the use of the cameras significantly increased the spotting time (i.e., it reduced productivity). A possible cause for the increase could be the lack of familiarity with the camera system and its use for spotting purposes.

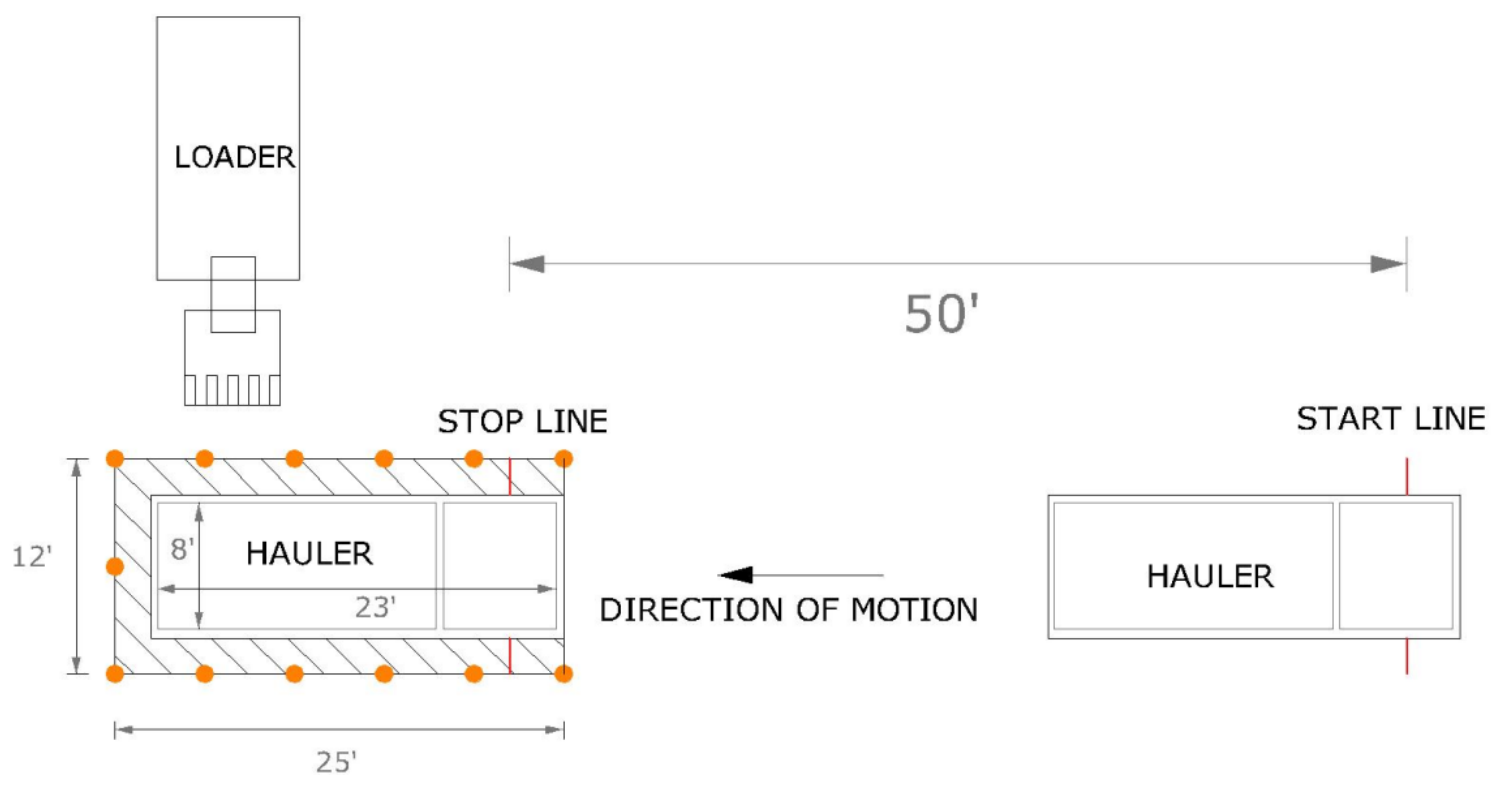

Figure 7.1 Setup of simulated work zone used to test camera system performance in assisting equipment operators in viewing equipment blind spot.

\subsection{Data Analysis}

To evaluate the influence of rear-mounted camera systems on the spotting time required to maneuver a dump truck into a loading position, hypothesis testing was performed using a twosample t-statistic. The data for this analysis was collected using time studies performed in a simulated loading zone. After checking each hypothesis, the confidence level required to state 
that the use of a rear-mounted camera system significantly influences spotting time was calculated.

\subsubsection{Results of Hypothesis Testing}

The null hypothesis tested was that the spotting time without the assistance of a rear-mounted camera was equal to the spotting time with the assistance of a rear-mounted camera. This hypothesis would be rejected for the alternative hypothesis, that the spotting time is reduced with the assistance of a rear-mounted camera if the test statistic was found within the rejection region. The desired result is the rejection of the null hypothesis because it is favorable if the spotting time can be reduced with the use of rear-mounted cameras. Table 7.1 shows the result of the hypothesis testing for the null hypothesis and the original alternative hypothesis. The converse to the original alternative hypothesis, that the use of rear-mounted cameras increases the spotting time, was also tested at $90 \%$ confidence level and is included in Table 7.1.

Table 7.1 Results of hypothesis testing for original and alternate alternative hypothesis

\begin{tabular}{|l|l|l|}
\cline { 2 - 3 } \multicolumn{1}{c|}{} & \multicolumn{1}{|c|}{$\begin{array}{c}\text { Reject } \mathbf{H}_{\mathbf{0}} \text { for } \\
\text { original } \mathbf{H}_{\mathbf{a}} \text { ? }\end{array}$} & $\begin{array}{c}\text { Reject } \mathbf{H}_{\mathbf{0}} \text { for } \\
\text { alternate } \mathbf{H}_{\mathbf{a}} \text { ? }\end{array}$ \\
\hline Camera 1 & No & Yes \\
\hline Camera 2 & No & Yes \\
\hline
\end{tabular}

For both camera systems the null hypothesis was not rejected for the original alternative hypothesis and was rejected for the alternate alternative hypothesis. This means that we can state with $90 \%$ confidence that the use of camera systems significantly increases spotting time. 


\subsubsection{Results of Confidence Analysis}

It was decided to calculate the confidence level required to state the use of rear-mounted cameras increases the spotting time required to maneuver a dump truck into a loading position. Since the alternative hypothesis being tested is now the increase of spotting time, a lower confidence is desired. The results for both camera 1 and 2 are given in Table 7.2.

Table 7.2 Results of confidence analysis for cameras 1 and 2

\begin{tabular}{|l|r|}
\cline { 2 - 2 } \multicolumn{1}{c|}{} & \multicolumn{1}{c|}{ Confidence } \\
\hline Camera 1 & $96.44 \%$ \\
\hline Camera 2 & $100.00 \%$ \\
\hline
\end{tabular}

The results show that it can be said with roughly $96 \%$ confidence that the use of camera 1 significantly increases the spotting time required to maneuver a dump truck into a loading position. This same statement can be made about camera 2 with $100 \%$ confidence. This means that the use of camera 2 is more likely to increase the spotting time. The difference in confidence level between camera 1 and camera 2 is small and might be attributed to differences associated with the truck drivers (i.e., age, eyesight, familiarity with the truck and camera system, etc.) and not necessarily the features of the cameras. Based on this analysis, camera 1 is the better camera to use for reducing spotting time associated with maneuvering a backing dump truck, however, camera 2 was found to be the better camera for improving visibility of workers in blind spots and hence reducing incidents of workers being struck by mobile equipment.

Recommendations to reconcile these differences are provided in Section 7.3.

\subsection{Chapter Summary}

This research explored the relationship between technologies available to monitor blind spots in mobile equipment and productivity. The influence of using rear-mounted camera systems to 
reduce the spotting time required to maneuver a dump truck into a loading position was evaluated in this study.

\subsubsection{Research Limitations}

One limitation is the amount of data collected to the spotting times required for the dump trucks to be maneuvered into a loading position. Only twenty runs were recorded for each of the two trucks while maneuvering with and without the assistance of the rear-mounted cameras. In order to assume the data to be normally distributed it is required to have at least forty runs for each truck, a total of forty runs more than what was done. Each run took around two to three minutes for set up and backing the truck into place. The runs were conducted during the workers' off hours and the workers had to be paid at the overtime rate. In addition, the Tippecanoe County Highway Maintenance office had to be reimbursed for fuel used during the data collection. As a result of the reimbursement costs and budget limitations only twenty runs were performed for the data collection.

\subsubsection{Recommendations for Future Research}

Future research should investigate the influence of proper training and the familiarity of the equipment operators with the use of the camera systems installed in their equipment. Time must be spent to teach the drivers how to use the systems and time must be given+ to the drivers so that they can become familiar with the use of the camera systems. 


\section{LIST OF REFERENCES}

American Society of Safety Engineers (ASSE). (2007). "Designing for Construction Worker Safety." <www.asse.org/membership/docs/John\%20Mroszczyk\%20Article.doc> (Mar 10, 2007).

Arboleda, C. A., (2002) "Causes of Fatalities in Trenching Operations-Analysis Using Models of Accident Causation." MSCE Thesis. Purdue University, West Lafayette, Indiana, December 2002.

Arditi, D., and Shi, J. (2004). "Effectiveness of Safety Vests in Nighttime Highway Construction.” ASCE, J. of Construction Engineering and Management, 130, pp. 725-732.

Bacon, K. (2002). "PPE That Makes A Visible Difference." Occupational Health \& Safety, 71(6), 81-84.

Benekohal, R. F., Kastel, L.M., and Suhale, M. (1992a). Evaluation and Summary of Studies in Speed Control Methods in Work Zones (FHWA-IL-UI-237). Illinois Department of Transportation, Springfield, IL.

Benekohal, R. F., Resende, P.T.V., and Zhao, W. (1992b). Speed Reduction Effects of Drone Radar in Rural Interstate Work Zones (Report FHWA-IL-238). University of Illinois , Urbana, IL.

Blackmon R.B., and Gramopadhye, A.K., (1995). Improving Construction Safety by Providing Positive Feedback on Backup Alarms. Journal of Construction Engineering and Management, Vol. 121, No. 2, June, pp. 166 - 171.

Bureau of Labor Statistics BLS (2007) "Occupational Injury and Illness Classification Manual” < http://www.bls.gov/iif/oshsec2.htm\#f> (September 26, 2007)

Bryden, J. E., and Andrew L.B., (1999). "Serious and Fatal Injuries to Workers on Highway Construction Projects". Transportation Research Record No. 1657, pp. 42-47.

Colbert, D. (2003). "Productivity and Safety Implications for Night-Time Construction Operations." Independent Research Study, School of Civil Engineering, Purdue University, West Lafayette, IN.

Duchon, J.C., and Laage, L.W. (1986). "The Consideration of Human Factors in the Design of a Backing-Up Warning System" Proceedings $30^{\text {th }}$ Annual Meeting, Vol. 1, Human Factors Society, Santa Monica, California, pp. 261-264.

El-Rayes, K. and Hyari, K. (2005) "Optimizing Lighting Arrangements for Nighttime Highway Construction Projects." ASCE Journal of Construction Engineering and Management, 131(12), 1292-1299. 
El-Rayes, K., and Hyari, K. (2002). Automated DSS for Lighting Design of Nighttime Operations in Highway Construction Projects. University of Illinois at Urbana-Champaign, Urbana, IL.

Fatality Assessment and Control Evaluation (FACE) Program (2003a). “Construction

Laborer dies after being Run Over and Crushed by a Grader at a Road Construction Site North Carolina”. National Institute for Occupational Safety and Health (NIOSH)

$<$ http://www.cdc.gov/niosh/face/In-house/full200203.html> (Oct 16, 2006)

Fatality Assessment and Control Evaluation (FACE) Program (2003b). "Police Officer Dies after being Backed Over by a Dump Truck - Massachusetts". National Institute for Occupational Safety and Health (NIOSH) <http://www.cdc.gov/niosh/face/stateface/ma/01 ma039.html> (Oct $18,2006)$

Fatality Assessment and Control Evaluation (FACE) Program (2003c). "A Traffic Controller Is Killed when Backed over by a Dump Truck". National Institute for Occupational Safety and Health (NIOSH) <http://www.cdc.gov/niosh/face/stateface/ca/01CA004> (Oct 18, 2006)

Fatality Assessment and Control Evaluation (FACE) Program (2003d). "A Construction Surveyor is Run Over by a Motor Grader that was Backing Up". National Institute for Occupational Safety and Health (NIOSH)

<http://www.cdc.gov/niosh/face/stateface/ca/01CA008> (Oct 18, 2006)

Fatality Assessment and Control Evaluation (FACE) Program (2004a). "Roadway Construction Worker Dies from Crushing Injuries when Backed Over by a Dump Truck - Virginia". National Institute for Occupational Safety and Health (NIOSH) <http://www.cdc.gov/niosh/face/Inhouse/full200206.html> (Oct 16, 2006)

Fatality Assessment and Control Evaluation (FACE) Program (2004b). "Engineering Technician Run Over and Killed by Backing Dump Truck". National Institute for Occupational Safety and Health (NIOSH) <http://www.cdc.gov/niosh/face/stateface/ne/04ne007.html> (Oct 18, 2006)

Fatality Assessment and Control Evaluation (FACE) Program (2004c). "A Road Construction Worker was killed when he was Run Over by an Asphalt Dump Truck". National Institute for Occupational Safety and Health

(NIOSH)<http://www.cdc.gov/niosh/face/stateface/ok/03ok047.html> (Oct 18, 2006)

Fatality Assessment and Control Evaluation (FACE) Program (2005a). "Hispanic Flagger Dies after being Run Over by a Dump Truck - North Carolina”. National Institute for Occupational Safety and Health (NIOSH) <http://www.cdc.gov/niosh/face/In- house/full200410.html> (Oct 16, 2006)

Fatality Assessment and Control Evaluation (FACE) Program (2005b). "Hispanic Laborer Run Over and Killed by Backing Dump Truck in Roadway Construction Zone”. National Institute for 
Occupational Safety and Health

(NIOSH) <http://www.cdc.gov/niosh/face/stateface/ne/04ne040.html> (Oct 18, 2006)

Fatality Assessment and Control Evaluation (FACE) Program (2006). "Traffic Control Supervisor Dies When Struck by an Asphalt Dump Truck while Picking up Cones on a Roadway Work Zone - Tennessee". National Institute for Occupational Safety and Health (NIOSH) <http://www.cdc.gov/niosh/face/Inhouse/full200510.html> (Jan 31, 2007)

Fatality Assessment and Control Evaluation (FACE) Program (2006b). "Hispanic Laborer on Roadway Construction Work Site Run Over and Killed by a Backing Flat Bed Dump Truck North Carolina". National Institute for Occupational Safety and Health (NIOSH) <http://www.cdc.gov/niosh/face/Inhouse/full200411.html> (Oct 16, 2006)

Federal Highway Administration (FHWA). (2000). "Work Zone Operations Best Practices Guidebook." $<$ http://ops.fhwa.dot.gov/wz/practices/best/documents/workzoneguidebook. pdf> (Jan.10, 2007).

Federal Highway Administration (FHWA). (2006). "Work Zone Safety Facts and Statistics" http://safety.fhwa.dot.gov/wz/wz_facts.htm> (JUN 13, 2007)

Ferreira, C. (2007). "Safety in Highway Work Zones: Strategies to Prevent Workers Injured by Mobile Equipment." MSCE thesis, School of Civil Engineering, Purdue University, West Lafayette, IN.

Hirasawa, M., Takemoto, A., Motoki, A., and Tetsuye, T. (2007). Quantifying the Degree to Which Each Improvement Influences Satisfaction (TRB 07-1466). Civil Engineering Research Institute for Cold Region, PWRI, Sapporo, Japan.

Human Subjects Office, Purdue University. (2007). "Committee on the Use of Human Research Subjects." <http://www.irb.purdue.edu/> (Apr. 14, 2007).

Hyari, K. H. R. (2004). “Optimizing Lighting Conditions For Nighttime Highway Construction Operations." Doctoral Dissertation, University of Illinois at Urbana-Champagne, Urbana, Illinois.

Laborers Health and Safety Fund of North America (LHSFNA), American Road of Transportation Building Association (ARTBA), International Union of Operating Engineers (IUOE), and National Asphalt Pavement Association (NAPA), (2006). Road Way Safety - A Construction Industry Consortium Program. http://wzsafety.tamu.edu/program_download/>, June 20, 2007

Laws, J. (2002) “Nighttime Hazards” Occupational Health \& Safety, 71(5), 122.

Mahoney, K.M., Porter, R.J., and Taylor, D. R. (2007). Design of Construction Work Zones on High-Speed Highways (NCHRP Report 581), National Academy Press, Washington D.C. 
Manual on Uniform Traffic Control Devices (MUTCD) - Chapter 6. (2003). United States Department of Transportation: Federal Highway Administration, Washington, D. C., 2004.

McCullouch B., (2003). Backing Accident Prevention Implementation Study. Report Project SPR-2750. School of Civil Engineering, Purdue University, West Lafayette, IN.

Meyer, E., and Walton, S. (2002). Comparison of Rumbler and Asphalt Rumble Strips. Smart Work Zone Deployment Initiative, Ames, IA.

Meyer, E. (2003). Long Term Effects of Radar-Activated Speed Displays. Smart Work Zone Deployment Initiative, Ames, IA.

Minnesota Department of Transportation. (1999). "Effectiveness of Law Enforcement in Reducing Vehicle Speeds in Work Zones.” Construction Programs Section, <http://www.atssa.com/mndot.htm> (Nov. 10, 2006).

Miller, L.R. (2007). "Effectiveness of Speed Control Measures on Nighttime Construction and Maintenance Projects.” Masters Thesis, Purdue University, West Lafayette, IN.

National Cooperative Highway Research Program NCHRP (2003) "Illumination Guidelines for Nighttime Highway Work." Recommended Illumination Guidelines, Transportation Research Board, Washington, D.C., 24-27.

National Cooperative Highway Research Program NCHRP (2007) "Work Zone Lighting: State of the Practice and Implementation Impediments." Work Zone Lighting Illumination Requirements, Texas Transportation Institute, College Station, TX, 11-27.

National Institute for Occupational Safety and Health NIOSH (2003a) "National Institute for Occupational Safety and Health (NIOSH) Fact Sheet" <http://www.cdc.gov/niosh/pdfs/2003116.pdf> (Jun 10, 2007)

National Institute for Occupational Safety and Health NIOSH (2003b) "Fatality Assessment and Control Evaluation: Face Program" <http://www.cdc.gov/niosh/docs/2003-146> (Jun 10, 2007)

NIOSH Fatality Assessment and Control Evaluation (FACE) Program. (2006). "NIOSH FACE Program In-House Report 2002-2006." <http://www.cdc.gov/niosh/face/Inhouse/full200206.html> (Jan. 11, 2007).

Noel, E.C., Dudek, C.L., Pendleton, O.J., Sabra, Z. A. (1998). "Speed Control through Freeway Work Zones: Techniques Evaluation.” Transportation Research Record, No. 1163, pp. 33-42.

Occupational Safety and Health Administration (OSHA), (2005). "Laws regulations and interpretations".<http://www.osha.gov/comp-links.html> (Jul 1, 2007) 
Pegula, S. (2004). "Fatal Occupational Injuries at Road Construction Sites." Monthly Labor Review, Vol. 127, pp. 43-47.

Radio Frequency Identification Journal (2007). "Glossary of RFID terms".

<http://www.rfidjournal.com/article/articleview/208>, July 3, 2007

Ross, H.E., Sicking, D.L., and Zimmer, R. A. (2000). Recommended procedures for the safety performance evaluation of highway features (NCHRP Report 350), National Academy Press, Washington D.C.

Pratt, S. G., Fosbroke, D. E., and Marsh, S. M. (2001). "Building Safer Work Zones: Measures to Prevent Worker Injuries from Vehicles and Equipment". U.S. Department of Health and Human Services, Centers for Decease Control and Prevention, National Institute for Occupational Safety and Health, DHHS (NIOSH) No. 2001-128.

Ruff, T.M., (2001) Test Results of Collision Warning Systems on Off-Highway Dump Trucks: Phase: 2. DHHS (NIOSH) Publication No. 2001-100 (NIOSH Report of I investigations 9654)

Ruff, T.M., (2003) Evaluation of Systems to Monitor Blind Areas behind Trucks Used in road Construction and Maintenance: Phase. DHHS (NIOSH) Publication No. 2003-113 (NIOSH Report of Investigations 9660).

Ruff, T.M., (2004) Evaluation of Devices to Prevent Construction Equipment Backing Incidents. SAE Commercial Vehicle Engineering Congress and Exhibition. Paper 2004-01-2725, October, Chicago, IL.

Schaufelberger, J. E. (1999). "Construction Equipment Cost Estimating.” Construction Equipment Management, Prentice-Hall, Inc., Upper Saddle River, New Jersey, 167-172.

Shafizadeh, K., Mannering, F., (2006). Statistical modeling of user perceptions of infrastructure condition: An application to the case of highway roughness. Journal of Transportation Engineering. Vol. 132, No. 2, pp. 133-140.

Toole, T. M., (2002). Construction Site Safety Roles. Journal of Construction Engineering and Management, Vol. 128, No. 3, May/June, pp. 202-210.

Valentín, V., (2007). "Effectiveness of Personal Protective Equipment for Improving Worker Visibility of Nighttime Construction and Maintenance Projects. " MSCE Thesis. Purdue University, West Lafayette, IN.

Washington, S., Karlaftis, M., and Mannering, F. (2003). "Statistical and Econometric Methods for Transportation Data Analysis." Chapman \& Hall/CRC, Boca Raton, Florida. 
APPENDICES 


\title{
Appendix A. Survey Distributed to Workers
}

\section{Perception of Primary Events of Fatal/Serious Occupational Injuries and other Safety Issues in Highway Construction and Maintenance Activities}

\author{
Questionnaire - Insight of Workers
}

\section{Introduction:}

Purdue University is conducting a research study to evaluate worker injury prevention strategies in construction and maintenance work zones. The study is sponsored by the Indiana Department of Transportation (INDOT) and has the general objective of improving work zone safety for construction and maintenance workers. One of the steps in this study, is the collection of data through surveys of the key players involved in highway construction and maintenance projects. In this case, the key players are: (i) the owners of the constructed projects (e.g. Departments of Transportation-DOTs), (ii) contractors (i.e., construction companies) and (iii) the workers employed by DOTs and workers employed by contractors.

We are requesting you to voluntarily complete this survey. The survey comprises questions primarily about safety, and your perception of hazardous events and occupations. Finally the survey seeks to obtain your assistance about identification of hazards in your workplace and methods to avoid them.

This questionnaire is specifically geared towards highway construction and maintenance workers and its main purpose is to make inferences about workers' knowledge of common types of hazardous events encountered in such projects. The questionnaire will take about 15 minutes of your time to complete. The information collected will be kept confidential and it will only be used for academic purposes. Thank you in advance for your cooperation since it is imperative to the success of this research.

The specific components of the survey are:
A. Employee Information
B. General Questions about Safety
C. Perception of Hazards and Events of Fatal/Serious Occupational Injuries
D. Insight of Near Misses and Imminent Hazards
E. General Information

If you have any questions, please contact:

Professor Dulcy M. Abraham

School of Civil Engineering Purdue University

West Lafayette, $\mathrm{N}-47907$

Tel: (765)- 496-1822

Fax: (765) - $494-0644$ 
DTIR DTTF School of Civil Engineering

PURDUE Construction Engineering and Management

U N I V E R S I T Y Perception of Primary Events of Eatal/Serious Occupational Injuries and other Safety Issues in Highway

Construction and Maintenance Activities

Address any inquiry to: Dr. Dulcy M. Abraham/ Carlos Ferreira at (765)- 496-1822

A. Employee Information

Please check the boxes that best describes you according to the following characteristics:

1. Ethnicity

White
Black
Hispanic or Latino
Asian
Other

2. Age and Sex

$\begin{array}{lll}\Gamma \text { Younger than } 18 & \Gamma^{45-54} & \text { O Male } \\ \Gamma 18-24 & 5_{55-64} & \text { O Female } \\ \Gamma 25-34 & \Gamma \text { Older than } 64 & \\ \Gamma 35-44 & & \end{array}$

3. Occupation

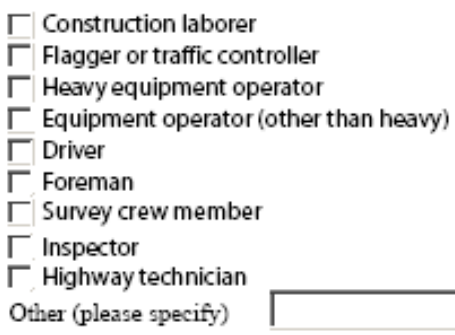

ГConstruction laborer

- Flagger or traffic controller

$\Gamma$ Heavy equipment operator

$\Gamma$ Equipment operator (other than heavy)

Г Driver

$\Gamma$ Foreman

$\Gamma$ Survey crew member

$\Gamma$ Inspector

$\Gamma$ Highway technician

Other (please specify)

4. How long have you been working in highway construction or maintenance?
$\ulcorner$ Less than 6 months
$\Gamma$ Between 6 months and 1 year
$\Gamma$ Between 1 year and 2 years
$\Gamma$ Between 2 years and 5 years
$\Gamma$ Between 5 years and 10 years
$\Gamma$ More than 10 years

B. General Questions about Safety

Please check the boxes that you consider, to be the best answer for the following questions:

1a. Do you know what a "Safety and Health" program is?

$$
\begin{aligned}
& \Gamma \text { Yes } \\
& \Gamma \text { No }
\end{aligned}
$$

If "Yes", provide a short description 
PURDUE School of Civil Engineering

PURDUE construction Engineering and Managenent

II N I V E B S Perception of Primary Events of Fatal/Serious Occupational Injuries and other Safety Issues in Highway

Construction and Maintenance Activities

Address any inquiry to: Dr. Dulcy M. Abraham/ Carlos Ferreira at (765)- 496-1822

1b. Has your employer or any of your supervisors ever asked your opinion about improving safety in your workplace?

$\Gamma$ Yes

$\Gamma$ No

2a. Does your company regularly conduct safety meetings?

$\Gamma$ Very often (at least one in a month)

$\ulcorner$ Often (once or twice every 3 months)

$\Gamma$ Rarely (once or twice in the last year)

$\Gamma$ Never

2b. If "Yes", Is attendance mandatory?

$\Gamma$ Yes

$\Gamma$ No

2c. If "No", do you attend the meetings?

$\Gamma$ Always

$\lceil$ Usually (two times every 3 meetings)

$\Gamma$ Rarely (one time every 3 meetings)

$\Gamma$ Never

3a. Does any of your supervisors advise you about the hazards of highway construction/maintenance activities, and how to avoid them?

$\Gamma$ Often (at least one in a month)

$\Gamma$ Sometimes (once or twice every 3 months)

$\Gamma$ Rarely (once or twice in the last year)

$\Gamma$ Never

3b. Does any of your supervisors advise you about the hazards of your specific occupation, and how to avoid them?

$\Gamma$ Often (at least one in a month)

$\Gamma$ Sometimes (once or twice every 3 months)

$\Gamma$ Rarely (once or twice in the last year)

$\Gamma$ Never 


\section{PURDUE \\ Construction Engineering and Management \\ Perception of Primary Erents of Fatal/Serious Occupational Injuries and other Safety Issues in Highway Construction and Maintenance Activities \\ Address any inquiry to: Dr. Dulcy M. Abraham/ Carlos Ferreira at (765)- 496-1822}

4a. Have you received safety training from your current employer?

$\Gamma$ Yes

$\Gamma$ No

ГI am not sure

4b. If "Yes", please check if it was a general training (the same for all employees) or a specific training (according to the activities you usually perform)

$\Gamma$ Both general and specific

$\Gamma$ Only general

$\Gamma$ Only specific

4c. Have you ever been assigned to perform activities for which you have not received any safety training?

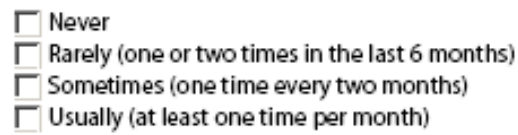

4d. Please check the box to the right that best fits your opinion about your level of satisfaction with the safety training received in each of the following aspects:

\begin{tabular}{|c|c|c|c|c|c|}
\hline \multirow{2}{*}{ Safety Aspect } & \multicolumn{2}{|c|}{$\begin{array}{l}\text { Completely } \\
\text { Unsatisfied }\end{array}$} & \multicolumn{2}{|c|}{$\begin{array}{c}\text { Some what } \\
\text { Satisfied }\end{array}$} & \multirow{2}{*}{$\begin{array}{c}\begin{array}{c}\text { Totally } \\
\text { Satisfied }\end{array} \\
5\end{array}$} \\
\hline & 1 & 2 & 3 & 4 & \\
\hline To work near traffic & $\Gamma$ & $\Gamma$ & $\Gamma$ & $\Gamma$ & $\Gamma$ \\
\hline To use adequate Personal Protective Equipment & $\Gamma$ & $\Gamma$ & $\Gamma$ & $\Gamma$ & $\Gamma$ \\
\hline $\begin{array}{l}\text { To set up, retrieve, or remove Trafic Control Devices (e.g., } \\
\text { cones, banrels, concrete barriers, rumble strips, signs) }\end{array}$ & $\Gamma$ & Г & $\Gamma$ & $\Gamma$ & $\Gamma$ \\
\hline To work around mobile equipment & $\Gamma$ & $\Gamma$ & $\Gamma$ & $\Gamma$ & Г \\
\hline To perform flagging activities & $\Gamma$ & $\Gamma$ & $\Gamma$ & $\Gamma$ & Г \\
\hline To work during nighttime hours & $\Gamma$ & $\Gamma$ & $\Gamma$ & $\Gamma$ & $\Gamma$ \\
\hline To perform trenching activities & $\Gamma$ & $\Gamma$ & $\Gamma$ & $\Gamma$ & $\Gamma$ \\
\hline To work near overhead power lines & $\Gamma$ & $\Gamma$ & $\Gamma$ & $\Gamma$ & $\Gamma$ \\
\hline $\begin{array}{l}\text { To work near underground electric current or other buried } \\
\text { utilities such as gas lines }\end{array}$ & $\underline{\Gamma}$ & $\Gamma$ & $\Gamma$ & $\Gamma$ & $\Gamma$ \\
\hline $\begin{array}{l}\text { To perform activities in elevated structures such as bridges, } \\
\text { formwork, elevated buckets, or near excavations }\end{array}$ & $\Gamma$ & $\Gamma$ & $\Gamma$ & $\Gamma$ & $\Gamma$ \\
\hline $\begin{array}{l}\text { To recognize and work in environments with high level of } \\
\text { noise }\end{array}$ & $\Gamma$ & Г & $\Gamma$ & $\Gamma$ & $\Gamma$ \\
\hline $\begin{array}{l}\text { To perform activities with exposure to health hazards such as } \\
\text { silica dust, asphalt fumes, lead, solvents, etc. }\end{array}$ & $\Gamma$ & $\Gamma$ & $\Gamma$ & $\Gamma$ & $\Gamma$ \\
\hline $\begin{array}{l}\text { To work in harsh environments such as intense hot and cold } \\
\text { weathers }\end{array}$ & $\Gamma$ & Г & $\Gamma$ & $\Gamma$ & $\Gamma$ \\
\hline
\end{tabular}




\section{DTIR DTE School of Civil Engineering \\ PURDUE Construction Engineering and Management \\ II \\ Construction and Maintenance Activities \\ Address any inquiry to: Dr. Dulcy M. Abraham/ Carlos Ferreira at (765)- 496-1822}

5a. Answer if you have worked for your employer in more than two (2) projects. Does any of your supervisors provide you with specific safety instructions for each new project you engage in?

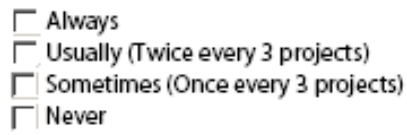

\section{Perception of Hazards and Events of Fatal/Serious Occupational Injuries}

Please, answer the following questions according to your perception of highway construction/maintenance activities:

1. Evaluate the following events or type of accidents from 1 to 5 according to the likelihood of their occurrence in highway construction and maintenance activities. Assign 1 to the event you consider is the least likely to happen and 5 to the most likely. Use the same rationale for intermediate numbers.

Worker struck by vehicle not related to the project (e.g., worker run-over by a

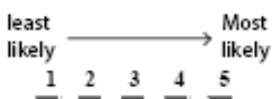
intruder vehicle such as sport utility vehicle, semi-trailer, vans, trucks, sedans, buses)

Worker struck by vehicle related to the project (e.g., worker run-over or backed- $1 \quad 2 \quad 3 \quad 4 \quad 5$ over by equipment such as motor graders, dump trucks, concrete mixer trucks, compactors)

Worker exposed to harmful substances or environments (e.g., contact with electric ${ }_{5} \quad 2 \quad 3 \quad 4$ current from overhead or underground power lines, depletion of oxygen due to cave-in of a trench or manhole activities, inhalation of hazardous substances)

Contact with objects or equipment (e.g., worker struck by a falling piece of $\Gamma^{1} \Gamma^{2} \frac{3}{\Gamma} \stackrel{4}{\Gamma^{\prime}} \stackrel{5}{\Gamma}$ concrete, struck by swinging section of heavy-duty guardrail, caught in or compressed by equipment and/or objects)

Falls (e.g., fall from a bridge, fall from equipment, equipment roll or slid over to an

$\begin{array}{llllll}1 & 2 & 3 & 4 & 5\end{array}$ embankment) 
PU⿴囗十丁E $\begin{aligned} & \text { School of Civil Engineering } \\ & \text { Construction Engineering and Management }\end{aligned}$

Perception of Primary Erents of Fatal/Serious Occupational Injuries and other Safety Issues in Highway Construction and Maintenance Activities

Address any inquiry to: Dr. Dulcy M. Abraham/ Carlos Ferreira at (765)- 496-1822

2. Evaluate the following occupations from 1 to 5 according to the risk or hazard exposure, for each occupation listed. Assign 1 to the occupation that you consider to have the least hazard exposure and 5 to the one you believe has the most hazard exposure. Use the same rationale for intermediate numbers.

\begin{tabular}{|c|c|c|c|c|c|}
\hline \multirow{2}{*}{ Occupation } & \multicolumn{3}{|c|}{$\begin{array}{l}\text { Least hazard } \\
\text { exposure }\end{array}$} & \multicolumn{2}{|c|}{$\begin{array}{l}\text { Most hazard } \\
\rightarrow \quad \text { exposure }\end{array}$} \\
\hline & & 2 & 3 & 4 & 5 \\
\hline Engineer & Г. & $\Gamma$ & $\Gamma$ & $\Gamma$ & $\Gamma$ \\
\hline Equipment Operator (other than heavy) & $\Gamma$ & $\Gamma$ & $\Gamma$ & $\Gamma$ & $\Gamma$ \\
\hline Driver & $\Gamma$ & $\Gamma$ & $\Gamma$ & $\Gamma$ & $\Gamma$ \\
\hline Flagger or Traffic Controller & $\Gamma$ & $\Gamma$ & $\Gamma$ & $\Gamma$ & $\Gamma$ \\
\hline Foreman & $\Gamma$ & $\Gamma$ & $\Gamma$ & $\Gamma$ & $\Gamma$ \\
\hline Construction Laborer & $\Gamma$ & $\Gamma$ & Г & $\Gamma$ & $\Gamma$ \\
\hline Heavy Equipment Operator (compactor, grader, etc) & $\Gamma$ & $\Gamma$ & $\Gamma$ & $\Gamma$ & $\Gamma$ \\
\hline Survey Crew Member & $\Gamma$ & $\Gamma$ & $\Gamma$ & $\Gamma$ & $\Gamma$ \\
\hline Inspector & $\Gamma$ & $\Gamma$ & $\Gamma$ & $\Gamma$ & $\Gamma$ \\
\hline Highway Technician & $\Gamma$ & $\Gamma$ & $\Gamma$ & $\Gamma$ & $\Gamma$ \\
\hline Others (please specify) $Г$ & $\Gamma$ & $\Gamma$ & $\Gamma$ & $\Gamma$ & $\Gamma !$ \\
\hline & $\Gamma$ & $\Gamma$ & $\Gamma$ & $\Gamma$ & $\Gamma$ \\
\hline
\end{tabular}

3. The behavior of individuals is sometimes the primary cause of accidents in construction/maintenance activities. Evaluate the following human behavioral causes according to their likelihood of occurrence in construction/maintenance work zones.

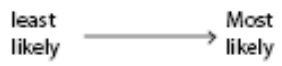

Lack of awareness of the injured worker: Accidents due to this factor occur when the $\begin{array}{llllll}1 & 2 & 3 & 4 & 5\end{array}$ worker is not aware of possible hazards at the moment of the incident (e.g., distracted worker $\Gamma|\Gamma| \Gamma \mid \Gamma$ nun over by reversing dump truck)

Worker misjudgment of a hazardous situation: Occurs when a worker does not properly $\quad \begin{array}{llllll}1 & 2 & 3 & 4 & 5\end{array}$ consider the risk that some circumstances represent (e.g., worker walking in a highway median $\Gamma$ $\Gamma \Gamma$ ! outside the protecting zone, workers stepping into an active lane)

Co-worker lack of awareness and/or misjudgment of a hazardous situation: A worker who $\begin{array}{ccccc}1 & 2 & 3 & 4 & 5\end{array}$ does not properly consider the risk that an activitiy might represent to a workmate or is unaware $\Gamma \Gamma \Gamma \Gamma \Gamma$ of the presence of other workers might get injured while he/she is performing his/her usual activities (e.g., a dump truck driver who starts moving his/her vehicle forward without noticing the presence of workers in front of the truck) 
PU⿴囗十丁E $\begin{aligned} & \text { School of Civil Engineering } \\ & \text { Construction Engineering and Management }\end{aligned}$

Perception of Primary Erents of Fatal/Serious Occupational Injuries and other Safety Issues in Highway Construction and Maintenance Activities

Address any inquiry to: Dr. Dulcy M Abraham/ Carlos Ferreira at (765)- 496-1822

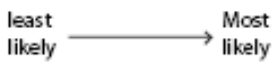

Lack of traffic control devices: Occurs when the employer (e.g., contractor) does not have in place sufficient traffic control devices (e.g., when there are insufficient signs, concrete barriers might be needed but they are not in place).

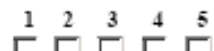

Negligence of a third party: associated to individuals not related to the construction/ maintenance project. Such as: durers and owners of intruder vehicles (e. vehicles without brakes, drunk drivers, a driver that does not follow the order given by flaggers)

Unsafe methods or sequencing: the normal sequencing of constuction activities does not occur, resulting in an activity being more hazardous than it usually is (e.g., a worker installing traffic control devices without the appropriate protection, use of malfunctioning equipment)

Not using provided safety equipment: A worker is provided with safety equipment but does not use it appropriately or simply does not make use of it (e.g., employee working in an elevated bucket not using available fall protection)

D. Insight of Near Misses and Imminent Hazards

Please, read the terms explained below and according to their significance, answer the subsequent questions.

1. Near Miss: Incidents within this category, correspond to those that were likely to end in an injury or fatality but they did not. For instance, if some of the events have occurred one or two seconds before/after, or if any of the subjects involved were physically positioned a couple of feet away from its final position; the incident could end in a regrettable consequence.

Have you or any of your coworkers been involved in a "Near Miss" incident within the last six (6) months?

$\lceil$ Yes $\square$ No If yes, please give a brief description of the event: 


\section{PURDUE}

U N I V E R S I T Y Perception of Primary Erents of Fatal/Serious Occupational Injuries and other Safety Issues in Highway Censtruction and Maintenance Activities

Address any inquiry to: Dr. Dulcy M. Abraham/ Carlos Ferreira at (765)- 496-1822

2. Imminent Hazard: A condition that if not corrected would probably result in an accident causing severe or permanently disabling injury or death to any of the workers.

Is there any "Imminent Hazard" in the construction/maintenance project you currently work on?

$\Gamma$ Yes $\Gamma$ No If yes, please give a brief description of the hazard:

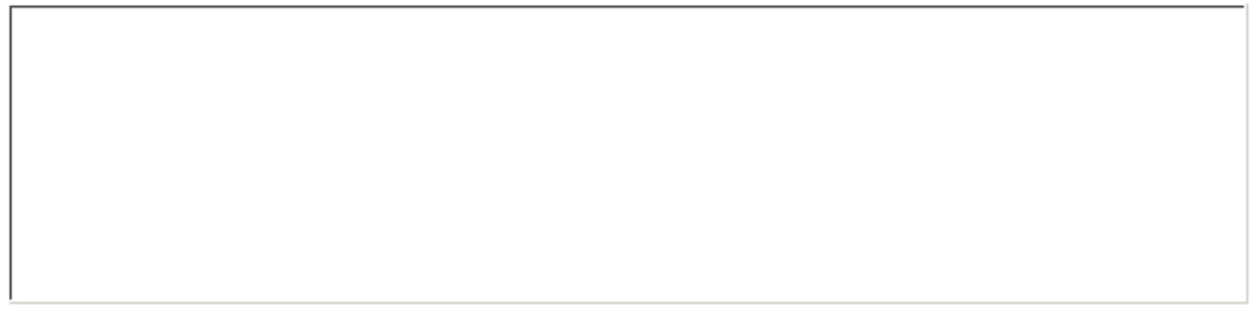

3. Do you have any suggestions or comments about how safety can be improved in your workplace?

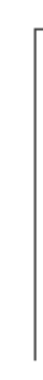

E. General Information

\begin{tabular}{|ll|}
\hline Name & \\
\hline \hline Company/Organization and location & \\
\hline Project name (if applicable) & \\
\hline Project location (if applicable) & \\
\hline
\end{tabular}

Your Cooperation is Greatly Appreciated

Submit by Email 


\section{Appendix B. Survey Distributed to Safety Officers in Departments of Transportation}

\section{Perception of Primary Events of Fatal/Serious Occupational Injuries and other Safety Issues in Highway Construction and Maintenance Activities}

\section{Introduction:}

Purdue University is conducting a research study to evaluate worker injury prevention strategies in construction and maintenance work zones. The study is sponsored by the Indiana Department of Transportation (INDOT) and has the general objective of improving work zone safety for construction and maintenance workers. One of the steps in this study, is the collection of data through surveys of the key players involved in highway construction and maintenance projects. In this case, the key players are: (i) the owners of the constructed projects (e.g. Departments of Transportation), (ii) contractors (i.e., construction companies) and (iii) the workers of both previously mentioned parties.

We are requesting you to voluntarily complete this survey. The survey comprises questions primarily about safety, and your perception of hazardous events and occupations. The survey seeks to obtain your assistance about identification of hazards in your workplace and methods to avoid them.

This questionnaire is specifically geared towards safety officers within State Departments of Transportation (DOTs) and its main purpose is to make inferences about safety officers' knowledge of common hazardous events, safety issues and to obtain their perception about how work zone safety can be improved in construction/maintenance projects. The questionnaire will take about 15 minutes of your time to complete. The information collected will be kept confidential and it will only be used for academic purposes. Thank you in advance for your cooperation since it is imperative to the success of this research.

The specific components of the survey are:

A. Safety Officer Information

B. General Questions about Safety

C. Perception of Hazards and Events of Fatal/Serious Occupational Injuries

D. Strategies Implemented in order to Reduce the Occurrence of Occupational Injuries

E. General Information

After completion of the questionnaire, please activate the "submit by e-mail" button located at the top of this page or at the end of the survey, and follow the instructions. If you prefer to send the survey via fax, please send it to:

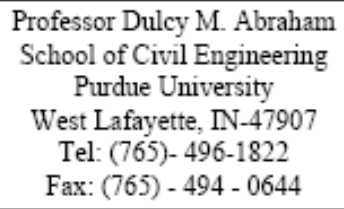




\section{PURDUE $\begin{gathered}\text { School of Civil Engineering } \\ \text { Construction Enginering and Management }\end{gathered}$}

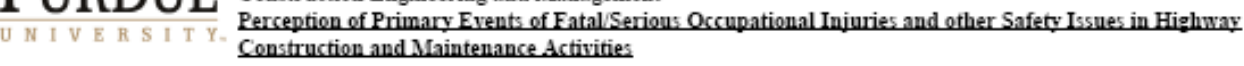

Address any inquiry to: Dr. Dulcy M. Abraham/ Carlos Ferreira at (765)- 496-1822

\section{A. Safety Officer Information}

Please check the boxes that best describes you according to the following characteristics:

1. Ethnicity

$\Gamma$ White

$\ulcorner$ Black

$\Gamma$ Hispanic or Latino

$\Gamma$ Asian

$\Gamma$ Other

2. Age and Sex

$\begin{array}{lll}\Gamma_{\text {Youngerthan } 18} & \Gamma_{45-54}^{45-24} & \text { O Male } \\ \Gamma_{18-24} & \Gamma_{55-64}-34 & \text { O Female } \\ \Gamma 35-44 & & \end{array}$

3. Degree

Occupation/Position

4. Are you responsible for worker's safety within your district/region?

$$
\begin{aligned}
& \ulcorner\text { Yes } \\
& \ulcorner\text { No }
\end{aligned}
$$

5. How long have you been performing safety managing roles?

$\digamma$ Less than 6 months

$\Gamma$ Between 6 months and 1 year

$\Gamma$ Between 1 year and 2 years

$\ulcorner$ Between 2 years and 5 years

$\Gamma$ Between 5 years and 10 years

$\ulcorner$ More than 10 years

B. General Questions about Safety

Please check the boxes that you consider, to be the best answer for the following questions:

1 Do you know what a "Safety and Health" program is?

$\Gamma$ Yes

$\Gamma$ No

If "Yes", provide a short description 
School of Civil Engineering

Construction Engineering and Management

Perception of Primary Events of Fatal/Serious Occupational Injuries and other Safety Issues in Highway Construction and Maintenance Activities

Address any inquiry to: Dr. Dulcy M. Abraham/ Carlos Ferreira at (765)- 496-1822

2a. Do you encourage your employees to report unsafe conditions/practices, and hazards encountered in the construction/maintenance work zones?

$\Gamma$ Yes
$\Gamma$ No

2b. Do you have procedures in place to identify and control hazards? If yes, please provide a brief description

$\Gamma$ Yes

$\ulcorner$ No

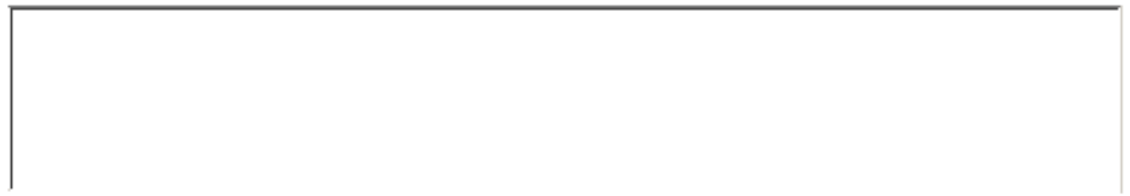

3a. Does your region/district regularly conduct safety meetings?

$\ulcorner$ Very often (at least one in a month)

$\lceil$ Often (once or twice every 3 months)

$\Gamma$ Rarely (once or twice in the last year)

$\Gamma$ Never

3b. If "Yes", Is attendance mandatory?

$\Gamma$ Yes

$\Gamma$ No

4. How often do you review and make necessary improvements to the safety program implmented by your region/district?

$\Gamma$ often (at least one time per year

$\Gamma$ Sometimes (once every two years)

$\Gamma$ Rarely (once every 3 years)

ГNever

5a. Do employees receive safety training?

$\Gamma$ Yes

$\Gamma$ No

5b. If "Yes", please check if it is a general training (the same for all employees) or a specific training (according to the activities each employee usually perform)

$\Gamma$ Both general and specific

$\Gamma$ Onlygeneral

$\Gamma$ Only specific 


\section{DTIR DT Tchool of Civil Engineering \\ Construction Engineering and Management \\ Perception of Primary Erents of Fatal/Serious Occupational Injuries and other Safety Issues in Highway \\ Construction and Maintenance Activities \\ Address any inquiry to: Dr. Dulcy M. Abraham/ Carlos Ferreira at (765)- 496-1822}

5c. Do you keep records of the training received by each employee?

$\Gamma$ Yes

$\Gamma$ No

$5 \mathrm{~d}$. Is there any procedure within your region/district for checking workers' understanding of the safety training and regulations provided? If "Yes", please provide a brief description

$\Gamma$ Yes

$\Gamma$ No

Se. Please check the box to the right that best fits your opinion about your level of satisfaction with the safety training received by the workers in each of the following aspects:

\begin{tabular}{|c|c|c|c|c|c|}
\hline \multirow{2}{*}{ Safety Aspect } & \multicolumn{2}{|c|}{\begin{tabular}{|l|} 
Completely \\
Unsatisfied
\end{tabular}} & \multicolumn{2}{|c|}{$\begin{array}{l}\text { Some what } \\
\text { Satisfied }\end{array}$} & \multirow{2}{*}{$\begin{array}{c}\begin{array}{c}\text { Totally } \\
\text { Satisfied }\end{array} \\
\mathbf{5}\end{array}$} \\
\hline & 1 & 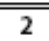 & 3 & 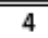 & \\
\hline To work near traffic & $\Gamma$ & $\Gamma$ & $\Gamma$ & $\Gamma$ & $\Gamma$ \\
\hline To use adequate Personal Protective Equipment & $\Gamma$ & $\Gamma$ & $\Gamma$ & $\Gamma$ & $\Gamma$ \\
\hline $\begin{array}{l}\text { To set up, retrieve, or remove Trafic Control Devices (e.g., } \\
\text { cones, barrels, concrete barriers, rumble strips, signs) }\end{array}$ & $\Gamma$ & $\Gamma$ & $\Gamma$ & $\Gamma$ & $\Gamma$ \\
\hline To work around mobile equipment & $\Gamma$ & $\Gamma$ & $\Gamma$ & $\Gamma$ & $\Gamma$ \\
\hline To perform flagging activities & $\Gamma$ & $\Gamma$ & $\Gamma$ & $\Gamma$ & $\Gamma$ \\
\hline To work during nighttime hours & $\Gamma$ & $\Gamma$ & $\Gamma$ & $\Gamma$ & $\Gamma$ \\
\hline To perform trenching activities & $\Gamma$ & $\Gamma$ & $\Gamma$ & $\Gamma$ & $\Gamma$ \\
\hline To work near overhead power lines & $\Gamma$ & $\Gamma$ & $\Gamma$ & $\Gamma$ & $\Gamma$ \\
\hline $\begin{array}{l}\text { To work near underground electric current or other buried } \\
\text { utilities such as gas lines }\end{array}$ & $\Gamma$ & $\Gamma$ & $\Gamma$ & $\Gamma$ & $\Gamma$ \\
\hline $\begin{array}{l}\text { To perform activities in elevated structures such as bridges, } \\
\text { formwork, elevated buckets, or near excavations }\end{array}$ & $\Gamma$ & $\Gamma$ & $\Gamma$ & Г! & $\Gamma$ \\
\hline $\begin{array}{l}\text { To recognize and work in environments with high level of } \\
\text { noise }\end{array}$ & $\Gamma$ & $\Gamma$ & $\Gamma$ & $\Gamma$ & $\Gamma$ \\
\hline $\begin{array}{l}\text { To perform activities with exposure to health hazards such as } \\
\text { silica dust, asphalt fumes, lead, solvents, etc. }\end{array}$ & $\Gamma$ & $\Gamma$ & $\Gamma$ & $\Gamma$ & $\Gamma$ \\
\hline $\begin{array}{l}\text { To work in harsh enviromments such as intense hot and cold } \\
\text { weathers }\end{array}$ & $\Gamma$ & 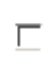 & $\Gamma$ & $\Gamma$ & 드 \\
\hline
\end{tabular}




\section{DT TRT Tchool of Civil Engineering \\ Construction Engineering and Management \\ Perception of Primary Erents of Fatal/Serious Occupational Injuries and other Safety Issues in Highway \\ Construction and Maintenance Activities: \\ Address any inquiry to: Dr. Dulcy M. Abraham/ Carlos Ferreira at (765)- 496-1822}

6. Does your district/region have established a procedure to be followed by the safety supervisor in place, in response to the following emergencies. If the answer is "Yes", please state your level of confidence in the procedure for each case.

\begin{tabular}{|c|c|c|c|c|c|c|c|}
\hline \multirow{3}{*}{ Emergency Case } & \multirow{2}{*}{\multicolumn{2}{|c|}{$\begin{array}{l}\text { Used by your } \\
\text { district/region }\end{array}$}} & \multicolumn{5}{|c|}{ Level of confidence in the procedure } \\
\hline & & & Poor & & Good & & xcellent \\
\hline & Yes & No & 1 & 2 & 3 & 4 & 5 \\
\hline An intruder vehicle crashing in or near the work zone & $\Gamma$ & $\Gamma$ & $\Gamma$ & $\Gamma$ & $\Gamma$ & $\Gamma$ & $\Gamma$ \\
\hline A seniously or fatally injured worker & $\Gamma$ & $\Gamma$ & $\Gamma$ & Г & $\Gamma$ & $\Gamma$ & $\Gamma$ \\
\hline $\begin{array}{l}\text { Contact of equipment, worker, or object with electric } \\
\text { current }\end{array}$ & $\Gamma$ & $\Gamma$ & $\Gamma$ & Г & $\Gamma$ & $\Gamma$ & Г \\
\hline Cave in or collapse of a trench & Г & $\Gamma$ & Г & Г! & $\Gamma$ & Г & Г \\
\hline Toxic chemical spill & $\Gamma$ & $\Gamma$ & $\Gamma$ & $\Gamma$ & $\Gamma$ & $\Gamma$ & $\Gamma$ \\
\hline
\end{tabular}

\section{Perception of Hazards and Events of Fatal/Serious Occupational Injuries}

Please, answer the following questions according to your perception of highway construction/maintenance activities:

1. Evaluate the following events or type of accidents from 1 to 5 according to the likelihood of their occurrence in highway construction and maintenance activities. Assign 1 to the event you consider is the least likely to happen and 5 to the most likely. Use the same rationale for intermediate numbers.

Worker struck by vehicle not related to the project (e.g., worker nun-over by a $\Gamma^{1} \stackrel{2}{\Gamma} \stackrel{3}{\Gamma} \frac{4}{\Gamma} \frac{5}{\Gamma}$ intruder vehicle such as sport utility vehicle, semi-trailer, vans, trucks, sedans, buses)

Worker struck by vehicle related to the project (e.g., worker run-over or backed- $\quad 1 \quad 2 \quad 3 \quad 4 \quad 5$ over by equipment such as motor graders, dump tucks, concrete mixer trucks, $\Gamma|\Gamma| \Gamma \mid \Gamma$ compactors) Worker exposed to harmful substances or environments (e.g., contact with electric
current from overhead or underground power lines, depletion of oxygen due to cave-in

of a trench or manhole activities, inhalation of hazardous substances)

Contact with objects or equipment (e.g., worker struck by a falling piece of $\ulcorner\lceil\ulcorner\Gamma \mid$ concrete, struck by swinging section of heavy-duty guardrail, caught in or compressed

by equipment and/or objects)

Falls (e.g., fall from a bridge, fall from equipment, equipment roll or slid over to an

$\begin{array}{llllll}1 & 2 & 3 & 4 & 5\end{array}$ embankment) 
DTIR DTF School of Civil Engineering

Construction Engineering and Management

Perception of Primary Erents of Fatal/Serious Oscupational Injuries and other Safety Issues in Highway Construction and Maintenance Activities

Address any inquiry to: Dr. Dulcy M. Abraham/ Carlos Ferreira at (765)-496-1822

2. Evaluate the following occupations from 1 to 5 according to the risk or hazard exposure for each occupation listed. Assign 1 to the occupation that you consider to have the least hazard exposure and 5 to the one you believe has the most hazard exposure. Use the same rationale for intermediate numbers.

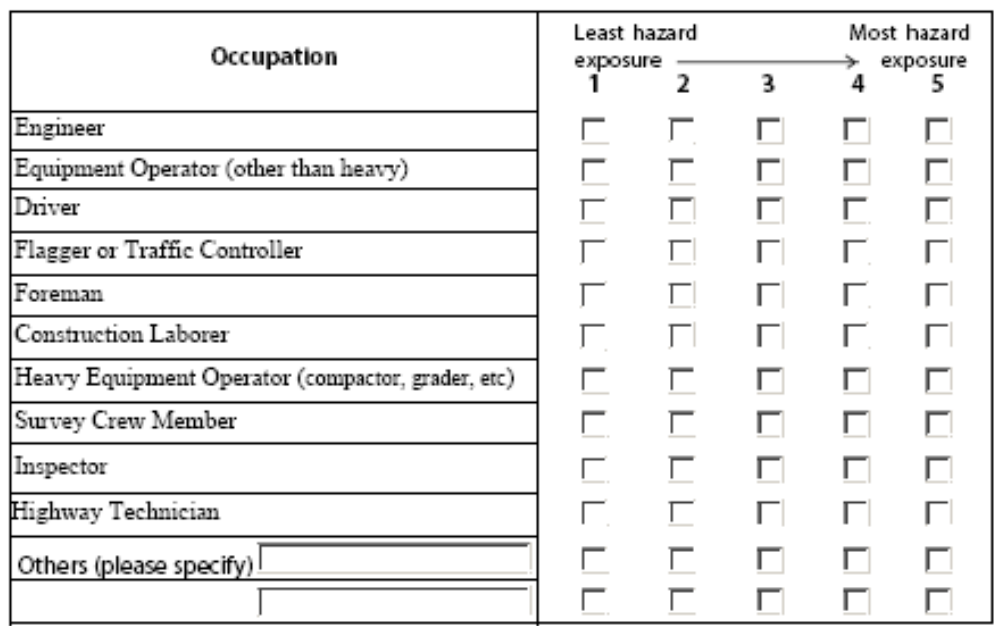

3. The behavior of individuals is sometimes the primary cause of accidents in construction/maintenance activities. Evaluate the following human behavioral causes according to their likelihood of occurrence in construction/maintenance work zones.

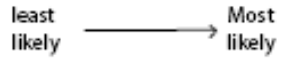

Lack of awareness of the injured worker: Accidents due to this factor occur when the $\begin{array}{llllll}1 & 2 & 3 & 4 & 5\end{array}$ worker is not aware of possible hazards at the moment of the incident (e.g., distracted worker $\Gamma|\Gamma \Gamma| \Gamma$ nun over by reversing dump truck)

$\begin{array}{lllllll}\text { Worker misjudgment of a hazardous situation: Occurs when a worker does not properly } & 1 & 2 & 3 & 4 & 5\end{array}$ consider the risk that some circumstances represent (e.g., worker walking in a highway median $\Gamma|\Gamma| \Gamma$ outside the protecting zone, workers stepping into an active lane)

Co-worker lack of awareness and/or misjudgment of a hazardous situation: A worker who $\begin{array}{lllllll}1 & 2 & 3 & 4 & 5\end{array}$ does not properly consider the risk that an activitiy might represent to a workmate or is unaware $\Gamma \Gamma|\Gamma| \Gamma \mid$ of the presence of other workers who might get injured while he/she is performing his/her usual activities (e.g., a dump truck driver who start moving his her vehicle forward without noticing the presence of workers in front of the truck) 
Lack of traffic control devices: Occurs when the employer (e.g., contractor) does not have in place sufficient traffic control devices (e.g., when there are insufficient signs, concrete barriers might be needed but they are not in place).

Negligence of a third party: associated to individuals not related to the construction

$\begin{array}{llllll}1 & 2 & 3 & 4 & 5\end{array}$ maintenance project. Such as: drivers and owners of intruder vehicles (e.g., vehicles without $\Gamma|\Gamma| \Gamma \Gamma$ brakes, drunk drivers, a driver that does not follow the order given by flaggers)

Unsafe methods or sequencing: the normal sequencing of construction activities does not occur, resulting in an activity being more hazardous than it usually is (e.g., a worker installing traffic control devices without the appropriate protection, use of malfunctioning equipment)

Not using provided safety equipment: A worker is provided with safety equipment but does $\quad \begin{array}{lllll}1 & 2 & 3 & 4 & 5\end{array}$ not use it appropriately or simply does not make use of it (e.g., employee working in an elevated $\Gamma|\Gamma| \Gamma \Gamma$ bucket not using available fall protection)

D. Strategies Implemented in order to Reduce the Occurrence of Occupational Injuries in Work Zones Please, answer the following questions according to your perception of highway construction/maintenance activities:

1. For each strategy below, state if your district/region is currently making use of it. If the response is "Yes", check the box to the right that best fits your opinion on the effectivenes, of the strategy in reducing the risk of occupational injuries in work zones.

\begin{tabular}{|c|c|c|c|c|c|c|c|}
\hline \multirow{2}{*}{ Strategy } & \multicolumn{2}{|c|}{$\begin{array}{l}\text { Used by your } \\
\text { district/region }\end{array}$} & \multicolumn{5}{|c|}{ Efectiveness } \\
\hline & Yes & No & 1 & 2 & 3 & 4 & 5 \\
\hline Enforcing safety policies, increasing supervision & $\Gamma$ & $\Gamma$ & $\Gamma$ & $\Gamma$ & $\Gamma$ & $\Gamma$ & $\Gamma$ \\
\hline $\begin{array}{l}\text { Maintaining and using prior training records for desizning, } \\
\text { and implementing safety strategies and evaluating outcomes }\end{array}$ & $\Gamma$ & $\Gamma$ & $\Gamma$ & Г & $\Gamma$ & $\Gamma$ & $\Gamma$ \\
\hline $\begin{array}{l}\text { Providing and enforcing the use of appropriate safety } \\
\text { equipment }\end{array}$ & $\Gamma$ & $\Gamma$ & $\Gamma$ & $\Gamma$ & $\Gamma$ & $\Gamma$ & $\Gamma$ \\
\hline $\begin{array}{l}\text { Planning and controlling methods and/or sequencing of } \\
\text { construction operations }\end{array}$ & $\Gamma$ & $\Gamma$ & $\Gamma$ & $\Gamma$ & $\Gamma$ & $\Gamma$ & $\Gamma$ \\
\hline $\begin{array}{l}\text { Assessing site conditions adequately in order to } \\
\text { strategically design the work zone }\end{array}$ & $\Gamma$ & $\Gamma$ & $\Gamma !$ & $\Gamma$ & $\Gamma$ & $\Gamma$ & $\Gamma$ \\
\hline
\end{tabular}


School of Civil Engineering

Construction Engineering and Management

Perception of Primary Erents of Fatal/Serious Occupational Injuries and other Safety Issues in Highway Construction and Maintenance Activities

Address any inquiry to: Dr. Dulcy M. Abraham/ Carlos Ferreira at (765)-496-1822

\begin{tabular}{|c|c|c|c|c|c|c|c|}
\hline \multirow{2}{*}{ Strategy } & \multicolumn{2}{|c|}{$\begin{array}{l}\text { Used by your } \\
\text { district/region }\end{array}$} & \multicolumn{5}{|c|}{ Efectiveness } \\
\hline & Yes & No & 1 & 2 & 3 & 4 & 5 \\
\hline Monitoring the use of provided safety equipment & $\Gamma$ & $\Gamma$ & $\Gamma$ & $\Gamma$ & $\Gamma$ & $\Gamma$ & $\Gamma$ \\
\hline $\begin{array}{l}\text { Improving regulations for motorists traveling through } \\
\text { work zones }\end{array}$ & $\Gamma$ & $\Gamma$ & $\Gamma$ & $\Gamma$ & $\Gamma$ & $\Gamma$ & $\Gamma$ \\
\hline
\end{tabular}

2. According to your perception, please list the weaknesses of the safety program currently under implementation in your district/region

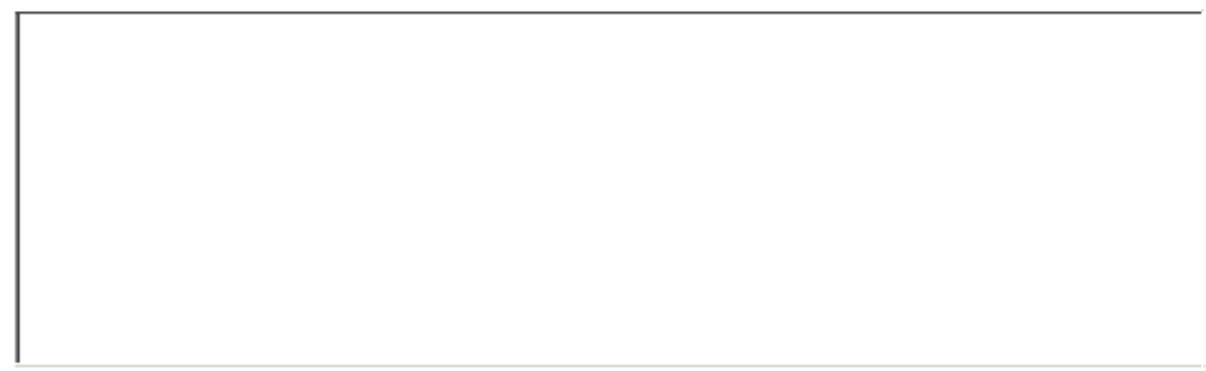

E. General Information

\begin{tabular}{|ll|}
\hline Name & \multicolumn{1}{|c|}{} \\
\hline \hline District/region & \multicolumn{1}{|}{} \\
\hline \hline Department of Transportation & \multicolumn{1}{|}{} \\
\hline \hline Approx. number of work zone workers within your district/region & \\
\hline
\end{tabular}

Your Cooperation is Greatly Appreciated

Submit by Email 


\section{Appendix C. Survey Distributed to Supervisors in Construction Companies}

\section{Perception of Primary Events of Fatal/Serious Occupational Injuries and other Safety Issues in Highway Construction and Maintenance Activities}

Questionnaire - Insight of Safety Managers

\section{Introduction:}

Purdue University is conducting a research study to evaluate worker injury prevention strategies in construction and maintenance work zones. The study is sponsored by the Indiana Department of Transportation (TNDOT) and has the general objective of improving work zone safety for construction and maintenance workers. One of the steps in this study, is the collection of data through surveys of the key players involved in highway construction and maintenance projects. In this case, the key players are: (i) the owners of the constructed projects (e.g. Departments of Transportation), (ii) contractors (i.e., construction companies) and (iii) the workers of both previously mentioned parties.

We are requesting you to voluntarily complete this survey. The survey comprises questions primarily about safety, and your perception of hazardous events and occupations. The survey seeks to obtain your assistance about identification of hazards in your workplace and methods to avoid them.

This questionnaire is specifically geared towards safety managers within highway construction/maintenace companies and its main puppose is to make inferences about safety managers' knowledge of common hazardous events, safety issues, and to obtain their perception about how work zone safety can be improved in construction/ maintenance projects. The questionnaire will take about 15 minutes of your time to complete. The information collected will be kept confidential and it will only be used for academic purposes. Thank you in advance for your cooperation since it is imperative to the success of this research.

The specific components of the survey are:

A. Safety Manager Information

B. General Questions about Safety

C. Perception of Hazards and Events of Fatal/Serious Occupational Injuries

D. Strategies Implemented in order to Reduce the Occurence of Occupational Injuries

E. General Information

After completion of the questionnaire, please activate the "submit by e-mail" button located at the top of this page or at the end of the survey, and follow the instructions. If you prefer to send the survey via fax, please print it out and send it to:

$$
\begin{gathered}
\text { Professor Dulcy M. Abraham } \\
\text { School of Civil Engineering } \\
\text { Purdue University } \\
\text { West Lafayette, IN-47907 } \\
\text { Tel: (765)- 496-1822 } \\
\text { Fax: (765) - 494-0644 }
\end{gathered}
$$

Address any inquiry to: Dr. Dulcy M. Abrabam/ Carlos Ferreira at (765) - 496 - 1822, (713) - $269-5984$ 


\section{PURDUE ${ }^{\text {School of Ciril Engineering }}$ \\ II N I Y R R S I T Y Perception of Primary Events of Fatal Serions Occupational Injuries and other Safety Issnes in Highway Construction and Maintenance Activities \\ Address any inquiry to: Dr. Dulcy M. Abraham/ Carlos Ferreira at (765)- 496-1822}

A. Safety Officer Information

Please check the boxes that best describes you according to the following characteristics:

1. Ethnicity

$\Gamma$ White

Г Black

TH Hispanic or Latino

Г Asian

Г Other

2. Age and Sex

Counger than 18

广 $18-24$

$\Gamma 25-34$

Г $45-54$

Г $55-64$

$\Gamma$ older than 64

C Male

Г| $35-44$

Female

3. Degree

Occupation/Position

4. Are you responsible for worker's safety within your company?

$\frac{\Gamma \text { Yes }}{\Gamma \text { No }}$

5. How long have you been performing safety managing roles?

$\Gamma$ Less than 6 months

C Between 6 months and 1 year

$\Gamma$ Between 1 year and 2 years

$\Gamma$ Between 2 years and 5 years

$\Gamma$ Between 5 years and 10 years

$\Gamma$ More than 10 years

B. General Questions about Safety

Please check the boxes that you consider, to be the best answer for the following questions:

1 Do you know what a "Safety and Health" program is?

$\Gamma$ Yes

$\Gamma$ No

If "Yes", provide a short description

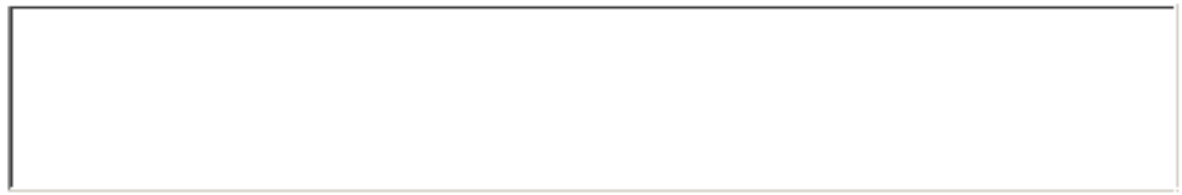




\section{PURDUE School of Civil Engineering \\ II N I Y R R S I T Y Perception of Primary Events of Fatal Serious Occupational Injuries and other Safety Issmes in Highway Censtruction and Maintenance Activities \\ Address any inquiry to: Dr. Dulcy M. Abraham/ Carlos Ferreira at (765)- 496-1822}

2a. Do you encourage your employees to report unsafe conditions/practices, and hazards encountered in the construction/maintenance work zones?

ГYes

2b. Do you have procedures in place to identify and control hazards? If yes, please provide a brief description

$\Gamma$ Yes

$\Gamma$ No

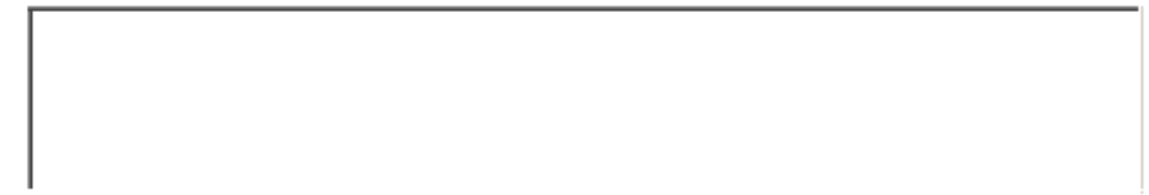

3a. Does your company regularly conduct safety meetings?

$\Gamma$ Very often (at least one in a month)

$\Gamma$ Often (once or twice every 3 months)

- Rarely (once or twice in the last year)

$\ulcorner$ Never

3b. If "Yes", Is attendance mandatory?

$\Gamma$ Yes
$\Gamma$ No

4. How often do you review and make necessary improvements to the safety program implmented by your company?

$\Gamma$ often (at least one time per year

$\Gamma$ Sometimes (once every two years)

$\Gamma$ Rarely (once every 3 years)

$\Gamma$ Never

5a. Do employees receive safety training?

$\Gamma$ Yes

$\Gamma$ No

5b. If "Yes", please check if it is a general training (the same for all employees) or a specific training (according to the activities each employee usually perform)

$\Gamma$ Both general and specific

$\Gamma$ Onlygeneral

$\Gamma$ Only specific 
School of Civil Engineering

Construction Engineering and Management

Perception of Primary Erents of Fatal/Serions Occupational Injuries and ofher Safety Issues in Highway Construction and Maintenance Activities

Address any inquiry to: Dr. Dulcy M. Abraham/ Carlos Ferreira at (765)- 496-1822

5c. Do you keep records of the training received by each employee?

IYes

$\Gamma$ No

$5 \mathrm{~d}$. Is there any procedure within your company for checking workers' understanding of the safety training and regulations provided? If "Yes", please provide a brief description

달

No

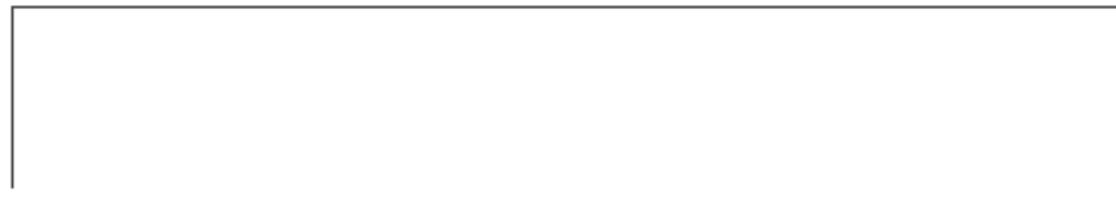

5e. Please check the box to the right that best fits your opinion about your level of satisfaction with the safety training received by the workers in each of the following aspects:

\begin{tabular}{|c|c|c|c|c|c|}
\hline \multirow{2}{*}{ Safety Aspect } & \multicolumn{2}{|c|}{\begin{tabular}{|l} 
Completely \\
Unsatisfied
\end{tabular}} & \multicolumn{2}{|c|}{$\begin{array}{l}\text { Some what } \\
\text { Satisfied }\end{array}$} & \multirow{2}{*}{$\begin{array}{c}\begin{array}{c}\text { Totally } \\
\text { Satisfied }\end{array} \\
\mathbf{5}\end{array}$} \\
\hline & 1 & 2 & 3 & 4 & \\
\hline To work near traffic & $\Gamma$ & $\underline{\Gamma}$ & $\Gamma$ & $\Gamma$ & $\Gamma$ \\
\hline To use adequate Personal Protective Equipment & $\Gamma$ & $\Gamma$ & $\Gamma$ & $\Gamma$ & $\Gamma$ \\
\hline $\begin{array}{l}\text { To set up, retrieve, or remove Trafic Control Devices (e.g., } \\
\text { cones, barrels, concrete barriers, rumble strips, signs) }\end{array}$ & $\Gamma$ & $\Gamma$ & $\Gamma$ & $\Gamma$ & $\Gamma$ \\
\hline To work around mobile equipment & $\Gamma$ & $\Gamma$ & $\underline{\Gamma}$ & $\Gamma$ & $\Gamma$ \\
\hline To perform flagging activities & $\Gamma$ & $\Gamma$ & $\Gamma$ & $\Gamma$ & $\Gamma$ \\
\hline To work during nighttime hours & $\Gamma$ & $\underline{\Gamma}$ & $\Gamma$ & $\Gamma$ & $\Gamma$ \\
\hline To perform trenching activities & $\Gamma$ & $\underline{\Gamma}$ & $\Gamma$ & $\Gamma$ & $\Gamma$ \\
\hline To work near overhead power lines & $\Gamma$ & $\Gamma$ & $\Gamma$ & $\Gamma$ & $\Gamma$ \\
\hline $\begin{array}{l}\text { To work near underground electric current or other buried } \\
\text { utilities such as gas lives }\end{array}$ & $\Gamma$ & $\underline{\Gamma}$ & $\underline{\Gamma}$ & $\Gamma$ & $\Gamma$ \\
\hline $\begin{array}{l}\text { To perform activities in elevated structures such as bridges, } \\
\text { formwork, elevated buckets, or near excavations }\end{array}$ & $\Gamma$ & Г & $\Gamma$ & $\Gamma$ & $\Gamma$ \\
\hline $\begin{array}{l}\text { To recognize and work in environments with bigh level of } \\
\text { noise }\end{array}$ & $\Gamma$ & $\Gamma$ & $\Gamma$ & $\Gamma$ & $\Gamma$ \\
\hline $\begin{array}{l}\text { To perform activities with exposure to health hazards such as } \\
\text { silica dust, asphalt fumes, lead, solvents, etc. }\end{array}$ & $\Gamma$ & $\Gamma$ & $\Gamma$ & $\Gamma$ & $\Gamma$ \\
\hline $\begin{array}{l}\text { To work in barsh exvirouments such as intense bot and cold } \\
\text { weathers }\end{array}$ & $\Gamma$ & $\Gamma$ & Г & Г & $\Gamma$ \\
\hline
\end{tabular}




\section{DTIR DT School of Civil Engineering \\ Construction Engineering and Management \\ Perception of Primary Erents of Fatal/Serions Occupational Injuries and other Safety Issnes in Highway \\ Construction and Maintenance Activities \\ Address any inquiry to: Dr. Dulcy M. Abraham/Carlos Ferreira at (765)- 496-1822}

6. Does your company have established a procedure to be followed by the safety supervisor in place, in response to the following emergencies. If the answer is "Yes", please state your level of confidence in the procedure for each case.

\begin{tabular}{|c|c|c|c|c|c|c|c|}
\hline \multirow{3}{*}{ Emergency Case } & \multirow{2}{*}{\multicolumn{2}{|c|}{$\begin{array}{l}\text { Used by your } \\
\text { district/region }\end{array}$}} & \multicolumn{5}{|c|}{ Level of confidence in the procedure } \\
\hline & & & Poor & & Goo & & wcellent \\
\hline & Yes & No & 1 & 2 & 3 & 4 & 5 \\
\hline An intruder vehicle crashing in or near the work zone & $\Gamma$ & $\Gamma$ & $\Gamma$ & $\Gamma$ & $\Gamma$ & $\Gamma$ & $\Gamma$ \\
\hline A seriously or fatally injured worker & $\Gamma$ & $\Gamma$ & $\Gamma$ & $\Gamma$ & $\Gamma$ & $\Gamma$ & $\Gamma$ \\
\hline $\begin{array}{l}\text { Contact of equipment, worker, or object with electric } \\
\text { current }\end{array}$ & $\Gamma$ & $\Gamma$ & $\Gamma$ & $\Gamma$ & $\Gamma$ & $\Gamma$ & $\Gamma$ \\
\hline Cave in or collapse of a trench & $\Gamma$ & $\Gamma$ & $\Gamma$ & $\Gamma$ & $\underline{\Gamma}$ & $\Gamma$ & Г \\
\hline Toxic chemical spill & $\Gamma$ & $\Gamma$ & $\Gamma$ & $\Gamma$ & $\Gamma$ & Г & $\Gamma$ \\
\hline
\end{tabular}

\section{Perception of Hazards and Events of Fatal/Serious Occupational Injuries}

Please, answer the following questions according to your perception of highway construction/maintenance activities:

1. Evaluate the following events or type of accidents from 1 to 5 according to the likelihood of their occurrence in highway construction and maintenance activities. Assign 1 to the event you consider is the least likely to happen and 5 to the most likely. Use the same rationale for intermediate numbers.

Worker struck by vehicle not related to the project (e.g., worker run-over by a $\stackrel{1}{\Gamma} \stackrel{2}{\Gamma} \stackrel{3}{\Gamma} \stackrel{4}{\Gamma} \stackrel{5}{\Gamma}$ intruder vehicle such as sport utility vehicle, semi-trailer, vans, trucks, sedans, buses)

Worker struck by vehicle related to the project (e.g., worker rum-over or backed- 1 over by equipment such as motor graders, dump trucks, concrete mixer trucks, $ᄃ \Gamma$ compactors) Worker exposed to harmful substances or environments (e.g, contact with electric
curreut from overbead or underground power lines, depletion of oxygen due to cave-in of a trench or manhole activities, inhalation of hazardous substances)

Contact with objects or equipment (e.g., worker struck by a falling piece of $\ulcorner\ulcorner\ulcorner\ulcorner\ulcorner$ concrete, struck by swinging section of heavy-dury guardrail, caught in or compressed by equipment and/or objects)

Falls (eg, fall from a bridge, fall from equipment, equipment roll or slid over to an
embankment) 


\section{PURDTE School of Civil Engineering \\ Construction Engineering and Management \\ Perception of Primary Erents of Fatal/Serions Occupational Injuries and other Safety Issues in Highway Construction and Maintenance Activities \\ Address any inquiry to: Dr. Dulcy M. Abraham/ Carlos Ferreira at (765)- 496-1822}

2. Evaluate the following occupations from 1 to 5 according to the risk or hazard exposure for each occupation listed. Assign 1 to the occupation that you consider to have the least hazard exposure and 5 to the one you believe has the most hazard exposure. Use the same rationale for intermediate numbers.

\begin{tabular}{|c|c|c|c|c|}
\hline \multirow{2}{*}{ Occupation } & \multicolumn{2}{|c|}{ Least hazard } & \multicolumn{2}{|c|}{$\begin{array}{l}\text { Most hazard } \\
\text { exposure }\end{array}$} \\
\hline & 1 & 3 & 4 & 5 \\
\hline Engineer & $\Gamma$ & $\Gamma$ & $\Gamma$ & $\Gamma$ \\
\hline Equipment Operator (other than heavy) & $\Gamma$ & $\Gamma$ & $\Gamma$ & $\Gamma$ \\
\hline Driver & $\Gamma$ & $\Gamma$ & $\Gamma$ & Г \\
\hline Flagger or Traffic Controller & $\Gamma$ & $\Gamma$ & $\Gamma$ & $\Gamma$ \\
\hline Foreman & Г & $\Gamma$ & $\Gamma$ & $\Gamma$ \\
\hline Construction Laborer & $\Gamma$ & $\Gamma$ & $\Gamma$ & $\Gamma$ \\
\hline Heavy Equipment Operator (compactor, grader, etc) & $\Gamma$ & $\Gamma$ & $\Gamma$ & $\Gamma$ \\
\hline Survey Crew Member & $\Gamma$ & $\Gamma$ & $\Gamma$ & $\Gamma$ \\
\hline Inspector & $\Gamma$ & $\Gamma$ & $\Gamma$ & $\Gamma$ \\
\hline Highway Technician & $\Gamma$ & $\Gamma$ & $\Gamma$ & $\Gamma$ \\
\hline Others (please specify) & $\Gamma$ & $\Gamma$ & $\Gamma$ & Г \\
\hline & $\Gamma$ & $\Gamma$ & $\Gamma$ & $\Gamma$ \\
\hline
\end{tabular}

3. The behavior of individuals is sometimes the primary cause of accidents in construction/maintenance activities. Evaluate the following human behavioral causes according to their likelihood of occurrence in construction/maintenance work zones.

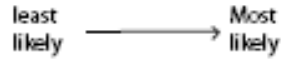

Lack of awareness of the injured worker: Accidents due to this factor occur when the $1 \quad 2 \quad 3 \quad 4 \quad 5$ worker is not aware of possible bazards at the moment of the incident (e.g., distracted worker $\Gamma|\Gamma| \Gamma \Gamma \Gamma$ rum over by reversing dump truck)

Worker misjudgment of a hazardous situation: Occurs when a worker does not properly $1 \quad 2 \quad 2 \quad 3 \quad 4 \quad 5$ consider the risk that some circumstances represent (e.g., worker walking in a highway median $\Gamma \Gamma \Gamma \Gamma \Gamma$ outside the protecting zone, workers stepping into an active lane)

Co-worker laclz of awareness and/or misjudgment of a hazardous situation: A worker who $\begin{array}{llllll}1 & 2 & 3 & 4\end{array}$ does not properly consider the risk that an activitiy might represent to a workmate or is unaware $\Gamma \Gamma \Gamma \mid \Gamma$ of the presence of other workers who might get injured while he/she is performing his/her usual activities (e.g., a dump truck driver who start moving his/her vehicle forward without noticing the presence of workers in front of the truck) 


\section{PURDUT School of Civil Engineering \\ II N I Y R R S I T Y Perception of Primary Erents of EatalSerions Occupational Iniuries and ofher Safety Issues in Highway Construction and Maintenance Activities \\ Address any inquiry to: Dr. Dulcy M. Abraham/ Carlos Ferreira at (765)- 496-1822}

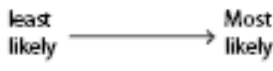

Lack of traffic control devices: Occurs when the employer (e.g., contractor) does not have in $\quad \begin{array}{lllll}1 & 2 & 3 & 4 & 5\end{array}$ place sufficient traffic control devices (e.g., when there are insufficient signs, concrete banriers might be needed but they are not in place).

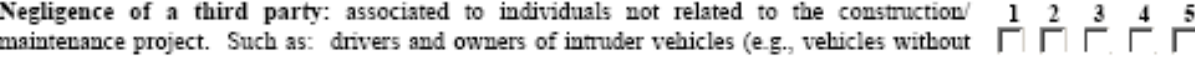
brakes, drunk drivers, a driver that does not follow the order given by flaggers)

Unsafe methods or sequencing: the normal sequencing of construction activities does not occur, resulting in an activity being more bazardous than it usually is (e.g., a worker installing traffic control devices without the appropriate protection, use of malfunctioning equipment)

Not using provided safety equipment: A worker is provided with safety equipment but does
not use it appropriately or simply does not make use of it (e.g, employee working in an elevated bucket not using available fall protection)

D. Strategies Implemented in order to Reduce the Occurrence of Occupational Injuries in Work Zones Please, answer the following questions according to your perception of highway construction/maintenance activities:

1. For each strategy below, state if your company is currently making use of it. If the response is "Yes", check the box to the right that best fits your opinion on the effectivenes, of the strategy in reducing the risk of occupational injuries in work zones.

\begin{tabular}{|c|c|c|c|c|c|c|c|}
\hline \multirow{2}{*}{ Strategy } & \multicolumn{2}{|c|}{$\begin{array}{l}\text { Used by your } \\
\text { distrikt/region }\end{array}$} & \multicolumn{4}{|c|}{$\begin{array}{l}\text { Efectiveness } \\
\text { Good }\end{array}$} & \multirow{2}{*}{$\begin{array}{c}\text { Excellent } \\
5\end{array}$} \\
\hline & Yes & No & 1 & 2 & 3 & 4 & \\
\hline Enforcing safety policies, increasing supervision & $\Gamma$ & $\Gamma$ & $\Gamma$ & $\Gamma$ & $\Gamma$ & Г & $\Gamma$ \\
\hline $\begin{array}{l}\text { Maintaining and using prior training records for designing, } \\
\text { and implementing safery strategies and evaluating outcomes }\end{array}$ & ᄃ & $\Gamma$ & $\Gamma$ & $\Gamma$ & $\Gamma$ & $\Gamma$ & $\Gamma$ \\
\hline $\begin{array}{l}\text { Providing and enforcing the use of appropriate safery } \\
\text { equipment }\end{array}$ & $\Gamma$ & $\Gamma$ & $\Gamma$ & $\Gamma$ & $\Gamma$ & Г & $\Gamma$ \\
\hline $\begin{array}{l}\text { Planning and controlling methods and/or sequencing of } \\
\text { construction operations }\end{array}$ & $\Gamma$ & $\Gamma$ & $\Gamma$ & $\Gamma$ & $\Gamma !$ & $\Gamma$ & $\Gamma$ \\
\hline $\begin{array}{l}\text { Assessing site conditions adequately in order to } \\
\text { strategically design the work zone }\end{array}$ & $\Gamma$ & $\Gamma$ & $\Gamma$ & $\Gamma$ & $\Gamma$ & $\Gamma$ & $\Gamma$ \\
\hline
\end{tabular}


PURDUE Schoolof C Cinil Enjiberiing

V N I V R R S I T Y Perception of Primary Erents of Fatal/Serions Occopational Injuries and other Safety Issues in Highway

Construction and Maintenance Activities

Address any inquiry to: Dr. Dulcy M. Abraham/ Carlos Ferreira at (765)- 496-1822

\begin{tabular}{|c|c|c|c|c|c|c|c|}
\hline \multirow{2}{*}{ Strategy } & \multicolumn{2}{|c|}{$\begin{array}{l}\text { Used by your } \\
\text { district/region }\end{array}$} & \multicolumn{4}{|c|}{ Efectiveness } & Excellent \\
\hline & Yes & No & 1 & 2 & 3 & 4 & 5 \\
\hline Monitoring the use of provided safety equipment & $\Gamma$ & $\Gamma$ & $\Gamma$ & $\Gamma$ & $\Gamma !$ & $\Gamma$ & $\Gamma$ \\
\hline $\begin{array}{l}\text { Improving regulations for motorists traveling through } \\
\text { work zones }\end{array}$ & $\Gamma$ & $\Gamma$ & $\Gamma$ & $\Gamma !$ & $\Gamma$ & $\Gamma$ & $\Gamma$ \\
\hline
\end{tabular}

2. According to your perception, please list the weaknesses of the safety program currently under implementation in your company

E. General Information

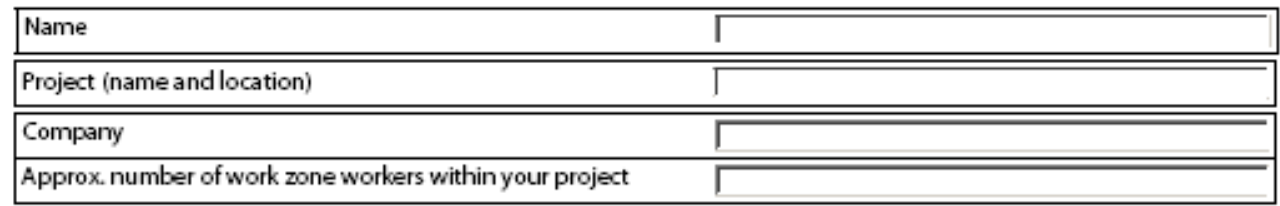

\title{
Your Cooperation is Greatly Appreciated
}

\author{
Submit by Email
}




\title{
Appendix D. Survey Administered to Owners
}

\section{Analysis of Work Zone Safety Strategies for Improving Worker Safety in Construction and Maintenance Operations \\ Questionnaire - Focus on Perspectives of the Owners}

\section{Introduction:}

Purdue University is conducting a research study to evaluate the effectiveness of currently used safety strategies in construction and maintenance work zones. The study is sponsored by the Indiana Department of Transportation (INDOT) and has the general objective of improving work zone safety for construction and maintenance workers. One of the steps in this study is the collection of data through surveys or interviews of the key participants involved in highway construction and maintenance projects. In this case, the key participants are: (i) the owners of the constructed projects (e.g. Departments of Transportation), (ii) contractors and (iii) the workers of both previously mentioned parties.

We are requesting you to voluntarily complete this survey, which comprises of questions primarily about safety and your perception of various safety strategies. Finally, the survey seeks to obtain your assistance about how to improve currently used safety strategies and what other methods can be implemented to improve worker safety.

This survey is specifically geared towards safety officers within State Departments of Transportation (DOTs) and its main purpose is to evaluate the effectiveness of currently used safety strategies and to obtain your perception about how work zone safety can be improved in construction/maintenance projects. The questionnaire will take about 30 minutes of your time to complete. The information collected will be kept confidential and it will only be used for academic purposes. Thank you in advance for your cooperation since it is vital to the success of this research.

Several questions will be presented in the following questionnaire under the following categories:
A. General Safety Information
B. Administrative Safety Strategies
C. Traffic Control Strategies
D. Measures to Improve Safety in Work Zones
E. Innovative Technologies for Hazard Control
F. Nighttime Traffic Control
G. Relative Ranking of Safety Strategies
$\mathrm{H}$ Demographic Information (Optional)
I. Additional Comments and suggestions
J. General Information

In addition to these questions you will be asked to provide some basic project information. Further, you could be videotaped while performing your work to collect data for in-depth analysis.

Please return the completed survey to the following address:

\author{
Professor Dulcy M. Abraham \\ Purdue University \\ School of Civil Engineering \\ 550 Stadium Mall Drive \\ West Lafayette, IN 47907-2051
}




\section{A. General Safety Information :}

Please check the appropriate answer(s) and or fill in comments.

1. Which of the following safety training(s) is required for the personnel at the construction or maintenance sites? (Check all that apply)

$\begin{array}{ll}\square \text { OSHA-10 hour } & \square \text { Neither of them } \\ \square \text { OSHA-30 hour } & \square \text { Other: Please specify }\end{array}$

2. Please indicate what is the frequency of safety meetings on project sites.

$\square$ On the start date of project $\quad \square$ Weekly
$\square$ Daily
$\square$ Other: Please specify

3. Do you require contractors to assign safety personnel at the project site?

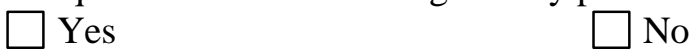

4. Do workers receive any training on safety practices to prevent injuries when they are hired?
$\square$ Yes
$\square$ No

5. Are safety meetings conducted or do workers receive safety training before the start of a specific activity, such as excavation?
$\square$ Yes
No

6. Is there a formal document that explains the procedures used to investigate near-misses and accidents?
$\square$ No
Yes. Please specify

7. On a scale of 1 to 5 how important is each of the following factors in evaluating the effectiveness of a safety strategy.

\begin{tabular}{|l|c|c|c|c|c|}
\hline \multirow{2}{*}{ Factor } & \multicolumn{4}{|c|}{ Scale of Importance } \\
\cline { 2 - 6 } & $\begin{array}{l}\text { Not at } \\
\text { all }\end{array}$ & $\begin{array}{l}\text { Not } \\
\text { very }\end{array}$ & $\begin{array}{l}\text { No } \\
\text { Opini } \\
\text { on }\end{array}$ & $\begin{array}{l}\text { Somewh } \\
\text { at }\end{array}$ & $\begin{array}{l}\text { Extreme } \\
\text { Iy }\end{array}$ \\
\cline { 2 - 6 } & 1 & 2 & 3 & 4 & 5 \\
\hline a. Easy implementation & $\square$ & $\square$ & $\square$ & $\square$ & $\square$ \\
\hline b. Implementation time & $\square$ & $\square$ & $\square$ & $\square$ & $\square$ \\
\hline c. Cost & $\square$ & $\square$ & $\square$ & $\square$ & $\square$ \\
\hline d. Success in injury prevention & $\square$ & $\square$ & $\square$ & $\square$ & $\square$ \\
\hline e. Providing a sense of security & $\square$ & $\square$ & $\square$ & $\square$ & $\square$ \\
\hline $\begin{array}{l}\text { f. Does not prompt the worker to } \\
\text { take unnecessary risks }\end{array}$ & $\square$ & $\square$ & $\square$ & $\square$ & $\square$ \\
\hline $\begin{array}{l}\text { g. Allows unrestricted movement for } \\
\text { performance of any work task }\end{array}$ & $\square$ & $\square$ & $\square$ & $\square$ & $\square$ \\
\hline
\end{tabular}




\begin{tabular}{|l|c|c|c|c|c|}
\hline & \multicolumn{5}{|c|}{ Scale of Importance } \\
\cline { 2 - 6 } & $\begin{array}{l}\text { Not at } \\
\text { all }\end{array}$ & $\begin{array}{l}\text { Not } \\
\text { very }\end{array}$ & $\begin{array}{l}\text { No } \\
\text { Opini } \\
\text { on }\end{array}$ & $\begin{array}{l}\text { Somewh } \\
\text { at }\end{array}$ & $\begin{array}{l}\text { Extreme } \\
\text { Iy }\end{array}$ \\
\cline { 2 - 6 } & 1 & 2 & 3 & 4 & 5 \\
\hline $\begin{array}{l}\text { h. Protection from vehicles intruding } \\
\text { the work zone }\end{array}$ & $\square$ & $\square$ & $\square$ & $\square$ & $\square$ \\
\hline $\begin{array}{l}\text { i. Protection from hazards that arise } \\
\text { from construction operations }\end{array}$ & $\square$ & $\square$ & $\square$ & $\square$ & $\square$ \\
\hline j. Other: Please specify & $\square$ & $\square$ & $\square$ & $\square$ & $\square$ \\
\hline
\end{tabular}

8. How do you rate the following safety hazards according to the level of risk faced by the worker in the work zone and the probability of occurrence?

\begin{tabular}{|c|c|c|c|c|c|c|}
\hline \multirow{3}{*}{ Risk } & \multicolumn{2}{|c|}{ Level of Risk } & \multirow[b]{2}{*}{ High } & \multicolumn{3}{|c|}{ Probability of Occurrence } \\
\hline & Low & $\begin{array}{l}\text { Mode } \\
\text { rate }\end{array}$ & & $\begin{array}{l}L \\
0 \\
w\end{array}$ & $\begin{array}{l}\text { Mode } \\
\text { rate }\end{array}$ & $\begin{array}{l}\text { Hig } \\
h\end{array}$ \\
\hline & 1 & 2 & 3 & 1 & 2 & 3 \\
\hline $\begin{array}{l}\text { a. Vehicles striking pedestrian } \\
\text { workers }\end{array}$ & $\square$ & $\square$ & $\square$ & $\square$ & $\square$ & $\square$ \\
\hline $\begin{array}{l}\text { b. Pedestrian workers injured } \\
\text { while avoiding intruding } \\
\text { vehicles }\end{array}$ & $\square$ & $\square$ & $\square$ & $\square$ & $\square$ & $\square$ \\
\hline $\begin{array}{l}\text { c. Injuries from the movement } \\
\text { of construction equipment } \\
\text { and vehicles within the } \\
\text { work zone }\end{array}$ & $\square$ & $\square$ & $\square$ & $\square$ & $\square$ & $\square$ \\
\hline $\begin{array}{l}\text { d. Exposure to hazardous or } \\
\text { toxic substances }\end{array}$ & $\square$ & $\square$ & $\square$ & $\square$ & $\square$ & $\square$ \\
\hline e. Electrocution & $\square$ & $\square$ & $\square$ & $\square$ & $\square$ & $\square$ \\
\hline f. Falls & $\square$ & $\square$ & $\square$ & $\square$ & $\square$ & $\square$ \\
\hline
\end{tabular}

\section{B. Administrative Safety Strategies:}

1. Which safety strategies are currently used in the construction and/or maintenance operations and how do you rate their performance for improving worker safety and preventing injuries? (Check all that apply)

\begin{tabular}{|c|c|c|c|c|c|c|c|}
\hline \multirow[b]{2}{*}{ Safety Strategy } & \multirow[b]{2}{*}{$\begin{array}{l}U \\
s \\
\text { e }\end{array}$} & \multicolumn{6}{|c|}{ Scale of Effectiveness } \\
\hline & & $\begin{array}{l}\text { Not } \\
\text { Appli } \\
\text { cabl } \\
\text { e }\end{array}$ & $\begin{array}{l}\text { Po } \\
\text { or }\end{array}$ & $\begin{array}{l}\text { Belo } \\
w \\
\text { Aver } \\
\text { age }\end{array}$ & $\begin{array}{l}A v \\
\text { er } \\
a g \\
e\end{array}$ & $\begin{array}{l}\text { Go } \\
\text { od }\end{array}$ & $\begin{array}{l}\text { Ex } \\
\text { ce } \\
\text { Ile } \\
\text { nt }\end{array}$ \\
\hline
\end{tabular}




\begin{tabular}{|c|c|c|c|c|c|c|c|}
\hline & & & 1 & 2 & 3 & 4 & 5 \\
\hline $\begin{array}{l}\text { a. Law enforcement for traffic } \\
\text { control }\end{array}$ & $\square$ & $\square$ & $\square$ & $\square$ & $\square$ & $\square$ & $\square$ \\
\hline $\begin{array}{l}\text { b. Methods to increase the } \\
\text { awareness of the work zone }\end{array}$ & $\square$ & $\square$ & $\square$ & $\square$ & $\square$ & $\square$ & $\square$ \\
\hline $\begin{array}{l}\text { c. Training programs for } \\
\text { workers and staff }\end{array}$ & $\square$ & $\square$ & $\square$ & $\square$ & $\square$ & $\square$ & $\square$ \\
\hline $\begin{array}{l}\text { d. Safety inspections of work } \\
\text { zones }\end{array}$ & $\square$ & $\square$ & $\square$ & $\square$ & $\square$ & $\square$ & $\square$ \\
\hline $\begin{array}{ll}\text { e. } & \text { Distribution of safety } \\
\text { information for road travelers }\end{array}$ & $\square$ & $\square$ & $\square$ & $\square$ & $\square$ & $\square$ & $\square$ \\
\hline f. Incentives for safer practices & $\square$ & $\square$ & $\square$ & $\square$ & $\square$ & $\square$ & $\square$ \\
\hline $\begin{array}{l}\text { g.Planning to minimize worker } \\
\text { exposure to risk }\end{array}$ & $\square$ & $\square$ & $\square$ & $\square$ & $\square$ & $\square$ & $\square$ \\
\hline $\begin{array}{l}\text { h. } \begin{array}{l}\text { Planning of internal work } \\
\text { space and activities }\end{array}\end{array}$ & $\square$ & $\square$ & $\square$ & $\square$ & $\square$ & $\square$ & $\square$ \\
\hline 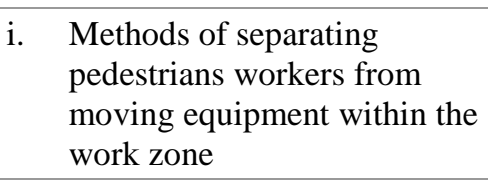 & $\square$ & $\square$ & $\square$ & $\square$ & $\square$ & $\square$ & $\square$ \\
\hline $\begin{array}{ll}\text { j. } & \text { Planning to reduce the } \\
\text { duration of work zones }\end{array}$ & $\square$ & $\square$ & $\square$ & $\square$ & $\square$ & $\square$ & $\square$ \\
\hline k. Tool-box meetings & $\square$ & $\square$ & $\square$ & $\square$ & $\square$ & $\square$ & $\square$ \\
\hline
\end{tabular}

2. Please answer the following questions related to law enforcement for traffic control: a. What type of law enforcement is currently being used?

b. How often is law enforcement used (period of time)?

c. In what types of project is this strategy mostly used?

3. What methods are currently used to increase the awareness of work zones? (Check all that apply):

$\square$ Information on radio $\quad \square$ Information on TV $\quad \square$ Special signs
$\square$ Other: Please specify

4. Please answer the following questions related to safety inspections of work zones:

a. Who performs the safety inspections in the project?

b. How is the safety inspection performed? Is there a format or checklist for the inspection?

c. In what types of project is this strategy mostly used?

d. How often are these inspections performed? 
$\square$ Daily $\square$ Weekly $\square$ Monthly $\square$ Other: Please specify

5. Please answer the following questions related to providing safety information to road travelers: a. What type of information is provided to road users?

b. What methods are currently used to inform road travelers? (Check all that apply):

$\square$ Information on radio $\square$ Information on TV $\square$ Flyers

$\square$ Other: Please specify

6. Please answer the following questions related to the use of incentives for safe work practices: a. Who receives these incentives?

b. What are the main characteristics of these incentives?

7. What are the main characteristics of the plan to minimize worker exposure to risk?

8. Please answer the following questions related to planning of internal work space and activities: a. How do you manage work space inside the work zone?

b. Who is authorized to make changes to the work zone set-up?

9. What is currently being done to reduce the duration of work zones? Is nighttime work an option?

10. Please answer the following questions related to toolbox meetings:

a. How often do workers attend toolbox meetings?

$\square$ Daily $\square$ Weekly $\square$ Bi-Weekly $\square$ Never $\square$ Other: Please specify

b. What topics are discussed at these meetings?

\section{Traffic Control Strategies:}

1. Which safety strategies are currently used at job sites and how do you rate their performance for preventing the intrusion of vehicles in the work zone? (Check all that apply)

\begin{tabular}{|c|c|c|c|c|c|c|c|}
\hline \multirow{3}{*}{ Safety Strategy } & \multirow{3}{*}{$\begin{array}{l}\boldsymbol{U} \\
\boldsymbol{S} \\
\boldsymbol{e} \\
\boldsymbol{d}\end{array}$} & & \multicolumn{5}{|c|}{ Scale of Effectiveness } \\
\hline & & $\begin{array}{l}\text { Not } \\
\text { Appli } \\
\text { cabl } \\
\text { e }\end{array}$ & $\begin{array}{l}\text { Po } \\
\text { or }\end{array}$ & $\begin{array}{l}\text { Belo } \\
\text { w } \\
\text { Aver } \\
\text { age }\end{array}$ & $\begin{array}{l}\text { Av } \\
\text { er } \\
\text { ag } \\
\text { e }\end{array}$ & $\begin{array}{l}\text { Go } \\
\text { od }\end{array}$ & $\begin{array}{l}\text { Ex } \\
\text { ce } \\
\text { lle } \\
\text { nt }\end{array}$ \\
\hline & & & 1 & 2 & 3 & 4 & 5 \\
\hline a. Warning signs & & $\square$ & $\square$ & $\square$ & $\square$ & $\square$ & $\square$ \\
\hline
\end{tabular}




\begin{tabular}{|l|c|c|c|c|c|c|c|}
\hline b. Signals & $\square$ & $\square$ & $\square$ & $\square$ & $\square$ & $\square$ & $\square$ \\
\hline c. Temporary detours & $\square$ & $\square$ & $\square$ & $\square$ & $\square$ & $\square$ & $\square$ \\
\hline d. Flaggers & $\square$ & $\square$ & $\square$ & $\square$ & $\square$ & $\square$ & $\square$ \\
\hline e. Speed control methods & $\square$ & $\square$ & $\square$ & $\square$ & $\square$ & $\square$ & $\square$ \\
\hline f. Others: Please specify & $\square$ & $\square$ & $\square$ & $\square$ & $\square$ & $\square$ & $\square$ \\
\hline
\end{tabular}

2. Please indicate what types of Warning Signs, if any, are currently used in the work zone.

$\begin{array}{ll}\square \text { State Regulation Signs } & \square \text { Arrow Panels } \quad \square \text { Warning Vehicles } \\ \square \text { None } & \square \text { Other: Please specify }\end{array}$

3. Please indicate what types of Speed Control Measures, if any, are currently used in the work zone.

$\square$ Regulatory speed zoning $\square$ Lane reduction $\square$ Speed control devices

$\square$ None $\square$ Other: Please specify

4. Does the project(s) follow the MUTCD for construction work zones?

$\square$ Yes $\square$ No

5. Do you decide which Traffic Control devices are used in the projects?
$\square$ Yes

a. If not, who decides this?

\section{Measures to Improve Safety in Work Zones:}

1. Which safety strategies are currently used at job sites and how do you rate their performance for improving safety in the work zone? (Check all that apply)

\begin{tabular}{|c|c|c|c|c|c|c|c|}
\hline \multirow{3}{*}{ Safety Strategy } & \multirow{3}{*}{$\begin{array}{l}U \\
s \\
e \\
d\end{array}$} & & \multicolumn{5}{|c|}{ Scale of Effectiveness } \\
\hline & & $\begin{array}{l}\text { Not } \\
\text { Appli } \\
\text { cabl } \\
\text { e }\end{array}$ & $\begin{array}{l}\text { Po } \\
\text { or }\end{array}$ & $\begin{array}{l}\text { Belo } \\
\text { w } \\
\text { Aver } \\
\text { age }\end{array}$ & $\begin{array}{l}\text { Av } \\
\text { er } \\
a g \\
e\end{array}$ & $\begin{array}{l}\text { Go } \\
\text { od }\end{array}$ & $\begin{array}{l}\text { Ex } \\
\text { ce } \\
\text { lle } \\
\text { nt } \\
\end{array}$ \\
\hline & & & 1 & 2 & 3 & 4 & 5 \\
\hline a. Temporary traffic barriers & $\square$ & $\square$ & $\square$ & $\square$ & $\square$ & $\square$ & $\square$ \\
\hline b. Worker safety apparel & $\square$ & $\square$ & $\square$ & $\square$ & $\square$ & $\square$ & $\square$ \\
\hline $\begin{array}{l}\text { c. Speed limits for heavy } \\
\text { equipment }\end{array}$ & $\square$ & $\square$ & $\square$ & $\square$ & $\square$ & $\square$ & $\square$ \\
\hline $\begin{array}{l}\text { d. Delineation of sidewalks or } \\
\text { footpaths for workers on foot }\end{array}$ & $\square$ & $\square$ & $\square$ & $\square$ & $\square$ & $\square$ & $\square$ \\
\hline $\begin{array}{l}\text { e. Spotter for assistance when } \\
\text { backing-up }\end{array}$ & $\square$ & $\square$ & $\square$ & $\square$ & $\square$ & $\square$ & $\square$ \\
\hline
\end{tabular}




\begin{tabular}{|l|l|l|l|l|l|l|l|l|}
\hline f. $\begin{array}{l}\text { Measures to reduce the } \\
\text { amount of workers on foot } \\
\text { near equipment }\end{array}$ & $\square$ & $\square$ & $\square$ & $\square$ & $\square$ & $\square$ & $\square$ \\
\hline g. $\quad$ Guardrail systems & $\square$ & $\square$ & $\square$ & $\square$ & $\square$ & $\square$ & $\square$ \\
\hline h. $\quad$ Body belt or harness & $\square$ & $\square$ & $\square$ & $\square$ & $\square$ & $\square$ & $\square$ \\
\hline i. $\quad$ Benching on excavations & $\square$ & $\square$ & $\square$ & $\square$ & $\square$ & $\square$ & $\square$ \\
\hline j. $\quad$ Braced excavations & $\square$ & $\square$ & $\square$ & $\square$ & $\square$ & $\square$ & $\square$ \\
\hline k. $\quad$ Trench box & $\square$ & $\square$ & $\square$ & $\square$ & $\square$ & $\square$ & $\square$ \\
\hline
\end{tabular}

2. Please indicate what types of Temporary Traffic Barriers, if any, are currently used in the work zone.

$\square$ Rigid- concrete barriers $\quad \square$ Movable barrier system $\quad \square$ Flexible barricades $\square$ None $\quad \square$ Other: Please specify

3. Please answer the following questions related to worker safety apparel:

a. Are workers required to wear safety apparel?

$\square$ Yes $\square$ No

b. What kind of safety apparel is currently used at the work zone?
$\square$ Hardhats
$\square$ Safety vests
$\square$ Hand protection (gloves)
$\square$ Eye protection (glasses)
High-visibility pants
$\square$ High-visibility safety vest
$\square$ None
$\square$ Other: Please specify

Ear protection

Steel-toe boots

4. What is the established speed limit for heavy equipment? $\mathrm{mph}$

5. What measures are currently applied to reduce the amount of workers on foot near heavy equipment?

6. Please answer the following questions related to the delineation of sidewalks or footpaths for workers on foot.

a. Who determines the delineation of sidewalks or footpaths for workers on foot?

b. What factors are considered in this delineation? In what types of projects is this strategy applied?

\section{E. Innovative Technologies for Hazard Control}


1. Which of the following Technologies for Hazard Control are currently used at job sites and rate their performance in the construction and/or maintenance operations? (Check all that apply)

\begin{tabular}{|c|c|c|c|c|c|c|c|}
\hline \multirow{3}{*}{ Safety Strategy } & \multirow{3}{*}{$\begin{array}{l}U \\
s \\
e \\
d\end{array}$} & & \multicolumn{5}{|c|}{ Scale of Effectiveness } \\
\hline & & $\begin{array}{l}\text { Not } \\
\text { Appli } \\
\text { cabl } \\
\text { e }\end{array}$ & $\begin{array}{l}\text { Po } \\
\text { or }\end{array}$ & $\begin{array}{l}\text { Belo } \\
w \\
\text { Aver } \\
\text { age }\end{array}$ & $\begin{array}{l}\text { Av } \\
\text { er } \\
a g \\
e\end{array}$ & $\begin{array}{l}\text { Go } \\
\text { od }\end{array}$ & $\begin{array}{l}\text { Ex } \\
\text { ce } \\
\text { Ile } \\
n t\end{array}$ \\
\hline & & & 1 & 2 & 3 & 4 & 5 \\
\hline a. Alert systems & $\square$ & $\square$ & $\square$ & $\square$ & $\square$ & $\square$ & $\square$ \\
\hline b. Radar triggered speed display & $\square$ & $\square$ & $\square$ & $\square$ & $\square$ & $\square$ & $\square$ \\
\hline $\begin{array}{l}\text { c. Light guard raised pavement } \\
\text { markers }\end{array}$ & $\square$ & $\square$ & $\square$ & $\square$ & $\square$ & $\square$ & $\square$ \\
\hline d. Removable rumble strips & $\square$ & $\square$ & $\square$ & $\square$ & $\square$ & $\square$ & $\square$ \\
\hline $\begin{array}{l}\text { e.Sensing devices that sound an } \\
\text { alarm when an object is near } \\
\text { equipment }\end{array}$ & $\square$ & $\square$ & $\square$ & $\square$ & $\square$ & $\square$ & $\square$ \\
\hline f. Parabolic mirrors & $\square$ & $\square$ & $\square$ & $\square$ & $\square$ & $\square$ & $\square$ \\
\hline f. Others: Please specify & $\square$ & $\square$ & $\square$ & $\square$ & $\square$ & $\square$ & $\square$ \\
\hline
\end{tabular}

2. List Technologies for Hazard Control that would be economically feasible to implement on a highway construction or maintenance project?

\section{F. Nighttime Traffic Control}

1. Which safety strategies are currently used how do you rate their performance to improve safety in nighttime construction operations? (Check all that apply)

\begin{tabular}{|c|c|c|c|c|c|c|c|}
\hline \multirow{3}{*}{ Safety Strategy } & \multirow{3}{*}{$\begin{array}{l}U \\
S \\
e \\
d\end{array}$} & & \multicolumn{5}{|c|}{ Scale of Effectiveness } \\
\hline & & $\begin{array}{l}\text { Not } \\
\text { Appli } \\
\text { cabl } \\
\text { e }\end{array}$ & $\begin{array}{l}\text { Po } \\
\text { or }\end{array}$ & $\begin{array}{l}\text { Belo } \\
w \\
\text { Aver } \\
\text { age }\end{array}$ & $\begin{array}{l}\text { Av } \\
\text { er } \\
\text { ag } \\
e\end{array}$ & $\begin{array}{l}\text { Go } \\
\text { od }\end{array}$ & $\begin{array}{l}\text { Ex } \\
\text { ce } \\
\text { Ile } \\
\text { nt }\end{array}$ \\
\hline & & & 1 & 2 & 3 & 4 & 5 \\
\hline a. Retro-reflective clothing & $\square$ & $\square$ & $\square$ & $\square$ & $\square$ & $\square$ & $\square$ \\
\hline $\begin{array}{l}\text { b. Flashing lights on body or } \\
\text { clothing }\end{array}$ & $\square$ & $\square$ & $\square$ & $\square$ & $\square$ & $\square$ & $\square$ \\
\hline
\end{tabular}




\begin{tabular}{|l|c|c|c|c|c|c|c|}
\hline $\begin{array}{l}\text { c. Retro-reflective tape on } \\
\text { equipment }\end{array}$ & $\square$ & $\square$ & $\square$ & $\square$ & $\square$ & $\square$ & $\square$ \\
\hline d. Work area lighting & $\square$ & $\square$ & $\square$ & $\square$ & $\square$ & $\square$ & $\square$ \\
\hline f. Others: Please specify & $\square$ & $\square$ & $\square$ & $\square$ & $\square$ & $\square$ & $\square$ \\
\hline
\end{tabular}

2. How many nighttime construction projects are currently in progress on your area?

$\square$ less than $10 \quad \square$ 11-25 $\square$ 26-40 $\square$ more than 40

3. Do you decide which Nighttime Traffic Control Measures are used on the job sites?
$\square$ Yes
$\square$ No

a. If not, who decides this?

\section{G. Relative Ranking of Safety Strategies}

Please rank the following safety strategies according to the importance that they have towards safety of workers on construction and maintenance sites. For each item choose a number from 1 to 5. Use the following scale (1 - less effective, 5 - essential for safety)

\begin{tabular}{|l|l|}
\hline \multicolumn{1}{|c|}{ Safety Strategy } & Relative Importance \\
\hline a. Administrative Safety Strategies & \\
\hline b.Traffic Control Strategies & \\
\hline c.Measures to Improve Safety in Work Zones & \\
\hline d. Innovative Technologies for Hazard Control & \\
\hline e. Nighttime Traffic Control & \\
\hline
\end{tabular}

\section{H. Demographic Information (Voluntary):}

\begin{tabular}{|c|l|c|}
\hline Age: & $\square$ younger than 18 $\square$ 18-30 $\square$ 31-40 \\
& $\square$ 41-50 $\square$ 51-60 $\square$ older than 60 \\
\hline Gender: & $\square$ Male $\square$ Female \\
\hline $\begin{array}{c}\text { Years of experience in } \\
\text { construction: }\end{array}$ & \\
\hline
\end{tabular}

\section{Additional Comments \& Suggestions:}

1. What other safety strategies should be implemented to improve worker safety and prevent injuries? 
2. In the space below please provide any additional comments regarding Safety Strategies, safety training and suggestions for ways to prevent worker injuries.

\section{J. General Information}

For survey control purposes, please complete the following information:

\begin{tabular}{|l|l|}
\hline Name & \\
\hline Company/Organization and Location & \\
\hline Job Title & \\
\hline Project Name (if applicable) & \\
\hline Project Location (if applicable) & \\
\hline
\end{tabular}




\title{
Appendix E. Survey Administered to General Contractors
}

\section{Analysis of Work Zone Safety Strategies for Improving Worker Safety in Construction and Maintenance Operations \\ Questionnaire - Focus on Perspectives of General Contractors}

\section{Introduction:}

Purdue University is conducting a research study to evaluate the effectiveness of currently used safety strategies in construction and maintenance work zones. The study is sponsored by the Indiana Department of Transportation (INDOT) and has the general objective of improving work zone safety for construction and maintenance workers. One of the steps in this study is the collection of data through surveys or interviews of the key participants involved in highway construction and maintenance projects. In this case, the key participants are: (i) the owners of the constructed projects (e.g. Departments of Transportation), (ii) contractors (i.e., construction companies) and (iii) the workers of both previously mentioned parties. We have contacted you in order to address two main objectives:

1. Obtain your permission to distribute surveys among the workers who perform activities on construction projects that are currently underway.

2. Request your participation as an interviewee.

We are requesting you to voluntarily complete this survey, which comprises questions primarily about safety and your perception of various safety strategies. Finally, the survey seeks to obtain your assistance about how to improve currently used safety strategies and what other methods can be implemented to improve worker safety.

This survey is specifically geared towards General Contractors and its main purpose is to evaluate the effectiveness of currently used safety strategies and to obtain your perception about how work zone safety can be improved in construction/maintenance projects. The questionnaire will take about 30 minutes of your time to complete. The information collected will be kept confidential and it will only be used for academic purposes. Thank you in advance for your cooperation since it is vital to the success of this research.

Several questions will be presented in the following questionnaire under the following categories:
A. Company Information
B. Project Information
C. General Safety Information
D. Administrative Safety Strategies
E. Traffic Control Strategies
F. Measures to Improve Safety in Work Zones
G. Innovative Technologies for Hazard Control
H. Nighttime Traffic Control
I. Overall Evaluation of Strategies
J. Demographic Information (Optional)
K. Additional Comments and suggestions
L. General Information

Please return the completed survey to the following address:

\author{
Professor Dulcy M. Abraham \\ Purdue University \\ School of Civil Engineering \\ 550 Stadium Mall Drive \\ West Lafayette, IN 47907-2051
}




\section{A. Company Information}

Please provide the following information about your company.

1. Indicate the size of your company based on approximate annual revenue in dollar amount ( $\mathrm{M}=$ million).

$\square<1 \mathrm{M}$
$\square 10-25 \mathrm{M}$
$\square \quad 150-250 \mathrm{M}$
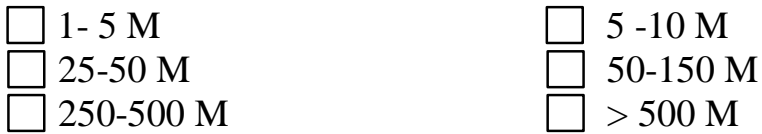

2. Does your company have a written safety program?

$\square$ Yes $\square$ No

a. If yes, does this program include the use and implementation of safety strategies?

$\square$ Yes $\square$ No

3. Do you have a designated person who is responsible for the safety aspects of the project?

$\square$ Yes $\square$ No

a. If yes, who is that designated person during the construction phase?

Safety Manager $\square$ Superintendent

Foreman

\section{B. Project Information:}

Please provide the following information regarding the project(s).

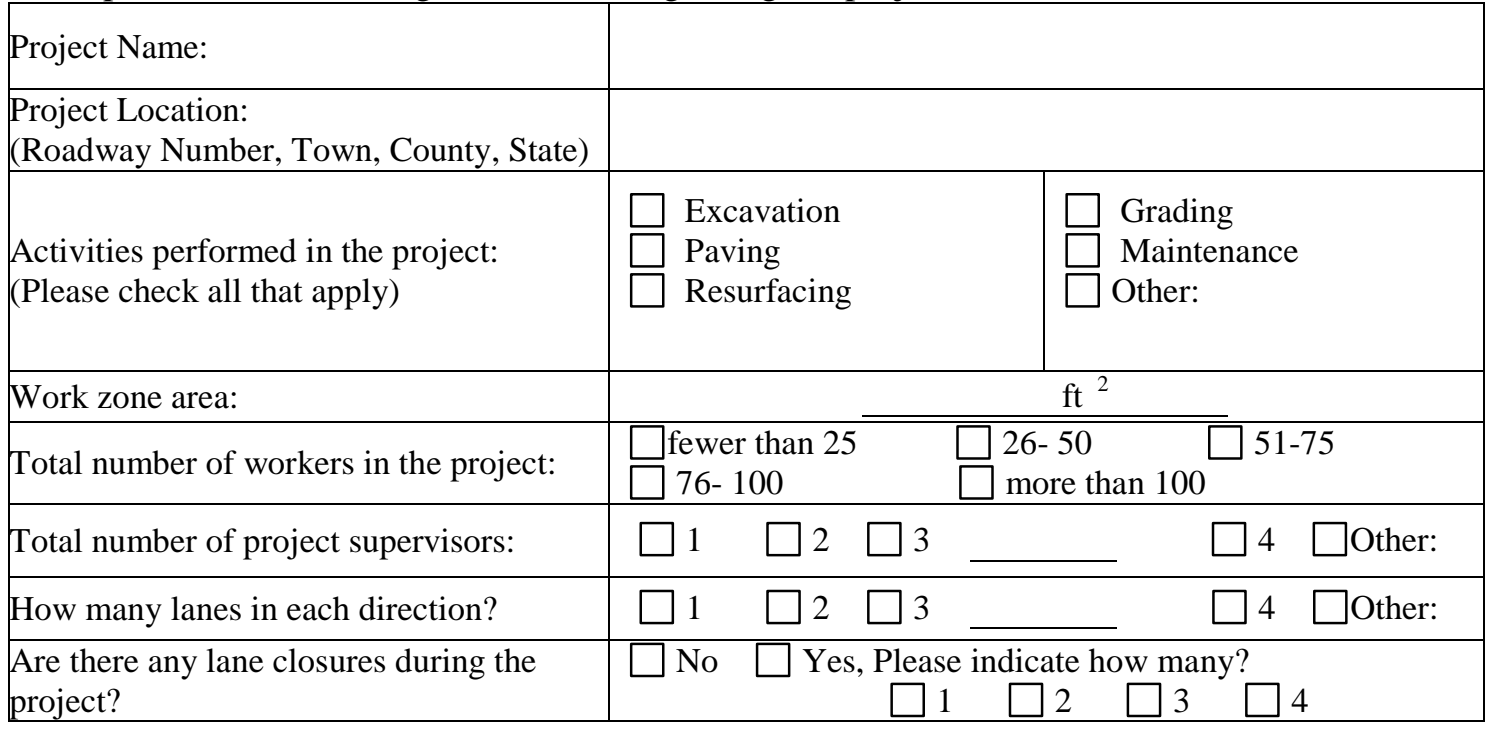

\section{General Safety Information:}

Please check the appropriate answer(s) and or fill in comments.

1. Which of the following safety training(s) is required for the personnel at the construction or maintenance site? (Check all that apply)
$\square$ OSHA-10 hour
Neither of them
OSHA-30 hour
Other: Please specify

2. Do workers receive any training on safety practices to prevent injuries when they are hired?
$\square$ Yes
$\square$ No 
3. Does your company perform pre-work safety meetings or safety training before the start of a specific activity?
$\square$ Yes
$\square$ No

4. Does the company have a formal document that establishes the procedures to investigate accidents and near misses?
$\square$ Yes

a. If yes, what is included in this document?

5. Based on your perception how would you rate the safety on the jobsite?

\begin{tabular}{|c|c|c|c|c|}
\hline Unsafe & Less than Safe & Somewhat & Safe & $\begin{array}{c}\text { Completely } \\
\text { Safe }\end{array}$ \\
\hline 1 & 2 & 3 & 4 & 5 \\
\hline$\square$ & $\square$ & $\square$ & $\square$ & $\square$ \\
\hline
\end{tabular}

6. On a scale of 1 to 5 how important is each of the following factors in evaluating the effectiveness of a safety strategy.

\begin{tabular}{|c|c|c|c|c|c|}
\hline \multirow{3}{*}{ Factor } & \multicolumn{5}{|c|}{ Scale of Importance } \\
\hline & $\begin{array}{l}\text { Not at } \\
\text { all }\end{array}$ & $\begin{array}{l}\text { Not } \\
\text { very }\end{array}$ & $\begin{array}{l}\text { No } \\
\text { Opini } \\
\text { on }\end{array}$ & $\begin{array}{l}\text { Somewh } \\
\text { at }\end{array}$ & $\begin{array}{l}\text { Extre } \\
\text { mely }\end{array}$ \\
\hline & 1 & 2 & 3 & 4 & 5 \\
\hline a. Easy implementation & $\square$ & $\square$ & $\square$ & $\square$ & $\square$ \\
\hline b. Implementation time & $\square$ & $\square$ & $\square$ & $\square$ & $\square$ \\
\hline c. Cost & $\square$ & $\square$ & $\square$ & $\square$ & $\square$ \\
\hline d. Success in injury prevention & $\square$ & $\square$ & $\square$ & $\square$ & $\square$ \\
\hline e. Providing a sense of security & $\square$ & $\square$ & $\square$ & $\square$ & $\square$ \\
\hline $\begin{array}{l}\text { f. Does not prompt the worker to } \\
\text { take unnecessary risks }\end{array}$ & $\square$ & $\square$ & $\square$ & $\square$ & $\square$ \\
\hline $\begin{array}{l}\text { g. Allows unrestricted movement for } \\
\text { performance of any work task }\end{array}$ & $\square$ & $\square$ & $\square$ & $\square$ & $\square$ \\
\hline $\begin{array}{l}\text { h. Protection from vehicles intruding } \\
\text { the work zone }\end{array}$ & $\square$ & $\square$ & $\square$ & $\square$ & $\square$ \\
\hline $\begin{array}{l}\text { i. Protection from hazards that arise } \\
\text { from construction operations }\end{array}$ & $\square$ & $\square$ & $\square$ & $\square$ & $\square$ \\
\hline j. Other: Please specify & $\square$ & $\square$ & $\square$ & $\square$ & $\square$ \\
\hline
\end{tabular}


7. How do you rate the following safety hazards according to the level of risk faced by the worker in the work zone and the probability of occurrence?

\begin{tabular}{|l|l|l|l|l|l|l|}
\hline \multicolumn{1}{|c|}{ Risk } & \multicolumn{2}{|c|}{ Level of Risk } & \multicolumn{3}{c|}{ Probability of Occurrence } \\
\hline & Low & $\begin{array}{l}\text { Mode } \\
\text { rate }\end{array}$ & High & $\begin{array}{l}\text { L } \\
\text { o }\end{array}$ & $\begin{array}{l}\text { Mode } \\
\text { rate }\end{array}$ & $\begin{array}{c}\text { Hig } \\
\text { w }\end{array}$ \\
\hline $\begin{array}{l}\text { a. Vehicles striking pedestrian } \\
\text { workers }\end{array}$ & $\square$ & $\square$ & $\square$ & $\square$ & $\square$ & $\square$ \\
\hline $\begin{array}{l}\text { b. Pedestrian workers injured } \\
\text { while avoiding intruding } \\
\text { vehicles }\end{array}$ & $\square$ & $\square$ & $\square$ & $\square$ & $\square$ & $\square$ \\
\hline $\begin{array}{l}\text { c. Injuries from the movement } \\
\text { of construction equipment } \\
\text { and vehicles within the } \\
\text { work zone }\end{array}$ & $\square$ & $\square$ & $\square$ & $\square$ & $\square$ & $\square$ \\
\hline $\begin{array}{l}\text { d. Exposure to hazardous or } \\
\text { toxic substances }\end{array}$ & $\square$ & $\square$ & $\square$ & $\square$ & $\square$ & $\square$ \\
\hline $\begin{array}{l}\text { e. Electrocution } \\
\text { f. Falls }\end{array}$ & $\square$ & $\square$ & $\square$ & $\square$ & $\square$ & $\square$ \\
\hline $\begin{array}{l}\text { g. Burns and cuts } \\
\text { h. Being buried or falling while } \\
\text { working in excavations or } \\
\text { trenches }\end{array}$ & $\square$ & $\square$ & $\square$ & $\square$ & $\square$ & $\square$ \\
\hline
\end{tabular}

\section{Administrative Safety Strategies:}

1. Which safety strategies are currently used in the construction and/or maintenance operations and how do you rate their performance for improving worker safety and preventing injuries? (Check all that apply)

\begin{tabular}{|c|c|c|c|c|c|c|c|}
\hline \multirow{3}{*}{ Safety Strategy } & \multirow{3}{*}{$\begin{array}{l}U \\
s \\
e \\
d\end{array}$} & & \multicolumn{5}{|c|}{ Scale of Effectiveness } \\
\hline & & $\begin{array}{l}\text { Not } \\
\text { Appli } \\
\text { cabl } \\
\text { e }\end{array}$ & $\begin{array}{l}\text { Po } \\
\text { or }\end{array}$ & $\begin{array}{l}\text { Belo } \\
w \\
\text { Aver } \\
\text { age }\end{array}$ & $\begin{array}{l}\text { Av } \\
e r \\
a g \\
e\end{array}$ & $\begin{array}{l}\text { Go } \\
\text { od }\end{array}$ & $\begin{array}{l}\text { Ex } \\
\text { ce } \\
\text { Ile } \\
\text { nt }\end{array}$ \\
\hline & & & 1 & 2 & 3 & 4 & 5 \\
\hline $\begin{array}{l}\text { a. Law enforcement for traffic } \\
\text { control }\end{array}$ & $\square$ & $\square$ & $\square$ & $\square$ & $\square$ & $\square$ & $\square$ \\
\hline $\begin{array}{l}\text { b. Methods to increase the } \\
\text { awareness of the work zone }\end{array}$ & $\square$ & $\square$ & $\square$ & $\square$ & $\square$ & $\square$ & $\square$ \\
\hline $\begin{array}{l}\text { c. Training programs for } \\
\text { workers and staff }\end{array}$ & $\square$ & $\square$ & $\square$ & $\square$ & $\square$ & $\square$ & $\square$ \\
\hline
\end{tabular}




\begin{tabular}{|c|c|c|c|c|c|c|c|}
\hline $\begin{array}{l}\text { d. Safety inspections of work } \\
\text { zones }\end{array}$ & $\square$ & $\square$ & $\square$ & $\square$ & $\square$ & $\square$ & $\square$ \\
\hline $\begin{array}{l}\text { e. Distribution of safety } \\
\text { information for road travelers }\end{array}$ & $\square$ & $\square$ & $\square$ & $\square$ & $\square$ & $\square$ & $\square$ \\
\hline f. Incentives for safer practices & $\square$ & $\square$ & $\square$ & $\square$ & $\square$ & $\square$ & $\square$ \\
\hline $\begin{array}{l}\text { g. Planning to minimize worker } \\
\text { exposure to risk }\end{array}$ & $\square$ & $\square$ & $\square$ & $\square$ & $\square$ & $\square$ & $\square$ \\
\hline $\begin{array}{l}\text { h. Planning of internal work } \\
\text { space and activities }\end{array}$ & $\square$ & $\square$ & $\square$ & $\square$ & $\square$ & $\square$ & $\square$ \\
\hline $\begin{array}{l}\text { i. Methods of separating } \\
\text { pedestrians workers from } \\
\text { moving equipment within the } \\
\text { work zone }\end{array}$ & $\square$ & $\square$ & $\square$ & $\square$ & $\square$ & $\square$ & $\square$ \\
\hline $\begin{array}{l}\text { j. Planning to reduce the } \\
\text { duration of work zones }\end{array}$ & $\square$ & $\square$ & $\square$ & $\square$ & $\square$ & $\square$ & $\square$ \\
\hline k. Tool-box meetings & $\square$ & $\square$ & $\square$ & $\square$ & $\square$ & $\square$ & $\square$ \\
\hline
\end{tabular}

2. What type of law enforcement is currently being used in the project?

3. What methods are currently used at the job site to increase the awareness of work zones? (Check all that apply)

$\square$ Information on radio $\quad \square$ Information on TV $\quad \square$ Special signs
$\square$ Other: Please specify

4. Please answer the following questions related to job site safety inspections:

a. Does the company perform routinely job site safety inspections?

$\square$ Yes $\square$ No

b. Who performs the safety inspections in the project?

c. How is the safety inspection performed? Is there a format or checklist for the inspection?

d. How often are these inspections performed?

$\square$ Daily $\square$ Weekly $\square$ Monthly $\square$ Other: Please specify

5. Does your company have an incentive program for safe work practices?

$\square$ Yes $\square$ No

a. If yes, who receives these incentives?

b. What are the main characteristics of these incentives?

6. Does the company have a plan to minimize worker exposure to risk?

$\square$ Yes $\square$ No 
7. Please answer the following questions related to planning of internal work space and activities:

a. How do you manage work space inside the work zone?

b. Who is authorized to make changes to the work zone set-up?

8. What is currently being done to reduce the duration of work zones? Is nighttime work an option?

9. Please answer the following questions related to toolbox meetings:
a. Does the company use the practice of toolbox meetings?
$\square$ Yes
$\square$ No

b. If yes, how often do workers attend to toolbox meetings?

$\square$ Daily $\square$ Weekly $\square$ Bi-Weekly $\square$ Never $\square$ Other: Please specify

c. What topics are discussed at these meetings?

10. With what frequency does the Owner (state DOTs) get involved in the safety aspects of the project?
$\square<25 \%$ of the time
$\square 25 \%-50 \%$
$\square 50 \%-75 \%$
$\square>75 \%$

\section{E. Traffic Control Strategies:}

1. Which safety strategies are currently used and how do you rate their performance for preventing the intrusion of vehicles in the work zone? (Check all that apply)

\begin{tabular}{|c|c|c|c|c|c|c|c|}
\hline \multirow{3}{*}{ Safety Strategy } & \multirow{3}{*}{$\begin{array}{l}U \\
s \\
e \\
d\end{array}$} & \multicolumn{6}{|c|}{ Scale of Effectiveness } \\
\hline & & $\begin{array}{l}\text { Not } \\
\text { Appli } \\
\text { cabl } \\
\text { e }\end{array}$ & $\begin{array}{l}\text { Po } \\
\text { or }\end{array}$ & $\begin{array}{l}\text { Belo } \\
w \\
\text { Aver } \\
\text { age }\end{array}$ & $\begin{array}{l}A v \\
\text { er } \\
a g \\
e\end{array}$ & $\begin{array}{l}\text { Go } \\
\text { od }\end{array}$ & $\begin{array}{l}\text { Ex } \\
\text { ce } \\
\text { lle } \\
\text { nt }\end{array}$ \\
\hline & & & 1 & 2 & 3 & 4 & 5 \\
\hline a. Warning signs & $\square$ & $\square$ & $\square$ & $\square$ & $\square$ & $\square$ & $\square$ \\
\hline b. Signals & $\square$ & $\square$ & $\square$ & $\square$ & $\square$ & $\square$ & $\square$ \\
\hline c. Temporary detours & $\square$ & $\square$ & $\square$ & $\square$ & $\square$ & $\square$ & $\square$ \\
\hline d. Flaggers & $\square$ & $\square$ & $\square$ & $\square$ & $\square$ & $\square$ & $\square$ \\
\hline e. Speed control methods & $\square$ & $\square$ & $\square$ & $\square$ & $\square$ & $\square$ & $\square$ \\
\hline f. Others: Please specify & $\square$ & $\square$ & $\square$ & $\square$ & $\square$ & $\square$ & $\square$ \\
\hline
\end{tabular}

2. Please indicate what types of Warning Signs, if any, are currently used in the work zone.
$\square$ State Regulation Signs
None
Arrow Panels
$\square$ Other: Please specify

3. Please indicate what types of Speed Control Measures, if any, are currently used in the work zone.

$\square$ Regulatory speed zoning $\square$ Lane reduction $\square$ Speed control devices 


\section{F. Measures to Improve Safety in Work Zones:}

1. Which safety strategies are currently used and how do you rate their performance for improving safety in the work zone? (Check all that apply)

\begin{tabular}{|c|c|c|c|c|c|c|c|}
\hline \multirow{3}{*}{ Safety Strategy } & \multirow{3}{*}{$\begin{array}{l}U \\
s \\
e \\
d\end{array}$} & \multicolumn{6}{|c|}{ Scale of Effectiveness } \\
\hline & & $\begin{array}{l}\text { Not } \\
\text { Appli } \\
\text { cabl } \\
\text { e }\end{array}$ & $\begin{array}{l}\text { Po } \\
\text { or }\end{array}$ & $\begin{array}{l}\text { Belo } \\
\text { w } \\
\text { Aver } \\
\text { age }\end{array}$ & $\begin{array}{l}\text { Av } \\
\text { er } \\
a g \\
\text { e }\end{array}$ & $\begin{array}{l}\text { Go } \\
\text { od }\end{array}$ & $\begin{array}{l}\text { EX } \\
C E \\
\text { IIE } \\
\text { nt }\end{array}$ \\
\hline & & & 1 & 2 & 3 & 4 & 5 \\
\hline a. Temporary traffic barriers & $\square$ & $\square$ & $\square$ & $\square$ & $\square$ & $\square$ & $\square$ \\
\hline b. Worker safety apparel & $\square$ & $\square$ & $\square$ & $\square$ & $\square$ & $\square$ & $\square$ \\
\hline $\begin{array}{l}\text { c. Speed limits for heavy } \\
\text { equipment }\end{array}$ & $\square$ & $\square$ & $\square$ & $\square$ & $\square$ & $\square$ & $\square$ \\
\hline $\begin{array}{l}\text { d. Delineation of sidewalks or } \\
\text { footpaths for workers on foot }\end{array}$ & $\square$ & $\square$ & $\square$ & $\square$ & $\square$ & $\square$ & $\square$ \\
\hline $\begin{array}{l}\text { e. Spotter for assistance when } \\
\text { backing-up }\end{array}$ & $\square$ & $\square$ & $\square$ & $\square$ & $\square$ & $\square$ & $\square$ \\
\hline $\begin{array}{l}\text { f. Measures to reduce the } \\
\text { amount of workers on foot } \\
\text { near equipment }\end{array}$ & $\square$ & $\square$ & $\square$ & $\square$ & $\square$ & $\square$ & $\square$ \\
\hline g. Guardrail systems & $\square$ & $\square$ & $\square$ & $\square$ & $\square$ & $\square$ & $\square$ \\
\hline h. Body belt or harness & $\square$ & $\square$ & $\square$ & $\square$ & $\square$ & $\square$ & $\square$ \\
\hline i. Benching on excavations & $\square$ & $\square$ & $\square$ & $\square$ & $\square$ & $\square$ & $\square$ \\
\hline j. Braced excavations & $\square$ & $\square$ & $\square$ & $\square$ & $\square$ & $\square$ & $\square$ \\
\hline k. Trench box & $\square$ & $\square$ & $\square$ & $\square$ & $\square$ & $\square$ & $\square$ \\
\hline
\end{tabular}

2. Please indicate what types of Temporary Traffic Barriers, if any, are currently used in the work zone.

$\square$ Rigid- concrete barriers $\square$ Movable barrier system $\square$ Flexible barricades

$\square$ None $\square$ Other: Please specify

3. Please indicate what types of Worker Safety Apparel, if any, are currently used in the work zone

$\square$ Hardhats

Hand protection (gloves)

High-visibility pants

None $\square$ Safety vests

$\square$ Eye protection (glasses)

High-visibility safety vest

Other: Please specify $\square$ Ear protection

$\square$ Steel-toe boots $\square$ High-visibility hard hats 


\section{G. Innovative Technologies for Hazard Control}

1. Which of the following Technologies for Hazard Control are currently used and rate their performance in the construction and/or maintenance operations? (Check all that apply)

\begin{tabular}{|c|c|c|c|c|c|c|c|}
\hline \multirow{3}{*}{ Safety Strategy } & \multirow{3}{*}{$\begin{array}{l}U \\
s \\
e \\
d\end{array}$} & & \multicolumn{5}{|c|}{ Scale of Effectiveness } \\
\hline & & $\begin{array}{l}\text { Not } \\
\text { Appli } \\
\text { cabl } \\
\text { e }\end{array}$ & $\begin{array}{l}\text { Po } \\
\text { or }\end{array}$ & $\begin{array}{l}\text { Belo } \\
\text { w } \\
\text { Aver } \\
\text { age }\end{array}$ & $\begin{array}{l}\text { Av } \\
\text { er } \\
\text { ag } \\
e\end{array}$ & $\begin{array}{l}\text { Go } \\
\text { od }\end{array}$ & $\begin{array}{l}\text { Ex } \\
\text { ce } \\
\text { Ile } \\
\text { nt }\end{array}$ \\
\hline & & & 1 & 2 & 3 & 4 & 5 \\
\hline a. Alert systems & $\square$ & $\square$ & $\square$ & $\square$ & $\square$ & $\square$ & $\square$ \\
\hline b. Radar triggered speed display & $\square$ & $\square$ & $\square$ & $\square$ & $\square$ & $\square$ & $\square$ \\
\hline $\begin{array}{l}\text { c. Light guard raised pavement } \\
\text { markers }\end{array}$ & $\square$ & $\square$ & $\square$ & $\square$ & $\square$ & $\square$ & $\square$ \\
\hline d. Removable rumble strips & $\square$ & $\square$ & $\square$ & $\square$ & $\square$ & $\square$ & $\square$ \\
\hline $\begin{array}{l}\text { e.Sensing devices that sound an } \\
\text { alarm when an object is near } \\
\text { equipment }\end{array}$ & $\square$ & $\square$ & $\square$ & $\square$ & $\square$ & $\square$ & $\square$ \\
\hline f. Parabolic mirrors & $\square$ & $\square$ & $\square$ & $\square$ & $\square$ & $\square$ & $\square$ \\
\hline f. Others: Please specify & $\square$ & $\square$ & $\square$ & $\square$ & $\square$ & $\square$ & $\square$ \\
\hline
\end{tabular}

2. Based on your perspective, list different Technologies for Hazard Control that would be economically feasible to apply on a highway construction or maintenance project?

\section{H. Nighttime Traffic Control}

1. Which safety strategies are currently used how do you rate their performance to improve safety in nighttime construction operations? (Check all that apply)

\begin{tabular}{|c|c|c|c|c|c|c|c|}
\hline \multirow{3}{*}{ Safety Strategy } & \multirow{3}{*}{$\begin{array}{l}U \\
s \\
e \\
d\end{array}$} & & \multicolumn{5}{|c|}{ Scale of Effectiveness } \\
\hline & & $\begin{array}{l}\text { Not } \\
\text { Appli } \\
\text { cabl } \\
\text { e }\end{array}$ & $\begin{array}{l}\text { Po } \\
\text { or }\end{array}$ & $\begin{array}{l}\text { Belo } \\
\text { w } \\
\text { Aver } \\
\text { age }\end{array}$ & $\begin{array}{l}\text { Av } \\
\text { er } \\
\text { ag } \\
\text { e }\end{array}$ & $\begin{array}{l}\text { Go } \\
\text { od }\end{array}$ & $\begin{array}{l}\text { Ex } \\
\text { ce } \\
\text { Ile } \\
\text { nt }\end{array}$ \\
\hline & & & 1 & 2 & 3 & 4 & 5 \\
\hline a. Retro-reflective clothing & $\square$ & $\square$ & $\square$ & $\square$ & $\square$ & $\square$ & $\square$ \\
\hline
\end{tabular}




\begin{tabular}{|l|l|l|l|l|l|l|l|}
\hline $\begin{array}{l}\text { b. Flashing lights on body or } \\
\text { clothing }\end{array}$ & $\square$ & $\square$ & $\square$ & $\square$ & $\square$ & $\square$ & $\square$ \\
\hline $\begin{array}{l}\text { c. Retro-reflective tape on } \\
\text { equipment }\end{array}$ & $\square$ & $\square$ & $\square$ & $\square$ & $\square$ & $\square$ & $\square$ \\
\hline \begin{tabular}{l} 
d. Work area lighting \\
\hline
\end{tabular} & $\square$ & $\square$ & $\square$ & $\square$ & $\square$ & $\square$ & $\square$ \\
\hline
\end{tabular}

2. Please indicate the average number of night hours worked per week on this project.

$\begin{array}{lll}\square \text { None } & \square<5 & \square 5-10 \\ \square 10-20 & \square>20 & \end{array}$

3. Who is in charge of deciding which Nighttime Traffic Control Measures are used the project?
$\square$ Safety Manager
$\square$ Personnel Manager
$\square$ Superintendent
$\square$ Foreman
$\square$ Other: Please specify

4. Who are the distributors of the used retro-reflective clothing on your projects?

\section{Relative Ranking of Safety Strategies}

Please rank the following safety strategies according to the importance that they have towards safety of workers on construction and maintenance sites. For each item choose a number from 1 to 5 . Use the following scale (1 - less effective, 5 - essential for safety)

\begin{tabular}{|l|l|}
\hline \multicolumn{1}{|c|}{ Safety Strategy } & Relative Importance \\
\hline a. Administrative Safety Strategies & \\
\hline b.Traffic Control Strategies & \\
\hline c.Measures to Improve Safety in Work Zones & \\
\hline d. Innovative Technologies for Hazard Control & \\
\hline e. Nighttime Traffic Control & \\
\hline
\end{tabular}

\section{J. Demographic Information (Voluntary):}

\begin{tabular}{|c|ll|}
\hline Age: & $\square$ younger than 18 $\square$ 18-30 $\square$ 31-40 \\
\hline Gender: & $\square$ Male & $\square$ 51-60 $\square$ older than 60 \\
\hline Gemale \\
\hline $\begin{array}{c}\text { Years of experience } \\
\text { in construction: }\end{array}$ & $\square$ Fears \\
\hline
\end{tabular}

\section{K. Additional Comments \& Suggestions:}

1. What other safety strategies should be implemented to improve worker safety and prevent injuries?

2. In the space below please provide any additional comments regarding Safety Strategies, safety training and suggestions for ways to prevent worker injuries. 


\section{General Information}

a. For survey control purposes, please complete the following information:

\begin{tabular}{|l|l|}
\hline Name & \\
\hline Company/Organization and Location & \\
\hline Job Title & \\
\hline Project Name (if applicable) & \\
\hline Project Location (if applicable) & \\
\hline
\end{tabular}




\section{APPENDIX F. Survey Administered to Construction and Maintenance Workers \\ Analysis of Work Zone Safety Strategies for Improving Worker Safety in Construction and Maintenance Operations \\ Questionnaire - Focus on Perspectives of the Workers}

\section{Introduction:}

Purdue University is conducting a study investigating work zone safety practices in the Midwest for construction and maintenance operations. To accomplish the goals of this study, a survey is being conducted among the key players in highway construction projects. In this case, the key players are: (i) The owners of the constructed projects, (ii) the workers and (ii) the contractors.

We request you to complete this survey which includes general questions about work/environment related aspects and specific questions related to safety. This questionnaire is specifically geared towards workers and its purpose is to evaluate the effectiveness of work zone safety strategies and implementation procedures.

The questionnaire will take about 20 minutes of your time to complete. The information collected will be kept confidential and it will only be used for academic purposes. Your participation in this survey is completely voluntary. It is the goal of this research to analyze currently used work zone safety practices to improve worker safety, thereby decreasing the number of accidents that cause injuries and fatalities during construction and maintenance operations. For this reason your cooperation is vital to the success of this research."

Several questions will be presented in the following questionnaire under the following categories:
A. General Safety Questions
B. Safety Training
C. Administrative Safety Strategies
D. Traffic Control Strategies
E. Measures to Improve Safety in Work Zones
F. Innovative Technologies for Hazard Control
G. Nighttime Traffic Control
H. Demographic Information (Optional)
I. Additional Comments and suggestions
J. General Information

In addition to these questions you will be asked to provide some basic project information. Further, you could be videotaped while performing your work to collect data for in-depth analysis.

Please return the completed survey to the following address:

$$
\begin{gathered}
\text { Professor Dulcy M. Abraham } \\
\text { Purdue University } \\
\text { School of Civil Engineering } \\
550 \text { Stadium Mall Drive } \\
\text { West Lafayette, IN 47907-2051 }
\end{gathered}
$$




\section{A. General Safety Questions:}

Please check the answer that best describes your experience during construction and maintenance work.

5. Does the staffing for your projects include the designation of a person (for example, safety officer) who is responsible to ensure safety procedures are followed?

$\square$ Yes $\square$ No

6. Which of the following safety training activities have you attended?(Check all that apply)

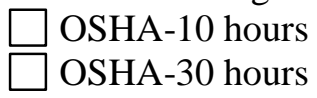

$\square$ None of them
$\square$ Other: Please specify

7. On a scale of 1 to 5 how important is each of the following factors in evaluating the effectiveness of a safety strategy.

\begin{tabular}{|c|c|c|c|c|c|}
\hline \multirow{3}{*}{ Factor } & \multicolumn{5}{|c|}{ Scale of Importance } \\
\hline & $\begin{array}{l}\text { Not at } \\
\text { all }\end{array}$ & $\begin{array}{l}\text { Not } \\
\text { very }\end{array}$ & $\begin{array}{l}\text { No } \\
\text { Opini } \\
\text { on }\end{array}$ & $\begin{array}{l}\text { Somewh } \\
\text { at }\end{array}$ & $\begin{array}{l}\text { Extreme } \\
\text { ly }\end{array}$ \\
\hline & 1 & 2 & 3 & 4 & 5 \\
\hline a. Easy implementation & $\square$ & $\square$ & $\square$ & $\square$ & $\square$ \\
\hline b. Implementation time & $\square$ & $\square$ & $\square$ & $\square$ & $\square$ \\
\hline c. Cost & $\square$ & $\square$ & $\square$ & $\square$ & $\square$ \\
\hline d. Success in injury prevention & $\square$ & $\square$ & $\square$ & $\square$ & $\square$ \\
\hline e. Providing a sense of security & $\square$ & $\square$ & $\square$ & $\square$ & $\square$ \\
\hline $\begin{array}{l}\text { f. Does not prompt the worker to } \\
\text { take unnecessary risks }\end{array}$ & $\square$ & $\square$ & $\square$ & $\square$ & $\square$ \\
\hline $\begin{array}{l}\text { g. Allows unrestricted movement for } \\
\text { performance of any work task }\end{array}$ & $\square$ & $\square$ & $\square$ & $\square$ & $\square$ \\
\hline $\begin{array}{l}\text { h. Protection from vehicles intruding } \\
\text { the work zone }\end{array}$ & $\square$ & $\square$ & $\square$ & $\square$ & $\square$ \\
\hline $\begin{array}{l}\text { i. Protection from hazards that arise } \\
\text { from construction operations }\end{array}$ & $\square$ & $\square$ & $\square$ & $\square$ & $\square$ \\
\hline
\end{tabular}

8. Please indicate three (3) elements in a work zone that make you feel safe. (Please, check only 3 )

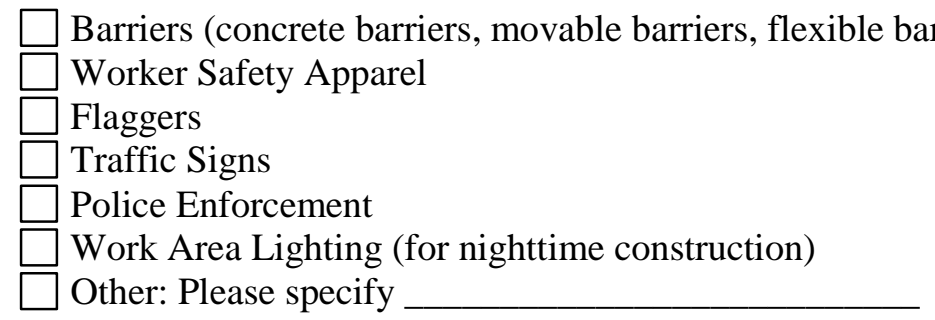


9. Based on your experience, how do you rate the following safety hazards according to the level of risk faced by the worker in the work zone and the probability of occurrence?

\begin{tabular}{|c|c|c|c|c|c|c|}
\hline \multirow{3}{*}{ Risk } & \multicolumn{3}{|c|}{ Level of Risk } & \multicolumn{3}{|c|}{ Probability of Occurrence } \\
\hline & Low & $\begin{array}{l}\text { Mode } \\
\text { rate }\end{array}$ & High & $\begin{array}{l}L \\
o \\
w\end{array}$ & $\begin{array}{l}\text { Mode } \\
\text { rate }\end{array}$ & $\begin{array}{l}\text { Hig } \\
h\end{array}$ \\
\hline & 1 & 2 & 3 & 1 & 2 & 3 \\
\hline $\begin{array}{l}\text { a. Vehicles striking pedestrian } \\
\text { workers }\end{array}$ & $\square$ & $\square$ & $\square$ & $\square$ & $\square$ & $\square$ \\
\hline $\begin{array}{l}\text { b. Pedestrian workers injured } \\
\text { while avoiding intruding } \\
\text { vehicles }\end{array}$ & $\square$ & $\square$ & $\square$ & $\square$ & $\square$ & $\square$ \\
\hline $\begin{array}{l}\text { c. Injuries from the movement } \\
\text { of construction equipment and } \\
\text { vehicles within the work zone }\end{array}$ & $\square$ & $\square$ & $\square$ & $\square$ & $\square$ & $\square$ \\
\hline $\begin{array}{l}\text { d. Exposure to hazardous or } \\
\text { toxic substances }\end{array}$ & $\square$ & $\square$ & $\square$ & $\square$ & $\square$ & $\square$ \\
\hline e. Electrocution & $\square$ & $\square$ & $\square$ & $\square$ & $\square$ & $\square$ \\
\hline f. Falls & $\square$ & $\square$ & $\square$ & $\square$ & $\square$ & $\square$ \\
\hline g. Burns and cuts & $\square$ & $\square$ & $\square$ & $\square$ & $\square$ & $\square$ \\
\hline $\begin{array}{l}\text { h. Being buried or falling while } \\
\text { working in excavations or } \\
\text { trenches }\end{array}$ & $\square$ & $\square$ & $\square$ & $\square$ & $\square$ & $\square$ \\
\hline
\end{tabular}

\section{B. Safety Training:}

1. How often do you attend to safety meetings

$\square$ Daily $\square$ Weekly $\square$ Bi-Weekly $\square$ Never $\square$ Other: Specify

2. Did you receive any training on safety practices to prevent injuries when you were hired? $\square$ Yes $\square$ No

3. If yes, what safety practices were covered in the training? (Check all that apply)

$\square$ How to use the personal safety apparel

$\square$ How to minimize exposure to risk

$\square$ Speed limits for construction equipment

$\square$ Limitations of safety strategies and equipment

Other: Please specify

4. Do you receive any on-going training regarding safety practices?

$\square$ Yes $\square$ No

a. If yes, how often?

$\square$ Daily $\square$ Weekly $\square$ Bi-Weekly $\square$ Monthly $\square$ Other: Specify 


\section{Administrative Safety Strategies:}

1. Which safety strategies are currently used in the construction and/or maintenance operations and how do you rate their performance for improving worker safety and preventing injuries? (Check all that apply)

\begin{tabular}{|c|c|c|c|c|c|c|c|}
\hline \multirow{3}{*}{ Safety Strategy } & \multirow{3}{*}{$\begin{array}{l}u \\
s \\
e \\
d\end{array}$} & \multicolumn{6}{|c|}{ Scale of Effectiveness } \\
\hline & & $\begin{array}{l}\text { Not } \\
\text { Appli } \\
\text { cabl } \\
\text { e }\end{array}$ & $\begin{array}{l}\text { Po } \\
\text { or }\end{array}$ & $\begin{array}{l}\text { Belo } \\
\text { w } \\
\text { Aver } \\
\text { age }\end{array}$ & $\begin{array}{l}\text { Av } \\
\text { er } \\
\text { ag } \\
\text { e }\end{array}$ & $\begin{array}{l}\text { Go } \\
\text { od }\end{array}$ & $\begin{array}{l}\text { Ex } \\
\text { ce } \\
\text { Ile } \\
\text { nt }\end{array}$ \\
\hline & & & 1 & 2 & 3 & 4 & 5 \\
\hline $\begin{array}{l}\text { a. Law enforcement for traffic } \\
\text { control }\end{array}$ & $\square$ & $\square$ & $\square$ & $\square$ & $\square$ & $\square$ & $\square$ \\
\hline $\begin{array}{l}\text { b. Methods to increase the } \\
\text { awareness of the work zone }\end{array}$ & $\square$ & $\square$ & $\square$ & $\square$ & $\square$ & $\square$ & $\square$ \\
\hline $\begin{array}{l}\text { c. Training programs for } \\
\text { workers and staff }\end{array}$ & $\square$ & $\square$ & $\square$ & $\square$ & $\square$ & $\square$ & $\square$ \\
\hline $\begin{array}{l}\text { d. Safety inspections of work } \\
\text { zones }\end{array}$ & $\square$ & $\square$ & $\square$ & $\square$ & $\square$ & $\square$ & $\square$ \\
\hline $\begin{array}{l}\text { e. Distribution of safety } \\
\text { information for road travelers }\end{array}$ & $\square$ & $\square$ & $\square$ & $\square$ & $\square$ & $\square$ & $\square$ \\
\hline f. Incentives for safer practices & $\square$ & $\square$ & $\square$ & $\square$ & $\square$ & $\square$ & $\square$ \\
\hline $\begin{array}{l}\text { g. Planning to minimize worker } \\
\text { exposure to risk }\end{array}$ & $\square$ & $\square$ & $\square$ & $\square$ & $\square$ & $\square$ & $\square$ \\
\hline $\begin{array}{l}\text { h. Planning of internal work } \\
\text { space and activities }\end{array}$ & $\square$ & $\square$ & $\square$ & $\square$ & $\square$ & $\square$ & $\square$ \\
\hline $\begin{array}{l}\text { i. Methods of separating } \\
\text { pedestrians workers from } \\
\text { moving equipment within the } \\
\text { work zone }\end{array}$ & $\square$ & $\square$ & $\square$ & $\square$ & $\square$ & $\square$ & $\square$ \\
\hline $\begin{array}{l}\text { 1. Planning to reduce the } \\
\text { duration of work zones }\end{array}$ & $\square$ & $\square$ & $\square$ & $\square$ & $\square$ & $\square$ & $\square$ \\
\hline m. Tool-box meetings & & $\square$ & $\square$ & $\square$ & $\square$ & $\square$ & $\square$ \\
\hline
\end{tabular}




\section{Traffic Control Strategies:}

2. Which safety strategies are currently used and how do you rate their performance for preventing the intrusion of vehicles in the work zone? (Check all that apply)

\begin{tabular}{|c|c|c|c|c|c|c|c|}
\hline \multirow{3}{*}{ Safety Strategy } & \multirow{3}{*}{$\begin{array}{l}U \\
S \\
e \\
d\end{array}$} & & \multicolumn{5}{|c|}{ Scale of Effectiveness } \\
\hline & & $\begin{array}{l}\text { Not } \\
\text { Appli } \\
\text { cabl } \\
\text { e }\end{array}$ & $\begin{array}{l}\text { Po } \\
\text { or }\end{array}$ & $\begin{array}{l}\text { Belo } \\
w \\
\text { Aver } \\
\text { age }\end{array}$ & $\begin{array}{l}\text { Av } \\
\text { er } \\
a g \\
e\end{array}$ & $\begin{array}{l}\text { Go } \\
\text { od }\end{array}$ & $\begin{array}{l}\text { Ex } \\
\text { ce } \\
\text { Ile } \\
\text { nt }\end{array}$ \\
\hline & & & 1 & 2 & 3 & 4 & 5 \\
\hline a. Warning signs & $\square$ & $\square$ & $\square$ & $\square$ & $\square$ & $\square$ & $\square$ \\
\hline b. Signals & $\square$ & $\square$ & $\square$ & $\square$ & $\square$ & $\square$ & $\square$ \\
\hline c. Temporary detours & $\square$ & $\square$ & $\square$ & $\square$ & $\square$ & $\square$ & $\square$ \\
\hline d. Flaggers & $\square$ & $\square$ & $\square$ & $\square$ & $\square$ & $\square$ & $\square$ \\
\hline e. Speed control methods & $\square$ & $\square$ & $\square$ & $\square$ & $\square$ & $\square$ & $\square$ \\
\hline f. Others: Please specify & $\square$ & $\square$ & $\square$ & $\square$ & $\square$ & $\square$ & $\square$ \\
\hline
\end{tabular}

2. Please indicate what types of Warning Signs, if any, are currently used in the work zone.
$\square$ State Regulation Signs
$\square$ Arrow Panels
None
Other: Please specify

3. Please indicate what types of Speed Control Measures, if any, are currently used in the work zone.

$\square$ Regulatory speed zoning $\square$ Lane reduction $\square$ Speed control devices

\section{E. Measures to Improve Safety in Work Zones:}

2. Which safety strategies are currently used and how do you rate their performance for improving safety in the work zone? (Check all that apply)

\begin{tabular}{|c|c|c|c|c|c|c|c|}
\hline \multirow{3}{*}{ Safety Strategy } & \multirow{3}{*}{$\begin{array}{l}\boldsymbol{U} \\
\boldsymbol{s} \\
\mathbf{e} \\
\boldsymbol{d}\end{array}$} & \multicolumn{6}{|c|}{ Scale of Effectiveness } \\
\hline & & $\begin{array}{l}\text { Not } \\
\text { Appli } \\
\text { cabl } \\
\text { e }\end{array}$ & $\begin{array}{l}\text { Po } \\
\text { or }\end{array}$ & $\begin{array}{l}\text { Belo } \\
\text { w } \\
\text { Aver } \\
\text { age }\end{array}$ & $\begin{array}{l}\text { Av } \\
\text { er } \\
a g \\
\text { e }\end{array}$ & $\begin{array}{l}\text { Go } \\
\text { od }\end{array}$ & $\begin{array}{l}\text { Ex } \\
\text { ce } \\
\text { Ile } \\
\text { nt }\end{array}$ \\
\hline & & & 1 & 2 & 3 & 4 & 5 \\
\hline a. Temporary traffic barriers & $\square$ & $\square$ & $\square$ & $\square$ & $\square$ & $\square$ & $\square$ \\
\hline b. Worker safety apparel & $\square$ & $\square$ & $\square$ & $\square$ & $\square$ & $\square$ & $\square$ \\
\hline
\end{tabular}




\begin{tabular}{|l|l|l|l|l|l|l|l|}
\hline $\begin{array}{c}\text { c. Speed limits for heavy } \\
\text { equipment }\end{array}$ & $\square$ & $\square$ & $\square$ & $\square$ & $\square$ & $\square$ & $\square$ \\
\hline $\begin{array}{c}\text { d. Delineation of sidewalks or } \\
\text { footpaths for workers on foot }\end{array}$ & $\square$ & $\square$ & $\square$ & $\square$ & $\square$ & $\square$ & $\square$ \\
\hline $\begin{array}{l}\text { e. Spotter for assistance when } \\
\text { backing-up }\end{array}$ & $\square$ & $\square$ & $\square$ & $\square$ & $\square$ & $\square$ & $\square$ \\
\hline $\begin{array}{l}\text { f. Measures to reduce the } \\
\text { amount of workers on foot } \\
\text { near equipment }\end{array}$ & $\square$ & $\square$ & $\square$ & $\square$ & $\square$ & $\square$ & $\square$ \\
\hline $\begin{array}{l}\text { g. Guardrail systems } \\
\text { h. Body belt or harness }\end{array}$ & $\square$ & $\square$ & $\square$ & $\square$ & $\square$ & $\square$ & $\square$ \\
\hline i. Benching on excavations & $\square$ & $\square$ & $\square$ & $\square$ & $\square$ & $\square$ & $\square$ \\
\hline j. Braced excavations & $\square$ & $\square$ & $\square$ & $\square$ & $\square$ & $\square$ & $\square$ \\
\hline k. Trench box & $\square$ & $\square$ & $\square$ & $\square$ & $\square$ & $\square$ & $\square$ \\
\hline
\end{tabular}

2. Please indicate what types of Temporary Traffic Barriers, if any, are currently used in the work zone.

$\square$ Rigid- concrete barriers $\square$ Movable barrier system $\square$ Flexible barricades $\square$ None $\square$ Other: Please specify

3. Please indicate what types of Worker Safety Apparel, if any, are currently used in the work zone

$\begin{array}{lll}\square \text { Hardhats } & \square \text { Safety vests } & \square \text { Ear protection } \\ \square \text { Hand protection (gloves) } & \square \text { Eye protection (glasses) } & \square \text { Steel-toe boots } \\ \square \text { High-visibility pants } & \square \text { High-visibility safety vest } & \square \text { High-visibility hard } \\ \square \text { hats }\end{array}$

None

Other: Please specify

\section{F. Innovative Technologies for Hazard Control}

1. Which of the following Technologies for Hazard Control are currently used and rate their performance in the construction and/or maintenance operations? (Check all that apply)

\begin{tabular}{|c|c|c|c|c|c|c|c|}
\hline \multirow{3}{*}{ Safety Strategy } & \multirow{3}{*}{$\begin{array}{l}u \\
s \\
e \\
d\end{array}$} & & \multicolumn{5}{|c|}{ Scale of Effectiveness } \\
\hline & & $\begin{array}{l}\text { Not } \\
\text { Appli } \\
\text { cabl } \\
\text { e }\end{array}$ & $\begin{array}{l}\text { Po } \\
\text { or }\end{array}$ & $\begin{array}{l}\text { Belo } \\
w \\
\text { Aver } \\
\text { age }\end{array}$ & $\begin{array}{l}\text { Av } \\
\text { er } \\
\text { ag } \\
\text { e }\end{array}$ & $\begin{array}{l}\text { Go } \\
\text { od }\end{array}$ & $\begin{array}{l}\text { Ex } \\
\text { ce } \\
\text { Ile } \\
\text { nt }\end{array}$ \\
\hline & & & 1 & 2 & 3 & 4 & 5 \\
\hline a. Alert systems & $\square$ & $\square$ & $\square$ & $\square$ & $\square$ & $\square$ & $\square$ \\
\hline
\end{tabular}




\begin{tabular}{|l|c|c|c|c|c|c|c|}
\hline b. Radar triggered speed display & $\square$ & $\square$ & $\square$ & $\square$ & $\square$ & $\square$ & $\square$ \\
\hline $\begin{array}{l}\text { c. Light guard raised pavement } \\
\text { markers }\end{array}$ & $\square$ & $\square$ & $\square$ & $\square$ & $\square$ & $\square$ & $\square$ \\
\hline $\begin{array}{l}\text { d. Removable rumble strips } \\
\begin{array}{l}\text { e.Sensing devices that sound an } \\
\text { alarm when an object is near } \\
\text { equipment }\end{array}\end{array}$ & $\square$ & $\square$ & $\square$ & $\square$ & $\square$ & $\square$ & $\square$ \\
\hline $\begin{array}{l}\text { f. Parabolic mirrors } \\
\text { f. Others: Please specify }\end{array}$ & $\square$ & $\square$ & $\square$ & $\square$ & $\square$ & $\square$ & $\square$ \\
\hline
\end{tabular}

\section{G. Nighttime Traffic Control}

1. Which safety strategies are currently used how do you rate their performance to improve safety in nighttime construction operations? (Check all that apply)

\begin{tabular}{|c|c|c|c|c|c|c|c|}
\hline \multirow{3}{*}{ Safety Strategy } & \multirow{3}{*}{$\begin{array}{l}U \\
\boldsymbol{U} \\
\boldsymbol{e} \\
\boldsymbol{d}\end{array}$} & & \multicolumn{5}{|c|}{ Scale of Effectiveness } \\
\hline & & $\begin{array}{l}\text { Not } \\
\text { Appli } \\
\text { cabl } \\
\text { e }\end{array}$ & $\begin{array}{l}\text { Po } \\
\text { or }\end{array}$ & $\begin{array}{l}\text { Belo } \\
w \\
\text { Aver } \\
\text { age }\end{array}$ & $\begin{array}{l}\text { Av } \\
\text { er } \\
\text { ag } \\
\text { e }\end{array}$ & $\begin{array}{l}\text { Go } \\
\text { od }\end{array}$ & $\begin{array}{l}\text { Ex } \\
\text { ce } \\
\text { Ile } \\
\text { nt }\end{array}$ \\
\hline & & & 1 & 2 & 3 & 4 & 5 \\
\hline a. Retro-reflective clothing & $\square$ & $\square$ & $\square$ & $\square$ & $\square$ & $\square$ & $\square$ \\
\hline $\begin{array}{l}\text { b. Flashing lights on body or } \\
\text { clothing }\end{array}$ & $\square$ & $\square$ & $\square$ & $\square$ & $\square$ & $\square$ & $\square$ \\
\hline $\begin{array}{l}\text { c. Retro-reflective tape on } \\
\text { equipment }\end{array}$ & $\square$ & $\square$ & $\square$ & $\square$ & $\square$ & $\square$ & $\square$ \\
\hline d. Work area lighting & $\square$ & $\square$ & $\square$ & $\square$ & $\square$ & $\square$ & $\square$ \\
\hline f. Others: Please specify & $\square$ & $\square$ & $\square$ & $\square$ & $\square$ & $\square$ & $\square$ \\
\hline
\end{tabular}

\section{H. Demographic Information (Voluntary):}

\begin{tabular}{|c|c|c|c|}
\hline Age: & \begin{tabular}{|l}
$\square$ \\
$\square$ \\
$\square$
\end{tabular} & $\begin{array}{c}18-30 \\
51-60\end{array}$ & 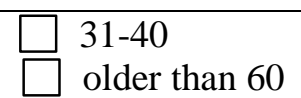 \\
\hline Gender: & Male & \multicolumn{2}{|c|}{ Female } \\
\hline \multirow{2}{*}{ Ethnicity: } & White $\square$ B & & \multirow[t]{2}{*}{ Hispanic or Latino } \\
\hline & $\square$ Native American & Other & \\
\hline $\begin{array}{l}\text { Years of experience in } \\
\text { construction: }\end{array}$ & \multicolumn{3}{|c|}{ years } \\
\hline
\end{tabular}




\begin{tabular}{|c|cc|}
\hline $\begin{array}{c}\text { Number of highway } \\
\text { projects worked on: }\end{array}$ & - Number \\
\hline $\begin{array}{c}\text { Types of projects in } \\
\text { which you work most } \\
\text { frequently }\end{array}$ & $\square$ Construction \\
\hline
\end{tabular}

\section{Additional Comments \& Suggestions:}

1. What other safety strategies should be implemented to improve worker safety and prevent injuries?

2. In the space below please provide any additional comments regarding Safety Strategies, safety trainings and suggestions for ways to prevent worker injuries.

\section{J. General Information}

For survey control purposes, please complete the following information:

\begin{tabular}{|l|l|}
\hline Name: & \\
\hline $\begin{array}{l}\text { Company/Organization and } \\
\text { Location: }\end{array}$ & \\
\hline $\begin{array}{l}\text { Project Name } \\
\text { (if applicable): }\end{array}$ & \\
\hline $\begin{array}{l}\text { Project Location } \\
\text { (if applicable): }\end{array}$ & $\square \begin{array}{l}\text { Construction Laborer } \\
\text { Job Title: }\end{array}$ \\
\hline$\square$ & $\begin{array}{l}\text { Flagger or Traffic Controller } \\
\text { Heavy Equipment Operator } \\
\end{array}$ \\
& $\begin{array}{l}\text { Other Equipment Operator } \\
\text { Driver }\end{array}$ \\
& $\begin{array}{l}\text { Foreman or Supervisor } \\
\text { Other: Please specify }\end{array}$ \\
\hline
\end{tabular}


APPENDIX G. Survey Distributed to Students for the Evaluation of the Videos

Performance Evaluation of Camera Systems to Reduce the Risk of Serious/Fatal Injuries Related to Mobile Equipment in Work Zones

Introduction:

Purdue University is conducting a study about safety of workers in constuction and maintenance work zones. To accomplish one of the goals of this study, this step aims to get the perspectives of different sets of people regarding the visibility of different cameras installed in the back of dump trucks. We are requesting you to voluntarily complete this survey

You will watch videos that show the view of the back of dump trucks while moving backwards through a work zone. Then, you will be given a questionnaire which includes general questions about the images from each of the cameras. The purpose of the questionnaire is to assess the stopping distance for a dump tuck moving backwards after a mannequin (simulating a worker) has been identified in the path of the vehicle, through the use of different cameras.

The information collected will be kept confidential and it will only be used for academic puposes. Your participation in this survey is completely voluntary. It is the goal of this research to develop strategies to improve worker safety in order to decrease the number of accidents related to mobile equipment in highway construction and maintenance work zones. For this reason your cooperation is vital to the success of this research. In addition to these questions you will be asked to provide some demographic information. 


\section{PURDUE School of Cinil Engineting}

Construction Engineering and Management

Performance Evaluation of Camera Systems to Reduce the Risk of Serions.Fatal Injuries Related to Mobile Equipment in Work Zones

Address any inquiry to Carlos Ferreira at (765)- 496-1822

\section{A. General Information}

Please check the boxes that best describes you according to the following characteristics:

1. Ethnicity

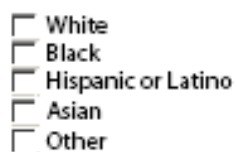

2. Age and Sex

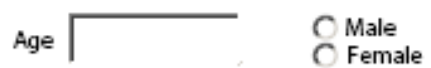

3. Are you currently?
$\Gamma$ Not affiliated with Purdue
$\Gamma$ Purdue Faculty
$\Gamma$ Purdue Undergraduate, year
$\Gamma$ Other Purdue Staff
$\Gamma$ Purdue Graduate, program :

2. Do you wear glasses or contact lenses?
O Yes
O No

\section{B. Backing Camera Systems Evaluation}

Based on the images that you have seen, evaluate the performance of the camera systems according to the following parameters.

\begin{tabular}{|c|c|c|c|c|c|c|c|c|c|c|c|c|c|c|c|c|c|}
\hline \multirow[b]{2}{*}{ Video } & \multirow{2}{*}{$\begin{array}{l}\text { Time when } \\
\text { mannequin is } \\
\text { identified }\end{array}$} & \multicolumn{4}{|c|}{ Field of View } & \multirow{2}{*}{\multicolumn{6}{|c|}{$\begin{array}{c}\text { Glare } \\
\text { Excessive....Acceptable }\end{array}$}} & \multicolumn{6}{|c|}{ Overall Image Quality } \\
\hline & & $\begin{array}{c}\text { Smal } \\
1\end{array}$ & 3 & 4 & & & & & & & & & or... & & 3 & Exc & \\
\hline 1 & & & & & & & & & & & & & & & & & \\
\hline 2 & & & & & & & & & & & & & & & & & \\
\hline 3 & & & & & & & & & & & & & & & & & \\
\hline 4 & & & & & & & & & & & & & & & & & \\
\hline 5 & & & & & & & & & & & & & & & & & \\
\hline 6 & & & & & & & & & & & & & & & & & \\
\hline 7 & & & & & & & & & & & & & & & & & \\
\hline 8 & & & & & & & & & & & & & & & & & \\
\hline 9 & & & & & & & & & & & & & & & & & \\
\hline 10 & & & & & & & & & & & & & & & & & \\
\hline
\end{tabular}




\section{PURDUE School of Civil Engineering}

PURDUE Construction Engineering and Management

D N I V X B S I T Y Performance Evaluation of Camera Systems to Reduce the Risk of Serions Fatal Injuries Related to

Mobile Equipment in Work Zones

Address any inquiry to Carlos Ferreira at (765)- 496-1822

\begin{tabular}{|c|c|c|c|c|c|c|c|c|c|c|c|c|c|c|c|}
\hline \multirow{3}{*}{ Video } & \multirow{3}{*}{$\begin{array}{l}\text { Time when } \\
\text { mannequin is } \\
\text { identified }\end{array}$} & \multicolumn{4}{|c|}{ Field of View } & \multirow{2}{*}{\multicolumn{5}{|c|}{\begin{tabular}{|c|} 
Glare \\
Excessive.....Acceptable
\end{tabular}}} & \multirow{2}{*}{\multicolumn{5}{|c|}{$\begin{array}{l}\text { Overall Image Quality } \\
\text { Poor }\end{array}$}} \\
\hline & & \multirow{2}{*}{\multicolumn{4}{|c|}{$\begin{array}{ccccc}\text { Small } & & & & \text { Large } \\
1 & 2 & 3 & 4 & 5\end{array}$}} & & & & & & & & & & \\
\hline & & & & & & \multicolumn{5}{|c|}{$\begin{array}{ccccc}\text { Excessive } & \text {...Acceptable } \\
1 & 2 & 3 & 4 & 5\end{array}$} & & 2 & 3 & 4 & 5 \\
\hline \multicolumn{16}{|l|}{11} \\
\hline \multicolumn{16}{|l|}{12} \\
\hline \multicolumn{16}{|l|}{13} \\
\hline \multicolumn{16}{|l|}{14} \\
\hline \multicolumn{16}{|l|}{15} \\
\hline \multicolumn{16}{|l|}{16} \\
\hline \multicolumn{16}{|l|}{17} \\
\hline \multicolumn{16}{|l|}{18} \\
\hline \multicolumn{16}{|l|}{19} \\
\hline \multicolumn{16}{|l|}{20} \\
\hline 21 & & & & & & & & & & & & & & & \\
\hline
\end{tabular}

